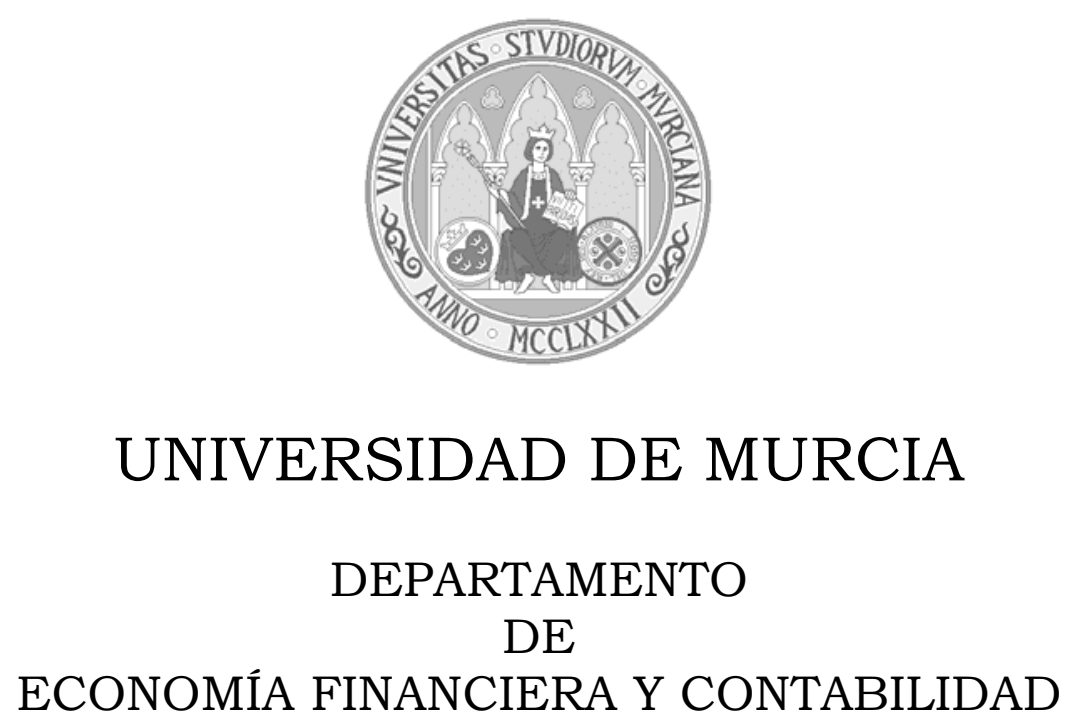

TESIS DOCTORAL

\title{
“LA AUDITORÍA DE CUENTAS EN ESPAÑA: UN ESTUDIO EMPÍRICO SOBRE LA FUNCIÓN, UTILIDAD Y COMPRENSIÓN DEL INFORME DE AUDITORÍA"
}

Doctorando:

Antonio Duréndez Gómez-Guillamón

Director:

Dr. D. Pedro Luengo Mulet

Murcia

2001 
AGRADECIMIENTOS 
En primer lugar me gustaría dar las gracias muy sinceramente al Dr. D. Pedro Luengo Mulet tanto por su labor de dirección como por su constante apoyo.

En segundo lugar también me gustaría dar las gracias al Dr. D. Domingo García Pérez de Lema por sus recomendaciones en la elaboración de la encuesta y en el tratamiento de los datos. De igual modo deseo expresar mi agradecimiento a los alumnos Dña. Cristina Zaragoza Díaz, Dña. Josefa Albaladejo Montoro y D. Alejandro Delgado Martínez por el gran esfuerzo realizado con el proceso de circularización de la encuesta, así como en el desarrollo de la base de datos, sin cuya ayuda no hubiera podido concluir el estudio. Además quiero expresar mi agradecimiento a mis compañeros de la Universidad Politécnica de Cartagena por su desinteresada ayuda y, sobretodo, por su amistad.

En último lugar quiero agradecer a todas las personas que con su colaboración han hecho posible el buen fin de la investigación, ya sean auditores, directivos de empresas, de entidades de crédito o de agencias y sociedades de valores. 
ÍNDICE 




CAPÍTULO I - Marco teórico de la auditoría de cuentas.........................................................

1.1. Concepto, origen y desarrollo institucional de la auditoría............................7

1.1.1. Marco conceptual de la auditoría de cuentas ....................................



1.1.1.2. Objeto de la auditoría.......................................................10

1.1.1.3. Origen y evolución de la auditoría..................................12

1.1.1.4. Tipos de auditoría............................................................18

1.1.2. La auditoría en España .................................................................19

1.1.2.1. Origen de la auditoría en España .....................................19

1.1.2.2. Las Corporaciones profesionales de auditores..............22

1.1.2.3. El papel del ICAC ..............................................................26

1.1.3. Los organismos internacionales de auditoría..............................28

1.1.3.1. La Federación Internacional de Contadores ..................28

1.1.3.2. El Instituto Americano de Auditores................................30

1.1.3.3. El Instituto de Contadores de Inglaterra y Gales..........31

1.1.3.4. La Federación Europea de Expertos Contables.............32

1.2. La auditoría de cuentas como servicio profesional ........................................34

1.2.1. La Función del auditor de cuentas....................................................34

1.2.1.1. Función original...................................................................34

1.2.1.2. Función actual ......................................................................

1.2.2. Los agentes intervinientes y usuarios del servicio de auditoría .......................................................................................

1.2.2.1. Las partes contratantes ................................................41

1.2.2.2. Los usuarios ajenos al contrato........................................42

1.2.3. Los servicios que presta el auditor y su independencia ...............44

1.2.3.1. La demanda de servicios multidisciplinares .................46

1.2.3.2. Problemática en torno a los servicios multidisciplinares .53 
1.3. El informe de auditoría: expectativas, comprensión y utilidad

1.3.1. El "gap de expectativas" en auditoría ............................................65



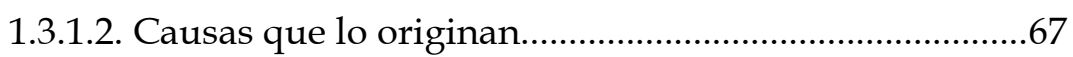

1.3.1.3. Propuestas para solucionarlo...........................................72

1.3.2. El proceso de comunicación entre auditor y usuarios:

el informe y el problema de su comprensión.................................77

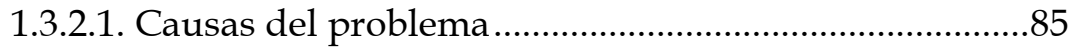

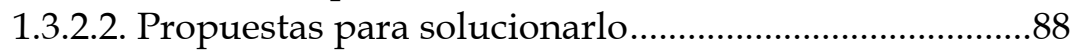

1.3.4. La utilidad asociada al trabajo del auditor ...................................93

1.3.4.1. La relevancia de la información contenida

en el dictamen

1.3.4.2. La utilidad del trabajo del auditor a efectos de gestión.

CAPÍTULO II - Revisión de la literatura empírica sobre la auditoría de cuentas: función, utilidad y comprensión del informe de auditoría............105

2.1. Estudios empíricos sobre la función de la auditoría ...................................106

2.1.1. Investigaciones mediante encuestas ............................................106

2.1.1.1. Humphrey, Moizer y Turley (1993) .............................108

2.1.1.2. García Benau et al. (1993) ..............................................112

2.1.1.3. Porter (1993) ..............................................................117

2.1.1.4. Informe MARC (1996)...............................................120

2.1.1.5. Estudio del IACJC (1997) .............................................124

2.1.1.6. García Benau, Garrido, Vico et al. (1999) .....................134

2.1.1.7. Estudio del IACJC (1999) ..............................................137

2.1.1.8. Herrador Alcaide (2000) .................................................140

2.2. Estudios empíricos sobre la utilidad de la auditoría.................................144

2.2.1. Investigaciones basadas en experimentos de laboratorio..........144

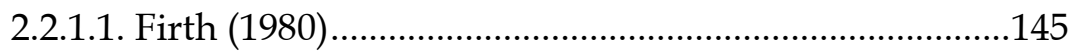

2.2.1.2. Wilkerson (1987) ...........................................................147

2.2.2. Investigaciones realizadas con el mercado de capitales ...........150

2.2.2.1. Baskin (1972) ...............................................................151

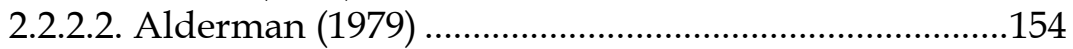


2.2.2.3. Ball, Walker y Whittred (1979) .....................................157

2.2.2.4. Melumad y Ziv (1997).................................................160

2.2.2.5. Del Brío González (1998) ...............................................162

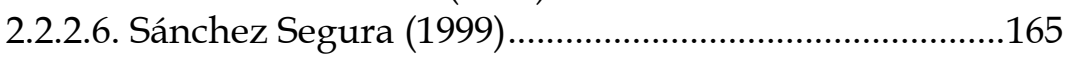

2.2.2.7. Gómez Aguilar et al. (1999)...........................................167

2.2.2.8. Cabal García (2000)........................................................169

2.2.3. Investigaciones mediante encuestas ...........................................172

2.2.3.1. Carcello, Hermanson y McGrath (1992) ......................173

2.3. Estudios sobre el proceso de comunicación con los usuarios:

el problema de comprensión del informe de auditoría

2.3.1. Investigaciones basadas en experimentos de laboratorio..........176



2.3.1.2. Bailey (1981) ……….....................................................180

2.3.1.3. Bailey, Bilynski y Shields (1983) ...................................184

2.3.1.4. Nair y Rittenberg (1987) …...........................................188

2.3.1.5. Mayper, Welker y Wiggins (1988)..............................192

2.3.1.6. Kelly y Mohrweis (1989) ................................................195

2.3.1.7. Holt y Moizer (1990)....................................................197

2.3.1.8. Innes, Brown y Hatherly (1997) ....................................200

2.3.2. Investigaciones mediante encuestas ...........................................203

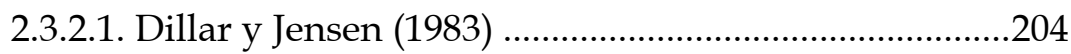

2.3.2.2. Geiger (1989) ....................................................................207

2.3.2.3. Miller, Reed y Strawser (1990 y 1993)..........................209

CAPÍTULO III - Estudio empírico nacional sobre la auditoría de cuentas: función, utilidad y comprensión del informe de auditoría. 213

3.1. Objetivo y planteamiento de las hipótesis ...............................................213

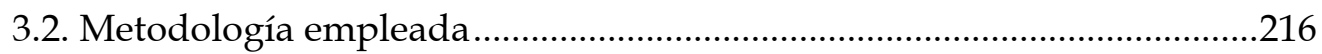



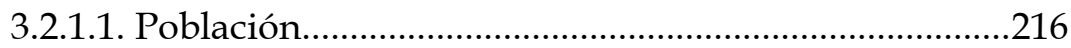



3.2.1.3. Fuente de datos...........................................................225

3.2.1.4. Fechas de circularización y recogida de datos ............226

3.2.1.5. Técnica de recogida de la información .........................227

3.2.1.6. Representante de las entidades encuestadas ...............228 
3.2.2.1. Preparación de las preguntas..........................................231

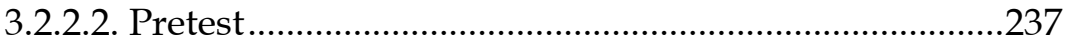

3.2.2.3. Documentación remitida al encuestado.......................238

3.2.2.4. Fiabilidad del cuestionario...............................................238

3.2.3. Metodología empleada en el análisis de datos...........................240

3.2.3.1. Grabación y validación de la información ....................240

3.2.3.2. Técnicas empleadas en la exploración de datos..........241

3.2.3.3. Técnicas empleadas en el análisis avanzado de datos ......................................................241

3.2.4. Limitaciones del estudio............................................................243

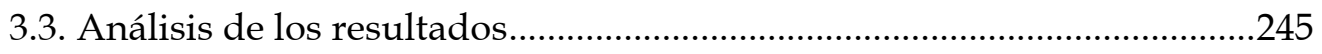



3.3.2. Contrastación de las hipótesis ........................................................253

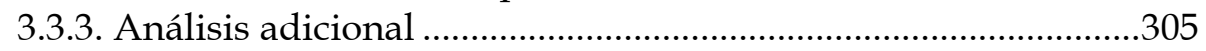

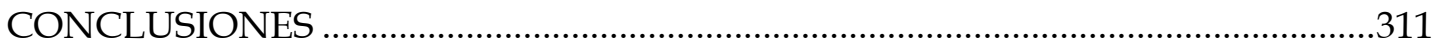

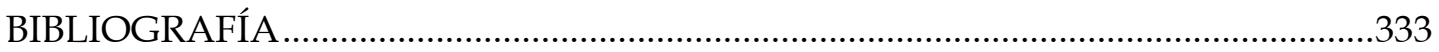

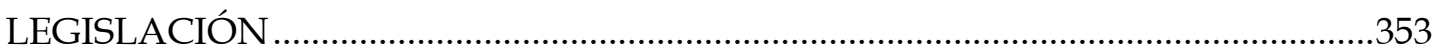

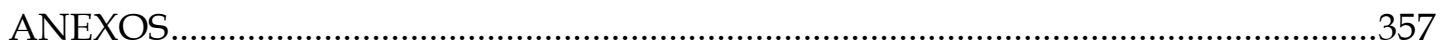




\section{ÍNDICE DE FIGURAS}

Figura $\mathrm{n}^{\mathrm{o}}$ 1: Etapas en el desarrollo de la auditoría de cuentas.....................................79

Figura $n^{\circ} 2$ : El proceso de comunicación entre el auditor y los usuarios.......................83

Figura $\mathrm{n}^{\mathrm{0}}$ 3: Características de la información financiera..............................................95 
Gráfico $\mathrm{n}^{\mathrm{0}}$ 1: Respuestas recibidas en términos porcentuales.................................... 246

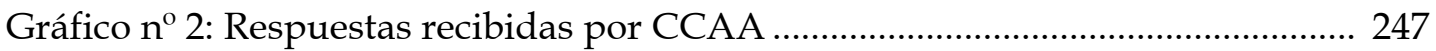

Gráfico $\mathrm{n}^{\mathrm{o}}$ 3: Número de cuestionarios recibidos de auditores según su forma 248 jurídica

Gráfico $\mathrm{n}^{\circ}$ 4: Número de cuestionarios recibidos de las entidades de crédito según su forma jurídica

Gráfico $\mathrm{n}^{\mathrm{o}}$ 5: Número de cuestionarios recibidos de las agencias y sociedades de valores según su forma jurídica..... 
Tabla $\mathrm{n}^{\circ}$ 1: Servicios profesionales prohibidos al auditor en la UE

Tabla $\mathrm{n}^{\mathrm{o}} 2$ : Incompatibilidades del auditor de cuentas.

Tabla $n^{\circ}$ 3: Auditores inscritos en el ROAC en 1999

Tabla $\mathrm{n}^{\mathrm{o}}$ 4: Auditores individuales inscritos como ejercientes en el ROAC

en 1999

Tabla $n^{\circ}$ 5:Trabajos realizados en 1999 relacionados por tipos de auditoría

Tabla $n^{\circ}$ 6: Muestra de auditores estratificada por CCAA

Tabla $n^{\circ}$ 7: Muestra de empresas estratificada por CCAA

Tabla $n^{\circ}$ 8: Cálculo del error muestral para las sociedades auditadas

Tabla $\mathrm{n}^{\circ}$ 9: Cálculo del error muestral para los auditores

Tabla n ${ }^{\circ}$ 10: Cálculo del error muestral para las entidades de crédito

Tabla $\mathrm{n}^{\circ}$ 11: Cálculo del error muestral para las agencias y sociedades de valores

Tabla $\mathrm{n}^{\mathrm{o}}$ 12: Tasa de respuestas recibidas

Tabla $\mathrm{n}^{\mathrm{o}}$ 13: Número de encuestas recibidas por grupos de estudio

Tabla $n^{\circ}$ 14: Número de respuestas recibidas por Comunidades Autónomas......

Tabla $\mathrm{n}^{\mathrm{o}}$ 15: Sexo de los encuestados por grupos de estudio.

Tabla $\mathrm{n}^{\mathrm{o}} 16$ : Edad de los encuestados por grupos de estudio

Tabla $n^{\circ} 17$ : Experiencia profesional de los encuestados por grupos

de estudio

Tabla $n^{\circ}$ 18: Puesto desempeñado por el encuestado por grupos de estudio

Tabla $\mathrm{n}^{\circ}$ 19: Nivel de estudios por grupos encuestados

Tabla $\mathrm{n}^{\mathrm{o}} 20$ : Estudios de postgrado por grupos de estudio

Tabla $n^{\circ}$ 21: Prueba de Kruskal-Wallis para los grupos encuestados $\left(1^{\text {a }}\right.$ hipótesis)

Tabla $\mathrm{n}^{\mathrm{O}}$ 22: Prueba de Kruskal-Wallis para las empresas agrupadas por CCAA ( $1^{\text {a }}$ hipótesis)

Tabla $n^{\circ}$ 23: Prueba de Mann-Whitney para las empresas agrupadas por la experiencia profesional del encuestado ( $1^{\mathrm{a}}$ hipótesis).

Tabla $n^{\circ}$ 24: Prueba de Mann-Whitney para las empresas agrupadas por el




nivel de estudios del encuestado ( $1^{\text {a }}$ hipótesis)

Tabla $n^{\circ}$ 25: Prueba de Mann-Whitney para los auditores según su forma jurídica ( $1^{\mathrm{a}}$ hipótesis).

Tabla $\mathrm{n}^{\circ}$ 26: Prueba de Kruskal-Wallis para los auditores agrupados por

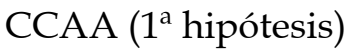

Tabla $\mathrm{n}^{\circ}$ 27: Prueba de Kruskal-Wallis para los auditores agrupados por la experiencia profesional del encuestado ( $1^{\mathrm{a}}$ hipótesis).

Tabla $n^{\circ}$ 28: Prueba de Kruskal-Wallis para los auditores agrupados por la edad del encuestado ( $1^{\text {a }}$ hipótesis).

Tabla $n^{\circ}$ 29: Prueba de Mann-Whitney para los auditores según el nivel de estudios del encuestado ( $1^{\text {a }}$ hipótesis )

Tabla $n^{\circ}$ 30: Prueba de Mann-Whitney para los auditores agrupados por los estudios de postgrado del encuestado ( $1^{\text {a }}$ hipótesis).

Tabla $n^{\circ}$ 31: Prueba de Kruskal-Wallis para las entidades de crédito agrupadas por CCAA ( $1^{\text {a }}$ hipótesis)

Tabla $n^{\circ}$ 32: Prueba de Kruskal-Wallis para las entidades de crédito agrupadas por la experiencia profesional del encuestado $\left(1^{\mathrm{a}}\right.$ hipótesis)......

Tabla $n^{\circ}$ 33: Prueba de Mann-Whitney para las entidades de crédito agrupadas por el nivel de estudios del encuestado ( $1^{\mathrm{a}}$ hipótesis)... 270

Tabla $n^{\circ}$ 34: Prueba de Kruskal-Wallis para las agencias y soc. de valores agrupadas por la experiencia profesional del encuestado $\left(1^{\mathrm{a}}\right.$ hipótesis)......

Tabla n ${ }^{\circ}$ 35: Prueba de Mann-Whitney para empresas y auditores

( $1^{\mathrm{a}} \cdot 1^{\mathrm{o}}$. hipótesis)

Tabla n ${ }^{\circ}$ 36: Prueba de Kruskal-Wallis para las empresas agrupadas por CCAA $\left(1^{\mathrm{a}} \cdot 1^{\mathrm{o}}\right.$. hipótesis)

Tabla $n^{\circ}$ 37: Prueba de Mann-Whitney para las empresas agrupadas por los estudios de postgrado del encuestado $\left(1^{\mathrm{a}} \cdot 1^{\mathrm{o}}\right.$. hipótesis)

Tabla $\mathrm{n}^{\circ}$ 38: Prueba de Kruskal-Wallis para los auditores agrupados por CCAA (1ª.1. hipótesis)

Tabla $n^{\circ}$ 39: Prueba de Mann-Whitney para los auditores agrupados por el 
nivel de estudios del encuestado $\left(1^{\mathrm{a}} \cdot 1^{\mathrm{o}}\right.$. hipótesis $)$

Tabla $n^{\circ}$ 40: Prueba de Kruskal-Wallis para los auditores agrupados por la edad del encuestado ( $1^{\mathrm{a}} \cdot 1$. hipótesis).

Tabla $n^{\circ}$ 41: Prueba de Kruskal-Wallis para los grupos encuestados (2a hipótesis)

Tabla $n^{\circ}$ 42: Prueba de Mann-Whitney para las empresas agrupadas por el sexo del encuestado ( $2^{\mathrm{a}}$ hipótesis).

Tabla $n^{\circ}$ 43: Prueba de Kruskal-Wallis para las empresas agrupadas por el nivel de estudios del encuestado (2a hipótesis)

Tabla $n^{\circ}$ 44: Prueba de Kruskal-Wallis para las empresas agrupadas por la experiencia profesional del encuestado ( $2^{\mathrm{a}}$ hipótesis)

Tabla $n^{\circ}$ 45: Prueba de Kruskal-Wallis para los auditores agrupados por CCAA ( $2^{\text {a }}$ hipótesis)

Tabla $\mathrm{n}^{\circ}$ 46: Prueba de Kruskal-Wallis para las entidades de crédito agrupadas por la experiencia profesional del encuestado $\left(2^{\mathrm{a}}\right.$ hipótesis).....

Tabla $\mathrm{n}^{\circ}$ 47: Prueba de Kruskal-Wallis para las agencias y soc. de valores agrupadas por la experiencia profesional del encuestado $\left(2^{\mathrm{a}}\right.$ hipótesis)

Tabla $n^{\circ}$ 48: Prueba de Mann-Whitney para las agencias y soc. de valores agrupadas por los estudios de postgrado del encuestado $\left(2^{\mathrm{a}}\right.$ hipótesis)

Tabla $n^{\circ}$ 49: Prueba de Mann-Whitney para las agencias y sociedades de valores agrupadas por el sexo del encuestado (2a hipótesis)

Tabla $n^{\circ}$ 50: Prueba de Kolmogorov-Smirnov para las entidades de crédito (hipótesis $2^{\mathrm{a}} \cdot 1^{\mathrm{o}}$ ).

Tabla $n^{\circ}$ 51: Prueba de Kolmogorov-Smirnov para las agencias y sociedades de valores (hipótesis $2^{\mathrm{a}} \cdot 2^{\mathrm{o}}$ ).

Tabla $n^{\circ}$ 52: Prueba de Kruskal-Wallis para los grupos encuestados ( $3^{a}$ hipótesis)

Tabla $n^{\circ}$ 53: Número de informes leídos por grupos de estudio 300

Tabla $\mathrm{n}^{\circ}$ 54: Prueba de Kruskal-Wallis para las empresas agrupadas por la edad del encuestado ( $3^{\text {a }}$ hipótesis) 
Tabla $\mathrm{n}^{0}$ 55: Prueba de Kruskal-Wallis para las empresas agrupadas por la experiencia profesional del encuestado ( $3^{\text {a }}$ hipótesis).

Tabla $\mathrm{n}^{\circ}$ 56: Prueba de Kruskal-Wallis para los auditores agrupados por CCAA ( $3^{\text {a }}$ hipótesis)

Tabla n ${ }^{\circ}$ 57:Prueba de Kruskal-Wallis para las entidades de crédito agrupadas por la experiencia profesional del encuestado ( $2^{\mathrm{a}}$ hipótesis)

Tabla $n^{\circ}$ 58: Prueba de Kruskal-Wallis para las agencias y sociedades de

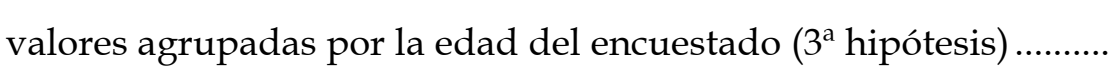

Tabla $\mathrm{n}^{\circ}$ 59: Prueba de Kruskal-Wallis para los grupos encuestados (adicional)

Tabla $\mathrm{n}^{\circ}$ 60: Colectivos interesados en el servicio de auditoría 308 
AAPA: $\quad$ American Association of Public Accountants

AECA: $\quad$ Asociación Española de Contabilidad y Administración de Empresas

AIA: $\quad$ American Institute of Accountants

AICPA: $\quad$ American Institute of Certified Public Accountants

ALSCAL: $\quad$ Análisis de las Proximidades Individuales

ANOVA: $\quad$ Análisis de la Varianza

APB: $\quad$ Accounting Principles Board

ARB: $\quad$ Accounting Research Bulletin

ARS: $\quad$ Accounting Research Division

ARSC: $\quad$ Accounting and Review Services Committee

ASB: $\quad$ Auditing Standards Board

ASEPUC: Asociación Española de Profesores Universitarios de Contabilidad

BOE: $\quad$ Boletín Oficial del Estado

BOICAC: Boletín Oficial del Instituto de Contabilidad y Auditoría de Cuentas

CAP: $\quad$ Committee on Auditing Procedure

CAR: $\quad$ Commission on Auditors' Responsibilities

CATI: Computer Assisted Telephone Interview

CCAA: Comunidades Autónomas

CEE: $\quad$ Comunidad Económica Europea

CICA: $\quad$ Canadian Institute of Chartered Accountants

CMD: $\quad$ Cuadrado Medio Intragrupos

CMG: $\quad$ Cuadrado Medio Intergrupos

CNMV: $\quad$ Comisión Nacional del Mercado de Valores

CPA: $\quad$ Certified Public Accountant

DOCE: $\quad$ Diario Oficial de la Comunidad Europea

FASB: $\quad$ Financial Accounting Standards Board

FEE: $\quad$ Federación Europea de Expertos Contables

FEI: $\quad$ Financial Executives Institute

FP: $\quad$ Formación Profesional

GAAP: Generally Accepted Accounting Principles

HSD: $\quad$ Diferencia Honestamente Significativa de Tukey

IASC: International Accounting Standards Committee

ICAC: Instituto de Contabilidad y Auditoría de Cuentas

ICAEW: Institute of Chartered Accountants in England \& Wales

ICAI: Institute of Chartered Accountants in Ireland

ICJC: $\quad$ Instituto de Censores Jurados de Cuentas

IACJC: Instituto de Auditores-Censores Jurados de Cuentas

IFAC: International Federation of Accountants

INDSCAL: Análisis de las Proximidades Individuales

IPA: $\quad$ Institute of Public Accountants

MANOVA: Análisis Multivariante de la Varianza

MARC: $\quad$ Maastricht Accounting and Auditing Research Center

MAS: $\quad$ Servicios de Asesoría de Gestión 
MBA: $\quad$ Master en Dirección de Empresas

MDS: $\quad$ Modelo de Escalas Multidimensionales

NC: $\quad$ Nivel de Confianza

NS: $\quad$ Estadísticamente No Significativo

NTA: $\quad$ Normas Técnicas de Auditoría

OPA: $\quad$ Oferta Pública de Adquisición de Acciones

PCGA: $\quad$ Principios de Contabilidad Generalmente Aceptados

PyG: $\quad$ Pérdidas y Ganancias

PYME: $\quad$ Pequeña y Mediana Empresa

RD: $\quad$ Real Decreto

REGA: Registro General de Auditores

REA: $\quad$ Registro de Economistas Auditores

ROAC: $\quad$ Registro Oficial de Auditores de Cuentas

SABE: $\quad$ Sistema de Análisis de Balances Españoles

SAP: $\quad$ Statements on Auditing Procedure

SAS: $\quad$ Statements on Auditing Standards

SCD: $\quad$ Suma de Cuadrados intragrupos

SCG: $\quad$ Suma de Cuadrados intergrupos

SEC: $\quad$ Securities and Exchange Commission

SPSS: $\quad$ Statistical Package for the Social Sciencies

SSAE: $\quad$ Statements on Standards for Attestation Engagements

SSARS: $\quad$ Statements of Standards for Accounting and Review Services

TRLSA: $\quad$ Texto Refundido de la Ley de Sociedades Anónimas

UE: Unión Europea

UK: $\quad$ Reino Unido

USA: $\quad$ Estados Unidos de Norteamérica 


\section{INTRODUCCIÓN}

La idea de llevar a cabo este trabajo de investigación nace como consecuencia de las inquietudes que percibo, en mi experiencia profesional en el campo de la auditoría de cuentas, del personal de algunas empresas sujetas a auditoría, al observar que el desconocimiento del trabajo que realiza el auditor provoca un sentimiento de insatisfacción. Esta sensación es consecuencia de que se concibe la auditoría como un mero trámite legal que nada aporta al buen funcionamiento de la sociedad y que incluso despierta, a veces, un sentimiento negativo hacia la labor del auditor. Estas circunstancias justifican la realización de un estudio, que ponga de relieve las percepciones tanto de los "usuarios", del informe de auditoría, como de los propios auditores de cuentas, con la finalidad de constatar la opinión que existe sobre la labor del auditor, así como de las expectativas que los usuarios guardan sobre la misma, de forma que los resultados puedan guiar al profesional para conseguir satisfacer, en el futuro, las demandas sociales que sean razonables.

El trabajo se ha estructurado en tres partes, tal y como se describen a continuación:

- Una primera en la que se desarrolla una revisión del marco teórico de la auditoría de cuentas y que incluye un repaso conceptual de su objeto, origen, evolución, tipología, así como de los organismos e instituciones que participan y regulan la auditoría de cuentas. En un epígrafe posterior, se trata la temática relativa a la "función social" de la auditoría, al papel de los agentes intervinientes y usuarios del servicio, así como a la problemática en torno a los "servicios multidisciplinares" y a la "independencia" del auditor. El último apartado, de esta primera parte, versa sobre el "gap de expectativas" 
en auditoría, el proceso de comunicación entre auditor y usuarios, y la problemática asociada a la utilidad que proporciona la labor del auditor.

- La segunda parte supone una revisión de la literatura empírica existente en torno al objetivo central de la tesis, es decir, sobre la función, utilidad y comprensión del informe que emite el auditor; diferenciando los estudios realizados por la doctrina según sean "experimentos de laboratorio", investigaciones realizadas en el mercado de capitales o bien mediante encuestas de opinión.

- La tercera parte del trabajo está dedicada exclusivamente a la exposición del estudio empírico, que se ha realizado a nivel nacional, para obtener las percepciones, que muestran tanto los propios auditores como los usuarios, acerca del dictamen que elabora el auditor. En la muestra de usuarios están representados los colectivos de las sociedades sujetas a auditoría de cuentas anuales, las entidades de crédito y las agencias y sociedades de valores, y las preguntas formuladas están relacionadas con la función, utilidad y comprensión del informe que emite el auditor. En esta última parte se incluyen las hipótesis planteadas, la metodología empleada y los resultados obtenidos.

Para finalizar la tesis doctoral se incluye un apartado con las principales conclusiones alcanzadas, las referencias bibliográficas citadas y los anexos explicativos del proceso de investigación. 
MARCO TEÓRICO DE LA AUDITORÍA DE CUENTAS 


\subsection{CONCEPTO, ORIGEN Y DESARROLLO INSTITUCIONAL}

\subsubsection{MARCO CONCEPTUAL DE LA AUDITORÍA DE CUENTAS}

\subsubsection{Concepto}

Cualquier trabajo de investigación sobre auditoría debe comenzar determinando de una manera clara su campo de actuación; sobre el concepto de auditoría se han dado diferentes definiciones tanto por la doctrina contable como por la legislación, de ahí que deba partirse de una noción amplia que ofrezca una visión global del mismo.

El Diccionario de la Lengua Española (Real Academia Española, 1992: 230) define la -auditoría- como "empleo de auditor", y la -auditoría contablecomo "revisión de la contabilidad de una empresa, sociedad, etc., realizada por un auditor"; mientras que el verbo -auditar- se refiere a la auditoría como acción de "examinar la gestión económica de una entidad a fin de comprobar si se ajusta a lo establecido por ley o costumbre"; ambas definiciones son excesivamente parcas $\mathrm{y}$, por tanto, no describen la totalidad de las funciones que tiene encomendadas en la actualidad la auditoría de cuentas.

En la doctrina en materia de contabilidad y auditoría se pueden encontrar definiciones sobre el concepto de "auditoría de cuentas" como las que se transcriben a continuación:

- Según Holmes (1978: 11) la auditoría puede definirse como “la revisión objetiva de los estados financieros originalmente elaborados por la administración". 
- Para Grinaker y Barr (1982: 15) la auditoría, en su más amplio sentido, puede definirse como "una investigación crítica para llegar a conclusiones ciertas sobre la contabilidad de los aspectos financieros y de operaciones de una organización económica".

- Kohler (1982: 23) señala que el término auditoría significa “cualquier revisión profesional o no profesional de registros o informes de contabilidad".

- Por su parte, Urías Valiente (1987: 57) entiende el concepto de auditoría como "aquella disciplina que, disponiendo de unas normas y unos procedimientos que le son propios, puestos en práctica por un profesional independiente, trata de establecer, mediante su examen, si los estados financieros presentan razonable o adecuadamente la situación económica y financieropatrimonial de una entidad, de acuerdo con principios de contabilidad generalmente admitidos y si estos se han aplicado uniformemente".

- Cañibano Calvo (1996: 49) señala que "la auditoría de los estados financieros es el examen y verificación de los estados financieros de una empresa con el objeto de emitir una opinión sobre la fiabilidad de los mismos", de forma que auditar consiste en "examinar y verificar información, registros, procesos, circuitos etc., con objeto de expresar una opinión sobre la bondad o fiabilidad".

También los organismos y asociaciones internacionales, en materia de contabilidad y auditoría, han elaborado diferentes definiciones en torno a la 
naturaleza del concepto de auditoría. Así, según el "Comité sobre conceptos de auditoría de AICPA" (1972: 18), la auditoría se concibe como "un proceso sistemático para obtener y evaluar evidencia, de una manera objetiva, respecto de las afirmaciones concernientes a actos económicos y eventos para determinar el grado de correspondencia entre estas afirmaciones y los criterios establecidos".

La definición legal de auditoría de cuentas aparece reflejada en el apartado segundo de la exposición de motivos, de la vigente Ley 19/1988 de Auditoría de Cuentas1, al indicar que es "la actividad que mediante la utilización de determinadas técnicas de revisión, tiene por objeto la emisión de un informe acerca de la fiabilidad de los documentos contables auditados; no limitándose, pues, a la mera comprobación de que los saldos que figuran en sus anotaciones contables concuerdan con los ofrecidos en el balance y en la cuenta de resultados, ya que las técnicas de revisión y verificación aplicadas permiten, con un alto grado de certeza y sin la necesidad de rehacer el proceso contable en su totalidad, dar una opinión responsable sobre la contabilidad en su conjunto y, además, sobre otras circunstancias que afectando a la vida de la empresa, no estuvieran recogidas en dicho proceso".

Continuando con la citada ley, su artículo primero dispone que "se entenderá por auditoría de cuentas la actividad consistente en la revisión y verificación de documentos contables, siempre que aquélla tenga por objeto la emisión de un informe que pueda tener efectos frente a terceros...consistirá en verificar y dictaminar si dichas cuentas expresan la imagen fiel del patrimonio y de la situación financiera de la empresa...así como el resultado de sus operaciones y los recursos obtenidos y aplicados en

\footnotetext{
${ }^{1}$ Véase en Normativa Básica de Contabilidad y Auditoría de Cuentas, López Hernández et al. (1996).
} 
el período examinado, de acuerdo con el Código de Comercio y demás legislación que le sea aplicable; también comprenderá la verificación de la concordancia del informe de gestión con dichas cuentas".

Abundando más en la legislación vigente, el Reglamento ${ }^{2}$ aprobado por el RD 1636/1990, que desarrolla la Ley de Auditoría de Cuentas, en su artículo primero, recoge que "se entenderá por auditoría de cuentas la actividad realizada por una persona cualificada e independiente, consistente en analizar, mediante la utilización de las técnicas de revisión y verificación idóneas, la información económico-financiera deducida de los documentos contables examinados y que tiene como objeto la emisión de un informe dirigido a poner de manifiesto su opinión responsable sobre la fiabilidad de la citada información, a fin de que se pueda conocer y valorar dicha información por terceros".

De las distintas versiones recopiladas se puede extraer, a modo de resumen, que la auditoría de cuentas es una actividad de revisión y verificación de información contable, realizada por un experto, con la finalidad de emitir un juicio profesional sobre la fiabilidad de dicha información.

\subsubsection{Objeto de la auditoría}

El Texto Refundido de la Ley de Sociedades Anónimas 3 (TRLSA) en su artículo 208, -sobre el objeto de la auditoría-, dispone que "los auditores de cuentas, actuando de conformidad con las normas que rigen la auditoría, comprobarán si las cuentas anuales ofrecen la imagen fiel del patrimonio, de

\footnotetext{
${ }^{2}$ Véase en El Marco Legal de la Auditoría en España, Casanovas Parella (1996).

${ }^{3}$ Véase en Código de Comercio y Otras Normas Mercantiles, García Luengo et al. (1999).
} 
la situación financiera y de los resultados de la sociedad, así como la concordancia del informe de gestión con las cuentas anuales del ejercicio".

Atendiendo a la Resolución ${ }^{4}$ del ICAC, por la que se publican las Normas Técnicas de Auditoría5, "el objetivo de la auditoría de cuentas anuales de una entidad considerada en su conjunto, es la emisión de un informe dirigido a poner de manifiesto una opinión técnica sobre si dichas cuentas anuales expresan, en todos sus aspectos significativos, la imagen fiel del patrimonio y de la situación financiera de dicha entidad, así como del resultado de sus operaciones en el período examinado, de conformidad con principios y normas de contabilidad generalmente aceptados".

Según la norma de auditoría norteamericana SAS n $n^{0}$, en el apartado sobre responsabilidad y funciones del auditor independiente, el propósito de una auditoría independiente es “determinar si los estados financieros del cliente son presentados de manera razonable, en todos los aspectos posibles y de acuerdo con los principios de contabilidad generalmente aceptados. Esta determinación solamente puede efectuarse después que el auditor independiente ha realizado una auditoría de acuerdo con las normas de auditoría generalmente aceptadas" (recopilado por Bailey y Holzmann, 1998: 2.03).

La IFAC, organismo internacional encargado de la elaboración de las “Normas Internacionales de Auditoría” (NIA), indica en su norma n 200 que "el objetivo de la auditoría de estados financieros es permitir al auditor expresar una opinión sobre si éstos han sido preparados, en todos sus

\footnotetext{
${ }^{4}$ Resolución del Instituto de Contabilidad y Auditoría de Cuentas, de 28 de marzo de 1990, por la que se publican las Normas Técnicas de Auditoría, que fue sustituida posteriormente por la Resolución del 19 de enero de 1991, y modificada parcialmente por las Resoluciones de 1 de diciembre de 1994 y de 22 de febrero de 1995, ICAC (1997).

${ }^{5}$ Véase en Normas de Auditoría, como interpretarlas para su aplicación, López Casuso (1995).
} 
aspectos significativos, de acuerdo con un conjunto, perfectamente identificado, de principios contables para la información financiera" (traducido por Tua y Gonzalo, 1999: 147).

Gironella y Gassó (1976: 92 y 94) distinguen entre dos objetivos de la auditoría de cuentas diferentes en el tiempo, en función de:

1. La Filosofía antigua: objetivo defensivo de prevención y descubrimiento de errores, fraudes $\mathrm{u}$ otras manipulaciones en los libros o registros contables.

2. La Filosofía moderna: objetivo de expresar un juicio profesional sobre la razonabilidad con la que los estados financieros presentan la información en ellos contenida.

\subsubsection{Origen y evolución de la auditoría}

Como señala el profesor Suárez Suárez (1991), los primeros antecedentes de la auditoría son casi tan antiguos como la propia historia de la humanidad, ya que la profesión auditora, en cuanto actividad de control de la actividad económico-financiera, surge en el momento en que la propiedad de los recursos financieros o fuentes de financiación y la responsabilidad de la asignación de los mismos a usos productivos no se encuentran en manos de la misma persona, es decir cuando se produce un deslinde entre la propiedad y la gestión. Sin embargo la auditoría, como se conoce hoy en día, no tiene su origen hasta la revolución industrial del siglo XVIII, con la aparición de las primeras sociedades anónimas, donde los accionistas, como meros aportantes del capital, exigen una garantía de que sus fondos han sido gestionados de manera adecuada, y de que las cuentas 
que les presentan los administradores son ciertas y fidedignas. Posteriormente la profesión auditora ha continuado extendiéndose a otros países como Estados Unidos, que se configura como la nación más avanzada en el desarrollo de la profesión, mientras que en países como España, no ha sido oficialmente reconocida hasta la promulgación de la Ley de Auditoría del año 1988, aún cuando ya existía la censura de cuentas que se desarrollaba desde principios del siglo XX, al crearse el "Instituto de Contadores Públicos de España" en 1912.

Pereda Sigüenza (1991: 31 y ss.) distingue tres etapas o fases en las que se ha ido desarrollando la auditoría, una "Edad Antigua", una "Edad MediaModerna" y una "Edad Contemporánea":

\section{- Edad Antigua}

En los pueblos primitivos al no existir una actividad comercial intensa no fue preciso un sistema de información complejo, de forma que se aplicaba el recuento como un sistema de control válido y efectivo. Es en el estamento político, en el seno de la civilización egipcia, cuando surge la figura del auditor "el que oye", que procede del término "audire"-oír-, con la finalidad de controlar el destino de los fondos públicos.

Posteriormente se encuentran vestigios también de la función auditora, como actividad de supervisión, en las culturas griega y romana.

\section{- Edad Media-Moderna}

A consecuencia del auge del comercio italiano con los países de Oriente y Occidente nacen las sociedades mercantiles colectivas y de 
participación, dando lugar a la necesidad de contar con un sistema de registro e información de las operaciones conocido como contabilidad. Así el desarrollo de la contabilidad originó que fuese Italia el país en el que nace la figura del revisor contable, de forma que en Venecia se pagaban los servicios al revisor en función del número e importancia de los errores y fraudes descubiertos. De manera que en los comienzos de la labor auditora su función fue principalmente la de descubrir fraudes, sobre todo en la gestión de los fondos públicos y en el comercio.

En el año 1310 ya se realizaban funciones de auditoría en Inglaterra a través de los "Consejos Londinenses". Más tarde, en 1581, se funda en Italia la asociación de revisores contables "Il colegio dei Raxonati". En París en 1640 aparece el "Tribunal de Cuentas", y en 1658 se crea en Milán y Bolonia la "Academia dei Ragioneri". Ya en el siglo XVIII, en el año 1739, se constituye en Milán el segundo "Colegio de Revisores Contables", cuyo propósito primordial es detectar errores e irregularidades en la llevanza de la contabilidad.

\section{- Edad Contemporánea}

Según señala Durández Adeva (1982: 30) la auditoría no nace como profesión, como actualmente se conoce y practica, hasta el período de la revolución industrial y la aparición de las sociedades anónimas en las que se desliga la propiedad del capital de los gerentes de las mismas, y se encarga a un profesional independiente la revisión de la labor encomendada a los administradores. De estos técnicos especializados en la revisión de la contabilidad surge la profesión de auditor o "accountant", que se potencia en 1854 con la creación del "Institute of Chartered Accountants of Scotland". 
La profesión auditora es reconocida, en Gran Bretaña, por la Ley de Sociedades de 1862, posteriormente, en 1879, a través de la "Companies Act" se obliga a las entidades bancarias a someter sus cuentas a auditoría, y a las sociedades mercantiles a la llevanza de una contabilidad ordenada. En 1880, la reina Victoria les confiere a los auditores de Inglaterra y Gales el derecho a llamarse "Chartered Accountants" y ese mismo año nace el "Institute of Chartered Accountants of England and Wales" que continua en la actualidad.

A partir de comienzos del siglo $\mathrm{XX}$ se intensifica la constitución de las empresas industriales y comerciales como sociedades anónimas, y esa transformación lleva aparejada que la auditoría se convierta en obligatoria, con el fin de garantizar la transparencia del tráfico mercantil de los países.

Debido a la influencia inglesa se va a desarrollar y consolidar la auditoría en Estados Unidos, surgiendo en el año 1887 la primera asociación americana de auditores la "American Association of Public Accountants (AAPA)". Posteriormente en 1896, en el Estado de Nueva York, aparece la primera ley que regula la profesión del auditor o contador público, tal y como se conoce al auditor en América, mediante la "Act to regulate the Profesión of Public Accountants" que otorga el título de "Certified Public Accountant" a las personas que logran superar una prueba de aptitud.

En 1916, la AAPA pasa a denominarse "Institute of Public Accountants (IPA)" constando de 1.150 miembros. Un año más tarde se cambia el nombre por el de "American Institute of Accountants (AIA)" y, a solicitud de la Comisión Federal de Comercio de Estados Unidos (Federal Trade Commission), elabora un documento, el "Uniform Accounting", que constituye el primer conjunto de estándares sobre procedimientos de 
auditoría de balances, que fueron publicados bajo el título de "Aproved Methods for the Preparation of Balance Sheet Statements". Para corregir sus deficiencias, en 1922, el AIA lo revisó y publicó bajo el título de "Verification of Financial Statements".

No obstante, lo que supuso un giro radical en la elaboración de la información financiera fue la crisis económica de 1929, momento a partir del cual se trabaja para paliar la falta de transparencia y de armonización de los principios contables, gracias a la iniciativa de la AIA y la Bolsa de Nueva York, y se acuña la expresión de "generally accepted accounting principles (GAAP)", principios de contabilidad generalmente aceptados.

Cuatro años más tarde, en 1933, la Comisión Federal del Congreso Norteamericano crea la "Securities and Exchange Commission (SEC)", órgano regulador y controlador de la bolsa a cuyo cargo corre el reconocimiento de los principios y normas de auditoría a aplicar, y se produce la publicación de dos leyes, las "Securities Acts" de 1933 y 1934; en las que se exigía que todas las sociedades que cotizaban en bolsa debían acompañar sus estados financieros de un informe de auditoría.

En 1939, el AIA crea el "Committee on Auditing Procedure (CAP)" que a su vez se subdivide en tres comisiones:

- La "Accounting Research Division" (ARS) dedicada al estudio e investigación de la contabilidad.

- El "Accounting Principles Board" (APB) dedicado a la emisión de principios de contabilidad. 
- El "Accounting Research Bulletin" (ARB) para la publicación de las investigaciones en materia de contabilidad.

La AIA pasa en el año 1957 a denominarse "American Institute of Certified Public Accountants (AICPA)" y este nuevo organismo se encarga de la emisión de los "Statements on Auditing Procedure" (SAP), conjunto de procedimientos de auditoría que desarrollan y profundizan en la profesión auditora. En 1972, se realizan los "Statements on Auditing Standards" (SAS) que recogen normas y procedimientos de auditoría y un año después nace el "Financial Accounting Standard Board" (FASB) órgano encargado de la elaboración y emisión de principios de contabilidad, siendo en la actualidad la principal fuente normativa contable en los Estados Unidos de Norteamérica.

Como indica el profesor Urías Valiente (1987: 59), a partir de los años 40 y 50 el objetivo de la auditoría ya no es la detección de errores y fraudes mediante la revisión de la totalidad de los registros contables, sino que el trabajo de auditoria sufre cambios sustanciales, reforzándose los siguientes cometidos:

- Se pone un mayor énfasis en la revisión y evaluación de los sistemas de control interno.

- Se centran los esfuerzos en las partidas que componen la Cuenta de Resultados.

- Se reduce el tiempo empleado en el trabajo de auditoría. 
- Se extrapola parte del trabajo realizado en momentos anteriores al cierre del ejercicio contable, apareciendo así los conceptos de "auditoría preliminar" y "auditoría final".

El auditor ya no certifica sobre la información revisada sino que emite una opinión profesional sobre la representatividad de una información financiera o contable.

\subsubsection{Tipos de auditoría}

Atendiendo al objetivo que persiga la auditoría se puede realizar la siguiente clasificación 6 :

- Auditoría financiera o externa: que consiste en la revisión y verificación de los estados contables de la empresa, con el propósito de emitir una opinión profesional independiente sobre la razonabilidad de su presentación y elaboración.

- Auditoría interna: que conlleva la revisión y verificación del funcionamiento del sistema de control interno que opera en el seno de las sociedades, y que se encarga de la correcta ejecución de los procedimientos y normas que la propia empresa ha establecido para desarrollar su actividad.

- Auditoría de gestión: este tipo de auditoría supone la evaluación de la gestión llevada a cabo por los administradores, con los recursos con los que cuenta una organización empresarial, con el fin de contrastar los objetivos propuestos y los resultados obtenidos. 
De la clasificación descrita se deduce que el término "auditoría" es aplicable a múltiples y variadas actividades, pero siempre con la finalidad de evaluar y comprobar un hecho o comportamiento realizado por un agente independiente del auditor. La investigación que se lleva a cabo, en el presente trabajo, se circunscribe a la primera, la "auditoría financiera o externa", aunque guarda una estrecha relación con la auditoría interna y la de gestión.

\subsubsection{LA AUDITORÍA EN ESPAÑA}

\subsubsection{Origen de la auditoría en España}

Según Goxéns Duch (1985: 19) los antecedentes de la censura de cuentas se remontan a mediados del siglo XIX, ya que en el artículo 34 del Real Decreto 17/1848 sobre compañías mercantiles por acciones, y más tarde en la Real Orden de 12 de diciembre de 1857, se establecen las normas para la inspección de la contabilidad, apuntándose en el artículo decimocuarto de la Real Orden citada, que el Gobierno Civil exigirá copia de los balances generales comprobándolos con los libros de contabilidad.

Sin embargo no existe un desarrollo explícito de la figura del censor de cuentas hasta la creación del "Instituto de Contadores Públicos de España" en 1912, y posteriormente la del "Colegio de Contadores Jurados de Bilbao", en 1927, así como los Colegios de Madrid, Barcelona y Vigo que nacen en 1936 y que pasan a integrarse, más tarde, dentro del "Instituto de Censores Jurados de Cuentas de España" que surge como primer exponente de la auditoría, bajo la dependencia del “Consejo Superior de Colegios Oficiales de Titulares Mercantiles", el 15 de febrero de 1942, aprobándose sus estatutos

\footnotetext{
${ }^{6}$ Una amplia revisión sobre la tipología de la auditoría se puede ver en Wanden-Berghe y Trigueros
} 
por la Dirección General de Comercio y Política Arancelaria del Ministerio de Industria y Comercio el 16 de abril de 1945.

El "Instituto de Censores Jurados de Cuentas" se constituye como una organización profesional de Derecho Público vinculada orgánicamente al Ministerio de Economía y Hacienda, con personalidad jurídica propia, que agrupa a auditores. Posteriormente con la Ley 7/95, de 21 de junio, de la Generalidad de Cataluña, se crea como corporación profesional de Derecho Público y, por tanto, se independiza el "Colegio de Censores Jurados de Cuentas de Cataluña".

El desarrollo de la profesión auditora se ha visto entorpecido por la figura del "accionista censor de cuentas" que crea el artículo 108 de la Ley de Régimen Jurídico de las Sociedades Anónimas7 , de 17 de julio de 1951, ya que como indican Polo y Sánchez Calero (citados por Arana Gondra y Lasso de la Vega, 1977: 137-38) los informes de los accionistas censores son completamente ineficaces, quedando reducidos en la práctica a un mero trámite rutinario que nada informa y nada aclara a los restantes accionistas. Esta figura del accionista no ha supuesto sino una traba al desarrollo de los profesionales, puesto que nació con importantísimas limitaciones tanto por su falta de cualificación profesional como por su falta de independencia, ya que emiten un informe siendo ellos parte interesada.

\footnotetext{
(1996).

${ }^{7}$ El artículo 108 indica textualmente que "el balance, la cuenta de pérdidas y ganancias, la propuesta sobre distribución de los beneficios y la memoria deberán ser sometidos al examen e informe de los accionistas censores de cuentas, quienes por escrito propondrán su aprobación o formularán los reparos que estimen convenientes...En el ejercicio de su función, el censor podrá examinar por sí mismo la contabilidad y todos los documentos y antecedentes relativos a los hechos contables, pero su informe ...sólo habrá de referirse a la exactitud y veracidad de los datos consignados en el balance y cuenta de pérdidas y ganancias y a los criterios de valoración y de amortización seguidos en el ejercicio por la sociedad."
} 
También se hace referencia a la censura de cuentas en el Real Decreto 7/64, de 30 de abril, y en el Reglamento de la Bolsa de Comercio aprobado por el Decreto 1506/67, de 30 de junio, en el que se indica que aquellas empresas cuyos valores fueran admitidos a cotización, estaban obligadas a suministrar, a la "Junta Sindical de la Bolsa", balances y cuentas de pérdidas y ganancias certificadas por técnicos titulados miembros del "Instituto de Censores Jurados de Cuentas". Así, tal y como mencionan García Benau et al. (1998: 92), el sentido de dicha certificación consistía en que se "acreditara la coincidencia del contenido de las cuentas anuales con lo que figuraba en los libros contables de la sociedad", por lo que no se realizaba una auditoría como se concibe en la actualidad, y por tanto su eficacia era escasa.

Posteriormente la reforma del Código de Comercio de 1973 no supuso, como se pensó, una ayuda para el desarrollo de la profesión auditora sino que simplemente recogió el requisito de que toda auditoría debía ser realizada por un experto con titulación universitaria superior, de manera que muchos de los censores que realizaban la labor auditora quedaron excluidos.

En el año 1977 se aprueba el Real Decreto 871/77, de 26 de abril, sobre el "Estatuto Profesional de los Economistas, Profesores y Peritos Mercantiles", que en su artículo 4 otorga a los "Economistas" competencias profesionales en el campo de la verificación contable o auditoría creándose el "Registro de Economistas Auditores".

Años después se hace referencia a la función privativa de los “Censores Jurados de Cuentas" en el artículo 51.5 de la Ley 8/80, por la que se aprueba el "Estatuto de los Trabajadores", que recoge la emisión de un informe en los casos de extinción de relaciones laborales por causas tecnológicas, económicas o de fuerza mayor, así como en el artículo 25.3 de la 
Ley 13/1980 de Educación Física y Deportes que dispone la obligatoriedad para las Federaciones Deportivas de la auditoría de sus cuentas por Censores pertenecientes al ICJC. Sin embargo no aparece la figura del auditor como tal, hasta la entrada en vigor de la Ley 19/88, de 12 de julio, de Auditoría de Cuentas.

El TRLSA aprobado mediante el Real Decreto Legislativo 1564/89, de 22 de diciembre, en sus artículos 203 y siguientes, que tratan de la "verificación de las cuentas anuales", regula de forma expresa la figura del auditor de cuentas como profesional encargado de la revisión de las cuentas anuales y del informe de gestión.

En 1990 se aprueba el Real Decreto 1636/90, de 20 de diciembre, que desarrolla la Ley 19/88 de Auditoría de Cuentas, y queda conformado el cuerpo legislativo que rige la profesión auditora hasta nuestros días. A partir de dicho Reglamento, el ICAC se encarga de la emisión y publicación, a través de sus resoluciones, de las normas técnicas de auditoría que guían al auditor en la realización de su trabajo.

\subsubsection{Las Corporaciones profesionales de auditores}

En el ámbito profesional existen tres Corporaciones de Derecho Público que aglutinan a la práctica totalidad de auditores de cuentas de España, y que son reconocidas en la Disposición Transitoria cuarta del Reglamento de Auditoría de Cuentas que desarrolla la Ley 19/1988, de 12 julio, de Auditoría de Cuentas, a saber:

- El “Consejo General de Colegios de Economistas de España”. 
- El “Consejo Superior de Colegios Oficiales de Titulares Mercantiles de España".

- El "Instituto de Censores Jurados de Cuentas de España".

Las funciones que el artículo 75, del citado Reglamento, encomienda a las Corporaciones representativas de los auditores son las siguientes:

1. Elaborar, adaptar y revisar las normas técnicas de auditoría (NTA), mediante iniciativa propia o a instancia del ICAC.

2. Realizar los exámenes de aptitud profesional, y organizar, colaborar e impulsar los cursos de formación teórica y la práctica necesaria para superar dicho examen.

3. Organizar los programas de formación permanente y de actualización que deben realizar los miembros de las Corporaciones.

4. Efectuar el control de calidad sobre la actividad profesional desarrollada por sus miembros, velando por el cumplimiento de la Ley y el Reglamento de Auditoría de Cuentas, así como por las normas técnicas de auditoría de las Corporaciones.

5. Vigilar el cumplimiento de las normas deontológicas.

6. Colaborar con el ICAC y proponerle la iniciación del procedimiento sancionador. 


\section{- El Instituto de Auditores-Censores Jurados de Cuentas}

El "Instituto de Censores Jurados de Cuentas" es una corporación de Derecho Público creada, en el año 1942, en el seno del “Consejo Superior de Colegios de Titulares Mercantiles de España", aprobándose sus estatutos en 1945. El 24 de septiembre de 1982 actualizó su normativa orgánica para adaptarse a las nuevas circunstancias y homologar la profesión con el resto de países de la $\mathrm{CEE}^{8}$.

La estructura orgánica de la Corporación esta formada por una "Asamblea General" representativa de todos los miembros, como órgano soberano, y un "Consejo Directivo" y una "Comisión Permanente" como órganos rectores.

Además los auditores que pertenecen a esta Corporación se adscriben a la Agrupación o Ente Territorial más cercana a su domicilio o despacho profesional, existiendo un total de 15 agrupaciones y un colegio autonómico.

Las tareas específicas que guían la labor del Instituto son las siguientes:

1. Velar por la calidad profesional de los auditores.

2. Velar por el comportamiento deontológico de los auditores.

3. Defender y tutelar a los destinatarios de la auditoría de cuentas, que incluyen no sólo la empresa auditada, sino también a todos los usuarios interesados. 
4. Ayudar y proteger a los miembros de la Corporación.

\section{- El Registro de Economistas-Auditores}

Creado en el año 1982, como órgano especializado del "Consejo General de Colegios de Economistas de España", con la finalidad de profesionalizar el ejercicio de la auditoría de cuentas y formar un colectivo sujeto a disciplina institucional.

Su estructura orgánica esta compuesta por la "Asamblea General", el "Consejo Directivo", la "Gerencia", la "Asamblea Consultiva" y tres "Comités" específicos, el de formación, el de práctica profesional y el de normas y procedimientos. Teniendo el "Consejo Directivo" la potestad de constituir comisiones de trabajo internas cuando lo estime oportuno.

En el seno de los "Colegios de Economistas" de toda España se incluyen las "Secciones REA" que conforman la representación territorial de la institución y, junto a las "Comisiones de Auditoría", tienen la función de acercar los servicios institucionales al lugar de trabajo de sus miembros. Hasta la fecha existen nueve delegaciones territoriales del Registro de Economistas Auditores.

Según se expone en el artículo segundo del Reglamento, que rige la Corporación, las funciones principales que tiene la misma son las siguientes:

1. Elaborar, adaptar y revisar las normas técnicas, éticas y de conducta profesional así como velar por su cumplimiento.

\footnotetext{
${ }^{8}$ Los estatutos actuales que rigen el funcionamiento del Instituto de Auditores Censores Jurados de
} 
2. Colaborar con el ICAC en el ejercicio del control técnico y sancionador.

3. Desarrollar los cursos de formación teórica que se necesitan para acceder a la profesión, así como realizar los exámenes de aptitud.

4. Mantener la formación de sus miembros y ordenar el ejercicio profesional.

\section{- El Registro General de Auditores}

La tercera Corporación de Derecho Público que reconoce la Ley de Auditoría como representativa mercantiles o diplomados en ciencias empresariales.

\subsubsection{El papel del ICAC}

El "Instituto de Contabilidad y Auditoría de Cuentas" nace en virtud de la Ley 19/88 de Auditoría de Cuentas, como un organismo autónomo de carácter administrativo dependiente del Ministerio de Economía y Hacienda, sustituyendo al "Instituto de Planificación Contable" y por tanto asumiendo las competencias de éste en materias de planificación y normalización contable. Pero además, y en relación con el ejercicio de la auditoría de cuentas en el territorio nacional, se le atribuyen las funciones siguientes:

a) El control y disciplina del ejercicio de la actividad auditora de cuentas en el territorio nacional.

Cuentas de España (IACJC) han sido aprobados por el Real Decreto 2777/82 de 24 de septiembre. 
b) La homologación y publicación de las normas técnicas de auditoría elaboradas por las Corporaciones de Derecho Público representativas de los auditores.

c) La custodia y gestión del "Registro Oficial de Auditores de Cuentas".

d) El ejercicio de la potestad sancionadora sobre los auditores.

e) La aprobación del contenido de los programas para los exámenes de acceso a la profesión.

f) El control, vigilancia y custodia de las fianzas a constituir por los auditores ejercientes.

g) La realización y promoción de las actividades de investigación, estudio, documentación, difusión y publicación para la mejora de la normalización contable y la auditoría.

h) La armonización de las normas contables y de auditoría con las disposiciones de la Unión Europea.

i) La coordinación y cooperación en materia contable y auditora con los organismos nacionales e internacionales. 
Orgánicamente el ICAC queda estructurado, tal y como se indica en su estatuto9", en un órgano rector formado por el "Presidente" y el "Comité Consultivo", y las siguientes unidades de gestión:

- Secretaría General.

- Subdirección General de Normalización y Técnica Contable.

- Subdirección General de Normas Técnicas de Auditoría.

- Subdirección General de Control Técnico.

\subsubsection{LOS ORGANISMOS INTERNACIONALES DE AUDITORÍA}

1.1.3.1. La Federación Internacional de Contadores (International Federation of Accountants)

La “Federación Internacional de Contadores" se constituye, en 1977, como una institución internacional que aglutina diferentes organizaciones de contadores nacionales en todo el mundo y en los diferentes ámbitos de trabajo ya sea en el ámbito público, privado, en materia de educación, así como en otro tipo de organizaciones no formadas por contadores pero que están relacionadas de manera directa con los profesionales de la auditoría.

Actualmente forman parte de IFAC, 153 organizaciones de 133 países diferentes, que representan alrededor de 2 millones de contadores.

\footnotetext{
${ }^{9}$ El Real Decreto 302/1989, de 17 de marzo, aprueba el estatuto y la estructura orgánica del ICAC (BOE $\mathrm{n}^{\circ} 77$, de 31 de marzo), que ha sido modificado por el Real Decreto 1784/2000, de 27 de
} 
El objetivo de IFAC se traduce en el desarrollo, en el ámbito mundial, de la profesión de contador a través de la armonización de normas con la finalidad de prestar servicios de alta calidad al público.

Las principales funciones que la institución tiene encomendadas son las siguientes:

a) Actuar como defensora de la normalización internacional, que persigue la aplicación de patrones comunes a todos los contadores profesionales, a través de normas técnicas y éticas que sirvan para todos los sectores de actividad.

b) Actuar como líder para adaptar la profesión a las necesidades sociales y liberalizar los servicios de los contadores.

c) Facilitar el establecimiento de unas normas internacionales estándar para todos los contadores.

d) La IFAC se asocia y reconoce la labor que realiza, otra institución internacional creada en 1973, el IASC, en materia de emisión de normas internacionales de contabilidad.

La estructura rectora de IFAC se compone de un "Consejo" y una "Asamblea", el primero nace como órgano ejecutivo y está formado por 18 vocales de distintos países, mientras que el segundo es el órgano que agrupa a los representantes de todas las organizaciones nacionales que forman la federación.

octubre. 
Los pronunciamientos que emite IFAC son las "normas" y "declaraciones", que recogen reglas contables y documentos de recomendación asociados a las áreas de auditoría y servicios relacionados, ética, formación, contabilidad de gestión y sector público.

\subsubsection{El Instituto Americano de Auditores (American Institute of Certified $\underline{\text { Public Accountants) }}$}

El "Instituto Americano de Auditores", nacido en 1887, es la asociación que reúne a los profesionales colegiados que ejercen en el campo de la auditoría en Estados Unidos ${ }^{10}$, y que supone, sin duda, un organismo de referencia para la profesión en todos los países del mundo dado su prestigio y grado de desarrollo en materia de contabilidad y auditoría, su principal propósito es el de proveer a sus miembros con la preparación y actualización necesaria que satisfaga con calidad las demandas de sus clientes y de la sociedad en general. Para la consecución de su propósito se plantea, entre otros, los siguientes objetivos:

a) Velar por el futuro de la profesión contable.

b) Desarrollar los medios necesarios para conseguir la especialización dentro de la profesión, así como informar, asistir y actualizar a sus miembros.

\footnotetext{
${ }^{10}$ Como indica el profesor Sánchez Fernández de Valderrama (1997: 49) “a pesar de haber sido Gran Bretaña la cuna de la auditoría, es en los Estados Unidos donde la profesión se manifiesta, regula y organiza, en la forma que actualmente conocemos. Ello es debido al gran desarrollo económico de esta nación y a la existencia del más importante mercado de capitales del mundo, la Bolsa de Valores de Nueva York".
} 
c) Promover y alentar el conocimiento de la información contable como instrumento útil, comprensible y beneficioso para los usuarios.

d) Fomentar la comprensión de las competencias, responsabilidades y profesionalismo de los auditores entre el público y la comunidad empresarial.

e) Trabajar por una regulación de la profesión más uniforme.

La estructura orgánica de AICPA se compone de tres cuerpos diferenciados; un "Consejo de Gobierno" encargado de desarrollar los programas y la política del Instituto, con aproximadamente 260 miembros que representan a todos los estados que componen el territorio norteamericano; una "Junta Directiva" que actúa como comité ejecutivo del Consejo, dirigiendo las actividades del Instituto y se compone de 23 miembros; y una "Junta Mixta" que promueve la uniformidad de las normas profesionales.

\subsubsection{El Instituto de Contadores de Inglaterra y Gales (Institute of} Chartered Accountants in England \& Wales)

El "Instituto de Contadores de Inglaterra y Gales" se constituye en 1880, y es en la actualidad el cuerpo de profesionales de la contabilidad más importante del Reino Unido con unos 118.000 miembros. Los profesionales que acceden a la profesión a través del instituto están habilitados para ejercer de auditores de cuentas.

Las principales funciones de ICAEW son las que siguen: 
a) Preparar y actualizar los conocimientos profesionales de los Contadores.

b) Mantener y velar por el cumplimiento de las normas de conducta ética entre sus miembros.

c) Proveer de los servicios que necesitan sus afiliados así como los estudiantes de la profesión.

d) Promover el avance de la teoría y práctica de la contabilidad.

El gobierno del Instituto lo ejercen sus miembros, mientras que el poder ejecutivo lo desarrolla un "Consejo" cuyos integrantes eligen un "Presidente" y unos representantes. Además existen comités de miembros que se constituyen para decidir sobre asuntos concretos. La administración del día a día recae en un staff permanente encabezado por el "Secretario General" cuya misión conlleva la gestión de los recursos humanos y financieros, el resto de tareas se encomiendan a tres "Direcciones":

1. La Dirección de formación.

2. La Oficina de las normas profesionales.

3. La Dirección de miembros.

\subsubsection{La Federación Europea de Expertos Contables (The European} Federation of Accountants)

La "Federación Europea de Expertos Contables", nacida el 1 de enero de 1987, es la asociación más representativa de la profesión contable de Europa, al incluir entre sus miembros a 38 organizaciones profesionales de 26 
países diferentes. La FEE al crearse absorbe a dos instituciones que, separadamente, velaban por el desarrollo de la profesión en el ámbito Europeo, la “Unión Europea de Expertos Contables, Económicos y Financieros (UEC11)" y el “Grupo de Estudio de Expertos Contables de la CEE", constituidas en 1951 y 1961 respectivamente.

El órgano de gobierno de la federación es la "Asamblea General" que se convoca cada dos años, mientras la dirección de la institución recae en el "Consejo".

Uno de los objetivos que recogen sus estatutos es el de promocionar y armonizar la práctica de la auditoría en Europa, tanto en el sector público como privado. Aunque el campo de actividad de la FEE es muy amplio, contabilidad, fiscalidad, contabilidad pública, banca, seguros, mercados de capitales, etcétera, en el ámbito de la profesión auditora juega un papel muy importante al haber desarrollado numerosos estudios entre los que cabe destacar los siguientes:

- Continuous Quality Assurance - Statutory Audit in Europe.

- Setting the Standards - Statutory Audit in Europe.

- Statutory Audit Independence and Objectivity.

- Discussion Paper on Providing Assurance on Environmental Reports.

\footnotetext{
${ }^{11}$ Como señalan Vela Pastor y Marco Granell (1982: 15) la creación de la UEC constituye uno de los primeros intentos que los profesionales de la contabilidad llevaron a cabo en orden a la armonización de las prácticas de dicha disciplina en distintos ámbitos geográficos.
} 


\subsection{LA AUDITORÍA DE CUENTAS COMO SERVICIO PROFESIONAL}

\subsubsection{LA FUNCIÓN DEL AUDITOR DE CUENTAS}

Este epígrafe aborda la función que ha desarrollado la auditoría de cuentas desde sus orígenes hasta nuestros días, y concretamente el rol que cumple el auditor en la sociedad entendido como "el conjunto de actitudes, valores y comportamientos que la sociedad adscribe a los individuos que mantienen la condición de auditores" (Beck, 1973: 118). Así, se ha distinguido entre la función original que cumplía el auditor durante el siglo XIX, a la que se ha hecho referencia, es decir lo que se esperaba de la auditoría en el momento de su reconocimiento como profesión, hasta la función actual que cumple el auditor hoy en día, diferenciando dentro de la función actual cuatro perspectivas: la profesional, la social, la económica y la legal.

\subsubsection{Función original}

La auditoría de cuentas nace en el momento en el que se separan la propiedad de la empresa y la gestión de la misma, a partir de las grandes sociedades anónimas donde los dueños del capital y el gestor no se conocen, de manera que los propietarios necesitan que una persona experta e independiente intervenga y dictamine sobre el uso y gestión de su aportación social. Debido a este contrato de agencia, entre propietarios del capital y administrador como agente, surge el servicio de auditoría, mediante el cual el auditor actúa, tal y como señalan Larriba y Gonzalo (1996: 10), como “validador de la información" que suministra el órgano de gestión. 
La relación de agencia se caracteriza por dos rasgos principales:

1. El hecho de que entre los participantes se produce una asimetría en la información, ya que los propietarios del capital suelen tener datos incompletos o nulos sobre la información con la que cuenta el gerente para tomar sus decisiones.

2. El hecho de que se produce un conflicto de intereses entre las partes, debido a que ambos tratan de maximizar sus utilidades que no son coincidentes (Segovia, 1998: 907).

En principio la censura de cuentas no tenía una función pública, tal y como se entiende hoy en día, constituyendo tan solo un negocio privado entre dos partes interesadas, un auditor, que debía realizar un trabajo de revisión de la contabilidad responsabilidad de la gerencia en busca de errores y fraudes, y la persona que le hizo el encargo.

\subsubsection{Función actual}

Como se ha visto la auditoría tuvo en su origen un objetivo de búsqueda de fraudes y errores, que suponía la revisión de la totalidad de las operaciones contables con el fin de verificar la exactitud aritmética de las cifras del balance. Sin embargo esta finalidad inicial ha sido superada y su objetivo actual consiste en emitir un juicio profesional sobre la razonabilidad en la elaboración de unos estados financieros, que deben formularse según unos "principios de contabilidad generalmente aceptados". En este sentido, el auditor no emite una certificación, puesto que no tiene una total certeza de la veracidad de dichas cuentas anuales al no haberlas revisado en su totalidad, sino que simplemente emite una opinión profesional, como 
experto en la materia. No obstante, dicha opinión tiene una repercusión que supera al demandante que solicita el servicio del auditor, puesto que su dictamen influye en terceras personas interesadas, ya sean proveedores, clientes, inversores, entidades financieras, instituciones, etc. De forma que un servicio, que nace en virtud de un contrato privado, tiene efectos en buena parte de la sociedad, lo que conduce a pensar que el auditor, de alguna manera, otorga "fe pública" sobre la credibilidad de unas cuentas anuales basándose en su criterio profesional y, por tanto, actúa como una especie de notario o fedatario público.

Ésta función actual se puede observar desde diferentes perspectivas como son la profesional, social, económica y legal.

\section{- Carácter profesional}

Con la expresión "carácter profesional" se hace referencia a la naturaleza profesional de la auditoría de cuentas aunque no esté expresamente reconocida por la Ley, en la que sólo se contempla como una actividad. El auditor de cuentas es, por tanto, un profesional reconocido en un "Registro Oficial" que presta un servicio muy determinado a las empresas, y que en el ejercicio de su trabajo debe guardar una serie de normas técnicas de obligado cumplimiento que sirven de guía al desarrollar su labor y que garantizan la prestación de un servicio de calidad a su clientela.

\section{- Carácter social}

Como indica el profesor Fernández Pirla (1992: 9) "la función auditora es inherente al carácter social de la contabilidad". Así la auditoría de cuentas, 
como es obvio, también cumple una función social, cada vez más visible o exigible, puesto que tiene repercusiones en la economía de las naciones hasta el punto que puede incidir en aumentar o rebajar la credibilidad del sistema de información económico-financiera que tienen las economías desarrolladas. La marcha de las empresas, como entidades privadas, no sólo afecta los intereses de sus accionistas, como propietarios de las mismas, sino que tiene efectos determinantes sobre el buen funcionamiento de las economías nacionales que tienden a ser más interdependientes y globalizadas, como así lo reconoce la Ley 19/1988, de Auditoría de Cuentas, en cuya exposición de motivos señala que "la auditoría de cuentas es un servicio que se presta a la empresa privada y que afecta e interesa no sólo a la propia empresa, sino también a terceros que mantengan relaciones con la misma". En este sentido Ruiz Blanco (1997: 1142) indica que los auditores han tomado conciencia del interés mostrado por el público en general y la Ley de Auditoría ha incorporado "la tendencia a reconocer la responsabilidad social del auditor... teniendo en cuenta la mayor participación de la sociedad en la actividad económica".

El buen funcionamiento de las sociedades depende de muchos factores, pero sobre todo de la gestión de sus administradores, aunque repercute también sobre los empleados, acreedores, clientes, instituciones públicas, inversores, entidades financieras y público en general quiénes se ven afectados en una mayor o menor medida por dicho funcionamiento. Por ello, la auditoría tiene una función social compleja e importante que no se circunscribe, en exclusiva, al ámbito privado, de manera que de no existir la figura del auditor, el Estado como garante del interés general debiera intervenir o controlar la actividad de las sociedades. 
Siguiendo este razonamiento cabe preguntarse cuál es la función social que otorga el carácter de "bien público" a la auditoría de cuentas, entendida esa función social como "externalidad" puesto que los beneficios derivados de la fiabilidad que aporta la auditoría a la información financiera, se extienden no solo a las personas que han encargado el servicio sino a todos los interesados en las cuentas anuales auditadas de las empresas, a las que se debe dar publicidad por obligación legal; basta sólo con solicitar dichas cuentas en el Registro Mercantil, para que terceras personas ajenas al encargo de la auditoría puedan beneficiarse de la actividad desempeñada por el auditor y encargada por un particular, de manera que, como indica García Benau et al. (1998: 37), "cabe la posibilidad de apropiarse de los beneficios que aporta el servicio realizado sin contribuir a su coste", hasta alcanzar una situación en la que el mercado puede no llegar a funcionar como mecanismo eficiente en la provisión del servicio de auditoría.

En este sentido como dice el profesor Samuelson (1988: 865) "los beneficios de un "bien público", a diferencia de los que se derivan de un "bien puramente privado", producen efectos externos de consumo indivisibles en más de un individuo. Por el contrario, si un bien se puede subdividir de manera que vender cada parte es posible competitivamente por separado a diferentes individuos sin producir ningún efecto externo en el resto, se trata de un bien privado". En el caso de la auditoría, y por la publicidad a que se someten las cuentas anuales de las empresas, se trata de un "bien público" que tiene repercusiones sobre personas ajenas a quienes lo solicitan. Sin embargo, parece impensable que la auditoría de cuentas pueda ser un servicio suministrado por el Estado a la Sociedad, y sólo tendría cabida esta posibilidad cuando la iniciativa privada no fuese capaz de proveerlo por no ser rentable, en cuyo caso, no cabe duda, que la Administración debería tratarlo como "bien público"; así como en el caso que 
la empresa privada fracasara o no fuera eficiente en la prestación del servicio, es decir, cuando la sociedad no estimara cubiertas sus necesidades.

\section{- Carácter económico}

Enlazando con lo expuesto anteriormente, la auditoría de cuentas tiene un "carácter económico" en el sentido que, al tratarse de un servicio prestado por la iniciativa privada, debe perseguir siempre la maximización del beneficio o rentabilidad derivada del ejercicio de su actividad. Lógicamente el auditor, como profesional liberal, tiene restricciones de tiempo y recursos que condicionan el desarrollo y calidad de su trabajo, y que actúan como una constante al estudiar el servicio que presta el auditor a la sociedad.

\section{- Carácter legal}

La auditoría de cuentas se realiza, en su mayor parte, como consecuencia de una obligación legal ${ }^{12}$ que, sobre la base de unos parámetros de dimensión y cifra de ventas, supone que las sociedades anónimas medianas y grandes deban someter sus cuentas a revisión por un auditor cualificado. Este carácter, o perspectiva legal de la auditoría de cuentas, nace como consecuencia de la citada función social o de la repercusión que tiene el buen o mal funcionamiento de las empresas en la sociedad. Lo que ha llevado a los gobiernos de las naciones a intervenir y habilitar un mecanismo

\footnotetext{
${ }^{12}$ Según establece el TRLSA en su artículo 203, en general todas las sociedades anónimas que no puedan formular balance abreviado durante dos ejercicios consecutivos, están obligadas a auditarse. Los requisitos para formular balance abreviado originarios del artículo 181 del TRLSA aprobado por el Real Decreto Legislativo 1564/1989, han sufrido dos modificaciones posteriores para adaptarlos a la legislación comunitaria, primero a través de la Disposición Adicional segunda de la Ley 2/1995, de 23 de marzo, de Sociedades de Responsabilidad Limitada y después por el Real Decreto 572/1997, de 18 de abril, hasta dejarlos en las cifras siguientes: a) el total de las partidas del activo no supere 395 millones, b) el importe neto de la cifra de negocio no supere los 790 millones, c) el número medio de empleados no sea superior a 50. Véase en Larriba Díaz-Zorita (1999).
} 
que garantice que, al menos, aquellas empresas que puedan tener una incidencia económico-social relevante permanezcan bajo un cierto grado de revisión o supervisión por agentes independientes de las mismas, de manera que no se deja el servicio totalmente en manos de la iniciativa privada, sino que el Estado obliga, en interés de la comunidad, y de los propios socios, a que se obtengan unas mínimas garantías de calidad de la información contable que suministran las compañías.

La Ley 19/1988, de Auditoría de Cuentas, en la exposición de motivos, expresa que con la revisión de las cuentas anuales se persigue una mayor transparencia de la información económico-contable de la empresa, como elemento consustancial al "sistema de economía de mercado", ya recogido en el artículo 38 de la Constitución Española. Además la integración de España en la Unión Europea, requiere la adaptación de la legislación nacional, a lo establecido para el conjunto de Europa, con el fin de permitir un mejor funcionamiento de las empresas por un conocimiento de su situación patrimonial y financiera de mayor calidad, circunstancias que repercuten directamente en una mayor eficiencia del "sistema de economía de mercado".

No obstante esta obligación legal de la auditoría ha tenido una tendencia a reducirse, puesto que los parámetros que han delimitado su obligado cumplimiento han sido modificados al alza de manera reiterada, por lo que cada vez son menos las empresas obligadas a auditarse. Parece razonable pensar que el motivo que ha llevado a las autoridades estatales a reducir el cupo de empresas que deben auditarse no es otro que el de evitarles unos gastos excesivos, cuando su dimensión sea pequeña. Pero, cabe plantearse, también, por qué las cuentas anuales de las pequeñas y medianas empresas no se auditan de forma obligatoria puesto que su 
incidencia en las economías nacionales y en los intereses sociales, aunque es pequeña de forma aislada, es muy relevante en su conjunto ya que constituyen el verdadero motor de muchas economías, como en el caso español. Un planteamiento alternativo consistiría en fijar unos honorarios que se ajustasen al tamaño y capacidad económica de las diferentes empresas, con el fin de que todas, independientemente de su dimensión, fueran auditadas, con lo que se ganaría en credibilidad de la información económico-financiera $\mathrm{y}$, por tanto, en un marco más transparente para la actividad económica.

\subsubsection{LOS AGENTES INTERVINIENTES Y USUARIOS DEL SERVICIO DE AUDITORÍA}

En el marco del servicio de auditoría de cuentas se han identificado dos grupos participantes que son independientes, pero vinculados ambos al trabajo del auditor: en primer lugar las dos partes que intervienen de forma activa en el servicio, auditor y empresa, y en el segundo todos los agentes que de forma pasiva se interesan por la opinión profesional del auditor.

\subsubsection{Las partes contratantes}

La labor que presta el auditor surge en virtud de un contrato ${ }^{13}$ privado entre dos partes, el auditor y la empresa auditada. A raíz de la "carta de encargo" o "contrato de auditoría" el auditor se compromete a realizar un trabajo de auditoría de cuentas y a emitir su juicio profesional sobre los estados financieros que audita, mientras la empresa queda obligada a efectuar una contraprestación económica que remunera los servicios recibidos del auditor. Auditor y empresa son, sin duda, los sujetos interesados y relevantes en torno al servicio de auditoría de cuentas. 
No obstante, y debido a que la mayoría de los trabajos de auditoría de cuentas anuales no se realizan de manera voluntaria sino obligatoria, aparece un tercer interviniente en el servicio, el Estado, como parte preocupada en velar por los intereses de la sociedad a través del establecimiento de la obligatoriedad de la auditoría en el caso de aquellas sociedades cuyo funcionamiento puede tener repercusiones importantes en la economía nacional; de manera que aquellas empresas que superan unos determinados límites de tamaño deban auditarse, para que sus cuentas sean intervenidas por un profesional ajeno a las mismas que, por su independencia y preparación, pueda juzgar la veracidad de dicha información económicofinanciera.

\subsubsection{Los usuarios ajenos al contrato}

Junto a las partes directamente relacionadas con el servicio de auditoría, y a causa del interés social que conlleva la misma, se encuentra un público interesado en conocer la opinión que el auditor ha dictaminado sobre la fiabilidad de las cuentas anuales de la empresa. Este grupo de terceros está compuesto, a grandes rasgos, por los siguientes colectivos:

- Los acreedores: cualquier persona o sociedad que mantenga relaciones con la sociedad auditada, y que la sitúen en una posición acreedora, siempre va a interesarse por la labor que lleva a cabo el auditor y el tipo de opinión profesional que emite, por cuanto dicha información puede serle útil para calibrar las posibilidades de cobro de sus créditos. Dentro de este grupo se incluyen:

\footnotetext{
${ }^{13}$ Un amplio tratamiento de la naturaleza jurídica del vínculo que liga al auditor con la sociedad se puede consultar en Pacheco Cañete (2000: 93-112).
} 
- Los acreedores comerciales: proveedores y acreedores de la empresa por sus relaciones comerciales.

- Las entidades financieras: igualmente interesadas en la opinión del auditor por las repercusiones que para el cobro, puede tener la posible insolvencia de las empresas a las que financian.

- El personal de la empresa: los empleados de la sociedad también pueden ser parte interesada en la realización de una auditoría de cuentas, en aquellos casos en que vean el servicio como una información relevante para tener conocimiento de la situación financiera de la empresa y como medio de comprobar su estabilidad laboral ante situaciones de crisis.

- Los inversores: grupo constituido por los inversores potenciales o reales en las empresas auditadas, y sobre todo en aquellas compañías cuyos títulos están admitidos a cotización en los mercados bursátiles, puesto que la información contenida en el dictamen del auditor puede ser relevante en el proceso de toma de decisiones.

- El Estado: representado tanto por la administración central como por la autonómica y por la local, está interesado en la auditoría de cuentas, por su función recaudadora de tributos a la que puede contribuir el papel de censura de cuentas que conlleva la propia auditoría y que puede poner de relieve fraudes a la Administración. Aparte de jugar un papel esencial como impulsor de la obligación de auditarse a determinadas empresas, velando por la transparencia del mercado como ente representativo de la sociedad. 


\subsubsection{LOS SERVICIOS QUE PRESTA EL AUDITOR Y SU INDEPENDENCIA}

El auditor de cuentas presta un servicio profesional de verificación contable que en la mayoría de las ocasiones viene a corresponder con la "auditoría de cuentas anuales", pero que no sólo se limita a ésta puesto que cada vez se le demanda una mayor variedad de tareas, que, a veces, se circunscriben a comprobaciones sobre determinados aspectos de la contabilidad de las empresas y a la emisión de dictámenes u otro tipo de revisiones limitadas. No obstante junto a los servicios que pueden constituir el núcleo de su actividad, muchos auditores de cuentas en España, realizan otros servicios que tradicionalmente han venido prestando a las empresas y que son más antiguos que la propia auditoría moderna; es el caso de los asesores y consultores de empresas en materia contable, financiera, fiscal, laboral, jurídica, seguros, recursos humanos, organización de empresas, gestión, calidad, implantación de sistemas de información, etc., que junto a dichos servicios han añadido el de la auditoría de cuentas como parte de los servicios integrales que prestan a sus clientes. En este sentido cabe apuntar dos grandes grupos de profesionales de auditoría diferenciados:

- Por un lado se encuentran los auditores personas físicas que junto a los servicios de asesoramiento de empresas en materias fiscales, contables, etcétera, prestan un servicio adicional de auditoría de cuentas. Se trata por tanto de profesionales cuya labor principal es la asesoría de empresas y que de manera esporádica cuando sus clientes, pequeñas y medianas empresas, se ven afectados por la obligación legal de auditarse reciben el servicio adicional de auditoría de cuentas. En estos casos puede plantearse el grave problema de la falta de objetividad del auditor, puesto que en numerosas ocasiones el auditor revisará 
y comprobará una información contable y fiscal de la sociedad auditada que él mismo ha elaborado o asesorado, en cuyo caso la objetividad e imparcialidad del auditor corre el riesgo de desaparecer.

- Por otro lado aparecen las sociedades de auditoría que en función de su tamaño y de los profesionales con que cuentan pueden incurrir en la misma problemática que los anteriores. En el caso de sociedades de auditoría de mayor tamaño se encuentran aquellas que tienen departamentos o divisiones diferenciadas en función de los servicios que prestan a sus clientes; respetando, en principio, la imparcialidad y objetividad que debe primar en el trabajo del auditor de cuentas. En cuanto a las grandes multinacionales de auditoría, se está asistiendo a un proceso por el cual las diferentes divisiones con que cuentan para prestar toda clase de servicios a sus clientes, se desmiembran de sus matrices y separan en sociedades independientes, con lo que se consigue una exclusividad en la prestación de los servicios que puede proporcionar una mayor especialización y objetividad ${ }^{14}$.

\footnotetext{
${ }^{14}$ Véase Expansión n ${ }^{\circ} 4261$, de 8 de agosto de 2000, en el que se hace referencia a la separación de las dos filiales de Andersen Worldwide, la firma de consultoría Andersen Consulting y la firma de auditoría Arthur Andersen. Además frente al proceso de unión de las grandes multinacionales de auditoría para hacer frente a la tendencia globalizadora de la economía mundial, como en el caso de las firmas Price Waterhouse y Coopers \& Lybrand que dio lugar en 1997 a la segunda firma mundial de auditoría y consultoría de empresas, PricewaterhouseCoopers, se ha interpuesto un obstáculo que puede cambiar la tendencia globalizadora, la Securities and Exchange Commission (SEC) norteamericana que junto a otras instituciones como la Federal Trade Comisión de USA y la Comisión Europea de la competencia, se opusieron a que otras dos grandes multinacionales de la auditoría se fusionaran, Ernst and Young y KPMG Peat Marwick, debido a que la prestación de servicios de auditoría y consultoría a un mismo cliente podían hacer perder la independencia de la firma. En este sentido la Comisión del Mercado de Valores de los Estados Unidos pretende que las grandes multinacionales de auditoría separen su negocio de auditoría del resto de actividades que realizan.
} 


\subsubsection{La demanda de servicios multidisciplinares}

Los clientes de los auditores y firmas de auditoría suelen demandar un servicio de asesoramiento integral que satisfaga sus necesidades de forma global, y que redunde en un menor coste y mayor rendimiento de los servicios que obtienen, así "el desarrollo de despachos multidisciplinares y su integración en organizaciones multiprofesionales es la respuesta a una demanda de mercado" (Durández Adeva, 1999: 9), por ello, la tendencia del mercado de los profesionales liberales en las ramas sociales va encaminada a recoger dentro de un mismo despacho profesional a auditores, economistas, abogados, ingenieros, informáticos, etc., que sean capaces de dar respuesta a las demandas de las empresas. En este sentido, García Benau et al. (1998: 151), hacen referencia a que la prestación de otros servicios adicionales implica dos tipos de ventajas "por un lado que determinados costes fijos son compartidos por auditoría y otros servicios como la consultoría, y por otro que la provisión conjunta genera eficiencias de conocimiento que se trasladan entre servicios".

Como indica Almela Díez (2000: 82), y como parte del proceso "globalizador de la economía", los profesionales de la auditoría "también adaptan sus estructuras a este planteamiento global y ofertan una mayor calidad y cantidad de servicios. Los despachos inicialmente dedicados a la auditoría de cuentas han entendido la necesidad de incorporar nuevos profesionales expertos en consultoría y asesoría legal, como ampliar el campo de acción de la auditoría más allá de la revisión de las cuentas del balance, me refiero a las auditorias medioambientales, a las auditorias laborales, etc." 
Dentro de los servicios que se solicitan a los despachos de profesionales, en los que aparece la figura del auditor, cabe señalar los siguientes:

1- "Auditoría de cuentas anuales", que se realiza, en la mayoría de los casos, como fruto de una obligación legal, que requiere de la emisión de una opinión profesional sobre el grado de fiabilidad con que se ha elaborado el balance, la cuenta de pérdidas y ganancias y la memoria explicativa de las mismas.

2- Trabajos de "revisión limitada" y "certificados" sobre la contabilidad, en los casos donde la legislación mercantil obliga a las sociedades que determinadas operaciones económicas, por su importancia y trascendencia, vengan intervenidas por un auditor de cuentas que dé fe de su veracidad, como en el caso de fusiones, liquidaciones y escisiones de empresas, ampliaciones y reducciones de capital, etc. Este tipo de revisiones, que en la legislación española son desarrolladas por el $\mathrm{ICAC}^{15}$, aparecen contempladas a través de las normas internacionales de auditoría de IFAC dentro del área de "Servicios Relacionados", y concretamente en las normas 910

\footnotetext{
${ }^{15}$ Aparte del "Informe de auditoría de cuentas anuales" los auditores pueden realizar y emitir informes sobre determinadas operaciones societarias a instancias de las empresas, a estos otros informes el Reglamento de Auditoría los denomina "Informes de revisión y verificación de otros estados o documentos contables". Estos informes de revisión limitada tienen por objeto la emisión de un dictamen dirigido a poner de manifiesto una opinión técnica sobre si la información contable revisada refleja adecuadamente los hechos económicos acaecidos en la sociedad, de acuerdo a los principios y normas contables que resulten de aplicación. Aparte del "Informe de auditoría de cuentas anuales" y de los "Informes de revisión y verificación limitados", la disposición adicional tercera del Reglamento de Auditoría de Cuentas, recoge la posibilidad de que el auditor desarrolle otros trabajos que no teniendo la consideración de los anteriores estén atribuidos por disposiciones legales a los mismos y que han de realizarse de acuerdo a la normativa específica que marque la Ley, aplicándose con carácter subsidiario las normas técnicas de los auditores. La legislación mercantil hace referencia a los mismos con la denominación de "informes especiales", "informes complementarios" y "certificaciones". Véase en "Otros trabajos que pueden realizar los economistas auditores", De Agustín Melendro y Gironella Masgrau (1999) y Casals Creus et al. (1998) pág. 631 y ss.
} 
"Auditoría limitada de los estados financieros" y 920 "Encargos de aplicar determinados procedimientos acordados con el cliente". Como indica Vergés Mamé (1998: 17) “estos servicios, aunque no entran propiamente en el ámbito de la auditoría de cuentas, constituyen sin embargo una parte, en ocasiones relevante, del trabajo profesional de auditoría".

3- "Peritajes, tasaciones y valoraciones" de empresas, activos, etc., que solicitan los clientes a los auditores por su buena cualificación profesional.

4- "Asesoramiento contable", que se solicita de los auditores por su muy alta preparación y experiencia, en materias como llevanza de la contabilidad, teneduría de libros y elaboración de las cuentas anuales, estados financieros intermedios y previsionales, etc., pero que, obviamente, resulta incompatible con la realización del servicio de auditoría al tiempo que se lleva la contabilidad de la sociedad. En este servicio se incluyen aquellos trabajos que las normas internacionales de auditoría definen como "Servicios Relacionados", a través de la norma 930 "Compromiso de elaborar información financiera", donde se señala que en este tipo de trabajos "se encarga al auditor la utilización de su experiencia contable diferente a su experiencia en auditoría para recopilar, clasificar y agregar información financiera" (IFAC, Traducido por Tua y Gonzalo, 1999: 930)

5- "Asesoramiento en materia fiscal", para la gestión y liquidación de los diferentes impuestos que gravan a las sociedades y sus relaciones con la Hacienda Pública y la Inspección de Tributos, servicio que tradicionalmente vienen prestando los titulares mercantiles, 
diplomados en ciencias empresariales, economistas y abogados, al que han incorporado la auditoría como un servicio adicional.

6- "Asesoramiento laboral", que recoge la elaboración de nóminas, seguros sociales, y en general todo tipo de relaciones que surgen entre el personal y la empresa, así como la gestión de las relaciones de la misma con la Seguridad Social y la Inspección de Trabajo; aunque no sea una materia donde el auditor de cuentas como tal pueda ejercer, sigue siendo otro de los servicios que se solicitan a los despachos multidisciplinares y que éstos prestan a través de sus diferentes departamentos.

7- "Asesoramiento jurídico o legal", que los despachos de profesionales satisfacen a través de su gabinete jurídico de abogados.

8- "Asesoramiento económico-financiero", también conocido, con la denominación inglesa, "corporate finance", para la elaboración de proyectos de inversión y financiación de las empresas, planes de viabilidad, etc.

9- "Auditoría de gestión", que consiste en la censura de la política de gestión que realiza la gerencia de la empresa, a través de la revisión y valoración de la misma. Se trata como indica Almela Díez (1996: 17) de “dictaminar acerca de que los estados financiero-contables no sólo son aceptables sino que también son representativos de una gestión correcta y acertada, puesto que de ello depende en gran medida el futuro de la empresa". 
10- "Auditoría operativa", donde se estudia y evalúa el funcionamiento eficaz y eficiente de los métodos de organización de la empresa, y por tanto queda entrelazada con la auditoría interna.

11- "Auditoría de prevención de riesgos laborales", recogida en el vigente Reglamento, aprobado por el RD 39/1997, que desarrolla la Ley de Prevención de Riesgos Laborales para aquellas empresas con más de 500 empleados, o para las que teniendo entre 250 y 500 desarrollen actividades que impliquen un alto grado de peligrosidad, y que se define en su artículo 30 "como instrumento de gestión que ha de incluir una evaluación sistemática, documentada y objetiva de la eficacia del sistema de prevención"16.

12- “Auditoría medioambiental”, definida por la Unión Europea como un instrumento de gestión que comprende una evaluación sistemática, documentada, periódica y objetiva de la eficacia de la organización, el sistema de gestión y procedimientos destinados a la protección del medio ambiente ${ }^{17}$.

13-"Auditoría interna", que comporta la revisión y verificación del funcionamiento del sistema de control interno que opera en el seno de las sociedades, y que se encarga de la correcta realización de los procedimientos y normas que la propia empresa ha establecido para desarrollar su actividad.

\footnotetext{
${ }^{16}$ Véase el artículo 30 de la Ley 31/1995 de Prevención de Riesgos Laborales.

${ }^{17}$ Según consta en el Reglamento 1836/93, de 29 de junio, del Consejo de la Unión Europea por el que se permite que las empresas del sector industrial se adhieran con carácter voluntario a un sistema comunitario de gestión y auditoría medioambientales (DOCE $\mathrm{n}^{\mathrm{o}} \mathrm{L} 168$, de 10-7-93), aunque no se empezara a aplicar hasta 1995. Como indican Llul y Perelló (2000: 64) y según la estimación de la FEE en mayo de 2000, las firmas de auditoría están participando en la verificación del $70 \%$ de los informes medioambientales auditados.
} 
14- "Auditoría del sector público", que cumple la misión de verificación contable pero en el ámbito de las entidades y sociedades de propiedad pública.

15- “Auditoría de legalidad", consistente en la comprobación por parte del auditor del cumplimiento de la normativa aplicable a una determinada entidad.

16- "Implantación de Sistemas de Calidad", con la finalidad de que las sociedades puedan obtener la certificación "ISO" en sus organizaciones. Los propios auditores reconocen que "tenemos los conocimientos y experiencia para ayudar a las empresas a prepararse y establecer los controles adecuados para que pueda obtener la certificación mediante la revisión, adecuación o implantación de procedimientos y de un sistema de calidad" (IACJC n ${ }^{\circ}$ 17, 2000: 81).

17- “Auditoría Informática”, cuyo fin principal es comprobar el correcto funcionamiento de los sistemas de información existentes en la empresa. Tal y como se expresa en las conclusiones de la primera ponencia, "Auditoría de Riesgos: Medioambiente, Informática, Riesgos Laborales" del XII Congreso Nacional del IACJC, se trata de áreas que pueden tener un efecto significativo en las cuentas anuales y que el auditor debe evaluar a través de sus propios medios o recurriendo a expertos, además se indica que " al ser riesgos elevados traen consigo la existencia de enormes oportunidades de -servicios complementarios- por parte del auditor" (IACJC no 17, 2000: 80).

18- "Servicios actuariales o de seguros". 
19- "Auditoría en Internet", conocida como "Web Trust", con la finalidad de certificar la transparencia de las prácticas comerciales, la integridad de las operaciones y la protección de datos personales en los "websites", que ha sido desarrollada por AICPA en Estados Unidos y CICA en Canadá y adoptada por el IACJC de España (IACJC n ${ }^{\circ}$ 7, 2000: 38).

20-“Auditoría de seguridad en materia de protección de datos personales", a raíz de la promulgación de la legislación que, a partir de 1999, regula las medidas de seguridad que deben tomar las empresas que manipulan y tratan datos de carácter personal, surge la necesidad de realizar una auditoría externa o interna para verificar el cumplimiento de determinadas normas de seguridad y protección de datos ${ }^{18}$, pero que, tal y como indica Vergés (2000: 7), la empresa se ha de plantear a qué tipo de profesional acudir, bien al auditor de cuentas, al auditor informático o al abogado, teniendo en cuenta que la capacitación que ha de tener el profesional que realice la auditoría no está indicada en la normativa.

21-Emisión de "informes concursales", que como apunta, Carro Arana (1997: 189-90), son "aquellas actuaciones que desempeñan al servicio de los Juzgados, como Peritos: comisario, depositario en la quiebra, interventor en la suspensión de pagos, y como órganos de la Junta de Acreedores: síndico en la quiebra."

22- "Outsourcing", responsabilizándose los profesionales de aquellas labores de información que la sociedad no asume con personal propio. García Ordaz y Martínez López (1995: 282) lo definen como el

${ }_{18}$ Véase el artículo 17 del Real Decreto 994/1999, de 11 de junio, por el que se aprueba el Reglamento de medidas de seguridad de los ficheros automatizados que contengan datos de carácter 
fenómeno consistente en la subcontratación de los sistemas informáticos, de forma que se evita tener que adquirir constantemente ordenadores y equipos informáticos, por lo que los sistemas de información son soportados por los ordenadores de una organización que presta este tipo de servicios, dejando a las empresas libres de una estructura que pueden utilizar para la actividad a la que se dediquen.

\subsubsection{Problemática en torno a los servicios multidisciplinares que presta el $\underline{\text { auditor }}$}

Al estar abierta la posibilidad de que el auditor o firma de auditoría preste otros servicios adicionales al de auditoría financiera, surgen interrogantes y conflictos en torno a lo que el auditor debe o no realizar aparte de su actividad principal, debido principalmente a que su independencia y objetividad pueden verse mermadas por estas labores que se compaginan y que incluso en ocasiones superan con creces a la auditoría de cuentas, en cuanto a su importancia, en relación con el conjunto de servicios que presta el auditor y sus ingresos.

Como señalan Cañibano y Castrillo (1997: 64) las posturas de la profesión son extremas, mientras "para algunos las amenazas que asumen los auditores, por prestar otros servicios a sus clientes son de tal calibre que la única alternativa es su prohibición. Frente a éstos, están los que abogan y alientan a compaginar los servicios de auditoría con otros servicios al considerar que la prestación de otros servicios contribuye a mejorar la comprensión del negocio del cliente y la calidad del servicio de auditoría."

personal que desarrolla la Ley Orgánica 15/1992, derogada por la Ley 15/1999, de 13 de diciembre, 
- Argumentos a favor de la prestación de servicios adicionales al de auditoría

Desde una perspectiva general las posturas mantenidas tanto por las instituciones como por la doctrina contable, a favor de la prestación de servicios multidisciplinares, son las siguientes.

\section{Postura Institucional}

Partiendo de lo establecido por la Ley y el Reglamento de auditoría de cuentas, y de lo que establecen las Normas Técnicas de Auditoría en las que se expresa que "se considerará que existe falta de independencia cuando el auditor sea el ejecutor material de la contabilidad o asuma funciones ejecutivas en la entidad auditada. El resto de servicios que el auditor puede prestar a su cliente, como consultoría y asesoramiento fiscal, no provocan, en principio, incompatibilidad en este sentido. Sin embargo, el auditor debe estar alerta de situaciones en las que su identificación con el cliente o la gestión de los negocios de éste menoscaben su imagen de independencia haciéndolo incompatible con la labor del auditor de cuentas".

En este sentido se encuentra el "Informe MARC" de la Comisión Europea sobre la "Función, posición y responsabilidad del Auditor Estatutario en la Unión Europea" (BOICAC n $\left.{ }^{\circ} 27,1996\right)$, en el que se recoge que "en todos los países estudiados (ver tabla $\mathrm{n}^{\circ} 1$ ) excepto Bélgica, Francia e Italia, las compañías auditoras están autorizadas en general a facilitar al menos otros servicios al cliente de auditoría estatutaria a través de la misma entidad legal."

de protección de datos de carácter personal. 
Tabla $n^{\circ} 1$

Servicios profesionales prohibidos al auditor en la UE

\begin{tabular}{|c|c|c|c|}
\hline País & Servicios permitidos & Servicios prohibidos & Restricciones \\
\hline \begin{tabular}{l|} 
Irlanda \\
Luxemburgo \\
Holanda \\
Suecia \\
Reino Unido
\end{tabular} & $\begin{array}{l}\text { - Teneduría de libros } \\
\text { - Contabilidad } \\
\text { - Fiscal } \\
\text { - Servicios legales } \\
\text { - Asesoría } \\
\text { - Inversión y finanzas } \\
\text { - Recuperación corporativa }\end{array}$ & & $\begin{array}{l}\text { En Irlanda el suministro de servicios de } \\
\text { contabilidad y teneduría está prohibido } \\
\text { si las sociedades cotizan en bolsa o en } \\
\text { compañías de interés público. } \\
\text { En el RU no le está permitido al auditor } \\
\text { actuar como liquidador, inspector o } \\
\text { síndico para la empresa auditada. } \\
\text { En la práctica en RU y Luxemburgo los } \\
\text { servicios legales debe prestarlos una } \\
\text { entidad legal distinta. }\end{array}$ \\
\hline Dinamarca & $\begin{array}{l}\text { - Teneduría de libros } \\
\text { - Contabilidad } \\
\text { - Fiscal } \\
\text { - Asesoría } \\
\text { - Inversión y finanzas } \\
\text { - Recuperación corporativa }\end{array}$ & - Servicios legales & \\
\hline Portugal & $\begin{array}{l}\text { - Teneduría de libros } \\
\text { - Contabilidad } \\
\text { - Fiscal } \\
\text { - Asesoría } \\
\text { - Inversión y finanzas }\end{array}$ & $\begin{array}{l}\text { - Servicios legales } \\
\text { - Recuperación corporativa }\end{array}$ & \\
\hline $\begin{array}{l}\text { Austria } \\
\text { Finlandia } \\
\text { Alemania } \\
\text { Noruega } \\
\text { España }\end{array}$ & $\begin{array}{l}\text { - Fiscal } \\
\text { - Servicios legales } \\
\text { - Asesoría } \\
\text { - Inversión y finanzas } \\
\text { - Recuperación corporativa }\end{array}$ & $\begin{array}{l}\text { - Teneduría de libros } \\
\text { - Contabilidad }\end{array}$ & \\
\hline Grecia & $\begin{array}{l}\text { - Fiscal } \\
\text { - Asesoría } \\
\text { - Inversión y finanzas } \\
\text { - Recuperación corporativa }\end{array}$ & $\begin{array}{l}\text { - Teneduría de libros } \\
\text { - Contabilidad } \\
\text { - Servicios legales }\end{array}$ & \\
\hline $\begin{array}{l}\text { Bélgica } \\
\text { Francia } \\
\text { Italia }\end{array}$ & & $\begin{array}{l}\text { - Teneduría de libros } \\
\text { - Contabilidad } \\
\text { - Fiscal } \\
\text { - Servicios legales } \\
\text { - Asesoría } \\
\text { - Inversión y finanzas } \\
\text { - Recuperación corporativa }\end{array}$ & $\begin{array}{l}\text { En Francia la prohibición sólo existe en } \\
\text { caso de darse bajo la misma } \\
\text { denominación legal. } \\
\text { En Italia si se pueden prestar servicios } \\
\text { en relación con la organización } \\
\text { contable. }\end{array}$ \\
\hline
\end{tabular}

Fuente: elaboración propia partiendo del Informe MARC (1996).

El "Informe MARC" hace referencia a la prestación de servicios de asesoría de gestión, como puede ser la consultoría sobre control interno, indicando que "la preocupación con respecto a este tema es que si una compañía auditora suministra tanto servicios de MAS como servicios de auditoría a un cliente determinado, esto puede crear problemas de independencia por el temor de perder los servicios de MAS como consecuencia de un trabajo de auditoría -fuerte-." (BOICAC n $\left.{ }^{\circ} 27,1996: 118\right)$ Este grave problema ha dado lugar a que en determinados países de la Unión 
Europea se hayan prohibido dichos servicios adicionales. Además la prestación de otros servicios también incide en el problema de la objetividad del auditor, puesto que el auditor se ve obligado a revisar su propio trabajo. A pesar de lo indicado, en el mismo informe, se expone que la investigación empírica ha concluido que la prestación de estos servicios adicionales contribuye a prestar un mejor servicio de auditoría ${ }^{19}$.

Por su parte el informe final sobre la "Comisión de Gobierno de las Sociedades", “Informe Hampel” (BOICAC n 35, 1998: 54), señala, como solución al problema de la falta de independencia, que los "Comités de Auditoría" que propugnaba el -Informe Cadbury- "son una garantía esencial de la independencia u objetividad de los auditores...en particular, el comité de auditoría debe cobrar especial importancia si los auditores prestan al mismo cliente un sustancial volumen de servicios de otros tipos. Sugerimos que el comité supervise la naturaleza y alcance de tales servicios, tratando de equilibrar el mantenimiento de la objetividad con el ofrecimiento de unos servicios completos al cliente."

La FEE aprueba, en 1995, un documento de opinión sobre “Auditoría, independencia y objetividad" en el que se expresa que "la prestación de otros servicios a un cliente de auditoría puede ser beneficiosa, ya que incrementará el entendimiento del auditor del negocio del cliente y puede resultar en una mejor auditoría. No obstante, puede representar amenazas a la objetividad del auditor y a la imagen o apariencia de independencia" (López Casuso, 1995: 74).

\footnotetext{
${ }^{19}$ El Informe MARC alude a dos investigaciones concretas para sustentar que la prestación de servicios adicionales mejora la calidad del servicio de auditoría, la realizada por Dassen en 1995 y por Moizer en 1992.
} 
Los “Tribunales de Justicia Españoles" no consideran, en principio, que la prestación de forma simultánea de los servicios de asesoría fiscal y auditoría suponga una pérdida de independencia del auditor frente al cliente; así ha resultado en el caso de un "Juzgado de Primera Instancia" de Barcelona que asegura no se puede alegar falta de independencia para rescindir un "contrato de auditoría" cuando la firma auditora presta también servicios de asesoría fiscal y consultoría ${ }^{20}$.

En las conclusiones del XII congreso del IACJC de España, en la mesa redonda sobre la "Problemática actual de la organización y gestión de los despachos y firmas de auditoría", se expone que "la multidisciplinariedad es una necesidad para nuestras firmas puesto que ha de permitir el crecimiento de las mismas hacia otras actividades complementarias a la de la auditoría tradicional" (IACJC no 17, 2000: 85). En este sentido Díez García (1999: 17), presidente del REA, manifiesta que "la independencia no debe ser utilizada como argumento meramente comercial para excluir a los auditores de un mercado de asesoramiento en general para el que están plenamente capacitados".

\footnotetext{
${ }^{20}$ Véase el diario económico Expansión $\mathrm{n}^{\circ} 4127$, de 2 de marzo de 2000. La sentencia anula la rescisión del contrato de auditoría que mantenía Daewoo con una firma de auditoría, la empresa afirmaba que uno de los motivos para terminar la relación profesional con la firma auditora era la existencia de dudas sobre la independencia de la mima, ya que la sociedad cliente aseguraba que la misma persona que realizaba la auditoría prestaba servicios de asesoramiento fiscal. La sentencia expresa que "existe falta de independencia cuando el auditor es el ejecutor material de la contabilidad o asume funciones ejecutivas" y además se expone que "el resto de servicios que el auditor puede prestar a su cliente, como consultoría y asesoramiento fiscal, no provocan, en principio incompatibilidad" y por tanto pérdida de independencia.
} 
Además la prensa ${ }^{21}$ especializada muestra claros signos de que los clientes demandan, cada vez más, junto al servicio de auditoría otro tipo de servicios adicionales, lo que determina una tendencia de las grandes firmas de servicios profesionales hacia la prestación de un servicio integral, en el que se incluyen tanto los servicios de auditoría como de consultoría de cualquier clase.

\section{Postura Doctrinal}

Por su parte investigadores como Cañibano y Castrillo (1997: 65) afirman que "el impedir la prestación de servicios diferentes a los de auditoría resulta una medida ineficaz al ser fácil de eludir y, además estamos seguros que el problema de independencia y objetividad no se soluciona por la separación de servicios de auditoría y servicios diferentes a los de auditoría."

Luengo Mulet (1997: 471) indica, en relación con la posible pérdida de independencia y objetividad del auditor que es al mismo tiempo consultor de la empresa, que "la única salida que cabe señalar en este punto consiste en dar un voto de confianza a la profesionalidad del auditor. Al igual que otros profesionales actúan asumiendo responsabilidades, sin tener legislado todo su campo de actividad, y gozan de la confianza y del respeto que generan, el auditor ha de tener paralela consideración como profesional".

\footnotetext{
${ }^{21}$ Véase el diario económico Expansión $n^{\circ} 4197$, de 25 de mayo de 2000. Como se desprende de una encuesta realizada en el mercado norteamericano, las empresas prefieren a sus auditores a la hora de contratar otros servicios, de manera que los "servicios de asesoramiento y consultoría" ganan más peso específico; el motivo tal y como indica el presidente del FEI (Financial Executives Institute) se debe a que las firmas de auditoría tienen un mejor conocimiento de las empresas que auditan y, por tanto, esto redunda en que presten otros servicios de forma más eficiente y económica. No obstante esta demanda real puede verse coartada por la actitud de la SEC (Securities and Exchange Commission) americana, por los problemas de independencia que pueden surgir al aumentar el peso de estos servicios adicionales sobre las sociedades que tradicionalmente se dedicaban a auditoría.
} 
- Argumentos en contra de la prestación de servicios adicionales al de $\underline{\text { auditoría }}$

\section{Postura Institucional}

Existen estudios que se han pronunciado limitando la prestación de servicios diferentes al de auditoría, como el informe "Le Portz" (BOICAC n ${ }^{\circ}$ 17, 1993: 70) en el que se establecen determinados servicios que deberían ser prohibidos para el auditor, entre los que se encuentran:

a) Las actividades que no tengan relación con la verificación de cuentas, su preparación o sus consecuencias, fundamentalmente:

- La asesoría en campos tales como el marketing, la comunicación o la información.

- La prestación de servicios relacionados con la actividad de producción de la sociedad.

- Servicios de asesoramiento en organización de empresas.

- Servicios de asesoramiento de gestión.

- Trabajos de reclutamiento.

b) Toda actividad que sea susceptible de crear vinculaciones personales o financieras que puedan amenazar la independencia del auditor de cuentas. 
c) Toda actividad que amenace la independencia del auditor poniéndole en la situación de tener que pronunciarse sobre documentos, valoraciones, soluciones o tomas de posición que él mismo haya contribuido a elaborar, tales como:

- Teneduría de libros.

- Valoraciones.

- Asesoría jurídica y fiscal.

- Asesoramiento en materia de fusión o de adquisición y participación en negociaciones en este campo.

- Toda prestación en la que el auditor deba actuar como defensor de la sociedad auditada.

El mismo informe recomienda que los honorarios que reciben los auditores por servicios de consultoría no deben sobrepasar a los de auditoría.

En este sentido el "Libro Verde" sobre la "Función, posición y responsabilidad civil del Auditor legal en la Unión Europea", contiene la siguiente reflexión, en torno a otros posibles servicios a prestar por el auditor y las medidas que se pueden adoptar para que no se vea mermada su objetividad; las medidas dirigidas a salvaguardar la independencia del auditor "podrían consistir en limitar los demás servicios a aquellos cuya naturaleza y calidad se correspondan con el perfil profesional del auditor y que ofrezcan pocas posibilidades de debilitar su objetividad, o en exigir que se desglosen sus honorarios de los servicios de auditoría y de otro tipo. Sin 
embargo, la práctica ha demostrado que esta solución no es una alternativa viable, ya que es demasiado fácil eludirla, haciendo que preste el servicio una empresa asociada o perteneciente al mismo grupo. En todos los casos, el auditor debiera asegurase que ni él ni su empresa intervienen en la administración o en la toma de decisiones del cliente" (BOICAC n 27, 1996: 36).

Posteriormente el "Parlamento Europeo" en una Resolución sobre el "Libro Verde" de la Comisión "Función, posición y responsabilidad civil del Auditor legal en la Unión Europea" considera "que...resulta imperativo delimitar los servicios distintos de la auditoría propiamente dicha" (BOICAC no 34, 1998: 218).

Organizaciones internacionales como AICPA, en su afán por mejorar la calidad del servicio de auditoría, como señalan Sierra Molina y Orta Pérez (1997: 89), ha establecido unos requisitos para que los despachos de auditores puedan conseguir unos estándares mínimos de calidad, que, entre otros, son los siguientes:

1. La prohibición de prestar determinados servicios de asesoramiento para clientes de auditoría que cotizan en bolsa, entre los que se incluyen:

- Pruebas psicológicas.

- Encuestas de opinión pública.

- Ayuda en fusiones y adquisiciones.

- Reclutamiento de ejecutivos.

- Servicios actuariales para compañías de seguros. 
2. La necesidad de que el auditor realice y remita un informe a AICPA sobre los servicios de asesoría administrativa prestados al cliente durante el año de auditoría y el total de comisiones que recibió por dichos servicios.

Por su parte la "Comisión de estudio de la profesión auditora" en Irlanda, perteneciente al ICAI (Response to review Group on Auditing, 2000), sugiere que se sigan los siguientes principios, con relación a los servicios prestados por el auditor a las empresas auditadas pero que no constituyen auditoría de cuentas:

1. Las firmas de auditoría no deben auditar su propio trabajo.

2. Las firmas no deben prestar servicios adicionales que afecten las cifras de los estados financieros tales como valoraciones.

3. Las firmas no deben prestar servicios de auditoría interna.

4. Se recomienda la aprobación de normas profesionales que especifiquen los servicios prohibidos a los auditores para los clientes a los que auditan.

\section{Postura Doctrinal}

Desde otro punto de vista, la doctrina contable ha expresado su preocupación por la pérdida de independencia que puede suponer que el auditor preste otros servicios adicionales al de auditoría, así: 
- Cobo González (1997: 198) es de la opinión de que se prohíban las actividades multidisciplinares, con el fin de lograr que la independencia del auditor desde el punto de vista externo sea más evidente, tal y como establecen las legislaciones en materia de auditoría en Bélgica y Francia. Dicho autor reseña que se debe establecer una "delimitación estricta de la actividad del auditor a la profesión sin permitir otro tipo de actividad aunque sea indirectamente a través de participaciones en sociedades".

- Por su parte Gonzalo Angulo (1995: 619) sostiene que "es posible asumir que la Administración y los usuarios, preocupados por la profesión lleguen a sostener que la prohibición de servicios relacionados puede aumentar la fiabilidad y la calidad de los servicios de auditoría, junto con el precio de los mismos, aunque tal prohibición, de conseguirse, se hará con la oposición numantina de la profesión en pleno si algún día llega a cuajar".

- Según Pedreira Pérez (1997: 324) "la objetividad del auditor puede verse cuestionada por su carácter de asesor en materia fiscal" razón por la que emite una opinión negativa sobre la compatibilidad.

- Pereda y Alvarado (2000: 86) estiman necesario establecer un "sistema común europeo de incompatibilidades" para evitar la pérdida de independencia de los auditores, tal y como se aprecia en la tabla $\mathrm{n}^{\circ} 2$, aunque distinguen el caso de los servicios que se prestan por el auditor individual, de aquellos servicios multidisciplinares que ofrecen los despachos que aglutinan profesionales de diversas actividades. 
Tabla $\mathrm{n}^{\mathrm{o}} 2$

Incompatibilidades del auditor de cuentas

\begin{tabular}{|c|c|c|}
\hline CLASE DE SERVICIO & AUDITOR & GRUPO DE ASESORÍA INTEGRAL \\
\hline Fedatario & Compatible & Compatible \\
\hline $\begin{array}{l}\text { Elaboración de Estados } \\
\text { Financieros }\end{array}$ & Incompatible & Compatible bajo control \\
\hline $\begin{array}{c}\text { Revisión de Estados } \\
\text { Financieros }\end{array}$ & Compatible & Compatible \\
\hline Fiscales & Incompatible & $\begin{array}{l}\text { Incompatible: servicios de protección } \\
\text { fiscal. } \\
\text { Compatible bajo control: servicios de } \\
\text { asesoría fiscal, elaboración de } \\
\text { impuestos,... }\end{array}$ \\
\hline Consultoría & Incompatible & Compatible bajo control \\
\hline Asesoría & $\begin{array}{c}\text { Compatible bajo } \\
\text { control en temas de } \\
\text { contabilidad y } \\
\text { control interno }\end{array}$ & Compatible bajo control \\
\hline $\begin{array}{l}\text { De implantación, de } \\
\text { transacciones y de } \\
\text { productos }\end{array}$ & Incompatible & Compatible bajo control \\
\hline Gerenciales y de plantilla & Incompatible & Incompatible \\
\hline
\end{tabular}

Fuente: Pereda y Alvarado (2000), pág. 86.

Las posturas mantenidas tanto por las instituciones como por la doctrina contable ponen de manifiesto la preocupación existente ante la pérdida de independencia que, en algunas ocasiones, puede producirse a causa de los "servicios adicionales" que se prestan a los clientes de auditoría. 


\subsection{EL INFORME DE AUDITORÍA: EXPECTATIVAS, COMPRENSIÓN Y UTILIDAD.}

\subsubsection{EL GAP DE EXPECTATIVAS EN AUDITORÍA}

\subsubsection{Definición}

Para definir el concepto, importado de la literatura anglosajona, de "gap de expectativas en auditoría" hay que remontarse a la década de los setenta y concretamente a los Estados Unidos, donde según Koh y Woo (1998), que realizan una amplia revisión sobre el tema, aparece Liggio (1974) como primer investigador en aplicar el término de "gap de expectativas" a la profesión auditora. Así se produce dicho gap ${ }^{22}$ o diferencia de expectativas "cuando tanto los auditores como el público mantienen diferentes percepciones sobre las obligaciones y responsabilidades del auditor así como sobre el mensaje transmitido por el informe de auditoría" (Koh y Woo, 1998: 147), de forma que no coinciden las expectativas de los usuarios con lo que realmente reciben del servicio prestado por el auditor.

Atendiendo al planteamiento de Humphrey (1991) el "gap de expectativas" se entiende como una diferencia de percepción sobre el papel del auditor, al comparar el punto de vista de accionistas y otros usuarios con lo que legalmente es razonable esperar del auditor.

Porter (1993) va más allá y, de su estudio empírico, deduce que el "gap de expectativas" está formado por dos componentes:

${ }^{22}$ Como indica Vara Arribas (1997: 822) de la traducción literal del término anglosajón "gap" se obtiene los vocablos españoles de "deficiencia", "ausencia", o "vacío" aunque la doctrina española ha 
a) Un "gap de razonabilidad", que se definiría como la diferencia entre lo que espera la sociedad que realice el auditor y lo que se puede esperar de manera razonable de su trabajo.

b) Un "gap de realización", definido como la diferencia entre lo que la sociedad espera de manera razonable que realice el auditor y lo que se percibe que consiguen. Esta parte del "gap" se produce como consecuencia de:

1. Insuficiencia de las normas, debida a diferencias entre las responsabilidades que se pueden esperar de los auditores y las responsabilidades recogidas en la ley y las normas profesionales.

2. Insuficiencia de los resultados, debida a diferencias entre los resultados obtenidos por el auditor de acuerdo con sus responsabilidades legales y los resultados que percibe la sociedad.

Esta doble visión de Porter la contemplan Innes, Brown y Hatherly (1997: 703) definiendo el "gap de expectativas" desde dos puntos de vista:

- Normativo: que considera las percepciones de la sociedad acerca de lo que los auditores deben hacer.

- Positivo: que considera las percepciones de la sociedad respecto de lo que los auditores hacen.

traducido la expresión de "gap de expectativas" por "diferencia de expectativas" entendida como carencia en la cobertura de expectativas. 
La mayoría de las investigaciones empíricas realizadas indagando los motivos del "gap" se refieren al planteamiento "positivo", que pretende comparar la diferencia de percepciones, entre usuarios y auditores, sobre lo que se espera que hagan y lo que se percibe acerca de lo que realmente hacen. Así, en determinados estudios empíricos como el planteado por Nair y Rittenberg (1987: 20) se contrasta, para el caso de auditores y empleados de entidades financieras, que el "gap de expectativas" existe puesto que los empleados de banca perciben que las funciones que atañen al trabajo del auditor van más allá de lo que perciben los auditores.

\subsubsection{Causas que originan el "gap de expectativas"}

Los principales motivos que se han señalado como causantes del "gap de expectativas"son los siguientes:

- Problemas de estructura y contenido del informe de auditoría. En los años setenta, gracias a las Comisiones "Cohen", "Treadway" y "Metcalf" en Estados Unidos, y al Comité "Adams" y "McDonald", en Canadá, se identifica que el formato del informe puede ser la causa de la diferencia de expectativas, de forma que, en 1988, se lleva a cabo la modificación del dictamen del auditor, y mediante la norma de auditoría SAS no 58 se amplía el contenido del informe, se pasa de las antiguas "certificaciones" al modelo de informe que se conoce actualmente en España importado de las normas anglosajonas. Mientras que en Europa, en el año 1992, se elabora el "Informe Cadbury" en el Reino Unido, y un año después, se modifica y amplía el contenido del dictamen con la emisión de la norma de auditoría SAS no 600, que viene a ser el 
equivalente inglés de la norma $\mathrm{n}^{\mathrm{o}} 58$ norteamericana. Posteriormente, el documento elaborado por la FEE, en 1996, sobre “La función, la posición y la responsabilidad del auditor legal en la Unión Europea", sirve de base para que ese mismo año se redacte el "Libro Verde", que contempla el problema de las expectativas defraudadas de los usuarios por el escaso contenido del informe con relación al trabajo que realiza el auditor, debido a que "los informes no ayudan a comprender qué es lo que hacen realmente los auditores...Sin esta información, cuesta trabajo entender cómo los inversores y otros usuarios pueden formarse una idea con un mínimo de fundamento sobre el valor que pueden dar al dictamen del auditor"(Comisión Europea, BOICAC n $\left.{ }^{\circ} 27,1996: 33\right)$. Este mismo problema es identificado, entre otros, en los trabajos de Landsittel (1987), Guy y Sullivan (1988) y Cabal García (2000b y 2000c).

- La sociedad desconoce la profesión y la función del auditor. Esto implica que los grupos sociales mantienen expectativas sobre el trabajo del auditor que no se ajustan a su cometido legal. En este sentido Cabal García (2000b: 125) indica que "la realidad actual es tal que la sociedad espera de la profesión auditora más de lo que ésta ofrece, desatándose un gap o diferencia de expectativas, porque los auditores no se pronuncian en los informes sobre todos los aspectos que esperan los usuarios, como consecuencia de que no se entiende o bien no es suficiente la función legal que tienen asignada estos profesionales". De la encuesta realizada por el IACJC (Libro Blanco, 1997) para comprobar "La situación, actitudes y expectativas de la auditoría en España", se extraen una serie de conclusiones que indican que la mayoría de la sociedad 
española, en un sentido muy amplio, desconoce la profesión auditora, de forma que el ciudadano medio no sabe cuál es el papel del auditor. Por su parte, Beck (1973) expone, tras realizar una encuesta a inversores particulares sobre la función asignada al auditor de cuentas, que los mismos esperan mucho más de su labor y que dicha expectativa es difícilmente modificable por un cuerpo profesional como el de los auditores; por ello señala que la sociedad intentará forzar a los mismos a adaptarse a sus necesidades, de manera que si no lo consigue reasignará aquellas expectativas defraudadas hacia otros profesionales que puedan satisfacerlas.

- El auditor no ejerce su trabajo con la suficiente responsabilidad o diligencia profesional. Porter (1993) manifiesta que el 16\% del "gap" es debido a que los auditores no realizan todas las responsabilidades que les corresponden. Así, según Gonzalo Angulo (1995: 615) el motivo principal del "gap de expectativas" se basa en "la insatisfacción del usuario con el servicio que el auditor le ofrece, en relación con la confianza que ha depositado en él". Para Gallizo y D'Silva (1995: 219) el origen, en España, de la insatisfacción por parte de los usuarios sobre el trabajo del auditor hay que buscarlo en "la sucesión de determinados escándalos financieros", que han desatado una gran polémica en torno a la fiabilidad de las auditorias y la responsabilidad de los auditores. Como indican Ruiz Barbadillo y Gómez Aguilar (1997: 225) el "gap de expectativas" incluye un "gap de actuación" determinado por el componente negligente del profesional que erosiona la credibilidad de la profesión auditora. En este sentido Carcello et al. (1992), concluyen en su estudio, para evaluar la calidad del servicio de 
auditoría, que los auditores se muestran especialmente preocupados con la necesidad de mejorar su respuesta a las necesidades de sus clientes.

- El problema de la falta de independencia del auditor. Gloeck y Jager (1993) lo identifican en su investigación, realizada en Sudáfrica, como uno de los motivos causantes de la diferencia de expectativas; al igual que otros autores como Gonzalo Angulo (1995) y Vico Martínez (1997: 227), éste último, señala que “de cara al cierre del gap de expectativas la dimensión del auditor que requiere mayor atención es la apariencia de independencia". En el mismo sentido se manifiestan Humphrey et al. (1993).

- La dificultad que encuentra la profesión en adaptarse a los cambios en la economía y en la sociedad. En este sentido Prado Lorenzo y González Bravo (1998: 876) consideran "los cambios experimentados por las sociedades de los países desarrollados en las últimas décadas" como los factores desencadenantes de las mayores responsabilidades que se esperan de los auditores, y propugnan una respuesta rápida de estos profesionales. De los resultados obtenidos por Porter (1993), en su estudio empírico, en Nueva Zelanda, se deduce que el $50 \%$ del origen del "gap de expectativas" se debe a que las funciones que tienen asignadas los auditores son insuficientes. Autores como Urías Valiente y Blasco Lang (1997: 130) hacen referencia a la necesidad de "modificar el objetivo de la auditoría, y por tanto sus alcances, sus procedimientos de trabajo y el contenido de los informes, lo que supone en suma cambiar la propia filosofía de la auditoría de cuentas tal y como está concebida en la actualidad", cuando 
revisan el contenido del informe de auditoría vigente en nuestro país, y constatan la brecha que surge entre las expectativas de los usuarios y lo que la legislación ofrece. Este hecho supone que las funciones que tienen asignadas los auditores son insuficientes, de manera que no se llega a cubrir las necesidades de los clientes, así y dentro de las demandas sociales se encuentran:

- La detección de "fraudes e irregularidades". Willingham (1975) señala que la demanda de los usuarios, respecto a la detección de fraudes por parte de los auditores, ha sido el objetivo de la auditoría durante más de cuatrocientos años y la profesión auditora ha decidido unilateralmente eliminarlo, como uno de los objetivos prioritarios de la auditoría, sin tener en cuenta que su necesidad sigue existiendo. Esta demanda, también, es identificada en los trabajos de Tweedie (1991), Gloeck y Jager (1993), García Benau et al. (1993), Gonzalo Angulo (1995), García Benau y Vico Martínez (1996) y Urías Valiente y Blasco Lang (1997).

- La necesidad de que el auditor se responsabilice o amplíe su labor en los casos en que peligra "la continuidad de la empresa". Problemática tratada, entre otras, en las investigaciones llevadas a cabo por Elliot y Jacobson (1987), Gloeck y Jager (1993), García Benau et al. (1993), Prado Lorenzo (1993), Gonzalo Angulo (1995), García Benau y Vico Martínez (1996) y Urías Valiente y Blasco Lang (1997).

- La necesidad de que el auditor enjuicie "la gestión de la empresa auditada" y colabore en mejorar el funcionamiento 
de la empresa. Así en la encuesta realizada por el IACJC (Libro Blanco, 1997) para verificar “La situación, actitudes y expectativas de la auditoría en España", se comprueba que los usuarios piensan que el auditor puede sustituir al gestor de la empresa, y se le atribuye la responsabilidad de una mala gestión. Esta demanda de los usuarios también la reconocen autores como García Benau et al. (1993).

\subsubsection{Propuestas para solucionar la diferencia de expectativas}

Una vez identificadas las causas del "gap de expectativas", las acciones que se han adoptado o propuesto con el fin de solventar el problema son las siguientes:

- La modificación del contenido y estructura del informe para aclarar el propósito y finalidad de la auditoría de cuentas, de forma que el modelo corto de informe de auditoría sufre, primero en Estados Unidos con la SAS n 58 y posteriormente en el Reino Unido con la SAS $n^{\circ} 600$, una ampliación que, según se ha contrastado en diversos estudios empíricos, ha supuesto un gran paso a la hora de reducir el "gap de expectativas". Así, Geiger (1989) sostiene que la modificación del informe norteamericano mejora el problema de la diferencia de expectativas, aunque afirma que aún se podría mejorar más. Del mismo modo Innes, Brown y Hatherly (1997) demuestran que, en el caso del Reino Unido, la extensión del informe cambia las percepciones de los usuarios, de forma que el modelo largo transmite mejor el propósito de la auditoría cerrando el "gap" con los auditores. No obstante, tal como afirma Humphrey (1991: 13), la existencia del "gap de expectativas", 
después de las modificaciones que se producen en el informe de auditoría norteamericano, sigue manteniéndose, lo que supone que dicho problema no sólo necesite de una extensión de su contenido sino que haga falta modificar la función del auditor. Esta propuesta es recogida por investigadores como García Benau y Vico Martínez (1995) y Gallizo y D'Silva (1995).

- La adaptación y ampliación de las actuales funciones que desempeñan los auditores. El informe MARC (1996), encargado por la Comisión Europea al "Centro de Investigación de Contabilidad y Auditoría de Maastricht", que se centra en el estudio de "La función, posición y responsabilidad del auditor externo en la Unión Europea", recoge, como recomendación a la problemática en torno a la profesión del auditor, que la auditoría cambia a lo largo del tiempo como resultado de los cambios del entorno, por ello los requisitos relativos a la educación del auditor, los informes de auditoría y la ejecución de una auditoría deberán ser adaptables. Según García Benau (1996: 61) para cerrar la diferencia de expectativas "los auditores deben aceptar mayores responsabilidades"; además atendiendo al planteamiento de Vara Arribas (1997: 841) la solución al "gap de expectativas" pasa por que sean los auditores los que finalmente se adapten a las expectativas de la sociedad, además señala que "los costes que esa ampliación del trabajo puedan suponer no serán fácilmente asimilados por un mercado estancado en su demanda y altamente competitivo en su oferta". Para Cabal García (2000b: 126) el problema de las expectativas en cuanto a las funciones que corresponden al auditor y, por tanto, el reflejo que debe darse en el informe, pasa por medidas constructivas por parte de los auditores de forma que se tiende a 
satisfacer las necesidades de los usuarios "tranquilizándoles en lo que respecta a cuestiones tan importantes y controvertidas como la ausencia de conductas fraudulentas e ilícitas por parte de la entidad auditada, su supervivencia o su respeto al entorno". Como consecuencia de lo indicado, se requiere del auditor la ampliación del contenido, de su informe, con la finalidad de conseguir una mayor utilidad y relevancia del trabajo que desarrolla. Para ello se propone extender o incluir párrafos en el dictamen que hagan referencia:

- Al control interno de la sociedad auditada. La agenda del nuevo presidente del ICAC incluye, entre otros, el tratamiento de "la modernización del informe de auditoría. Uno de los temas que Bruselas está comenzando a estudiar es el contenido del informe de auditoría; el objetivo es responder a las demandas de los usuarios para minimizar el -gap de expectativas- y estudiar la posible incorporación de párrafos nuevos relativos a temas como el cumplimiento legal en un sentido amplio o alguna referencia al control interno del cliente." 23 Autores como Urías Valiente y Blasco Lang (1997: 130) se manifiestan con la misma postura.

- A las situaciones que pongan en peligro la continuidad de la empresa. Como afirman los profesores Larriba y Gonzalo (1996: 15) entre las expectativas que se deben cubrir para dar respuesta a las demandas sociales se encuentra la de "incrementar la información proporcionada en el informe de auditoría, así como su legibilidad y comprensión, extendiéndolo a otros

${ }^{23}$ Véase el diario Expansión del día 2 de noviembre de 2000. 
aspectos fundamentales de la entidad y del negocio auditado, sobre todo en lo que se refiere a aquellos aspectos que pudieran afectar la continuidad de la propia entidad." El "Libro Blanco" del IACJC (1997: 160) indica que el informe del auditor debe "clarificar las expectativas de los usuarios sobre la posibilidad del auditor de informar del futuro de la sociedad...siempre y cuando la dirección pueda aportar la información necesaria y responsabilizarse de la misma." Otros estudios como los de Urías Valiente y Blasco Lang (1997: 130) recogen la misma propuesta.

- A la evaluación de la gestión empresarial. En este sentido el profesor Urías (1990: 143) indica que "el dictamen debe alcanzar, para que sea eficaz, a la situación económica y a los procedimientos de gestión con que se ha conseguido. Con ello, la opinión se amplía para recoger los aspectos organizativos y proyectivos, ya que un ente económico es un organismo vivo y de poco vale dictaminar con referencia a situaciones estáticas."

- A la evaluación del cumplimiento de la legalidad vigente ${ }^{24}$ por la empresa auditada. El citado “Libro Blanco” del ICJC (1997: 160) indica que se debe tratar la problemática en torno a la información sobre infracciones legales y estatutarias, la forma en que deben ser manifestadas en el informe, cuándo y a quiénes se debe informar, así como la concreción de la

\footnotetext{
${ }^{24}$ Esta problemática ya se ha incorporado a la profesión, en España, a través de la "Norma Técnica de Auditoría sobre Cumplimiento de la Normativa Aplicable a la entidad auditada", de forma que el auditor queda obligado a obtener un conocimiento general de la normativa aplicable a la empresa y al sector en el que ésta opera, y de cómo la entidad está cumpliendo con ella. Además si se produce un incumplimiento significativo deberá reflejarlo en su informe y deberá comunicarlo al órgano de administración de la empresa o, en su caso al Comité de Auditoría, así como, cuando proceda según
} 
responsabilidad del auditor y de los administradores en estas cuestiones.

- A la detección de fraudes e irregularidades ${ }^{25}$.

- La utilización de políticas y documentos alternativos al informe de auditoría para aclarar la función del auditor y sus responsabilidades, así AICPA a través de la emisión, en el año 1997, de la SAS n 83 y de la SSAE $\mathrm{n}^{\mathrm{o}} 7$ trata de mejorar la comunicación y el entendimiento con el cliente para intentar, mediante determinadas políticas y procedimientos, que se minimice el riesgo de malentendidos con los clientes con relación a la naturaleza, el ámbito y los límites del trabajo que lleva a cabo el auditor. Este preceptivo entendimiento, se les solicita a los auditores que lo documenten en sus "papeles de trabajo" de forma que quede constancia escrita de que el cliente entiende la función que tiene encomendada el auditor, así se procura el conocimiento del cliente sobre:

1. Los objetivos del "contrato de auditoría".

2. Las responsabilidades de la gerencia de la sociedad.

3. Las responsabilidades del auditor.

4. Los límites del trabajo del auditor.

ley, a las autoridades reguladoras (Banco de España, CNMV, Dirección General de Seguros). Resolución de 16 de junio de 2000, del ICAC (BOICAC nº 42, junio 2000).

${ }^{25}$ La Norma Técnica de Auditoría sobre "Errores e Irregularidades", indica que el auditor no es responsable de la prevención de errores e irregularidades, sin embargo debe tener en cuenta la existencia de dichos errores e irregularidades $\mathrm{y}$, cuando sean significativos, deberá reflejarlos en su informe. Adicionalmente el auditor debe comunicar a la dirección, de la sociedad, la existencia de errores significativos e irregularidades, aún cuando estas últimas no tengan un efecto relevante sobre las cuentas anuales; también se deberá comunicar, cuando proceda según ley, a las autoridades reguladoras (Banco de España, CNMV, Dirección General de Seguros). Resolución de 15 de junio de 2000, del ICAC (BOICAC nº 42, junio 2000). 
Estos objetivos se consiguen, sobre todo, como señalan Gibson et al. (1998), a través de la "carta de encargo", de manera que ésta constituye otra vía imprescindible para que el auditor manifieste y expresa la finalidad de su trabajo y se pueda comprender lo que hace. En España, estas aspiraciones se quieren alcanzar gracias a la publicación de la norma técnica de auditoría referente a la "carta de encargo" o "contrato de auditoría" regulada por el ICAC a través de su Resolución ${ }^{26}$ de junio de 1999. Por ello, dicha carta supone una importante vía de solución al "gap", ya que en la misma se deben establecer de forma clara las responsabilidades y limitaciones del auditor y la auditoría, sus honorarios, así como la responsabilidad y manifestaciones de los administradores. No obstante, el problema de comprensión de la función del auditor continuaría existiendo para los usuarios, del informe de auditoría ajenos a la empresa contratante, que no tienen acceso a esta información.

- El establecimiento de normas claras y precisas sobre las situaciones que afectan a la independencia del auditor, tal como indican Gallizo y D’Silva (1995), García Benau (1996) y Vico Martínez (1997).

\subsubsection{EL PROCESO DE COMUNICACIÓN ENTRE AUDITOR Y USUARIOS:} EL INFORME Y EL PROBLEMA DE SU COMPRENSIÓN

El auditor refleja todo su trabajo en un documento que se conoce como "informe o dictamen de auditoría", que puede ser de cuentas anuales cuando expresa su juicio profesional sobre los estados financieros de la sociedad en

\footnotetext{
${ }^{26}$ El modelo estándar de "carga de encargo" se aprobó por el ICAC mediante su Resolución, de 16 de junio de 1999, por la que se hace pública la Norma Técnica de Auditoría sobre "Contrato de Auditoría o Carta de encargo".
} 
su conjunto, o limitarse a determinadas operaciones o áreas de la empresa denominándose en este caso "informe especial" o "revisión limitada".

Como indica Illescas Ortiz (1995: 653) "el informe es un documento privado y mercantil, y por razón de su contenido integra una declaración de ciencia o conocimiento", documento privado por nacer de la voluntad de contratar un servicio entre dos particulares, la sociedad demandante del servicio y el auditor de cuentas, y mercantil por ser fruto de tráfico comercial y cumplir con los requisitos que exige la Ley 19/88, de Auditoría de Cuentas. Este carácter viene recogido de manera expresa en las Normas Técnicas de Auditoría (ICAC, Resolución de 19 enero de 1991) sobre "la publicidad del informe de auditoría de cuentas anuales", donde se indica que es un documento mercantil obtenido como fruto de un contrato privado, por ello dicho informe sólo debe entregarse a quienes realizaron el encargo de la auditoría, siendo responsabilidad de los administradores entregar una copia del mismo junto con las cuentas anuales a los socios, además de llevar las gestiones registrales que exige la legislación mercantil en materia de cuentas anuales.

La legislación vigente pone de manifiesto, a través de las "Normas Técnicas de Auditoría" (NTA), en las que se recogen los modelos normalizados de informes de auditoría de cuentas anuales, que los modelos son de obligada adopción por parte de los auditores de cuentas y varían en función de las circunstancias en las que se emite la opinión, con el objetivo de:

a) “Orientar al auditor de cuentas.

b) Conseguir la máxima uniformidad de redacción que facilite la comprensión de dichos informes por los usuarios de cuentas 
anuales...el objetivo primordial en cualquier circunstancia es dar al lector del informe una descripción clara y adecuada del alcance de la auditoría y de las conclusiones del auditor en base a su juicio profesional".

El auditor de cuentas tiene que realizar, como culminación de su labor, la emisión del "dictamen o informe de auditoría", última fase del proceso de la auditoría de cuentas (ver figura ${ }^{\circ} 1$ ), momento en que a través de dicho documento, el auditor comunica de forma expresa al agente que le realizó el encargo los resultados de su trabajo.

Figura $n^{\circ} 1$

Etapas en el desarrollo de la auditoría de cuentas

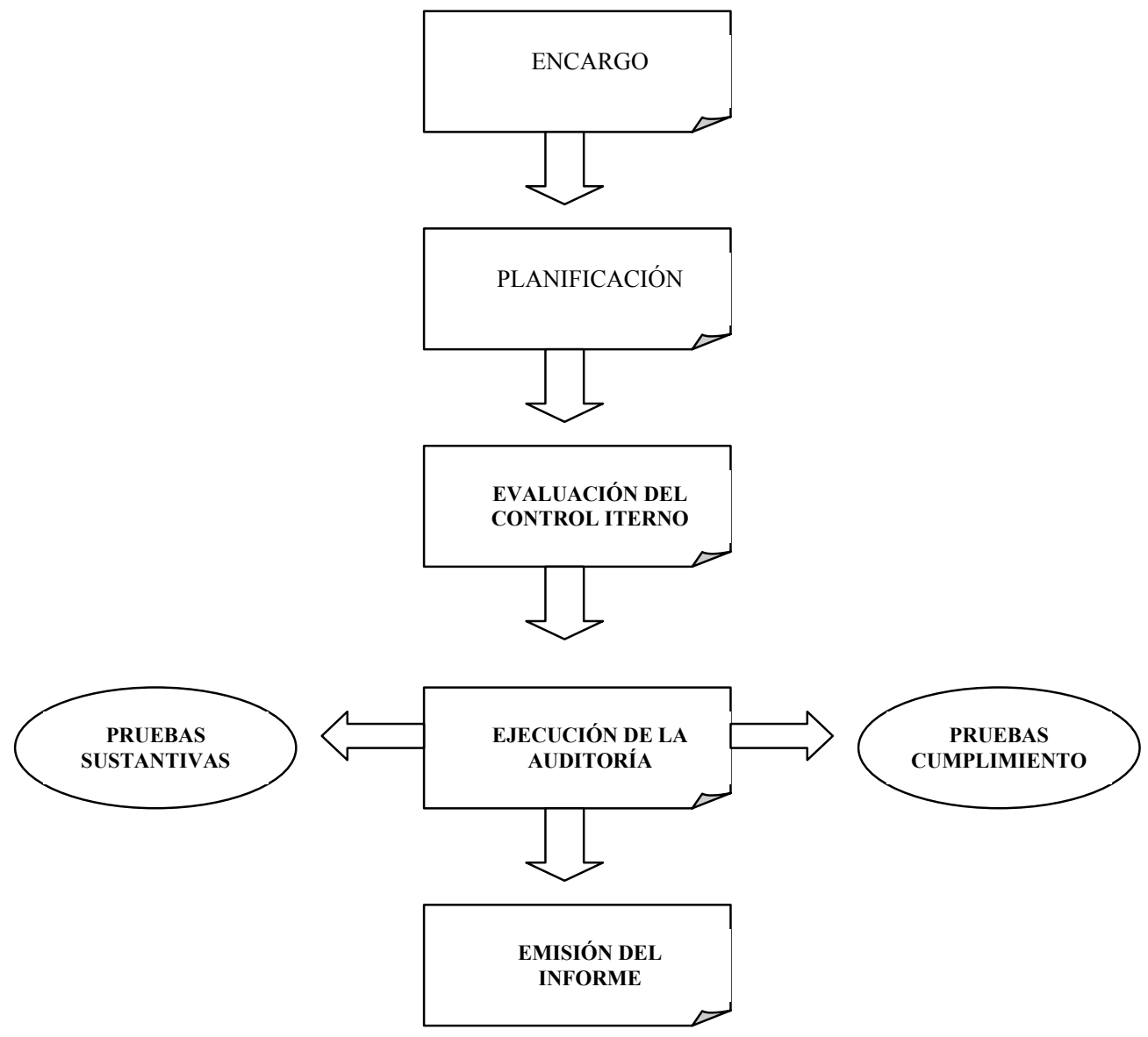

Fuente: elaboración propia. 
La regulación de la auditoría de cuentas contempla la importancia de la redacción del informe del auditor puesto que la propia legislación expresa que el mismo trasciende a las partes contratantes del servicio, y por ello indica que todos los usuarios, de un documento mercantil que nace en virtud de un "contrato privado", pero que posteriormente pasa a ser de "utilidad pública" cuando es depositado junto a las cuentas anuales en el Registro Mercantil, deben poder comprenderlo para obtener información que les sea relevante.

Sobre la base de la "función pública" que se atribuye al servicio de auditoría, debe mejorarse y ampliarse el contenido del informe, que hasta ahora, como viene apuntando la doctrina contable anglosajona desde los años setenta, sufre de deficiencias en el proceso de comunicación entre el auditor y los usuarios, provocando un "gap en la comunicación" originado por la redacción y el contenido de los informes de auditoría, problema de comunicación que se produce, sobre todo, con aquellos usuarios de la información contable que no son parte de la empresa auditada, tales como inversores, proveedores, Administración, entidades financieras, público en general; así como con los accionistas de las grandes sociedades mercantiles, como las sociedades admitidas a cotización en los mercados secundarios, que tampoco tienen un contacto directo con el auditor. Esta circunstancia de incomprensión del informe, puede variar en las pequeñas y medianas empresas donde es más probable que los accionistas, bien directamente o a través del órgano de administración, accedan a las cuestiones que les plantean interrogantes en cuanto a la labor realizada por el auditor y sus resultados.

Sin embargo no puede obviarse que la empresa auditada y el auditor no sólo se comunican a través del informe de éste último, sino que el proceso 
de auditoría tiene como resultado, también, una "carta de recomendaciones" sobre el control interno contable dirigida a la gerencia y, en su caso, determinados "ajustes y reclasificaciones contables" que siempre son aclarados y consensuados con el auditor, además del contacto directo y duradero que se mantiene con los responsables de la sociedad auditada.

Muchos de los clientes del auditor y los terceros interesados acuden al informe de auditoría como barómetro de la situación financiera de la empresa, y no sólo como mero documento acreditativo de la fiabilidad con la que se han elaborado las cuentas anuales. En este sentido, con la futura armonización para los informes de auditoría de los Estados miembros de la Unión Europea, surge una oportunidad para que se elabore un nuevo modelo de dictamen que satisfaga a todas las partes interesadas incluyendo, en la medida de lo posible, una información más relevante y comprensible. No debe de olvidarse que el auditor es proveedor de un servicio, y como tal tiene la obligación de satisfacer las necesidades del mercado, por ello debe adaptarse, en la medida de sus capacidades, a sus exigencias.

El problema de la "comunicación" queda íntimamente ligado al de las "expectativas", por ello el informe debe ser lo más compresible posible, de manera que no surjan dudas en cuanto a la finalidad de la auditoría de cuentas, y el lenguaje, aunque no pueda obviarse uno propio como sucede en todas las profesiones, debe ser lo más elocuente posible, ya que el dictamen, que se emite y redacta para terceros, no es un documento interno de los profesionales. Además, y aunque perjudique la flexibilidad del mismo, no se puede perder cierta homogeneidad, pues de cara a una futura armonización si no se establecen unas pautas comunes nunca podrán ser comparables entre diferentes países. 
Al hablar de comunicación y satisfacción del cliente se trasciende a áreas de conocimiento como son el "marketing" y el "comportamiento del consumidor" que escapan del ámbito de la auditoría y la contabilidad, pero que no se pueden obviar al ser la auditoría un servicio dirigido hacia una clientela, y existir unas necesidades que cubrir por parte del auditor.

\section{Comunicación}

Según afirma Schiffman (1997: 283) “la comunicación es la transmisión de un mensaje de un emisor a un receptor por conducto de un medio de cierta clase". Para el caso de la auditoría los participantes en el proceso quedan claramente identificados (ver figura $\mathrm{n}^{\mathrm{o}} 2$ ), existe: un mensaje escrito, formado por el juicio profesional que emite el auditor; un emisor, el auditor; un receptor, la empresa auditada y los usuarios interesados; y un conducto, el informe del auditor. Además se considera un quinto elemento esencial en el proceso de comunicación, la "retroalimentación", que permite saber si el mensaje del auditor es comprendido en la forma deseada. De este proceso de retroalimentación se desprende, en determinadas ocasiones, que el mensaje que codifica el auditor y descodifican los usuarios en función de su experiencia y características específicas, no se comprende o mal interpreta, porque "la comunicación tiende a ser más efectiva cuando el emisor tiene experiencia, estatus o se le ve como objetivo, imparcial, en relación con el tema tratado"(Fiske y Hartley, 1980).

Al tener muchos de los usuarios de la información contable escasa formación en materia contable y de auditoría, para que el mensaje que emite el auditor sea perfectamente comprensible y su función claramente delimitada es necesario replantear el contenido del informe, ya que "la tarea del emisor es luchar por un mensaje simple, claro, interesante y reiterativo, 
de tal manera que transmita, al menos, los puntos principales al público objetivo escogido" (Kotler, 1996: 656); o bien formar a los usuarios con unos conocimientos mínimos que permitan al público en general acceder a este tipo de información, aunque ambas acciones también se pueden realizar conjuntamente.

\section{Figura $\mathrm{n}^{\circ} 2$}

El proceso de comunicación entre auditor y usuarios

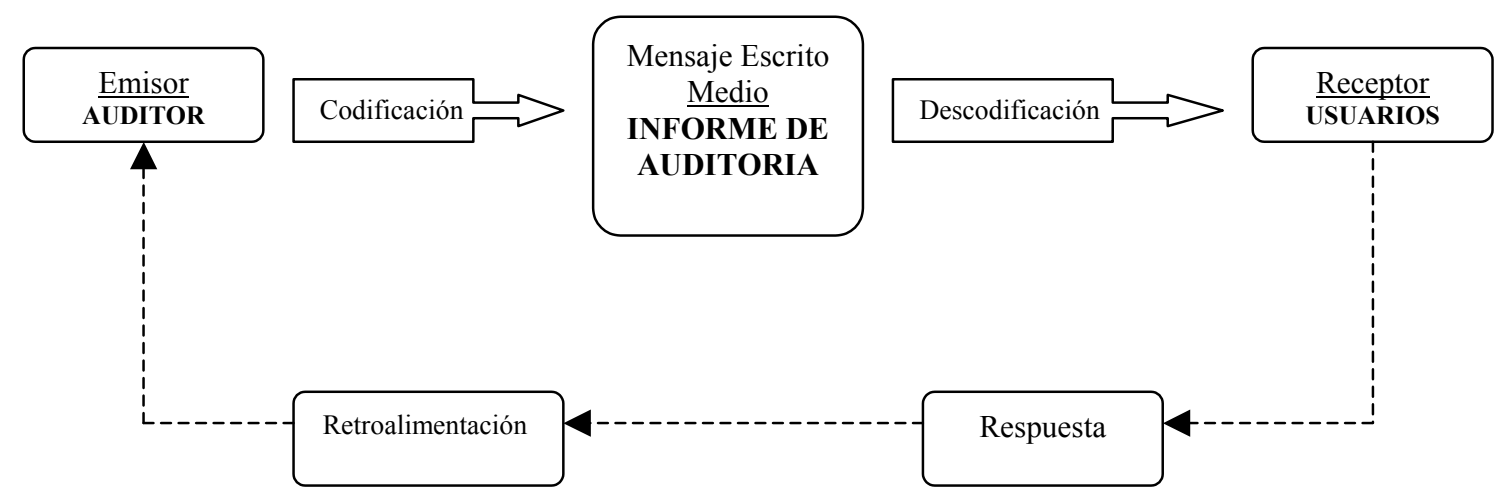

Fuente: elaboración propia partiendo del planteamiento de Kotler (1995: 656).

Como manifiesta Orta Pérez (1996: 59) "los términos del informe u opinión de un auditor son una parte crucial; si los auditores no consiguen comunicarse efectivamente, el propósito se frustra". En este sentido Didis (1997) propone una serie de reglas para mejorar el proceso de comunicación con los usuarios de los informes de "auditoría interna", que son perfectamente extrapolables a la auditoría externa:

a) La redacción del informe debe ser un proceso continuo durante el desarrollo de la auditoría.

b) El texto debe ser lo más breve posible mediante el uso de frases cortas y sucintas. 
c) La redacción de las salvedades debe hacerse empleando palabras y expresiones que eviten reacciones emocionales o defensivas, para evitar que los clientes perciban la auditoría como algo negativo.

d) El texto debe estar perfectamente organizado.

e) Se debe utilizar un lenguaje que los lectores puedan comprender evitando palabras oscuras y expresiones técnicas. Como señalan Hatherly y Skuse (1991) se debe emplear un "natural language" que favorezca el entendimiento de un lector medio.

En resumen, como señala Bromage (1989: 13) el informe debe ser “directo, conciso, objetivo, verificable, convincente y, sobretodo, interesante".

\section{$\underline{\text { Satisfacción }}$}

Una vez que el lenguaje y la redacción queden perfectamente delimitados, deberá abordarse qué se incluye en el informe en relación con las demandas de los usuarios. Siempre se podrá incluir información sobre el proceso realizado por el auditor 27 , indicando las partes revisadas, los fallos que ha considerado significativos y los criterios que ha seguido para delimitar la "materialidad". Sin embargo, también existen expectativas sobre el trabajo que el auditor desarrolla según su función legal, que la sobrepasan y que sin duda van a requerir importantes recursos en términos de tiempo y preparación, que o soporta él, en sus costes, o bien repercute a sus clientes. Existen determinadas demandas sociales que van más allá no solo de las atribuciones legales de los auditores, sino de sus propias capacidades. No obstante, al ser el auditor proveedor de un servicio, el objetivo que debe

\footnotetext{
${ }^{27}$ Como señalan García Benau y Pucheta Martínez (2001), el modelo de informe español es de los pocos que no incluyen referencia alguna a la descripción del proceso de la auditoría, a diferencia de los países anglosajones.
} 
guiar su trabajo, siempre, debe ser la consecución de la satisfacción de su clientela, y teniendo en cuenta que "el nivel de satisfacción es una función de la diferencia entre el valor percibido y las expectativas" (Kotler, 1996: 46), y habiéndose comprobado la existencia del "gap de expectativas" de forma que la percepción de los usuarios sobre el servicio de auditoría es inferior a sus expectativas, se deduce que muchos de los usuarios de los informes se encuentran insatisfechos. Por ello se cuestiona su función actual y la forma de plasmar su trabajo en el informe de auditoría, por lo que el auditor debe intentar reducir la diferencia hasta que consiga, al menos, igualar percepciones y expectativas.

\subsubsection{Causas que originan el problema de comprensión del informe}

Los principales motivos que originan el problema de comprensión del informe, que emite el auditor, son los que se detallan a continuación:

- Una redacción del informe estandarizada, para evitar diferencias de interpretación y ganar calidad en la uniformidad, que deja el informe del auditor reducido a un mero símbolo. A escala internacional, y a finales de los años setenta, es la "Comisión sobre las responsabilidades del auditor" (Comisión Cohen) de AICPA, en Estados Unidos, una de las primeras instituciones en identificar, como causa de que no se leyeran los informes de auditoría, las deficiencias en el proceso de comunicación de la opinión del auditor. En este sentido, García Benau (1997: 159-160) señala que "han existido protestas en lo relativo a la complicada terminología y estilo que se utilizan en la redacción de los informes de auditoría...La estandarización de la terminología utilizada en los informes suele estar ligada a la utilización de códigos 
que resultan prácticos para los lectores familiarizados con los mismos, pero incomprensibles para los usuarios no familiarizados."

- El empleo de terminología técnica. En España, y según señala el que fuera presidente del ICAC (Gómez Ciria, 1997: 10), “con relación al contenido del informe, una de las críticas que se realiza es que está redactado en términos muy técnicos con un lenguaje poco habitual dificultando la correcta interpretación de su contenido". Alcarria Jaime (1997: 83) apunta en las reflexiones finales realizadas, sobre un análisis de informes de auditoría en empresas no cotizadas, que por motivos de brevedad en la redacción "algunos de los comentarios incluidos en los informes pueden ser de difícil comprensión para los usuarios no iniciados y sin un conocimiento algo más que básico de los aspectos contables". Por su parte Cabal García (2000b: 126 y 2000c: 22) indica que una de las causas de la diferencia de expectativas entre usuarios y auditores es ocasionada por los problemas de "formato" del informe de auditoría, ya que para determinados usuarios "el modelo actual de informe, sintético, uniforme y con un contenido marcadamente técnico escapa a su comprensión por causa de su deficiente formación en materia contable y auditora". En el mismo sentido se expresa Ruiz Barbadillo (1997: 61) cuando manifiesta "la dificultad que supone para los usuarios comprender un lenguaje técnico cargado de frases formales".

Desde otra perspectiva, y en general, los auditores han mostrado una postura pasiva y reticente a aceptar problemas derivados de la falta de comprensión del informe, escudándose en que el informe de auditoría es fruto de un trabajo especializado del que se desprende un vocabulario técnico necesario como en todas las 
profesiones. Sin embargo, el "Libro Blanco" de la auditoría, editado por el Instituto de Auditores Censores Jurados de Cuentas (IACJC, 1997), recoge que "actualmente el informe no suele tener problemas de comprensión para el usuario, siempre que tenga conocimientos aunque someros para entender la información financiera. Quizás los problemas de exposición vienen originados cuando en los informes se incluyen salvedades explicadas con un lenguaje demasiado técnico o cuando se trata de explicar, de manera muy resumida, los problemas para evitar un documento demasiado largo. Sobre este extremo la profesión está dispuesta a atender las posibles demandas de los usuarios para que los informes sean más claros y comprensibles".

- La Ambigüedad del lenguaje. Larriba y Gonzalo Angulo (1996: 13) hacen referencia a la "defraudación, diferencia o bache de expectativas" que surge a causa de que los informes de auditoría no satisfacen las demandas de los usuarios, entre otras razones, por la ambigüedad del lenguaje y la imprecisión de las opiniones.

- Una insuficiente exposición sobre la finalidad y el alcance de la responsabilidad del trabajo del auditor. Nair y Rittenberg (1987) ponen de manifiesto que el proceso de comunicación entre banqueros y auditores no es tan bueno en los casos de "revisiones limitadas" y "compilaciones", debido a que no se percibe de manera clara: la responsabilidad del auditor, la naturaleza de los procedimientos llevados a cabo y el grado de seguridad que se transmite en dichos informes. Mayper, Welker y Wiggins (1988) deducen, de su experimento, que la profesión contable necesita una mejora en el proceso de comunicación de los objetivos y el significado de los dictámenes elaborados por los auditores. Ruiz Barbadillo (1998: 148) 
expone que después de "tres décadas de investigación empírica no puede afirmarse con rotundidad que dicho informe posibilita que el lector del mismo comprenda la naturaleza de la auditoría -dimensión educativa del informe-, ni que el mismo aporte información valorable por los decisores -dimensión informativa-." En este mismo sentido se pronuncian Gaffney y Lynn (1991).

\subsubsection{Propuestas para solucionar los problemas de comprensión}

Las propuestas que, hasta la fecha, se han formulado con relación al problema de comunicación entre auditor y usuarios por la falta de comprensión del informe son las que siguen:

- El desarrollo de políticas educacionales tanto en auditoría como en materias financieras que informen a los usuarios y a la sociedad en general sobre el propósito de la auditoría de cuentas, de forma que se comprenda el mensaje contenido en los informes. Nair y Rittenberg (1987) apuntan que el proceso educacional en materias financieras puede mejorar la comunicación de los mensajes contenidos en los informes, familiarizando a los usuarios con dicha información; en el mismo sentido se manifiestan Vidal Hernández-Mora (1997) y Humphrey et al. (1993). Bailey, Bylinski y Shields (1983) concluyen su estudio indicando que AICPA debe tratar de educar a los usuarios, sobre la finalidad del mensaje contenido en los informes de auditoría, a través de programas educacionales. Este problema de comunicación se intentó subsanar, por el ASB de AICPA en 1982, a través de un programa educacional para explicar el propósito del informe de auditoría, que supuso llegar a la conclusión que los conocimientos sobre informes de auditoría de los lectores condicionaban los 
diferentes mensajes percibidos entre los usuarios. En esta línea, y en España, el Registro de Economistas Auditores ha editado un "Manual para el usuario de Informes de Auditoría" que tiene la misión de "aclarar el desfase de expectativas entre lo que es la auditoría y lo que no es, y delimitar las funciones del auditor mediante unos cuadros comparativos de -lo que hace el auditor- y -lo que no hace el auditor-, para poder así entender la estructura de un informe de auditoría y los tipos de opinión que en esos informes se pueden introducir, que conforman los distintos modelos de informe de auditoría de cuentas"(REA, junio 1998: 3).

- La modificación de la actual estructura del informe, con la finalidad de aclarar el propósito de la auditoría, así como el trabajo que realiza el auditor. Para ello se propone extender o incluir párrafos que hagan referencia:

- Al objetivo y naturaleza de la auditoría. Desde el punto de vista institucional el "Libro Verde", elaborado por la Comisión Europea (BOICAC no 27, 1996: 33), apunta "la necesidad de proporcionar más información sobre el contenido y la naturaleza del trabajo en el que se basa el informe de auditoría...Es necesario que en él se expongan claramente las responsabilidades del auditor de informar sobre los estados financieros". Por su parte, el Consejo Directivo del REA (enero 1997: 21) desarrolla una serie de recomendaciones en las que se expone: "estamos de acuerdo en que sería beneficioso armonizar el contenido de los informes de los auditores, haciéndolos más comprensibles...Como punto de partida para unificar los informes de auditoría en todos los países europeos, 
sería aconsejable comenzar adoptando la redacción del Informe de Auditoría de la IFAC. Sería beneficioso clarificar a quién va dirigido y quién puede hacer uso del informe de auditoría. Esto aclararía la responsabilidad de los órganos de gobierno de la sociedad y dejaría en justo término los pasivos por reclamaciones a los auditores".

- Al proceso del trabajo que ha realizado el auditor. El "Libro Verde", elaborado por la Comisión Europea (BOICAC n 27, 1996: 33) explica que para reducir el "gap de expectativas", el informe debe ampliar su contenido informativo "sobre qué ha hecho efectivamente el auditor, qué criterios profesionales ha aplicado en la realización de su tarea y si la información financiera preparada por la sociedad cumple con los requisitos legales y complementarios. También sería necesario que el auditor expusiera claramente en su informe cualquier reserva que pudiera tener."

- A la "materialidad" aplicada por el auditor. Así, para Gómez Ciria (1997) una posible solución pasa por incluir en el informe de auditoría la "materialidad" aplicada por el auditor en el desarrollo de su trabajo, para poner de manifiesto que emite un juicio profesional en términos de "materialidad" y no de exactitud, pues en la medida de sus posibilidades queda obligado a cubrir las necesidades de sus clientes. Según García Delgado (1994), en el informe de auditoría, como vínculo de comunicación del auditor con los usuarios, se debe incorporar en el "párrafo de alcance" o en un "anexo", información sobre los márgenes de tolerancia o niveles de importancia relativa 
empleados por el auditor, con la finalidad de mejorar la comprensión de la opinión que se emite en el informe. En el mismo sentido se expresan Urías Valiente y Blasco Lang (1997).

- El empleo de un lenguaje menos técnico que mejore la comprensión del informe, en general, y de las salvedades en particular. Así, según el director general de la Bolsa de Barcelona (REA, 1997: 3), los auditores deben dar información más clara sobre las "incertidumbres" y su cuantificación. Gonzalo Angulo (1995: 623) sostiene que existen “constantes demandas para que los informes de auditoría pasen, de contener una información codificada y difícilmente inteligible por los no expertos, a ser de tipo más divulgativo, más explicativo, contando los problemas detectados antes de evaluar su incidencia cuantitativa en las principales cifras contables, y de tener una redacción oscura y concisa a describir narrativamente y con claridad las responsabilidades por la información y los puntos donde el auditor encuentra los mayores obstáculos de cara al futuro, es un clamor cada vez más difícil de ignorar por parte de la profesión y de las autoridades que la regulan".

Urías Valiente y Blasco Lang (1997: 140) indican que "la claridad en la redacción del informe es una característica esencial de la actividad de auditoría de cuentas", y por ello animan a los auditores a superar ciertas rigideces que se dan en el informe, así como a realizar una redacción de los "párrafos de énfasis y de salvedades" que sea más asequible para el público en general, aunque señalan que nunca serán totalmente accesibles para aquellas personas que no tengan una mínima formación financiera y contable. Otra medida indirecta que indican los autores, consiste en la posibilidad de que los auditores 
puedan asistir a las "juntas de accionistas" para responder ante quienes va dirigido su trabajo, a todas aquellas cuestiones que plantean dudas. Estas sugerencias no caben a juicio de los autores "en los encorsetados límites del modelo de informe corto", que toma su estructura de las antiguas "certificaciones" contables; y por ello es necesario ampliar el contenido del mismo hacia un modelo largo alejado del formato estándar, incluyendo los aspectos que contribuyan a una mejor toma de decisiones por los usuarios del mismo.

Para García Benau (1997: 160) el problema de la falta de comprensión del informe por la terminología empleada tiene difícil solución, ya que "es realmente complicado plantear un informe de auditoría, resultado de un trabajo eminentemente técnico, sin recurrir al uso de términos y expresiones propias de la contabilidad o la auditoría de cuentas, sin que, a su vez, el informe se convierta en un cúmulo de explicaciones de los propios términos o largos párrafos para explicarlos sin tener que recurrir a ellos." No obstante, también indica que "una reformulación de los informes de auditoría haría que gran parte de los usuarios potenciales lo fueran reales....El contenido de dichos informes debe adecuarse a los deseos de dichos usuarios. Aspectos como, por ejemplo, la posición de la empresa ante ciertos riesgos, las pensiones, la seguridad de la empresa, la viabilidad futura de la empresa y/o la existencia de información financiera fraudulenta, deberían ser abordados por dichos informes. El auditor debería ayudar a los usuarios a comprender el contenido de la información financiera." (1996: 63).

Por su parte el IACJC (septiembre 2000: 136) hace alusión al problema de comunicación que se deriva del informe de auditoría, y 
señala que "bajo el punto de partida de que el informe del auditor es una forma de comunicación, los principios de la teoría de la comunicación resultarían aplicables a la contabilidad y a la auditoría en todas sus diferentes derivaciones. Ello implica que, con las adaptaciones que se considere necesarias, las características cualitativas de la información o de otro tipo de información debe ser aplicada para analizar las bases de los criterios que se utilizan para la determinación de la forma y contenido de los informes de los auditores." De manera que la información que incluye el informe del auditor debe poseer dos características:

1. Ser comprensible.

2. Ser útil para la toma de decisiones, es decir ser fácil de entender para los usuarios de la información y a la vez relevante para la toma de decisiones de los mismos.

Además, se alude a la necesidad de armonizar el informe de auditoría a escala internacional, con la finalidad de que sea comparable a nivel global, y también se hace referencia a que la armonización conlleva una desventaja relativa debido a su falta de flexibilidad ante circunstancias determinadas, que no siempre se divulgan en el informe, y que sí pueden ser útiles a los usuarios.

\subsubsection{LA UTILIDAD ASOCIADA AL TRABAJO DEL AUDITOR}

Para poder aseverar que la información financiera, que se incluye en el informe del auditor, cumple cualitativamente con las necesidades de los usuarios debe cumplir con unos requisitos mínimos que AECA (Principios Contables, 1999: 47-55) ha marcado en dos principales: 
1. Relevancia: cuando la información posee utilidad notoria, potencial o real, para los fines perseguidos por los diferentes destinatarios, de forma que una información es relevante cuando es susceptible de influir en la toma de decisiones por los usuarios.

2. Fiabilidad: referida a la capacidad de una información de expresar con el máximo rigor las características básicas y condiciones de los hechos reflejados, circunstancia que, junto con la relevancia, persigue garantizar la utilidad de la información financiera.

A su vez para conseguir que la información financiera con carácter genérico y, por tanto, también, la contenida en el dictamen del auditor, sea relevante $y$ fiable ${ }^{28}$ se ha de cumplir con una serie de características asociadas a ambos conceptos, según se expone en la figura $n^{\circ} 3$.

Partiendo de los requisitos que debe contener toda información, e íntimamente relacionado con el "gap de expectativas", surge la interrogante sobre la utilidad para la toma de decisiones de los agentes que se interesan por el informe de auditoría. En este sentido se expresa Yubero Hermosa (2001: 189) cuando indica que "la opinión del auditor...es de poca utilidad para la toma de decisiones, ya que se está realizando un informe sobre cifras atrasadas, obsoletas, la información, por lo tanto, no es oportuna. En definitiva los usuarios demandan cada vez más información prospectiva, y acuden a otros sistemas de información para obtenerla y así decidir".

\footnotetext{
${ }^{28}$ A estos dos requisitos de calidad necesarios para la información financiera, IASC (traducido por Gonzalo Angulo y Tua Pereda, 1997) añade otros dos, los de "comprensibilidad" y "comparabilidad" que para AECA serían características incluidas en los conceptos de relevancia y fiabilidad.
} 
Figura n 3 Características de la información financiera

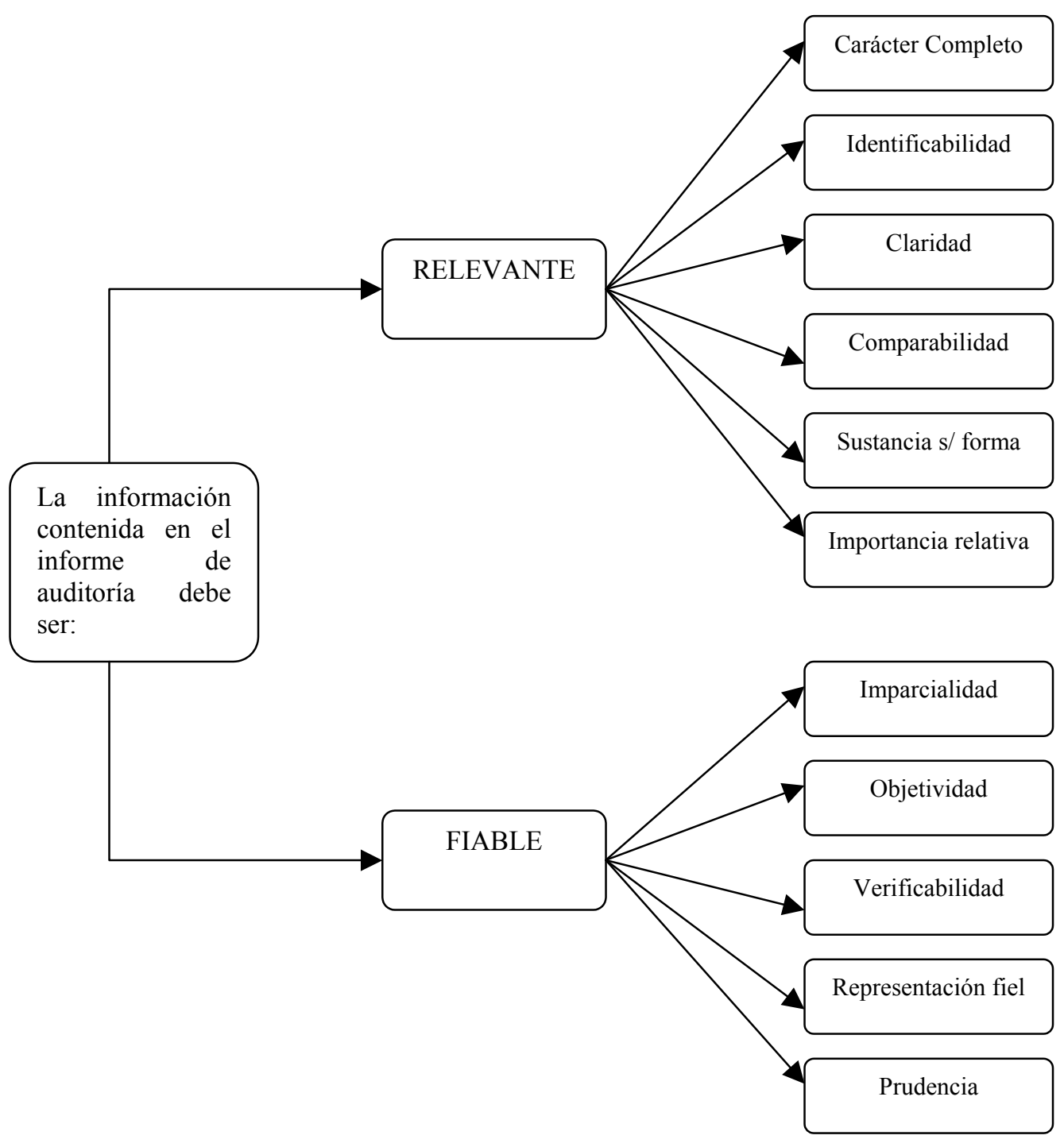

Fuente: elaboración propia a partir de AECA (1999).

Como afirma Ruiz Barbadillo (1998: 130 y 137) el desinterés de los usuarios por la información incluida en el informe de auditoría puede tener dos interpretaciones, o bien se debe a ciertas barreras a la comunicación entre auditor y usuarios (dificultad de comprensión del lenguaje) o bien " se basa en la posible ausencia de información relevante o desconocida por los usuarios en el informe de auditoría” de manera que “...éste debe tener contenido informativo si realmente pretende ser un instrumento útil de información". En este sentido García Benau y Pucheta Martínez (2001: 192) 
escriben que "no sería adecuado imputar la falta de comprensión del informe como una de las posibles causas que podrían explicar el aparente desinterés de los usuarios...deberíamos analizar si la ausencia de contenido informativo del informe para la toma de decisiones es otro de los motivos que podría explicar el escaso interés que despierta el informe de auditoría a los usuarios".

Sin embargo para comprender la hipótesis de utilidad o no de la auditoría para la toma de decisiones, debe primero revisarse la función actual del auditor y las expectativas que tienen los usuarios. Según la legislación vigente española el auditor tiene la obligación de emitir su juicio profesional sobre la fiabilidad de la información económico-financiera que han elaborado los administradores, pero sin llegar a más, es decir el objetivo principal que guía al auditor no es el de realizar un informe que sirva a efectos de gestión sino que solamente aporta seguridad a las cuentas ya preparadas. Para que el trabajo de "auditoría financiera" tuviera una finalidad que sirviera, tanto a la empresa auditada como al resto de usuarios, para la toma de decisiones estratégicas o de organización se debería hablar ya de "auditoría de gestión" y no financiera.

No obstante el hecho de que la función actual del auditor no lleve aparejada una utilidad de gestión, no significa ni que no sea útil ni que no pueda modificarse su actual papel, para adaptarse a las exigencias de la sociedad.

De hecho y tal como la Real Academia de la Lengua define el vocablo "útil", es decir toda actividad "que trae o produce provecho, comodidad, fruto o interés" (Real Academia Española, 1992: 2052), está más que demostrado que la "auditoría financiera o de cuentas anuales" aporta 
fiabilidad a la información económico-financiera de los estados auditados y, por tanto, cumple con la condición de utilidad en alguna medida. Esta aportación de "credibilidad" es lo que subyace en la "auditoría financiera", como reconoce el profesor Fernández Peña (1993), mientras indica que para que la información que proviene de los estados financieros sea útil debe cumplir con las características de comprensibilidad, relevancia, corrección, comparabilidad y oportunidad, a estas particularidades Cañadas Molina y González Quintana (2000: 311) añaden las de claridad, transparencia y objeto de amplia difusión, que en suma corroboran los cánones marcados por AECA e IASC.

Sin embargo, abundando no ya en la comprobada relevancia del trabajo sino en cuestionarse si es lo suficientemente útil como cabría esperar, es cuando se plantean los interrogantes en torno a la satisfacción y razonabilidad en las expectativas.

Gonzalo Angulo (1995: 625) es claro al indicar que la falta de utilidad puede desencadenar un proceso de rechazo social hacia la labor del auditor, señalando que "si los usuarios no perciben, clara y distintamente, que el auditor les ayuda a tomar decisiones, y no se limita a pasar unos procedimientos de rutina para emitir una opinión que no entienden ni pueden utilizar....si la utilidad social, en definitiva, no es patente, la reputación del profesional estará cuestionada, y el propio cuerpo social prescindirá de un miembro tan dudoso".

\subsubsection{La relevancia de la información contenida en el dictamen}

El hecho de que la información contenida en el dictamen no sea útil o relevante a efectos de gestión, sobretodo para la empresa auditada y en 
menor medida para terceros, no implica que no aporte "valor añadido" a los usuarios. En este sentido sí parece haberse contrastado que la "auditoría de cuentas anuales", por la que los auditores emiten su juicio profesional sobre la veracidad de datos financieros sobre la base de la aplicación correcta o incorrecta de principios contables, conlleva un incremento de la "fiabilidad" que la sociedad en general otorga a la información auditada.

Así, se han desarrollado numerosos estudios, con el mercado de capitales, para tratar de inferir la relevancia de la información contenida en el dictamen del auditor a través de su impacto en los precios de las acciones sujetas a cotización. Investigaciones, como las que se exponen a continuación, han contrastado que el informe del auditor es relevante en la toma de decisiones de determinados usuarios:

- Se observa que la opinión que emite el auditor es relevante a la hora de conceder financiación ajena, por parte de las entidades financieras a las empresas auditadas, ya que actualmente y en los casos que la auditoría es obligatoria, el informe de auditoría es un elemento imprescindible para obtener servicios de financiación. Dicha utilidad viene avalada por estudios como el realizado por Firth (1980).

- Del mismo modo, que con las entidades financieras, se ha contrastado la relevancia de la información que suministra el informe de auditoría para los inversores, así de las investigaciones llevadas a cabo por Firth (1978), Ball, Walker y Whittred (1979), Banks y Kinney (1982), Wilkerson (1987), Loudder et al. (1992), Jones (1996), Sánchez Segura (1999) y Gómez Aguilar et al. (1999), se desprende cierta utilidad para el dictamen; mientras que de los estudios realizados por Baskin (1972), Alderman (1979), Dodd et al. (1984), Del Brío González (1998) y Cabal 
García (2000) se deriva lo contrario, es decir la relevancia de la información que contiene es pequeña o nula.

\subsubsection{La utilidad del trabajo del auditor a efectos de gestión.}

De los resultados obtenidos en variados estudios se ha concluido que el informe del auditor aporta información adicional útil para muchos usuarios de la información contable, pero que son ajenos a la propia gerencia de la empresa sometida a auditoría de cuentas anuales. De esta forma cabe plantearse hasta que punto el trabajo del auditor es útil, también, a efectos de gestión, partiendo de la premisa insalvable que la finalidad que guía al auditor no es la evaluación de la gestión sino la de juzgar la exactitud de la presentación y elaboración de los estados financieros. En este sentido Gallizo y D'silva (1995: 239) afirman que “desde hace algunos años existe una importante coección sobre los honorarios de auditoría por parte de las empresas, debido en parte a que muchos empresarios no ven la auditoría como un elemento que aporte valor añadido al negocio".

Obviamente y al no ser el objetivo del auditor opinar sobre la gestión, parece razonable que el trabajo que lleva a cabo no sirva a efectos de aportar "valor añadido", para conseguir una gestión más eficaz de la empresa auditada. No obstante tampoco se puede olvidar que el trabajo desarrollado por los auditores aunque queda plasmado, de cara al público, en el informe de auditoría, no es sólo éste el referente único de su labor, ya que junto al dictamen, se emite una "carta de recomendaciones" dirigida al órgano de gestión de la sociedad en la que se le detallan aquellas debilidades que se han detectado en el control interno, pero que no suponen una revisión exhaustiva por parte del auditor de todos los mecanismos de control interno. De esto se deduce, que el auditor sí aporta algo a la gestión de la misma pero mediante 
un documento al que accede sólo la entidad auditada y que no tiene efectos de cara a terceros ajenos a la misma.

De lo expuesto se deriva que aunque el fin principal que guía al auditor no sea el enjuiciamiento de la gestión, no quiere decir que éste objetivo no sea modificable y adaptable a las necesidades sociales, y más teniendo en cuenta que los usuarios requieren del auditor que opine sobre la dirección, objetivo que como tal cubre hoy en día el servicio de "auditoría de gestión ${ }^{29 \prime}$, esto supone que, a pesar de existir la posibilidad de la auditoría de gestión para satisfacer estas necesidades sociales, ésta última nace también por un contrato privado de forma que el acceso al informe del auditor quedaría restringido sólo a la empresa, por lo que éste servicio seguiría sin satisfacer las necesidades de los usuarios externos a la empresa auditada. Como señalan Prado Lorenzo y González Bravo (1998: 876) "la falta de cobertura de las nuevas necesidades de directivos y usuarios externos se ha traducido en críticas hacia la auditoría financiera y demandan del auditor una mayor implicación en la evaluación de cuestiones como la calidad de la gestión o la capacidad de la empresa para continuar en el mercado". Surge, por lo expresado, un conflicto de objetivos entre "auditoría financiera" y de "gestión", ya que las necesidades sociales no se cubren con la última, a no ser que fuera obligatorio el dar publicidad a la misma, por ello no parece descabellado que la propia "auditoría financiera" pueda asumir cierta responsabilidad a efectos de gestión que tuviera efectos públicos. Los inversores, proveedores, entidades de crédito, Administración y en general todos los usuarios externos están cada vez más interesados en la información

\footnotetext{
${ }^{29}$ La naturaleza de la "auditoría de gestión", que ya ha sido expuesta en el apartado primero, se centra en la labor del auditor "que no se limita a la verificación que supone la auditoría financiera, sino que ha de proyectar sus conocimientos y su técnica en el enjuiciamiento de la política económica, o política de gestión seguida en la empresa, emitiendo su opinión sobre la eficacia en el cumplimiento de objetivos y la eficiencia en el orden de los costes, llegando incluso a ofrecer fórmulas para mejorar la gestión" (Fernández Pirla, 1992: 11).
} 
contable pero no sólo como algo que aporte fiabilidad sino que añada información útil para la toma de decisiones.

Según Mallo Rodríguez (2000: 21) y debido a la defraudación de expectativas respecto a la función actual del auditor cabe cuestionarse "...si sería conveniente ampliar el alcance de la auditoría financiera con un dictamen de auditoría estratégica que se pronunciara sobre la probabilidad de obtención de ganancias futuras de la empresa". 
REVISIÓN DE LA LITERATURA EMPÍRICA SOBRE LA AUDITORÍA DE CUENTAS: FUNCIÓN, UTILIDAD Y COMPRENSIÓN DEL INFORME DE AUDITORÍA 
En este capítulo se relacionan y revisan una serie de estudios empíricos que sirven de sustento al proceso de investigación realizado; habiéndose clasificado en tres grandes bloques en función del objetivo perseguido:

a) El primer bloque recoge los trabajos relacionados con la "función" que cumple el servicio de auditoría.

b) El segundo bloque contiene los estudios relacionados con la "utilidad" que presta la auditoría de cuentas a la sociedad a través del informe que emite el auditor.

c) El tercero incluye las investigaciones referidas a los "problemas de comunicación" entre auditores y usuarios debidos, principalmente, a la falta de comprensión de los informes de auditoría.

Dentro de cada uno de los tres epígrafes se ha realizado una subclasificación atendiendo a la metodología utilizada en el desarrollo de la investigación y a su cronología, de manera que, en los casos que procede, se han separado los trabajos en:

1. Estudios empíricos basados en experimentos de laboratorio.

2. Estudios empíricos basados en experimentos realizados con el mercado de capitales.

3. Estudios empíricos realizados mediante encuestas de opinión. 
Como afirma García Benau (1997: 154) “la gran ventaja que supone la realización de estudios empíricos en esta cuestión es que se obtiene evidencia acerca de las diferencias entre las expectativas de los auditores y usuarios, ante diversas cuestiones relativas a la auditoría, permitiendo además medir el tamaño del vacío existente."

\subsection{ESTUDIOS EMPÍRICOS SOBRE LA FUNCIÓN DE LA AUDITORÍA}

En este apartado se incluyen las investigaciones empíricas realizadas, hasta la fecha, seleccionadas en función de su relevancia y actualidad, con las que se ha tratado de realizar una revisión que aglutine todas las perspectivas desde que comenzó la investigación en dicho ámbito, así como los trabajos que se han llevado a cabo en España en relación con el llamado "gap de expectativas", que afecta a las diferentes percepciones que tienen los interesados en la labor de la auditoría, en cuanto a la función actual del auditor y a las demandas que la sociedad hace.

\subsubsection{INVESTIGACIONES MEDIANTE ENCUESTAS}

Se trata de estudios realizados utilizando la metodología propia de áreas de conocimiento ajenas al ámbito contable, como el "marketing" y más concretamente la "investigación de mercados", de la que el área de "economía financiera y contabilidad" comienza, en nuestro país, a tomar prestadas determinadas herramientas metodológicas como son las encuestas de opinión; es por ello que aparecen problemas adicionales para los no versados en dicha metodología.

Así se relacionan las encuestas del IACJC, en 1997, sobre los problemas de los auditores, al igual que el estudio realizado por García 
Benau, Garrido, Vico et al., en 1999, sobre la calidad de la auditoría que, a pesar de no tratar directamente la función de la auditoría, sí que sirven como subrogados del problema por investigar las diferentes percepciones, que muestran los usuarios del servicio de auditoría, tanto en relación con la función que realiza el auditor como a lo que ellos esperan.

Por orden cronológico se tratan los siguientes:

- Humphrey, Moizer y Turley, 1993.

- García Benau, Humphrey, Moizer y Turley, 1993.

- Porter, 1993.

- Centro de Investigación de Contabilidad y Auditoría de Maastricht, 1996.

- IACJC, 1997.

- García Benau, Garrido, Vico et al., 1999.

- IACJC, 1999.

- Herrador Alcaide, 2000. 
2.1.1.1. Estudio empírico para contrastar la diferencia de expectativas en torno a la auditoría en el Reino Unido (Humphrey, Moizer y Turley 1993)

Objetivo: Se pretende analizar los motivos que originan el "gap de expectativas" entre auditores y usuarios del servicio de auditoría en el Reino Unido.

Experimento: La investigación tiene como objetivo indagar, mediante la respuesta a un cuestionario, las percepciones, que muestran tanto auditores como profesionales de la contabilidad, directores financieros, analistas de inversiones, empleados de banca y periodistas especializados en economía, sobre la finalidad de la auditoría.

\section{Metodología:}

Cuestionario: La recogida de información se ha realizado a través de un cuestionario postal estructurado en las cuatro partes que siguen:

$1^{\text {a }}$ Con preguntas relativas a la función del auditor y la naturaleza de la auditoría.

$2^{\text {a }}$ Que incluye cuestiones para identificar los atributos con los que los encuestados califican la labor realizada por los auditores.

$3^{\text {a }}$ Incluye una serie de pequeños casos sobre los que se solicita, a los distintos grupos, que respondan lo que estiman que haría el auditor en determinadas circunstancias. 
$4^{\mathrm{a}}$ Por último se les realizan preguntas para evaluar la personalidad de los encuestados.

Se exponen una serie de afirmaciones a las que se debe contestar basándose en el grado de acuerdo, y en una escala tipo "Likert" graduada de 1 muy en desacuerdo hasta 7 muy en acuerdo, además el segundo bloque se define utilizando la técnica del "diferencial semántico 30 ".

El cuestionario es anónimo y todas las preguntas se presentan en formato cerrado. Se utiliza el mismo cuestionario para todos los grupos encuestados, ya que se pretende contrastar la opinión intergrupo.

Muestra: Se envía un total de 2245 cuestionarios; de los que se reciben en conformidad 935, lo que supone un nivel de respuesta muy elevado del $38.2 \%$.

La muestra se desglosa por grupos como sigue:

1. 600 auditores y profesionales de la contabilidad, que representan una muestra del listado oficial publicado por ICAEW.

2. 1000 directores financieros pertenecientes a las 1000 mayores empresas del Reino Unido, publicadas por “The Times 1000 list of major UK companies".

3. 400 analistas financieros obtenidos de la base "Briton's Index of Investment Research Analysts in the UK".

\footnotetext{
${ }^{30}$ Según Múria Albiol y Gil Saura (1998), las preguntas formuladas con la técnica del "diferencial semántico" se elaboran con una escala que presenta dos polos opuestos sobre los que debe situarse el entrevistado, además normalmente no se rotulan y si se hace es mediante una escala numérica.
} 
4. 220 empleados de banca.

5. 225 periodistas de prensa financiera.

Técnica utilizada: Se realiza un contraste de "diferencia de medias" entre los grupos, con el fin de obtener información relevante en cuanto a las diferentes percepciones que del trabajo de auditoría tienen los seis colectivos. Se muestran las diferencias con un nivel de significación estadística del 5\% y se aplica el test del "análisis de la varianza en un sentido de una clasificación por rangos de Kruskall-Wallis", dicha prueba ofrece un contraste no paramétrico para contrastar si más de dos muestras independientes pertenecen a diferentes poblaciones. Posteriormente se realiza una comparación entre grupos a través de la prueba estadística de la "Chicuadrado". De forma puntual se utiliza el "test de los signos de Wilcoxon". Por último se realiza un "análisis factorial", con el fin de determinar que factores son los principales causantes de las diferentes percepciones entre los grupos encuestados.

Conclusiones: De los resultados de la encuesta se extrae que los auditores tienen diferentes percepciones, respecto a los usuarios encuestados, en lo relativo a la naturaleza de la auditoría y al trabajo que desempeña el auditor; con ello queda demostrada la existencia del "gap de expectativas". Además se señalan como factores principales de dicho "gap", a principios de los noventa, los siguientes:

1. El papel del auditor en relación con la detección de fraudes.

2. La responsabilidad del auditor frente a terceros. 
3. La naturaleza de determinadas valoraciones en balance.

4. Las amenazas a la independencia del auditor.

5. Aspectos puntuales sobre el desarrollo del trabajo del auditor.

\section{Limitaciones:}

1. No se establecen métodos aleatorios en la selección de la muestra de alguno de los grupos encuestados, lo que condiciona la generalización de las conclusiones.

2. Para algunos de los grupos encuestados el "marco muestral" escogido no es representativo de la población. 
2.1.1.2. Estudio empírico para contrastar la diferencia de expectativas en torno a la auditoría en España y el Reino Unido (García Benau, Humphrey, Moizer y Turley 1993)

Objetivo: Se pretende analizar cómo es percibida la actuación de los auditores, tanto en España como en el Reino Unido, por parte de tres colectivos relacionados con la actividad: los propios auditores, los directores financieros y el colectivo de usuarios de la información contable.

Experimento: La investigación persigue averiguar, a través de las percepciones que muestran los colectivos que participan directa o indirectamente en el desarrollo de la auditoría, cuáles son las expectativas reales puestas en la auditoría de cuentas en España, para luego llevar a cabo una comparación con las expectativas que los mismos grupos presentan en el Reino Unido.

\section{Metodología:}

Cuestionario: La recogida de información se realiza a través de un cuestionario postal, estructurado en las nueve partes que siguen:

$1^{\text {a }}$ Relativa a los auditores y al proceso de auditoría.

$2^{\text {a }}$ Sobre el papel que debería ser realizado por los auditores, tanto en lo referente a la auditoría de estados financieros como a la empresa auditada. 
$3^{\mathrm{a}}$ En relación con aspectos que determinan la responsabilidad del auditor frente a terceros, tal como fraudes y errores al emitir el informe.

$4^{\mathrm{a}}$ Incluye aspectos relacionados con prohibiciones y restricciones de las firmas auditoras, haciendo énfasis en la independencia del auditor.

$5^{\text {a }}$ Comprende temas referidos a actividades que desarrolla el auditor en las que se quiere conocer el grado de eficacia con que se ejecutan.

$6^{\mathrm{a}}$ y $7^{\mathrm{a}}$ En las que se preguntan cuestiones sobre el tipo de decisión a tomar por los auditores en determinados casos de estudio.

$8^{\text {a }}$ Que incluye veinticinco afirmaciones sobre cuestiones generales de la personalidad del entrevistado, con el fin de analizar hasta que punto la visión personal sobre la vida puede condicionar las respuestas dadas.

$9^{a}$ En la que se plantean cuestiones referidas a información personal y profesional del encuestado.

En el cuestionario se realizan una serie de afirmaciones a las que se debe contestar basándose en el grado de acuerdo del entrevistado, para lo que se emplea una escala tipo "Likert" graduada de 1 muy en desacuerdo hasta 7 muy en acuerdo. El cuestionario es anónimo y todas las preguntas se presentan en "formato cerrado", utilizándose el mismo para auditores, directores financieros y usuarios, ya que se pretende contrastar la opinión intergrupo. 
Muestra: Se envía un total de 3.005 cuestionarios, de los que se devuelven por error en la dirección 145, quedando una muestra real de 2.860. Se reciben con conformidad 436, lo que implica un nivel de respuesta del 15.25\%.

La muestra se desglosa por grupos como sigue:

1. 998 auditores, con el siguiente detalle: 176 socios de empresas medianas y grandes, 176 socios de firmas pequeñas, 300 personas físicas prestando servicios por cuenta ajena, 292 ejercientes a título individual, 50 pertenecientes a multinacionales de auditoría.

2. 1.244 usuarios de la información contable, con el siguiente detalle: 169 pertenecientes a periódicos financieros, 260 a analistas de inversión, 159 a sociedades y agencias de valores, 485 a entidades financieras, 21 a profesores universitarios, 150 a profesionales independientes.

3. 763 directores financieros: 666 pertenecientes a grandes empresas y 97 a empresas con actividad en el extranjero.

Fechas: el envío y la recepción de los cuestionarios se realizan entre los meses de junio a noviembre de 1992.

Fuente: La información relativa a los auditores se obtiene del listado del ROAC que publica el ICAC, la de analistas financieros se consigue del "Instituto Español de Analistas Financieros", mientras que la de las Sociedades y Agencias de valores se saca de los "Registros Oficiales de la Comisión Nacional del Mercado de Valores". Las encuestas de entidades financieras se envían a los departamentos de riesgos, de las oficinas principales, de los bancos más importantes. Los profesionales independientes 
son seleccionados a través de los "Colegios de Economistas", mientras que los directores financieros se obtienen de la información proporcionada por la CNMV.

Técnica utilizada: Se realiza un contraste de "diferencia de medias" entre los grupos, con el fin de obtener información relevante en cuanto a las diferentes percepciones que del trabajo de auditoría tienen los tres colectivos. Se muestran las diferencias con un nivel de significación estadística del 5\% o del $1 \%$, utilizando el test del "análisis de la varianza de una clasificación por rangos de Kruskall-Wallis", dicha prueba ofrece un contraste no paramétrico para comprobar si tres muestras independientes pertenecen a diferentes poblaciones. Posteriormente, las respuestas de cada uno de los grupos estudiados en España se comparan con sus equivalentes en el Reino Unido a través del "test de Wilcoxon-Mann-Whitney", con el fin de identificar las diferencias estadísticas significativas en cada uno de los tres pares de distribuciones, con un nivel de significación del 5\%.

Conclusiones: A continuación se han extractado algunas de las principales conclusiones del estudio:

- La expresión anglosajona "audit expectations gap" se refiere a la diferencia de expectativas entre usuarios y auditores en torno a cuáles son o deberían ser las funciones del auditor.

- Del trabajo se desprende que en España existe una creencia generalizada de que la auditoría reporta beneficios para la empresa. 
- Se reconoce la "función social" del auditor por el servicio que presta a la sociedad.

- Los usuarios de los informes financieros se muestran más partidarios de prohibir el "asesoramiento" por parte del auditor que el resto de grupos. El 53\% de los auditores se pronuncia en desacuerdo con la prohibición de compaginar ambos servicios.

- Una amplia mayoría considera que el auditor debe asegurarse de la "gestión continuada" de la empresa.

- Al auditor se le responsabiliza de proteger a la empresa contra el "fraude", tanto en su detección como en su prevención.

- Se exige una importante responsabilidad al auditor en cuanto a la aportación de mejoras en la "gestión" de la empresa.

- La diferencia de expectativas entre grupos encontrada en España es menor que la encontrada en el Reino Unido. Los auditores españoles están mucho más cerca de los puntos de vista de los usuarios y directores financieros.

- Los auditores españoles aceptan mayores responsabilidades que los británicos.

- Se produce una mayor insatisfacción sobre el informe de auditoría en UK que en España. 
Limitaciones: No se establecen métodos aleatorios en la selección de la muestra de alguno de los grupos encuestados lo que condiciona la generalización de las conclusiones. 


\subsubsection{Estudio empírico para contrastar el "gap de expectativas" en Nueva} Zelanda (Porter 1993)

Objetivo: Se persigue contrastar el "gap de expectativas" entre auditores y usuarios en Nueva Zelanda, así como establecer la estructura, composición y alcance de dicha diferencia.

Experimento: La investigación pretende indagar, mediante una encuesta, las percepciones que muestran tanto auditores como directores de empresas públicas, profesores de auditoría, analistas de inversiones, abogados, periodistas especializados en economía y público en general, en relación con el trabajo que desarrolla el auditor y lo que cabe esperar del mismo.

Conclusiones: De los resultados obtenidos en el estudio, se deduce que el $50 \%$ de los motivos que explican el "gap de expectativas" se debe a que las funciones que tienen asignadas los auditores son insuficientes, un 34\% de dicho "gap" se ocasiona porque los grupos sociales mantienen expectativas sobre el trabajo del auditor que van más allá de lo razonable, mientras que el $16 \%$ restante es debido a que los auditores realizan un trabajo que no cumple con las responsabilidades que les corresponden.

Se descubre que el "gap de expectativas" está formado por dos componentes:

c) Un "gap de razonabilidad", que se definiría como la diferencia entre lo que espera la sociedad que realice el auditor y lo que cabe esperar de manera razonable de su trabajo. 
d) Un "gap de realización", definido como la diferencia entre lo que la sociedad espera de manera razonable que realice el auditor y lo que se percibe que consiguen. Esta parte del gap se produce por:

1. La insuficiencia de las normas, debida a diferencias entre las responsabilidades que se pueden esperar de los auditores y las responsabilidades recogidas por la ley y las normas profesionales.

2. La insuficiencia de los resultados, debida a diferencias entre los resultados obtenidos por el auditor de acuerdo a sus responsabilidades legales y los resultados que percibe la sociedad. 


\subsubsection{Encuesta encargada por la Comisión Europea, al Centro de} Investigación de Contabilidad y Auditoría de Maastricht, para el estudio de la función, posición y responsabilidad del auditor estatutario en la Unión Europea (Conocido como Informe MARC, 1996)

Objetivo: El investigador se plantea dos propósitos principales: el primero obtener un resumen objetivo y en detalle de la legislación de los diferentes Estados Miembros de la Unión Europea con respecto a la función, posición y responsabilidad del auditor externo; en segundo lugar se pretende analizar las principales diferencias en la legislación auditora de los países y su impacto en el funcionamiento del mercado interno de auditoría en el ámbito europeo.

Experimento: La primera fase del estudio consiste en la recopilación de la legislación auditora de los diferentes países, a través de un cuestionario que se prepara a tal fin y que es contestado por auditores de las cuatro firmas multinacionales de auditoría que colaboran en el estudio. En este sentido la sociedad Arthur Andersen cubre los países de Austria, Alemania, Grecia y Noruega, por su parte Coopers \& Lybrand recopila la información de Bélgica, Francia, Italia y Luxemburgo, mientras que Ernst \& Young lo hace para Dinamarca, Finlandia, Países Bajos, y por último Price Waterhouse se encarga de Irlanda, Portugal, España y Reino Unido. No obstante, las respuestas de los auditores se revisan por un total de 33 cuerpos profesionales y/o gubernamentales, para verificar la objetividad de la información suministrada. La segunda fase del estudio consiste en el análisis de las diferencias entre las legislaciones desde una perspectiva económica.

Metodología: La obtención de la información de la primera parte se efectúa a través de un cuestionario, con las características siguientes: 
- Se escoge un formato de "preguntas abiertas" para que los encuestados puedan proporcionar información histórica.

- El cuestionario aparece estructurado en ocho bloques: $1^{\circ}$. Introducción. $2^{\circ}$ y $3^{\circ}$. Sobre el nombramiento de los auditores. $4^{\circ}$. Independencia del auditor y actividades incompatibles. $5^{\circ}$. Función y posición del auditor estatutario y su relación con los órganos de la compañía. $6^{\circ}$. Relación del auditor con los cuerpos de gobierno de la empresa. $7^{\circ}$. Responsabilidad de los auditores hacia la compañía y hacia terceros. $8^{\circ}$. Contenido del informe de auditoría.

- Las respuestas se revisan por terceras personas pertenecientes a los cuerpos profesionales de auditores, así como por las autoridades gubernamentales de cada país que juegan un papel importante respecto de la profesión de auditor. Con esta medida se pretende mejorar la calidad de la información obtenida.

- Por último, se utiliza una lista adicional de preguntas específicas para obtener aclaraciones sobre aquellos temas que no se hubieran resuelto mediante el primer cuestionario.

Conclusiones: De los resultados obtenidos se detallan, a continuación, las conclusiones más relevantes para la investigación que se ha llevado a cabo:

1. En todos los países analizados, exceptuando Bélgica, Francia e Italia, las firmas de auditoría están autorizadas en general a facilitar, al menos, algún otro servicio al cliente de auditoría a través de la misma entidad legal (los servicios preguntados son: teneduría de libros y 
contabilidad, impuestos, servicios legales, asesoría, servicios de inversión y financieros y recuperación corporativa), aunque suelen existir restricciones.

2. Sólo en unos pocos países, el auditor externo tiene que pronunciarse en un informe público, distinto al informe de auditoría, sobre asuntos diferentes a la consecución de la imagen fiel de las cuentas anuales y al cumplimiento de la Ley de Sociedades Anónimas.

3. En ningún país los auditores tienen la obligación de auditar estados financieros parciales y emitir informes de "auditoría medioambiental".

4. De acuerdo con la cuarta Directiva Comunitaria los auditores tienen la posibilidad de publicar el informe de auditoría en dos formatos, uno corto y otro largo, este último no solo contiene la opinión del auditor, sino que además incluye una descripción más amplia del proceso de auditoría y de sus resultados. No obstante, en todos los países estudiados se emplea el formato corto de informe, salvo Austria y Alemania en los que se exige junto al informe corto otro con formato largo.

5. Uno de los problemas que plantean las auditorias obligatorias es la determinación de las funciones que cubre el servicio de auditoría, ya que en las legislaciones de los países no se especifica directamente el contenido de la misma. 
6. Las medidas dirigidas a mejorar la calidad de la auditoría, como son las restricciones a la publicidad, oferta de servicios, alcance de los servicios, etc., no suelen mejorar de forma eficaz la calidad.

7. Existe una preocupación por problemas de independencia cuando los auditores prestan, junto al servicio de auditoría, servicios de asesoramiento, por el temor de perder este último como consecuencia de un trabajo de auditoría "fuerte ${ }^{31 ", ~ p u e s ~ r e a l i z a r ~ d i c h o ~ s e r v i c i o ~}$ puede conllevar que el auditor necesite auditar su propio trabajo, y por ello algunos estados miembros prohíben el servicio. No obstante, no existe evidencia empírica convincente de que los servicios de asesoría de gestión creen problemas de independencia.

8. La auditoría varía a lo largo del tiempo como resultado de los cambios del entorno, por ello los requisitos legales relativos a la educación del auditor, el informe de auditoría y la ejecución de una auditoría deberán ser adaptables.

\section{Limitaciones:}

1. Los resultados del cuestionario sólo ofrecen información sobre las leyes y reglamentaciones relevantes y no sobre el funcionamiento real de los mercados de auditoría en la Unión Europea.

2. Existe una dificultad añadida, debido a que la investigación sobre el mercado de auditoría en Europa es escasa, pues la mayoría de estudios previos corresponden a los países anglosajones.

\footnotetext{
${ }^{31}$ Con dicha expresión se hace referencia a la posibilidad de que, en los casos que el auditor emite una opinión con salvedades o adversa, pueda correr el riesgo de perder clientela.
} 
2.1.1.5. Encuesta sobre la situación, actitudes y expectativas de la auditoría en España, incluida en el Libro Blanco de la Auditoría de Cuentas (encargada por el IACJC a la empresa Vox Pública, 1997)

Objetivo: Se plantean dos objetivos principales:

1. Analizar la situación, actitudes y expectativas generadas por la posible reforma de la Ley 19/1988 de Auditoría de Cuentas.

2. Investigar y medir la situación, actitudes y expectativas ante un previsible proceso de unidad asociativa entre los profesionales auditores.

Experimento: La información necesaria para la consecución de los objetivos se ha obtenido de los diferentes grupos sociales interesados y relacionados con la profesión auditora, siendo los participantes los grupos siguientes:

- Auditores de cuentas asociados y no asociados a las tres Corporaciones de Derecho Público representantes de los auditores el IACJC, el REA y el REGA.

- Auditores inscritos como ejercientes y no ejercientes en el ROAC.

- Empresas clientes de los auditores.

- Representantes de organismos e instituciones oficiales: responsables de firmas de auditoría, notarios y registradores mercantiles. 
- Profesionales y académicos de reconocido prestigio: profesores universitarios y economistas.

Metodología: Para recabar la información se han utilizados dos técnicas, una cuantitativa para recopilar las opiniones de auditores, empresarios y representantes de organismos e instituciones oficiales, a través de "entrevistas telefónicas asistidas por ordenador" (CATI), y otra cualitativa mediante entrevistas en profundidad para recoger la opinión de expertos.

\section{Metodología empleada con el grupo de investigación: Auditores}

- Universo: auditores de cuentas de España ejercientes y no ejercientes, que supone un total de 14.332 individuos.

- Muestra: 745 entrevistas mediante "selección sistemática aleatoria simple" de los registros de profesionales en cada estrato, definido según la Corporación a la que pertenecen (IACJC; REA; REGA; No asociados), y su situación como ejerciente o no ejerciente.

- Fuente de datos: la información se obtiene del ICAC, a través del BOICAC n ${ }^{\circ}$ 25, y de la publicación del "Anuario del ROAC".

- Ámbito de aplicación: Nacional.

- Técnica de recogida de datos: "entrevista telefónica asistida por ordenador" (CATI). Se realiza un total de 3.696 llamadas telefónicas entre llamadas válidas, ausentes, con números incorrectos, negativas, citas fuera de plazo y fuera de cuota. 
- Error Muestral: $\pm 3.54 \%$, para un "nivel de confianza" del 95.5\%, 2 de desviación típica y $\mathrm{p}=\mathrm{q}=50$ en el peor de los casos.

- Fechas de recogida de datos: "briefing32" y lanzamiento del estudio el día 6 de marzo de 1997, toma de información del 6 al 11 de marzo de 1997.

- Equipo de entrevistadores: 1 técnico en muestreo, 1 supervisor de campo, 15 entrevistadores.

\section{Metodología empleada con el grupo de investigación: Empresas}

- Universo: Empresas radicadas en España con obligación legal de auditarse, es decir, que cumplen con dos de los tres requisitos siguientes: $1^{\circ}$. Importe neto de la cifra de negocio igual o superior a 600 millones. $2^{\circ}$. Número medio de empleados mayor o igual a $50.3^{\circ}$. Valor del activo mayor o igual a 300 millones. Se obtiene un universo de 16.284 empresas.

- Muestra: 202 entrevistas realizadas de manera estratificada según el número de empleados y la cifra de ventas: empresas grandes, caracterizadas por tener un número de empleados mayor o igual a 50 y un volumen de negocio mínimo de 1.000 millones (82 entrevistas), y empresas medianas (120 entrevistas) a su vez dividas en tres subestratos: a) con facturación inferior a 600 millones y más de 50 empleados, b) con facturación entre 600 y 999 millones, c) con facturación entre 1.000 y 1.499 millones y con menos de 50 empleados. 
- Fuente de datos: la base de datos de empresas "Fomento de la Producción" para el año 1995.

- Ámbito de aplicación: Nacional.

- Representante de la empresa entrevistado: Consejeros Delegados, Presidentes o Directores Financieros.

- Técnica de recogida de datos: "entrevista telefónica asistida por ordenador" (CATI). Se realizan un total de 734 llamadas telefónicas entre llamadas válidas, ausentes, con números incorrectos, negativas, citas fuera de plazo y fuera de cuota.

- Error Muestral: $\pm 6.99 \%$, para un "nivel de confianza" del 95.5\%, -2 de desviación típica y $\mathrm{p}=\mathrm{q}=50$ en el peor de los casos.

- Fechas de recogida de datos: "briefing" y lanzamiento del estudio el día 7 de marzo de 1997, toma de información del 7 al 14 de marzo de 1997.

- Equipo de entrevistadores: 1 técnico en muestreo, 1 supervisor de campo, 3 entrevistadores.

${ }^{32}$ Información previa que entrega el anunciante, a la agencia de publicidad, para el diseño del mensaje 
Metodología empleada con el grupo de investigación: Instituciones y Organismos Públicos, Registradores Mercantiles, Notarios y Presidentes de Firmas de Auditoría.

- Universo: Representantes de "organismos públicos" que poseen un alto grado de responsabilidad en relación con el control y supervisión de la aplicación de las normas de auditoría, procediendo de: el Ministerio de Economía y Hacienda, la Dirección General de Seguros, el Banco de España, la Comisión Nacional del Mercado de Valores y las Bolsas de Valores. Como representantes de "otros agentes" se escogen, Registradores Mercantiles y Notarios; como representantes de firmas de auditoría se seleccionan a sus presidentes.

- Muestra: 40 personas entrevistadas de las diferentes instituciones. En el caso de los representantes de "organismos públicos" se realiza una selección subjetiva según el criterio del investigador, para los representantes de "otros agentes" se realiza una selección sistemática de la muestra.

- Fuente de datos: La información de los representantes de "organismos públicos" se obtiene de fuentes públicas, para "otros agentes" (Notarios y Registradores Mercantiles) se obtiene de las guías telefónicas de las principales ciudades españolas.

- Ámbito de aplicación: Nacional.

y la realización de la campaña publicitaria, Santesmases (1998: 972). 
- Técnica de recogida de datos: "entrevista telefónica asistida por ordenador" (CATI). Se realiza un total de 89 llamadas telefónicas entre llamadas válidas, ausentes, con números incorrectos, negativas, citas fuera de plazo y fuera de cuota.

- Error Muestral: no se suministran, porque a juicio del investigador la propia estructura muestral confiere a la información un carácter más cualitativo que cuantitativo, y no se considera útil la cuantificación de los errores de muestreo.

- Fechas de recogida de datos: "briefing" y lanzamiento del estudio el día 11 de marzo de 1997, toma de información del 11 al 18 de marzo de 1997.

- Equipo de entrevistadores: 1 técnico en muestreo, 1 supervisor de campo, 3 entrevistadores.

\section{$\underline{\text { Metodología empleada con el grupo de investigación: Expertos }}$}

- Se elabora un panel de expertos y personalidades de reconocido prestigio en el ámbito de la auditoría de cuentas, a los que se realiza entrevistas en profundidad.

- Fechas de recogida de datos: "briefing" y lanzamiento del estudio el día 10 de febrero de 1997, toma de información del 10 de febrero al 14 de marzo de 1997.

- Equipo de entrevistadores: 1 técnico cualitativista, 1 transcriptor. 


\section{Conclusiones:}

\section{Principales conclusiones obtenidas del estudio:}

1. Respecto a la percepción de los auditores sobre la problemática de la profesión y las posibles soluciones, los principales problemas citados conciernen: a la desunión profesional, la guerra de precios por la competencia desleal, de las grandes firmas de auditoría respecto a las pequeñas, y la responsabilidad del auditor. Las soluciones pasan por la autorregulación, en la que todos los grupos coinciden, en materias técnicas, deontológicas y profesionales; salvo en el caso de los representantes de la Administración, de los que el 50\% esta a favor y la otra mitad en contra de que se deje autorregular los temas relativos a la deontología y la profesión.

2. De la valoración que hacen los empresarios y la Administración sobre la situación de los auditores destaca que el 89.6\% de los empresarios se declara muy o bastante satisfecho con el servicio de auditoría recibido. A las empresas se les pregunta: ¿Qué pediría a los auditores de cuentas que no les estén dando ahora mismo?, el $45 \%$ responde que no necesitan más servicios, el $24.8 \%$ solicita más involucración con la empresa mediante una postura más activa, el $8.4 \%$ solicita mayores servicios de control interno y/o auditoría interna, el $6.9 \%$ pide un seguimiento de la empresa más continuo, otro 6.9\% considera necesario una mayor agilidad del auditor y, por tanto, menos tiempo para recabar la información, por último un $1.5 \%$ solicita más flexibilidad y/o atención a las peculiaridades de cada empresa. 
3. Actitudes ante la reforma legislativa: tanto la mayoría de auditores como la Administración consideran regular el actual marco legal de la auditoría, por el contrario los empresarios lo ven bueno o muy bueno. No obstante los tres grupos opinan, de forma mayoritaria, que la actual Ley debe ser modificada. Para los auditores los principales temas a modificar son, por este orden: $1^{\mathrm{o}}$. Redefinir el control de la Administración. $2^{\circ}$. La responsabilidad del auditor. $3^{\circ}$. El control deontológico y de calidad. $4^{\circ}$. El acceso a la profesión. 5 . Las normas técnicas. $6^{\circ}$. El eliminar rigideces en la actuación del auditor. $7^{\circ}$. La contratación de los auditores. $8^{\circ}$. El nombramiento de los auditores. $9^{\circ}$. Las sanciones. $10^{\circ}$. El régimen de incompatibilidades.

\section{Principales conclusiones obtenidas de las entrevistas al panel de expertos:}

1. Sobre el estado de la situación actual de la profesión:

a. La mayoría de la sociedad española, en un sentido muy amplio, desconoce la profesión auditora.

b. El ciudadano medio no conoce cuál es el papel del auditor.

c. Existe mucho confusionismo entre cuál tiene que ser la labor del auditor y la valoración que la sociedad hace de la misma.

d. El auditor no puede sustituir al gestor. 
2. Sobre la Ley de auditoría y su reforma:

a. Existe excesiva regulación por parte de la Administración.

b. El excesivo intervensionismo perjudica la función auditora y la profesión de auditor.

c. El auditor no es responsable de una mala gestión empresarial.

d. La responsabilidad que pueda tener un auditor no exime de la responsabilidad a la empresa en ningún caso.

e. Habría que integrar y desarrollar la legislación vigente, en auditoría, y establecer una ley marco que permita que la propia profesión se regule.

f. La nueva Ley de Auditoría debe clarificar las posiciones y las responsabilidades del gestor y del auditor, del cliente y del profesional.

g. La auditoría como profesión sería mejor considerada socialmente si se reconoce legalmente como tal.

h. Existe una necesidad de unificación de las tres Corporaciones representativas de auditores. 


\section{Limitaciones:}

1. Los representantes de la Administración, notarios, etc., no siguen un proceso de selección aleatorio, por lo que las conclusiones no son generalizables.

2. Las conclusiones del panel de expertos no son generalizables, se han seleccionado según el criterio subjetivo del investigador. 
2.1.1.6. Estudio empírico para comprobar la calidad del servicio de auditoría a través de la percepción que muestran los clientes demandantes del servicio (García Benau, Garrido, Vico et al. 1999)

Objetivo: Analizar la calidad del servicio de auditoría en España a través de la imagen que tienen, de los auditores, los usuarios del servicio.

Experimento: La investigación se realiza con los directores financieros de las 2.000 mayores empresas españolas, obteniendo la información del ranking en función de la facturación publicado por la revista "Actualidad Económica" en el año 1995, y tiene como finalidad comprobar cómo perciben las empresas auditadas las cualidades que definen a sus auditores, así como las que debe tener su ideal de auditor, para determinar hasta que punto se cumplen las expectativas que las empresas tienen sobre las cualidades óptimas que debe cumplir todo auditor.

Metodología: La información del estudio se recaba a través de una encuesta postal enviada entre el mes de noviembre de 1996 y febrero de 1997. De los 2.000 cuestionarios enviados, se devuelven $37 \mathrm{y}$ se contestan 247, lo que supone un índice de respuesta del $12.58 \%$. La técnica empleada para medir las actitudes de los encuestados se basa en el "diferencial semántico", a través de 30 adjetivos y frases bipolares que son valorados en una escala de 1 a 7 puntos, dejando una opción de respuesta "no sabe". Las técnicas estadísticas utilizadas, para la extracción de los resultados, consisten en "medidas de estadística descriptiva" y en las pruebas de la "U de Mann Whitney" y el "test de Wilcoxon" como pruebas no paramétricas. La "U de Mann Whitney" se emplea para valorar la significatividad de la diferencia entre los valores medios obtenidos de dos muestras independientes; en este caso la diferente valoración que otorgan los clientes de las seis grandes 
firmas internacionales de auditoría de la que conceden los clientes del resto de firmas de auditoría. Por otro lado se utiliza el "test de Wilcoxon" para comprobar el nivel de significatividad al comparar las puntuaciones medias dentro de dos muestras relacionadas, como son los clientes de las seis grandes firmas de auditoría por un lado y los del resto de firmas de auditoría por el otro. Los resultados reflejan diferencias estadísticamente significativas, al 10\%, entre las percepciones de la imagen que tienen de sus auditores los clientes de las seis grandes multinacionales y el resto de firmas.

\section{Conclusiones:}

1. La calidad desde el punto de vista de los auditores no se relaciona exclusivamente con aspectos técnicos relativos al trabajo del auditor, de manera que la "imagen" que se percibe de los auditores, desde el exterior, constituye un parámetro definitorio de calidad.

2. Existe una diferencia significativa entre la imagen que se percibe de los auditores de las grandes multinacionales de auditoría y el resto.

3. Las sociedades auditadas por las seis grandes firmas no se encuentran satisfechas en cuanto al precio del servicio, a la actitud poco imaginativa del auditor, a la disposición a asumir riesgos y al deseo de conceder una mayor preponderancia a la actividad de consultoría que a la auditoría.

4. Los clientes del resto de firmas de auditoría, distintas a las multinacionales, se muestran descontentos con: la ausencia de carácter internacional, la modernidad del auditor y la buena cobertura del servicio en el territorio nacional. 


\section{Limitaciones:}

- Como sucede con todas las encuestas de opinión, surge el problema de la subjetividad asociada a la elección de los adjetivos y frases que sirven para evaluar la actitud de los encuestados.

- Los resultados son sólo representativos de los directivos financieros de las grandes empresas pero no de la pequeña y mediana empresa. 
2.1.1.7. Encuesta de opinión, realizada a auditores, sobre los problemas y el futuro de la profesión auditora en España (IACJC septiembre 1999)

Objetivo: La encuesta tiene como objetivo conocer la opinión de los auditores de cuentas, ejercientes en España, sobre la situación actual de la profesión y sus principales problemas e inquietudes.

Experimento: Se realiza una encuesta telefónica al conjunto de auditores ejercientes en España, pertenecientes a las tres Corporaciones de Derecho Público representativas de los auditores; IACJC, REA y REGA, así como a una minoría de auditores ejercientes pero no asociados. Mediante dicha encuesta se obtienen las valoraciones y percepciones que tienen los profesionales sobre determinados aspectos de su profesión.

Metodología: La información se consigue a través de una encuesta postal encargada por el IACJC de España a la empresa "Vox Pública”, especializada en estudios de opinión, con las características siguientes:

- Universo: El conjunto de auditores de cuentas ejercientes en España.

- Muestra: 802 entrevistas realizadas previa selección aleatoria de los entrevistados, perteneciendo el 53.1\% al IACJC, el 29\% al REA, el $17.5 \%$ al REGA y el $0.4 \%$ a auditores no asociados.

- Fuente de datos: el listado del "Registro Oficial de Auditores de Cuentas" (ROAC) publicado por el ICAC.

- Ámbito de aplicación: Nacional. 
- Técnica de recogida de datos: "entrevistas telefónicas asistidas por ordenador" (CATI).

- Error Muestral: se obtiene un error del $\pm 3.22 \%$, para un "nivel de confianza" del 95.5\%.

\section{Conclusiones:}

1. El $81.2 \%$ de los auditores considera urgente la aprobación de la modificación de la Ley 18/1988, de Auditoría de Cuentas, considerando el $99.3 \%$ que deben participar los profesionales en la reforma legal.

2. El $81.3 \%$ manifiesta que la profesión debe poder autorregularse, de forma que pueda decidir con relación al desarrollo de la profesión sin intervensionismo de la Administración. Así, el 67.6\% afirma que deben ser los propios profesionales quienes solucionen los problemas que tiene la auditoría, mientras el $26.6 \%$ considera que junto a los profesionales también debe participar la Administración.

3. El $90.4 \%$ de los entrevistados se muestra favorable a la unificación de las tres Corporaciones que agrupan a la profesión, mientras que el $74 \%$ considera que la división tripartita de la profesión es mala, además se muestran a favor, en su mayoría, de la propuesta de unificación realizada por el IACJC.

4. Para los profesionales de la auditoría, los principales problemas que afectan a la profesión son por este orden: la delimitación de la 
responsabilidad, la independencia, el control de calidad, la autorregulación profesional y la formación profesional continuada.

Limitaciones: Los encuestados no se han escogido de forma que las tres Corporaciones aparezcan representadas en la misma proporción, sino que ha primado la importancia del número de auditores adscritos a cada Corporación, lo que puede dar lugar a un sesgo por las diferencias en cuanto a los planteamientos que mantiene cada una de ellas. 
2.1.1.8. Encuesta de opinión realizada a auditores de la Comunidad de Madrid para analizar el informe de auditoría como conclusión y objetivo del trabajo del auditor (Herrador Alcaide 2000)

Objetivo: Uno de los dos objetivos que pretende contrastar el estudio, trata de investigar el punto de vista de los auditores sobre el debate internacional en torno a las funciones del auditor y las expectativas puestas en el dictamen que emite, así como sobre el grado de aceptación que muestran los mismos en torno a las medidas que, hasta el momento, se han expuesto para reducir el "gap de expectativas".

Experimento: Se realiza una encuesta de opinión, al conjunto de auditores ejercientes en la Comunidad Autónoma de Madrid, a través de correo ordinario, con la finalidad de obtener las valoraciones y percepciones que tienen los profesionales sobre determinados aspectos de su profesión.

Las hipótesis planteadas se han agrupado dentro de los siguientes bloques:

i. Características profesionales.

ii. Autenticación del informe-independiente del auditor.

iii. La función del informe en las decisiones de inversión.

iv. Extensión, estructura del contenido del informe.

v. Fraudes e irregularidades.

vi. Idoneidad del control interno.

vii. Continuidad de la entidad auditada.

viii. Evidencia.

ix. Riesgo inherente y de control.

x. Evaluación de la evidencia para el informe. 
Metodología: Se efectúa una encuesta postal con las siguientes características:

- Universo: el conjunto de auditores de cuentas ejercientes en la Comunidad de Madrid, la población se establece en 937 auditores.

- Muestra: se obtiene una muestra de 273 auditores, a través de la técnica de "muestreo aleatorio simple unietápico", con "arranque aleatorio" y sin "reemplazamiento", dividiéndose en dos submuestras; el 40\% de sociedades de auditoría y el 60\% de auditores individuales.

- Fuente de datos: listado del "Registro Oficial de Auditores de Cuentas" (ROAC) publicado por el ICAC.

- Ámbito de aplicación: Comunidad Autónoma de Madrid.

- Error Muestral: se obtiene un error muestral del $\pm 5 \%$, asignando una probabilidad de aciertos/fallos del 50\% ( $p=q=50)$.

Para la exploración de datos se ha realizado, un análisis primario mediante la aplicación de "estadística descriptiva" con el fin de identificar y caracterizar la realidad cuantificada, y un análisis secundario para el contraste de hipótesis a través de la prueba de "significación de la media" para la validación global de la hipótesis, además de un "análisis de las proporciones" para las conclusiones parciales de cada hipótesis. 
Conclusiones: De las conclusiones del estudio se ha extraído como más significativas las que siguen:

1. Los auditores perciben que la estructura del informe, con sus diferentes párrafos, es adecuada para explicar las funciones que se les atribuyen. No obstante, consideran positiva una posible modificación de la estructura del mismo.

2. En cuanto a la extensión del informe y el lenguaje empleado, también opinan que son adecuados a la finalidad de su trabajo y, por tanto, no aprecian problemas de comprensión por los tecnicismos empleados, de lo que se deduce que perciben una correcta transmisión de los resultados que obtiene el auditor para un "usuario medio".

3. Una vez que se comprueba que la "diferencia de expectativas" respecto a la suficiencia del informe no es muy grande, la investigación se centra en el contenido informativo del dictamen sobre tres temas principales; fraude, control interno y continuidad:

- De los resultados se desprende que es necesaria una reforma de la información que se ofrece en el dictamen sobre fraudes e irregularidades.

- Se considera necesario ampliar el contenido que se incluye, en el informe, sobre el control interno de la empresa auditada.

- Según la opinión de los auditores, la actual estructura del informe es adecuada para reflejar la revisión que hace el auditor sobre la continuidad de la actividad empresarial. 
Limitaciones: En el estudio se indica que se ha recibido una tasa de respuesta baja; también se plantea el problema del tratamiento de la respuesta parcial, es decir de aquellas preguntas no contestadas. 


\subsection{ESTUDIOS EMPÍRICOS SOBRE LA UTILIDAD DE LA AUDITORÍA}

En este apartado se incluyen las investigaciones que tienen por objeto verificar la "utilidad" del trabajo del auditor a través de la relevancia de la información contenida en el dictamen, para lo que se han utilizado diversas metodologías que han servido para agrupar los estudios, ya sean experimentos de laboratorio, trabajos con el mercado de capitales o investigaciones con encuestas de opinión.

\subsubsection{INVESTIGACIONES BASADAS EN EXPERIMENTOS DE} LABORATORIO.

En este epígrafe se agrupan estudios realizados mediante la metodología del "experimento en laboratorio" que implica amplios y detallados estudios, pero con muestras o individuos normalmente no aleatorios, sino basados en la comodidad o facilidad de acceso a los participantes o en los criterios subjetivos de selección del investigador, es decir, con unas condiciones que permiten al investigador controlar directamente todos o casi todos los factores importantes que pueden afectar a los resultados del experimento (Dillon, Madden y Firtle, 1997).

Se han estudiado los siguientes:

- Firth, 1980.

- Wilkerson, 1987. 
2.2.1.1. Estudio del impacto de las salvedades de los informes de auditoría sobre las decisiones de concesión de préstamos (Firth 1980)

Objetivo: El propósito de su experimento consiste en constatar si las decisiones de concesiones de préstamos se ven afectadas por los informes que contienen salvedades.

Experimento: Los protagonistas del estudio son una muestra de personal de entidades financieras encargados de la concesión de préstamos, así como de analistas de riesgos pertenecientes al Reino Unido, a los que se les envía las cuentas anuales junto con el informe de auditoría, de una empresa ficticia, cambiando únicamente las opiniones vertidas en el informe de auditoría, tanto "limpia" como con distintas "salvedades", y se les pregunta la cantidad que como máximo estarían dispuestos a prestar o invertir en la empresa.

Metodología: El experimento se desarrolla mediante el envío de un cuestionario postal, que incluye las cuentas anuales y el informe de auditoría, a 2.200 empleados de banca, miembros del "Instituto de Banqueros del Reino Unido", que agrupa a los miembros de la profesión, así como a 120 analistas de riesgos pertenecientes a grandes empresas industriales.

Las respuestas a los cuestionarios son analizadas a través de un análisis estadístico de "diferencia de medias", así como de la prueba de la "t de Student".

Conclusiones: Los resultados del experimento dan lugar a las siguientes conclusiones: 
1. Ambos grupos conceden gran importancia a las salvedades de los informes relativas al "principio de empresa en funcionamiento" y a las "salvedades por valoración de activos", de forma que, en ambos casos, obtendrían problemas a la hora de obtener financiación ajena.

2. Sin embargo los informes con salvedades por incumplimiento de los "principios de contabilidad generalmente aceptados" tienen muy poco impacto en las decisiones sobre concesión de préstamos.

\section{Limitaciones:}

1. Las decisiones que toman los grupos se realizan en una situación experimental y, por tanto, sus reacciones no tienen por qué coincidir con las que tendrían en una situación real.

2. Además, a la hora de tomar la decisión de qué cantidad prestar no se tiene en cuenta que, tanto los banqueros como los analistas de riesgos, poseen otra información adicional a la que se les suministra en el experimento.

3. También supone una situación artificial que se les pregunte por una cantidad a prestar de forma genérica, y no se les plantee una situación específica de financiación como sucede en la vida real.

4. El proceso de selección de la muestra no se realiza de forma aleatoria, por lo que las conclusiones no son generalizables. 
2.2.1.2. Estudio sobre la relación que existe entre el comportamiento de determinadas variables financieras y de mercado con la emisión de informes de auditoría con salvedades por incertidumbres o contingencias (Wilkerson $\underline{1987)}$

Objetivo: Corroborar la existencia de una relación entre el comportamiento de determinadas variables financieras, definidas por el autor, con la emisión de informes de auditoría con salvedades, como manera de verificar la utilidad de la información contenida en el dictamen del auditor.

Experimento: El período objeto del estudio se desarrolla, desde 1972 a 1981, con empresas que se enfrentan a posibles litigios por una presunta violación de las "Leyes Federales Norteamericanas Antitrust" al mantener unos precios fijos y constituir un monopolio horizontal. La muestra final de empresas utilizada es de 49, una vez depurada la inicial de 162, de las cuales todas han sido auditadas por grandes firmas y de ellas sólo 16 habían recibido inicialmente una "salvedad por incertidumbre".

El experimento compara el valor que toman ciertas variables financieras, para cada una de las empresas, sabiendo que estando en la misma situación de monopolio unas reciben informes con "salvedades" y otras "limpios". Enfocándolo respecto a las características especiales de una empresa, el investigador pretende delimitar una serie de variables que pueden estar asociadas con la decisión de emitir una opinión con o sin salvedades.

Metodología: El estudio se centra en el comportamiento de una variable "financiera" y dos de "mercado" usando un modelo de aproximación "tipo logit", con la existencia o no de salvedad como variable dependiente binaria 
y las tres variables financieras y de mercado como independientes; para comprobar la fiabilidad estadística del modelo se realiza la "prueba de la Chi-cuadrado". Las variables que toma el autor son, a saber:

1. La variable financiera que denomina "Exposure", que se define como el cociente entre el "ratio de ventas intra-industria" y el "neto patrimonial" de cada empresa.

2. La variable de mercado "Accumerror", que es un tipo de rentabilidad de las acciones, medida a través de los errores en las predicciones de los valores de las acciones debidos a sucesos de litigio por la posición de monopolio.

3. La variable de mercado "Semivar", definida como las "varianzas" a la baja en la rentabilidad de las cotizaciones de las acciones.

Para cada una de las variables se ha calculado su "valor medio", agrupando aquellas empresas que presentan informes con y sin salvedades, $\mathrm{y}$ se ha realizado la "prueba $\mathrm{t}$ de diferencias de medias" para constatar diferencias entre grupos.

Conclusiones: Los resultados del experimento indican que el valor de la variable "Exposure" es mayor para aquellas sociedades que reciben informes con "salvedades". Se contrasta que, en cuanto a las variables denominadas como de "mercado", existen rentabilidades en las acciones inferiores en el período anterior al que se recibe el informe con "salvedad por incertidumbre". Del estudio se infiere, por tanto, que la emisión de informes sí afecta de una manera u otra a las rentabilidades de las cotizaciones, de forma que los usuarios de los informes de auditoría sí conceden importancia a las salvedades contenidas en los mismos. 


\section{Limitaciones:}

1. La muestra obtenida está formada por muy pocas observaciones que reducen la calidad de los resultados obtenidos.

2. Existe cierto grado de subjetividad por parte del investigador al definir y seleccionar las variables financieras analizadas.

3. Lo reducido de la muestra y el proceso de selección no permite inferir ningún tipo de conclusión genérica. 


\subsubsection{INVESTIGACIONES REALIZADAS CON EL MERCADO DE CAPITALES.}

A continuación se exponen una serie de trabajos de investigación experimentales que han sido aplicados, con el mercado de capitales, para inferir resultados, con datos bursátiles, sobre la "utilidad" o "relevancia" de la información que contiene el informe de auditoría y, por tanto, comprobar la trascendencia del servicio que presta el auditor para la sociedad en general:

- Baskin, 1972.

- Alderman, 1979.

- Ball, Walker y Whittred, 1979.

- Melumad y Ziv, 1997.

- Del Brío González, 1998.

- Sánchez Segura, 1999.

- Gómez Aguilar, Larrán Jorge y Ruiz Barbadillo, 1999.

- Cabal García, 2000.

Junto a las investigaciones que se han descrito con una mayor profundidad, existen otras, no menos importantes, como las realizadas por Firth (1978), Banks y Kinney (1982), Chow y Rice (1982), Elliott (1982), Dodd, et al. (1984), Dopuch et al. (1987), Feroz et al. (1991), Loudder et al. (1992) y Jones (1996), en las que se pretende contrastar el efecto de la opinión emitida, por el auditor, sobre el precio de las acciones de sociedades que cotizan en bolsa. Además, tanto Bailey (1982) como Craswell (1985) realizan una revisión crítica de la metodología empleada en los primeros trabajos sobre el contenido informativo del dictamen del auditor en el mercado de capitales. 
2.2.2.1. Estudio del contenido informativo del informe de auditoría a través del impacto de las salvedades, por la falta de aplicación uniforme de los principios de contabilidad, sobre el precio de las acciones (Baskin 1972)

Objetivo: El objetivo del trabajo de Baskin recae en la obtención de evidencia empírica que demuestre la relevancia de la información que contienen los informes de auditoría.

Experimento: La investigación se realiza sobre una población constituida por 1.978 empresas, extraídas de una publicación anual de AICPA, que cotizan en el mercado de valores de Nueva York. Tras un proceso de eliminación y verificación, se obtiene una muestra formada por 137 empresas junto con un grupo de control.

La hipótesis nula a contrastar queda definida como:

$\mathrm{H}_{0}$ : La salvedad que se expone en los informes de auditoría, por la no aplicación uniforme de los principios de contabilidad generalmente aceptados, no posee contenido informativo.

Metodología: La metodología del experimento se basa en la "hipótesis de eficiencia de los mercados de capitales", que sostiene que los cambios en los precios de las acciones, debidos a la utilización que hacen los inversores de determinada información, pueden utilizarse para inferir el contenido informativo de dichos datos, siempre que se pueda aislar dicha información en el tiempo de otros factores informativos adicionales.

La variable que se utiliza para comprobar el efecto que tiene la información, que suministra el informe de auditoría y reciben los inversores, 
sobre el precio de la acción es el cambio semanal que se produce en la rentabilidad de dichas acciones, medido a través del logaritmo neperiano del cambio semanal de la cotización de las acciones. Como dicho cambio en el precio puede deberse a factores inherentes a la empresa, al sector y a las condiciones económicas en general, el autor utiliza un modelo de "regresión lineal" para eliminar el efecto general de las condiciones del mercado.

El instrumento estadístico utilizado para estudiar la respuesta de los precios a los estímulos de la información suministrada, en el informe del auditor, se define a través del diseño de dos estadísticos compuestos por variables que afectan al precio de las acciones; mientras que la hipótesis se contrasta a través de un "análisis de la varianza", de dichos estadísticos, en uno y dos sentidos.

Conclusiones: Los resultados obtenidos llevan a no rechazar la hipótesis nula, de manera que la "salvedad" que se expone en el informe de auditoría, por la no aplicación uniforme de los "principios de contabilidad generalmente aceptados", no posee contenido informativo para la mayoría de los inversores.

\section{Limitaciones:}

1. Existe una gran dificultad práctica a la hora de aislar el efecto que pueda tener la "opinión" del auditor, de otra información a la que tengan acceso los inversores cuando toman sus decisiones de inversión, así como de la información que les suministran las cuentas anuales a las que se les adjunta el informe. 
2. El mercado puede anticipar las salvedades, que se manifiestan en los informes de auditoría, de manera previa al momento en que realmente se emiten las cuentas anuales junto con el informe del auditor.

3. La existencia de factores educacionales, experiencia previa, etc., puede condicionar la importancia que se le concede al informe. 
2.2.2.2. Estudio del contenido informativo de los informes de auditoría con $\underline{\text { salvedades por incertidumbres (Alderman 1979) }}$

Objetivo: El propósito del autor no es otro que determinar la "utilidad" que tienen para los inversores los informes de auditoría con salvedades por incertidumbres, a través de la influencia que tiene el conocimiento de dichas "salvedades" sobre el riesgo asociado a las decisiones de inversión ya que, como sustenta la "teoría financiera de la diversificación de la cartera del inversor", la esencia de las decisiones de inversión y financiación consiste en la obtención de un equilibrio entre la "tasa esperada de rentabilidad" y el "riesgo esperado"; por ello se pretende comprobar que las salvedades por incertidumbres son útiles para los inversores a la hora de evaluar el riesgo de una inversión.

Experimento: Se lleva a cabo con 600 empresas tomadas de un estudio realizado por AICPA, entre los años 1968 y 1971, que se supone son representativas del conjunto del tejido industrial y comercial de Estados Unidos, de las que sólo se seleccionan veinte, aquellas que presentan informes de auditoría con salvedades por incertidumbres, así como un "grupo de control" que presenta informes de auditoría sin "salvedades", y se analiza el efecto que tienen las "salvedades" sobre el riesgo que tienen en cuenta los inversores cuando toman la decisión de invertir.

Metodología: El experimento se efectúa con el "modelo de mercado", propuesto por Markovitz (1959) y ampliado por Sharpe (1963), en el que se explicita una relación lineal entre los logaritmos neperianos de la rentabilidad de un título y la del mercado. 
Con el fin de analizar los componentes del "riesgo sistemático" y "no sistemático", se realiza una regresión, durante 36 meses por encima y por debajo del mes en el que se emite el informe de auditoría, obteniéndose 37 observaciones para cada análisis de regresión. Posteriormente para aislar el efecto de la "salvedad", sólo se toman las empresas que en el año anterior al de la salvedad habían recibido informes de auditoría "limpios"; también se eliminan aquellos informes que contienen otras "salvedades" aparte de la incertidumbre.

Para determinar si las muestras de cada matriz, formada por empresas con informes con salvedades y sin salvedades, difieren, en cuanto a su impacto en el riesgo, se realiza un análisis a través del "estadístico Chicuadrado". Además para comprobar si las sociedades que presentan una opinión con "salvedades por incertidumbre" muestran mayores niveles de "riesgo no sistemático", se aplica el test no paramétrico de la "U de MannWhitney"; mientras que un análisis de corte transversal indica que los niveles de "riesgo sistemático" no son distintos, de manera significativa, entre las empresas que reciben informes de auditoría "limpios" y aquellas que los obtienen con "salvedades por incertidumbre".

Conclusiones: Los resultados alcanzados indican que las opiniones del auditor con "salvedad por incertidumbre" tienen poca influencia en los componentes del riesgo, de forma que el mercado previamente ha recogido la información que suministra la salvedad y la ha reflejado en el valor de las acciones, o lo que es lo mismo, dicha opinión no suministra información adicional que sea tenida en cuenta por los inversores. A pesar de ello, las acciones de las sociedades que reciben informes con "salvedades" muestran, en general, mayores niveles de "riesgo no sistemático", como consecuencia se deduce que este tipo de "salvedades" confunde a los usuarios de la 
información contable y por ello se ignoran. El autor recomienda que, para esta clase de "salvedades", se elimine a la hora de redactar el informe la expresión "sujeto a".

\section{Limitaciones:}

1. Una limitación metodológica del modelo se produce debido a que los dividendos de las acciones no se incluyen en la variable que recoge la rentabilidad del mercado.

2. Una segunda limitación viene dada por los pocos elementos que intervienen en la muestra y que pueden condicionar la validez de las conclusiones.

3. El proceso de selección "no aleatorio" de la muestra no deja posibilidad a extrapolar los resultados obtenidos para el conjunto de la población. 
2.2.2.3. Estudio sobre el contenido informativo de los informes de auditoría con salvedades a través de su incidencia en el precio de las acciones (Ball, Walker y Whittred 1979)

Objetivo: La investigación tiene como objetivo la verificación de si la publicación de los informes de auditoría con "salvedades" implica la revisión, por parte de los accionistas de sociedades cotizadas, del valor de sus títulos en el mercado.

Experimento: Para realizar el experimento se obtienen 194 informes de auditoría con salvedades, de empresas que cotizan en Bolsa en Australia durante el período 1961-1972, pertenecientes a 141 sociedades. De esta primera selección se descartan una serie de empresas, por la escasa negociación de sus títulos, o porque sus precios pueden verse afectados por la concesión de dividendos, la emisión de bonos, "split" de las acciones, etc., que puede dar lugar a alteraciones en el precio de las acciones que no se pueden aislar del experimento, obteniéndose una muestra final de 117 informes pertenecientes a 101 empresas; a continuación se realiza un análisis de los movimientos que se originan en la cotización de las acciones con datos semanales, y se estudia el efecto que tiene la publicación de las "salvedades" sobre dichos precios.

Para salvar el problema de la falta de homogeneidad en las "salvedades" de los informes, la muestra se divide en varios subgrupos con "salvedades" similares.

La hipótesis nula a contrastar se redacta como: 
$\mathrm{H}_{0}$ : No existe diferencia esperada entre la rentabilidad de las acciones de las sociedades que muestran informes con salvedades respecto del mercado.

Metodología: El modelo utilizado supone estimar una rentabilidad "anormal" de las cotizaciones de las empresas, que reciben "salvedades", respecto de la rentabilidad del mercado, obtenida como un índice, que indica las rentabilidades semanales de las acciones, ajustado de dividendos y cambios en la capitalización bursátil. El modelo utilizado por los autores resulta ser el "modelo de mercado", salvo que con algunos parámetros predeterminados.

Para contrastar la diferencia entre las rentabilidades de las acciones de la muestra y la del mercado se utilizan dos pruebas estadísticas; una paramétrica, el test de la "t de Student", y otra no paramétrica, la "prueba de Wilcoxon para datos emparejados y clasificados por su signo".

Conclusiones: Los resultados a los que llegan los autores evidencian que determinados tipos de "salvedades", contenidas en los informes de auditoría, están asociadas con cambios en la valoración que dan los inversores al precio de sus acciones, de forma que las acciones de las empresas que muestran informes con salvedades, por errores en la amortización de edificaciones, denotan una significativa revisión al alza de su valor, mientras que las acciones de empresas que muestran "otro tipo de salvedades", diferentes a la anterior y a aquellas que se derivan de problemas de valoración, muestran una leve reducción de su precio. De lo expuesto se deduce que los informes de auditoría, que contienen "salvedades", sí tienen un contenido informativo o son de utilidad para los inversores a la hora de tomar sus decisiones. 


\section{Limitaciones:}

1. Uno de los principales problemas recae en la dificultad de aislar el efecto de la publicación del informe del auditor de otras circunstancias que también afectan al precio de las acciones.

2. Otra segunda dificultad se produce por el hecho de que las "salvedades" de los informes no son homogéneas y, mientras unas pueden ser vistas por los inversores como debidas a una mala gestión de los administradores, otras pueden interpretarse como simples desacuerdos en criterios contables con los auditores, de manera que existe una gran subjetividad en la valoración que hacen los inversores de las opiniones emitidas por el auditor.

3. Un problema exclusivo de los auditores australianos, en el período objeto del estudio, se debe a la modificación que se produce en las Normas Técnicas de Auditoría, en 1967, y que supuso un cambio en la actitud reticente, que hasta la fecha tenían los mismos, a la hora de emitir informes de auditoría con "salvedades".

4. También surgen problemas metodológicos como la subjetividad al definir el índice elaborado por Brown y Walter (1974) para ver la rentabilidad de la cartera de mercado, o la subjetividad al subdividir la muestra en grupos más o menos homogéneos en función del tipo de "salvedad".

5. La muestra se selecciona de forma subjetiva $y$, por tanto, las conclusiones no son generalizables. 
2.2.2.4. Estudio planteado para analizar las reacciones del mercado a las opiniones con salvedades que emiten los auditores en sus informes (Melumad y Ziv 1997)

Objetivo: Comprobar el contenido informativo de las "salvedades", incluidas en los informes de auditoría, a través de las repercusiones que tienen las mismas en el mercado.

Experimento: Los autores distinguen entre opiniones con "salvedades que son evitables ex-post" de aquellas que no lo son, entendiéndose por evitables aquellas que pueden ser obviadas por los auditores mediante la oportuna rectificación de las cuentas anuales por parte de los administradores. Los investigadores sostienen que se puede esperar una reacción negativa del mercado para las "salvedades que no son evitables", mientras que en caso de serlo un administrador racional sólo aceptará un informe con salvedades si piensa que es mejor opción que la de modificar las cuentas anuales, con ello deducen que las reacción del mercado para aquellos casos de "salvedades evitables" no sería tan clara. En el experimento los autores se centran en el uso de "salvedades que son evitables" y plantean un modelo de equilibrio en el que un administrador racional aceptará un informe con salvedades siempre que, haciéndolo, consiga una mayor credibilidad en la información financiera de su empresa por parte de los usuarios, lo que supondrá un aumento en el valor de mercado de la sociedad.

Metodología: Se presenta un modelo matemático, para dos ejercicios, mediante el que se obtiene el valor de mercado de una determinada sociedad y se observa el efecto que pueda tener la emisión de un informe de auditoría con salvedades sobre dicho valor, manteniendo el resto de variables constantes. La diferencia de valor entre un ejercicio y otro es denominada, 
por Melumad y Ziv, como la reacción del mercado ante una opinión con salvedades.

Conclusiones: Los autores demuestran que dependiendo del equilibrio imperante, es posible que las reacciones del mercado ante las opiniones con salvedades sean positivas, debido a que la reacción observada del mercado, ante una "salvedad evitable", es una combinación de una reacción negativa ante los errores encontrados por el auditor y una reacción positiva ante la decisión de la empresa de informar y ser transparente, a pesar del desacuerdo del auditor.

\section{Limitaciones:}

1. Una de las hipótesis de partida, sobre la que los investigadores desarrollan el modelo, se basa en que en caso de litigio entre usuarios y responsables de la información contable, los inversores demandarán a la dirección de la empresa y nunca a los auditores, supuesto poco realista.

2. Existe una limitación debida a la imposibilidad de aislar y documentar la reacción del mercado a un solo suceso.

3. El modelo propuesto por los autores no es aplicado empíricamente, por lo que no se obtienen conclusiones sobre su eficacia, no obstante se incluye por su concepción para ser contrastado con datos reales. 
2.2.2.5. Estudio empírico para comprobar el efecto de las salvedades de los informes de auditoría en la cotización de las acciones de la Bolsa de Madrid (Del Brío González 1998)

Objetivo: El estudio se propone conocer cómo reaccionan los inversores, de la Bolsa de Madrid, ante la emisión de informes con "salvedades" de empresas cotizadas durante el período 1991-94 y, por tanto, su efecto en el precio de las acciones, como manera de inferir la "relevancia de la información" contenida en el informe del auditor de cuentas.

Experimento: La autora se plantea la hipótesis de que la distribución estadística de las cotizaciones de las acciones de aquellas empresas que reciben informes "limpios" es igual a las que presentan informes con "salvedades". La investigación se separa en dos partes una primera donde se realiza el estudio agregado comparando empresas con informes "limpios" y con "salvedades", y una segunda en la que se separan los informes con salvedades, en función del tipo de salvedad, con el fin de verificar si un tipo de salvedades contiene más información que otra.

Se plantean las siguientes hipótesis nula y alternativa:

$\mathrm{H}_{0}$ : No hay diferencia entre los retornos de las empresas con informe limpio y con salvedades.

$\mathrm{H}_{1}$ : Hay diferencia entre los retornos de las empresas con informe limpio y con salvedades.

Metodología: La metodología se basa en el estudio de "eventos", mediante el "modelo de mercado" y el "modelo de Holthausen", siendo el evento a 
analizar la fecha de publicación del informe y lo que se investiga la existencia de algún "retorno anormal", calculado respecto a un índice de referencia el "Ibex-35" (mediante regresión), en los días cercanos a la fecha en que se conoce el informe, posteriormente se comparan dichos retornos con los de un "grupo de control" formado por empresas con informes "limpios". El período de estudio se extiende desde 20 días antes hasta 20 días después de la fecha de publicación del informe. Una vez hallados los retornos de las empresas con "salvedades" y los retornos de las empresas con informes "limpios", se comprueban los residuos obtenidos en ambas regresiones y se contrasta la hipótesis nula de igual distribución de residuos; con el fin de estudiar las diferencias en los retornos se utiliza el "test, no paramétrico de dos colas, de Wilcoxon", puesto que las diferencias pueden darse en los dos sentidos (debido a problemas de normalidad en las distribuciones), para datos emparejados y clasificados por su signo.

Conclusiones: De los resultados obtenidos se desprende que no se puede rechazar la hipótesis nula, de forma que los inversores de la Bolsa de Madrid no reaccionan ante las "salvedades" contenidas en los informes de auditoría, ni cuando se analizan tomadas en su conjunto ni cuando se analiza su efecto de forma individual, por tanto, se deduce que los informes de auditoría con salvedades no poseen relevancia para la toma de decisiones de los inversores en Bolsa. Una explicación, ya mencionada para entender los resultados, se basa en la posibilidad de que el mercado ya haya anticipado la información por medio de otras fuentes distintas al informe del auditor, o bien que se deba a la falta de "utilidad" de la función auditora. 


\section{Limitaciones:}

1. La dificultad de identificar el "evento", es decir, el día de publicación del informe de auditoría.

2. La muestra es reducida debido al bajo número de días de cotización de algunas empresas, y a la imposibilidad de emparejar empresas del "grupo de control" con las analizadas.

3. El "modelo de mercado" tiene limitaciones cuando se trabaja con datos diarios ya que los resultados de las regresiones son heterogéneos y además el valor de la $\mathrm{R}^{2}$ es bajo, lo que supone que el "modelo de mercado" no sea suficientemente válido para calcular los "residuos".

4. Existe otra limitación importante, al no poder aislar el efecto del informe de auditoría de otra información paralela que pueda afectar el precio de las acciones, como puede ser la propia información contenida en las cuentas anuales que se publica junto al informe de auditoría, o determinados sucesos como el anuncio de distribución de dividendos, fusiones, ofertas públicas de adquisición de acciones, etc. 
2.2.2.6. Estudio empírico realizado para comprobar el alcance y significado del informe de auditoría (Sánchez Segura 1999)

Objetivo: Contrastar el significado y el contenido informativo de los informes de auditoría a través de un enfoque positivo y una metodología empírica.

Experimento: Se realiza con una muestra de 220 empresas que han depositado sus cuentas anuales en la CNMV, de manera ininterrumpida, entre los años 1991 y 1995, obteniéndose un total de 1.100 observaciones empresas-años. La autora pretende dar respuesta, entre otras, a las siguientes cuestiones:

- ¿Perciben los inversores la importancia de las salvedades y son relevantes en la formación del precio de las acciones?.

- ¿Tienen las salvedades contenido informativo y sirven para modificar las expectativas de los inversores?.

Metodología: Las técnicas estadísticas y econométricas utilizadas son las siguientes: análisis basado en la " $X^{2}$ de Pearson", "análisis de la varianza" y estudio de los parámetros resultantes de la estimación de "modelos logit" y de "regresión lineal", tanto univariantes como multivariantes, habiendo fijado los niveles de significación estadística a partir del 90\%, en los modelos de regresión, y a partir del $95 \%$ en los "test de la $X^{2}$ "y de la "F de Snedecor." Las variables empleadas para el contraste de las hipótesis planteadas vienen definidas, de la siguiente forma: como variables dependientes las "salvedades" contenidas en los informes de auditoría, graduadas en función de su gravedad, y como variables independientes el 
tamaño de la empresa, el sector, el auditor, el hecho de cotizar o no en el mercado bursátil, el hecho de incurrir o no en pérdidas, la obtención o no de resultados extraordinarios netos negativos, la rentabilidad financiera, el nivel de endeudamiento, la intensidad de inventarios y la de cuentas a cobrar.

\section{Conclusiones:}

1. Las "salvedades" de los informes de auditoría son relevantes desde el punto de vista del "valor"de la empresa, ya que los inversores las incorporan a los mecanismos de formación de los precios de las acciones en el mercado de capitales, de manera que cuanto más grave es la salvedad impuesta por los auditores, más afectado y penalizado resulta el precio de las acciones.

2. Las "salvedades" de los informes no poseen contenido informativo para los inversores, es decir no incorporan información adicional a la que ya tienen a través de otras fuentes alternativas.

Limitaciones: Las variables dependientes de las regresiones, es decir, las "salvedades" han sido graduadas en función de su gravedad de manera intuitiva y subjetiva. 
2.2.2.7. Estudio empírico sobre el informe de auditoría y su relevancia en los mercados de capitales (Gómez Aguilar, Larrán Jorge y Ruiz Barbadillo 1999)

Objetivo: Los autores se plantean dos objetivos: el primero consistente en analizar si el informe del auditor es, por sí mismo, relevante a la hora de valorar las empresas, y el segundo en comprobar cómo el informe afecta a la relevancia que tienen dos variables contables, los "beneficios" y los "fondos propios", a la hora de ser tenidas en cuenta en la toma de decisiones de los inversores del mercado de capitales.

Experimento: Para desarrollar la investigación se toma una muestra de empresas no financieras de la Bolsa de Madrid, utilizando dos bases de datos; por un lado la base de la CNMV denominada "Auditorias de Sociedades Emisoras" y por otro lado la base "Extel Financial Company Análisis". El estudio se desarrolla entre los años 1991 y 1996, e implica la necesidad de contar con tres tipos de datos, información contable, bursátil e informe de auditoría, siendo el total de casos estudiados de 500 para el modelo que utiliza más observaciones.

Para contrastar si el informe presenta o no relevancia valorativa se plantea la siguiente hipótesis nula:

$\mathrm{H}_{01}$ : El informe de auditoría no adquiere relevancia al objeto de determinar el valor de la empresa.

Con la finalidad de verificar en que medida los atributos de valor de "beneficios" y "fondos propios" se ven condicionados por la naturaleza del informe de auditoría (opinión limpia, con salvedades, denegada, desfavorable) se plantea la siguiente hipótesis nula: 
$\mathrm{H}_{02}$ : La relevancia del resultado y de los recursos propios no depende de la naturaleza del informe de auditoría.

Metodología: Para el desarrollo del estudio se utilizan "modelos de niveles", apoyados en el "modelo de Felthman y Ohlson", en los que se relacionan información contable y precios de mercado (cotizaciones de acciones), para constatar si tanto la cifra de "beneficios" como la de "fondos propios" recogen atributos importantes para determinar el "valor" de una empresa, además se incluye una nueva variable independiente: la opinión de auditoría. Posteriormente se realizan un total de 20 regresiones lineales, diez para contrastar cada una de las hipótesis nulas planteadas. Con el fin de evitar problemas de heterocedasticidad se deflactan todas las variables del modelo con el número de acciones y, en los casos que persiste, se calculan los parámetros del modelo con el "test de White".

Conclusiones: Se rechazan las hipótesis nulas planteadas por la evidencia obtenida que permite concluir que el informe de auditoría es "relevante" para los inversores, ya que afecta al precio de las acciones, y además la naturaleza del informe incide en la relevancia de los "beneficios" y los "fondos propios", con lo que la fiabilidad de las cifras contables se ve condicionada por la opinión del auditor; de esto se desprende que el informe de auditoría contiene información útil para los inversores en Bolsa.

Limitaciones: Al efectuar algunas de las regresiones del estudio surgen problemas por lo reducido del tamaño de las submuestras, además el valor de la $\mathrm{R}^{2}$ obtenida es bajo. 
2.2.2.8. Estudio empírico que mide el contenido informativo del informe de auditoría a través de su impacto en el mercado bursátil (Cabal García 2000)

Objetivo: Analizar el contenido informativo del informe de auditoría, tratándolo de inferir de su impacto en las rentabilidades de los títulos que cotizan en bolsa.

Experimento: Para realizar el estudio se examinan los informes de auditoría de las empresas que cotizan en la Bolsa de Madrid entre los ejercicios 1993 y 1996, analizándose un total de 1.161 informes, de los que 367, que muestran una "opinión con salvedades", se consideran como la población objeto de estudio. Sin embargo y tras un proceso de depuración de la muestra, para los casos de cotizaciones altamente infrecuentes, los casos en que se producían anuncios de fusiones, suspensiones de pagos, OPAS, dividendos y aquellos en los que la aplicación del "modelo de mercado" conducía a parámetros no significativos, se obtiene una muestra de partida de 97 empresas con "opiniones calificadas" con la que se analiza el impacto que el anuncio del informe de auditoría con salvedades produce sobre los precios de los títulos.

La hipótesis nula que se pretende contrastar asume la ausencia de rentabilidades o residuos "anormales", entendidos como la diferencia entre la rentabilidad realmente obtenida por las acciones y la rentabilidad esperada de los mismos, es decir la que se hubiese logrado de no producirse el suceso.

Metodología: La metodología que se utiliza, para inferir el contenido informativo de las salvedades, es la de "eventos" que permite comprobar si, en las inmediaciones de la fecha en que se hace público el dictamen, se obtienen rentabilidades "anormales" en las cotizaciones. Dichas 
rentabilidades "anormales" vienen definidas como la diferencia entre la rentabilidad realmente obtenida por el título y la esperada para la misma fecha. La rentabilidad esperada se estima a través del "modelo de mercado" mediante el que se establece una relación lineal entre la rentabilidad de mercado y la de un título determinado. El período de estimación de la rentabilidad esperada es un intervalo en el que se trabaja con series temporales de las rentabilidades reales de los títulos, así como con el "Índice General de la Bolsa de Madrid", y en el que mediante regresiones, en un periodo de 180 días precedente a la fecha del suceso, se llega a los valores de los parámetros que conforman el modelo. Los datos necesarios para el desarrollo del modelo se obtienen de la "Sociedad de Difusión de la Información de la Bolsa de Madrid".

Para contrastar la hipótesis se utiliza el estadístico definido, por Dodd y Warner (1983), que "normaliza" las "rentabilidades anormales" diarias de cada título dividiéndolas por sus respectivas desviaciones típicas, con la finalidad de que se llegue a muestras idénticamente distribuidas.

Conclusiones: Del análisis estadístico agregado se desprende que el conocimiento de los informes de auditoría con salvedades no produce efectos en el mercado. Sin embargo del análisis desagregado se comprueba que el mercado reacciona ante aquellas "salvedades" capaces de reducir la incertidumbre de los inversores, al desacreditar gravemente la razonabilidad de la información contable o al cuantificar las magnitudes implicadas permitiendo efectuar ajustes y mejorar la calidad de las previsiones. 


\section{Limitaciones:}

1. La dificultad de identificar la fecha exacta del anuncio del "evento", esto es, de la fecha en la que el mercado conoce los informes de auditoría.

2. El problema de aislar el efecto del informe de auditoría de la información que aparece en las cuentas anuales y que se suministra al mismo tiempo.

3. La coincidencia temporal de los días de registro, para algunos de los anuncios considerados, supone que se pueda producir dependencia en el corte transversal al agregarse las "rentabilidades anormales" de los títulos afectados, implicando sesgos significativos en los resultados de los tests estadísticos.

4. Otro problema soslayado es la coincidencia del "evento" con otra serie de información en el mercado como: anuncios de fusiones, OPAS, dividendos, etc.

5. La cotización infrecuente de determinados títulos implica que se deban eliminar de la muestra muchas observaciones, para que las estimaciones sean lo mejor posibles, lo que supone reducir la muestra y, por tanto, el contar con mayores dificultades en la obtención de buenos resultados.

6. El proceso subjetivo de selección de la muestra no permite realizar generalizaciones. 


\subsubsection{INVESTIGACIONES MEDIANTE ENCUESTAS}

En este epígrafe se incluye el estudio realizado por Carcello, Hermanson y McGrath en el que se mide la calidad del servicio de auditoría, y que se expone al poder considerar la "calidad33", en determinados casos, como un subrogado de la "utilidad" de la auditoría.

- Carcello, Hermanson y McGrath, 1992.

${ }^{33}$ Jarne Jarne, et al. (1998) utilizan como herramientas para la evaluación de la "calidad" en auditoría tres variables cualitativas: relevancia, fiabilidad y oportunidad, de manera que el concepto de calidad en auditoría queda íntimamente ligado al de utilidad para los usuarios del servicio. 
2.2.3.1. Estudio empírico para evaluar la calidad de la auditoría a través de las percepciones que de la misma tienen los socios de las firmas de auditoría, $\underline{\text { los administradores que elaboran la información contable y los usuarios de }}$ dicha información (Carcello, Hermanson y McGrath 1992)

Objetivo: Obtener los atributos esenciales con los que debe cumplir toda auditoría, con el fin de conseguir un servicio de calidad que satisfaga a los usuarios de la información contable.

Experimento: El experimento persigue que los encuestados, auditores, administradores y otros usuarios de la información económico-financiera, evalúen una serie de atributos que definen la "calidad" de una auditoría, para lo que se les suministra un cuestionario a una muestra de individuos compuesta por: 650 auditores pertenecientes a seis grandes firmas de auditoría, 108 gerentes de fondos de inversión, 100 gerentes de fondos de pensiones, 103 empleados de compañías de seguros de vida, 203 de entidades financieras y 653 gerentes de empresas.

Metodología: El estudio se realiza a través de una encuesta postal en la que se solicita a los participantes que evalúen 41 atributos o expresiones que pueden definir la "calidad" de la auditoría, para ello se utiliza una escala de medición tipo "Likert" que se formaliza en 5 grados definidos entre muy en desacuerdo y muy de acuerdo. La tasa de respuesta obtenida es del 38\% para los auditores, del $40 \%$ para los gerentes de empresas y del 23\% para otros usuarios de la información contable.

Los métodos estadísticos que se utilizan, para el tratamiento de la información recibida, se basan en el estudio de los "valores medios" de cada atributo que define la calidad de la auditoría y en el "análisis factorial" que 
reduce la extensa gama de atributos a un pequeño grupo de datos agregados más fáciles de manejar e interpretar. Con la finalidad de determinar si los grupos de usuarios de la información contable difieren en sus percepciones, sobre la calidad de la auditoría, se realiza un "análisis multivariante de las varianzas" (MANOVA), utilizando los factores que definen la calidad como variables dependientes y los diferentes grupos encuestados como variables independientes.

Conclusiones: Los factores que son percibidos como más importantes al evaluar la "calidad" son los siguientes:

1. El equipo de auditores y la experiencia con el cliente.

2. La experiencia en el sector.

3. La capacidad de la sociedad de auditoría para cumplir con las necesidades del cliente.

4. La capacidad de la firma de auditoría para cumplir con las Normas Técnicas de Auditoría. Además se observa que, los encargados de la elaboración de la información contable y los usuarios de la misma, evalúan la calidad de la auditoría de manera diferente a como lo hacen los socios de las firmas de auditoría.

Los auditores se muestran especialmente preocupados con:

1. La naturaleza y extensión de los servicios de consultoría que proveen a sus clientes de auditoría. 
2. La tenencia del título de auditor por parte de sus profesionales.

3. Los controles de calidad que deben efectuar para minimizar su responsabilidad legal.

4. La necesidad de mejorar su respuesta a las necesidades de sus clientes.

\section{Limitaciones:}

1. La subjetividad asociada a los atributos que se presentan a los individuos en la encuesta.

2. El que determinados atributos puedan medir, en vez de la calidad de la auditoría, el grado de respuesta a las necesidades de los clientes. 


\subsection{ESTUDIOS SOBRE EL PROCESO DE COMUNICACIÓN CON LOS USUARIOS: EL PROBLEMA DE COMPRENSIÓN DEL INFORME DE AUDITORÍA}

Esta sección aglutina los trabajos que han tenido como objeto de estudio el "proceso de comunicación" entre el auditor y los usuarios del informe de auditoría, para detectar empíricamente si realmente existen defectos de "comprensión" del mensaje que emite el auditor. Los estudios se han clasificado atendiendo a la metodología empleada en los mismos, ya sean experimentos de laboratorio, investigaciones con el mercado de capitales o encuestas de opinión.

\subsubsection{INVESTIGACIONES BASADAS EN EXPERIMENTOS DE LABORATORIO}

En este epígrafe se relacionan las investigaciones efectuadas mediante la metodología del "experimento de laboratorio", que implica amplios y detallados estudios pero con muestras o individuos normalmente no aleatorios, si no basados en la comodidad o facilidad de acceso a los participantes o en los criterios subjetivos de selección del investigador.

- Libby, 1979.

- Bailey, 1981.

- Bailey, Bylinski y Shields, 1983.

- Nair y Rittemberg, 1987.

- Mayper, Welker y Wiggins, 1988.

- Kelly y Mohrweis, 1989.

- Holt y Moizer, 1990.

- Innes, Brown y Hatherly, 1991 y 1997. 
2.3.1.1. Experimento sobre las percepciones de auditores y banqueros con relación al mensaje transmitido por el informe de auditoría (Libby 1979)

Objetivo: El objetivo principal que se plantea el autor trata de verificar si el mensaje que comunica el auditor, a través de su informe de auditoría, es consistente con la percepción que tienen los empleados de banca que se encargan de la concesión de préstamos a las empresas.

Experimento: El estudio se realiza con treinta socios auditores, de cinco grandes firmas de auditoría de Chicago, con experiencia en emisión de informes de auditoría de sociedades limitadas; junto a ellos participan veintiocho empleados de banca, de cinco grandes bancos de Chicago, con experiencia en financiación de empresas y familiarizados con los informes de auditoría.

A los dos grupos se les presenta un cuestionario, sobre su experiencia profesional en relación con la auditoría, junto con diez diferentes tipos de informes elaborados con los estándares de auditoría norteamericanos de la SAS n $n^{\circ}$, emitidos por AICPA en 1974, es decir con el modelo de informe de auditoría corto, que en 1988 fue sustituido por el actual modelo largo. La primera labor que se les solicita consiste en la valoración de la "similitud" de los mensajes, que se pueden apreciar en los diez tipos de informes, a través de una escala con un intervalo de 0 a 9 puntos. Del mismo modo se les pide que valoren los informes con una escala compuesta por frases con diferentes adjetivos.

Metodología: Para medir las percepciones que los banqueros y los auditores tienen del mensaje que se comunica, a través del informe de auditoría, se utiliza un "modelo de distancia geométrica" (modelo INDSCAL) que sirve 
para identificar tanto las diferentes percepciones, entre ambos grupos, como para medir las ponderaciones que tienen esas diferencias respecto de los distintos informes de auditoría.

El experimento requiere que auditores y prestamistas valoren la finalidad del mensaje del auditor contenido en el informe de auditoría, incluyéndose las distintas posibilidades de "opinión", para ello se utiliza una "escala multidimensional" que sirve para observar las percepciones de cada grupo, así como las diferencias que surgen entre dichas percepciones. En último lugar el autor trata de comprobar la relación que existe entre las diferencias en las percepciones y una serie de variables circunstanciales o del entorno.

Conclusiones: El resultado al que se llega refleja que no existen grandes diferencias en las percepciones de los dos grupos, por lo que el miedo a que se produzcan fallos en la "comunicación" de los mensajes contenidos en el informe de auditoría, entre los usuarios con mejor formación económicofinanciera, no está justificado.

\section{Limitaciones $^{34}$ :}

1. Que los informes de auditoría empleados sean sólo los elaborados por las grandes firmas de auditoría introduce un sesgo, ya que la mayoría de las sociedades de auditoría son pymes.

2. Los participantes en el estudio son auditores y banqueros altamente cualificados, cuando existen otra serie de usuarios de los informes que

\footnotetext{
${ }^{34}$ Véase las críticas realizadas por Schultz (1979) y Bertholdt (1979) al experimento llevado a cabo por Libby.
} 
no tienen este grado de cualificación y que, por tanto, sí pueden ser más sensibles a posibles malentendidos en el proceso de comunicación del mensaje del auditor.

3. El hecho de que el informe no se presente junto a las cuentas anuales puede dar lugar a errores en el experimento, ya que éstas pueden ayudar a comprender el mensaje del informe de auditoría.

4. Se presentan etiquetas que identifican el tipo de "opinión" del informe de auditoría, lo que supone un elemento que puede influenciar la reacción de los sujetos por no ser una situación realista.

5. Las conclusiones del experimento no son generalizables por el método de selección de la muestra. 
2.3.1.2. Estudio empírico para analizar las percepciones que tienen los analistas financieros del mensaje contenido en los informes de auditoría, así como la credibilidad de los responsables de elaborar los estados financieros (Bailey WT 1981)

Objetivo: Investigar la forma en que el informe de auditoría y los estados financieros tienen influencia en los usuarios de la información contable.

Experimento: El experimento se basa en la "teoría de la comunicación" que supone que la credibilidad de la información, que se transmite en los estados financieros y en el informe del auditor, depende de las percepciones que tienen los receptores del mensaje sobre las "fuentes" de las que proceden dichos mensajes. La población con la que se trabaja esta compuesta por "Analistas Financieros Colegiados", tanto en Estados Unidos como en Canadá, de los que se extrae una muestra aleatoria de 1.778 individuos, que se divide en 14 submuestras de 127 individuos, a los que se les asigna el experimento junto con un "grupo de control".

El autor plantea 4 hipótesis a contrastar, dos sobre la identidad de la "fuente" de que provienen unos determinados mensajes de los estados financieros, y otras dos sobre los efectos del informe en las percepciones que tienen los analistas sobre la credibilidad del auditor y de los administradores.

Las hipótesis a contrastar se definen, a saber:

$\mathrm{H}_{01}$ : Las opiniones limpias, con salvedades por no cumplir con el principio de uniformidad, con salvedades por incumplimiento de los PCGA y opiniones adversas, contienen la misma información sobre la 
identidad de la fuente de la que emanan los mensajes de los estados financieros.

$\mathrm{H}_{02}$ : Los mensajes contenidos en la cuenta de resultados se percibe que provienen de la misma fuente.

$\mathrm{H}_{03}$ : Las opiniones limpias, con salvedades por no cumplir con el principio de uniformidad, con salvedades por incumplimiento de los PCGA y opiniones adversas, contienen la misma información sobre la credibilidad de la dirección.

$\mathrm{H}_{04}$ : La credibilidad, como fuente de información percibida de un auditor externo, no es función de la opinión que emite.

Metodología: El experimento se realiza a través del envío de cuestionarios postales a la muestra seleccionada, recibiéndose 358 contestaciones que suponen un $20 \%$ del total. A los individuos encuestados se les suministra un boletín con el siguiente contenido: descripción de la compañía, información sobre la cifra de negocio y los beneficios para 5 años y los estados financieros de dos años consecutivos con sus respectivos informes de auditoría; a continuación se les solicita que realicen una predicción de la cifra de ventas, existencias y beneficios para el año siguiente, que evalúen los mensajes que perciben de los estados financieros, así como que identifiquen la "fuente" de dichos mensajes, y por último que se pronuncien sobre el grado de credibilidad de la "fuente", utilizando para ello una escala tipo "Likert" para medir tres dimensiones: la "seguridad", la "cualificación" y el "dinamismo". 
Los métodos estadísticos que se emplean para la obtención de los resultados son los siguientes: estadísticos descriptivos como la "media aritmética" para estudiar la puntuación concedida a cada factor, además se realizan "regresiones" para estudiar la credibilidad que se otorga a la "fuente" de la que emana la información contable; por último se aplica el "test de la Chi-cuadrado" para el contraste de las hipótesis, rechazándose las hipótesis segunda y cuarta.

\section{Conclusiones:}

1. La credibilidad del auditor depende del tipo de informe que emite, de manera que ésta se incrementa con la severidad de la "salvedad", alcanzando su máximo valor cuando la opinión emitida es "adversa".

2. Del estudio se desprende que el grado de influencia de los mensajes, contenidos en los estados financieros, depende del "origen" o la "fuente" de la que emanan dichos mensajes.

3. Los analistas financieros perciben que los auditores están mucho más relacionados con el proceso de elaboración de las cuentas anuales de lo que piensan los segundos.

4. El autor concluye indicando que debe revisarse el contenido de los informes de auditoría por problemas de "comunicación". 


\section{Limitaciones:}

1. En el estudio se señala que la calidad de las respuestas puede ser menor que en el caso en que los participantes hubiesen recibido incentivos económicos para contestar.

2. Otra limitación se basa en el hecho de que los analistas financieros no conocen de igual forma estados financieros auditados y sin auditar. 
2.3.1.3. Estudio empírico para verificar si el nuevo modelo de informe de auditoría norteamericano, propuesto por el ASB, provoca cambios en los $\underline{\text { mensajes percibidos por los usuarios (Bailey, Bylinski y Shields 1983) }}$

Objetivo: Los autores se plantean dos objetivos principales; estudiar las diferencias, entre el mensaje percibido del informe corto (SAS n ${ }^{\circ} 1$ de AICPA 1972) y el propuesto por el ASB, medidas a través de las "cualidades" o "atributos" que debe tener el borrador propuesto, junto con la comprobación de las diferencias en las percepciones del mensaje contenido en el informe de auditoría para dos grupos de usuarios que poseen un nivel de conocimientos de auditoría distinto.

Experimento: Se realiza un "experimento de laboratorio" en el que participan dos grupos con diferentes grados de conocimiento en materias contables; por un lado 27 individuos con formación en contabilidad y auditoría (personas que habían realizado el examen para el acceso a auditor), y por otro lado 44 individuos con conocimientos en contabilidad pero no en auditoría (estudiantes de $4^{\circ}$ curso de la carrera de contabilidad). A los participantes se les suministra un dossier dividido en tres secciones:

$1^{\text {a }}$. En la que se les entrega un cuestionario con 45 parejas de informes de auditoría (ordenadas aleatoriamente), realizadas sobre la base de 10 informes de auditoría con diferentes tipos de "opinión", solicitando a cada sujeto que valorase en una escala de 1 a 9 puntos el grado de "similitud" entre las parejas de informes.

$2^{\text {a }}$. En el cuestionario se les pide que valoren los 10 diferentes informes con 12 "atributos" o "cualidades", en una escala de nueve puntos. 
$3^{\text {a }}$ En la que se valora la "similitud de los atributos" que se han usado previamente. El experimento tiene una duración de 2 horas, tras las que se les entrega una pequeña gratificación a los participantes.

Las tres hipótesis a contrastar son las siguientes:

$\mathrm{H}_{01}$ : No existe una diferencia relativa en los mensajes percibidos de la redacción del informe de auditoría actual y el borrador propuesto por la ASB para un conjunto determinado de informes.

$\mathrm{H}_{02}$ : No existe una diferencia absoluta en los mensajes percibidos de la redacción del informe de auditoría actual y el borrador propuesto por la ASB para un conjunto determinado de informes.

$\mathrm{H}_{03}$ : Existen diferencias en los mensajes percibidos, para un conjunto de informes, entre dos grupos de usuarios que poseen un nivel de conocimiento diferente en materia de informes de auditoría.

Metodología: La información se obtiene mediante un cuestionario elaborado, en un laboratorio, por los sujetos encuestados y es analizada a través de las siguientes técnicas estadísticas: las doce escalas obtenidas en la segunda parte del cuestionario se evalúan mediante un "análisis multivariante de las varianzas" (MANOVA) y un "análisis de las varianzas” (ANOVA), mientras que los datos relativos a la similitud de los informes y atributos, de las partes primera y tercera del experimento, se valoran a través de un "modelo de escalas multidimensionales" (MDS), usando el programa "ALSCAL MDS" que convierte la escala ordinal en métrica. Los tres grupos de datos, de las tres partes del experimento, se analizan de forma separada utilizando un "modelo de distancias Euclideas", para ello los juicios de similitud son 
tomados como "medidas ordinales" mientras que los estímulos se analizan como "medidas de intervalo".

\section{Conclusiones:}

1. Del estudio empírico se desprende que los cambios propuestos en la redacción del informe producen una absoluta, pero no relativa, diferencia en las percepciones de los sujetos entre el modelo de informe actual y el borrador.

2. Los sujetos perciben que el modelo de informe propuesto asigna más responsabilidad en la elaboración de las cuentas anuales, a los administradores y menos al auditor, que el informe actual.

3. En cuanto a la hipótesis sobre si dependiendo del nivel de conocimientos de auditoría se perciben mensajes diferentes, los análisis estadísticos producen resultados opuestos, mientras que según el "análisis MDS" (multidimensional scaling) no existen percepciones diferentes, con el "test ANOVA" se obtiene lo contrario.

4. Los autores concluyen indicando que AICPA debe tratar de concienciar a los usuarios sobre la finalidad del mensaje contenido en los informes de auditoría a través de programas educacionales.

\section{Limitaciones:}

1. El escaso número de participantes en el experimento impide la generalización de las conclusiones obtenidas. 
2. El alto grado de subjetividad asociado con los tipos de informes escogidos, ya que nunca pueden aparecer todas las variantes posibles, así como la subjetividad de los "atributos" elegidos como caracterizadores de los informes de auditoría.

3. El sesgo que supone trabajar con estudiantes y no con usuarios reales de los informes de auditoría.

4. Los informes de auditoría utilizados son ficticios. 
2.3.1.4. Estudio empírico sobre el grado de comprensión, por parte de los $\underline{\text { usuarios, de los informes de auditoría de cuentas anuales y otros tipos de }}$ dictámenes emitidos por auditores (Nair y Rittenberg 1987)

Objetivo: Comprobar el grado de comprensión del mensaje contenido en los informes de auditoría y otra serie de dictámenes emitidos por el auditor, como son las "revisiones limitadas" y las "compilations" (compilaciones) 35 .

Experimento: El experimento se realiza con 40 empleados de banca encargados de la concesión de créditos a empresas, pertenecientes a pequeños bancos norteamericanos, así como con 40 socios o gerentes de firmas auditoras norteamericanos, no pertenecientes a las grandes multinacionales de auditoría, especializados en la emisión de otros tipos de informes aparte del de auditoría de cuentas anuales. A los participantes se les entrega 9 informes de auditoría de cuentas anuales con todos los tipos de opinión, al igual que "informes de revisión limitada" y "compilaciones", y se les solicita que identifiquen la pareja de informes que consideran con mayor parecido en términos del mensaje que comunican, indicando el "grado de similitud" a través de una escala formada por un intervalo de 0 a 9 puntos. Adicionalmente se les suministra una serie de frases calificativas para que indiquen el punto hasta el que creen que cada frase es aplicable a cada uno de los nueve informes diferentes, en función de su baja o alta aplicabilidad; dichas frases tratan de verificar la "eficacia comunicativa" del mensaje que trasmite cada tipo de informe, la función del auditor al emitir los informes y

\footnotetext{
${ }^{35}$ Como indican las normas de auditoría de AICPA, los trabajos de compilación son aquellos que proporciona el contador con respecto a estados financieros no auditados de entidades que no cotizan en bolsa, y que tienen por objeto la emisión de un "informe de compilación", donde el auditor declara que no realizó una auditoría o revisión y no expresa opinión u otra forma de seguridad sobre los estados financieros, su trabajo se limita a preparar o asistir en la elaboración de estados financieros sin expresar seguridad alguna de que los estados son exactos y completos o si se han elaborado de acuerdo a los principios de contabilidad generalmente aceptados (SSARS-1). Véase también "Otros servicios de atestación y contabilidad" en Auditoría un Enfoque Integral, Whittington y Pany (2000), pág. 562 y ss.
} 
el conocimiento de sobre quién recae la responsabilidad de la elaboración de las cuentas anuales.

Metodología: La recogida de la información se realiza de manera presencial, de forma que los investigadores se desplazan al lugar de trabajo de los participantes; dicha información se analiza utilizando tres diferentes pruebas:

1. Un análisis comparativo, basado en "escalas multidimensionales", para verificar las similitudes percibidas para los diferentes tipos de informes, a través del "programa INDSCAL" (individual differences scaling) para mediciones ordinales, así como mediante el estudio de las correlaciones entre las diferentes "dimensiones".

2. Un "análisis factorial" de las frases calificativas que describen los tipos de informes con el fin de determinar patrones de similitud.

3. Un "test de diferencia de medias" entre los diferentes tipos de informes y para cada frase calificativa; utilizando el "test de la Chicuadrado", para comprobar si la distribución de las puntuaciones asignadas a cada pareja de informes es diferente entre los dos grupos de participantes. De igual modo se emplea el "test de la U de MannWhitney", el "test-Retest" y la "prueba Kruskal's stress".

\section{Conclusiones:}

1. Los banqueros perciben que los auditores tienen una mayor responsabilidad a la hora de elaborar los estados financieros de lo que éstos asumen. 
2. El proceso de comunicación, entre auditores y banqueros, no es tan bueno en los casos de "revisiones limitadas" y "compilaciones", debido a que no se percibe de manera clara: la responsabilidad del auditor, la naturaleza de los procedimientos llevados a cabo y el grado de seguridad que se transmite en dichos informes.

3. Se necesitan descripciones adicionales sobre la naturaleza de los procedimientos aplicados por los auditores.

4. Se debe aclarar el grado de responsabilidad asumido tanto por los auditores como por los administradores.

5. Existe un límite de mensajes, entre los distintos informes, que puede ser comunicado de manera efectiva.

6. El proceso educacional en materias económico-financieras puede mejorar la "comunicación", de los mensajes contenidos en los informes, familiarizando a los usuarios con dicha información.

\section{Limitaciones:}

1. El estudio se realiza con una muestra "no aleatoria" muy pequeña, escogida sin aplicar un criterio científico, de forma que las conclusiones no son extrapolables.

2. El problema de la subjetividad asociada a las frases elegidas por los autores para calificar los diferentes informes. 
3. El estudio no tiene en cuenta a todos los usuarios de los informes de auditoría como pueden ser analistas financieros, accionistas, el Estado, etc.

4. Existe una limitación debida a que no se han considerado todos los posibles tipos de salvedades que se pueden incluir en los informes de auditoría. 
2.3.1.5. Estudio empírico para investigar las percepciones que se tienen sobre los mensajes que contiene el informe del auditor (Mayper, Welker y Wiggins $\underline{1988)}$

Objetivo: El propósito del estudio no es otro que investigar la existencia de diferencias en la percepción de los mensajes contenidos en los informes de auditoría, en las "compilaciones" y en las "revisiones limitadas", entre auditores y empleados de banca encargados de la concesión de créditos a empresas.

Experimento: El experimento se realiza mediante el envío de una encuesta a 62 auditores, pertenecientes a 30 firmas de auditoría de Houston, de los que responden el 78.5\%; junto a ellos participan 50 banqueros empleados de 10 bancos de la misma zona, de los que contestan el 64\%. A todos se les entrega un dossier, que incluye dos partes: una primera con las instrucciones generales, y una segunda con dos tareas experimentales que consisten en desarrollar una comparación entre parejas formadas por seis tipos de informes (dos informes de auditoría limpios y con salvedades, dos informes de revisión limitada limpios y con salvedades, y dos compilaciones), para medir el "grado de similitud" de los mensajes. Además se les solicita que valoren los seis informes recibidos en función de 15 características definidas por los autores.

Metodología: Se emplea el método desarrollado por Libby (1979) de "escalas multidimensionales" (MDS), dicho modelo representa la distancia psicológica que tiene en mente el individuo entre los estímulos presentados, pero adaptado para comprobar la diferencia en las percepciones. Así, se utiliza el programa de diferencias individuales denominado "ALSCAL MDS" y el "modelo de distancias Euclídeas"; mientras que la selección de la 
dimensión se realiza con el "test Scree" y "the Young's S-stress formula", que indica el mejor método en la aplicación de dos dimensiones para cada grupo del modelo. Se utiliza una "Orthogonal Procustrean Technique" para hacer similares los espacios de respuesta de ambos grupos y mejorar la información obtenida de cara a su manipulación estadística; junto a esto, se estudia la correlación de las diferencias relativas en los espacios de respuesta, entre grupos, a través del "coeficiente de correlación producto-momento de Pearson", así como mediante la "correlación de Spearman". Para contrastar las diferentes percepciones, en cuanto a las 15 características que se valoran en la segunda parte del experimento, se utilizan dos tests estadísticos; el "test $\mathrm{T}^{2}$ de Hotelling" y la "prueba t para parejas". Por último se emplea el "test no paramétrico de Mann-Whitney" sin que los resultados difieran de los obtenidos a través de la "prueba t para parejas".

Conclusiones: Los resultados del experimento indican que banqueros y auditores externos tienen interpretaciones diferentes para las dimensiones utilizadas al definir la similitud de distintos tipos de informes del auditor. Estos resultados sugieren que la profesión contable puede necesitar de una mejora en el "proceso de comunicación" de los objetivos y el significado de los dictámenes elaborados por los auditores.

\section{Limitaciones:}

1. La muestra de auditores no es aleatoria pues se hace a elección del investigador, y en la misma zona geográfica, al igual que sucede con los banqueros, por lo que no se pueden realizar generalizaciones. 
2. Los autores hacen referencia al corto espacio de tiempo concedido a los individuos para responder.

3. Como en otros estudios, existe una clara limitación asociada a la subjetividad de las características empleadas para interpretar la "similitud" de los informes. 
2.3.1.6. Estudio empírico para contrastar si el nuevo modelo de informe de auditoría norteamericano, de la SAS $\mathrm{n}^{\mathrm{o}} 58$, consigue aumentar la comprensión del mensaje que emite el auditor para banqueros e inversores (Kelly y Mohrweis 1989)

Objetivo: El estudio trata de comprobar si la nueva redacción del informe de auditoría, que establece la SAS n 58 norteamericana, y que viene a sustituir al modelo corto (vigente en USA entre 1948 y 1988, salvo por pequeñas modificaciones), tiene impacto en las percepciones que los usuarios del informe, representados por empleados de banca e inversores, poseen sobre el mensaje transmitido a través del mismo.

Experimento: Se realiza un "experimento de laboratorio" con 50 empleados de banca y 50 inversores, seleccionados por el investigador, a los que se les entrega el modelo viejo y nuevo de informe de auditoría con un cuestionario de preguntas graduadas a través de una "escala Likert" de siete puntos, y referidas al mensaje que transmite el informe en relación con los objetivos y responsabilidades de los auditores, así como sobre la mejora de la redacción.

Metodología: Para evaluar cómo las variables independientes analizadas, informe antiguo versus nuevo e inversores versus banqueros, influyen en las percepciones que se reciben del mensaje que transmite el informe, se realiza un "análisis de la varianza en dos sentidos" (ANOVA) considerando las cuestiones a responder como las variables dependientes. Adicionalmente para algunas preguntas se aplica el "test no paramétrico de Kruskal-Wallis", obteniéndose los mismos resultados que con el test paramétrico. Posteriormente se lleva a cabo la "prueba $t$ " para contrastar si la respuesta media de ambos grupos participantes es significativamente diferente de la posibilidad de no percibir cambios respecto al informe antiguo. 
Conclusiones: De los resultados obtenidos en el "experimento" se desprenden las siguientes conclusiones:

1. El nuevo modelo de informe logra aclarar, tanto para los banqueros como para los inversores, que la dirección de la empresa es la responsable de elaborar las cuentas anuales.

2. Con el nuevo informe se consigue una mejor comprensión del propósito que tiene el trabajo del auditor.

\section{Limitaciones:}

1. La principal limitación del estudio, como sucede en los "experimentos de laboratorio", es la imposibilidad de extrapolar los resultados a la población de la que proviene una muestra seleccionada de manera “no aleatoria" y circunscrita a una zona geográfica limitada.

2. Los resultados tampoco son generalizables para los informes de auditoría que presentan salvedades, ya que a los entrevistados sólo se les entregan los modelos de informe con los párrafos estándar. 
2.3.1.7. Estudio empírico para comprobar cómo se interpretan los informes de auditoría en el Reino Unido (Holt y Moizer 1990)

Objetivo: Determinar el significado y la interpretación que los informes de auditoría tienen para los usuarios de dicha información.

Experimento: Los individuos con los que se realiza el estudio son usuarios de las cuentas anuales de las empresas, así como auditores del Reino Unido. Concretamente en el experimento participan: tres socios auditores, dos auditores gerentes, un broker, dos gerentes de "fondos de inversión", dos directivos de banca, dos gerentes de "pymes", tres profesores universitarios de contabilidad y cinco estudiantes universitarios de contabilidad. A los participantes en el experimento se les suministran 30 informes de auditoría diferentes y se les entrevista personalmente para comprobar el significado que tienen para ellos los diferentes informes. Posteriormente se les suministra otros 8 informes de auditoría y se les entrega un cuestionario para cumplimentar, empleando el método del "diferencial semántico" creado por Osgood et al. (1957), mediante el que se solicita que valoren los informes con unos determinados adjetivos o frases a través de una escala, de la que se obtiene un "mapa multidimensional" que caracteriza el contenido de los informes. De igual forma en los casos en los que no se pueden crear antónimos para los adjetivos, propuestos con el método del "diferencial semántico", se utiliza la escala de "Likert", con siete graduaciones, para medir el acuerdo o desacuerdo de los participantes con determinadas ideas expresadas en frases. 
La hipótesis nula que se pretende contrastar se define como:

$\mathrm{H}_{0}$ : Los contables y el resto de usuarios de la información contable tienen la misma percepción del significado asociado a los informes de auditoría.

Metodología: El proceso de recogida de la información se basa en entrevistas personales con los participantes, así como en la elaboración de un cuestionario del que se recibe un porcentaje de respuestas del 36,5\%. Las técnicas estadísticas utilizadas para la obtención de resultados son las siguientes: para comprobar la "consistencia" de los datos de las encuestas se aplica el "test de la Chi-cuadrado", con el "test de Wilcoxon para datos emparejados y clasificados por su signo" (Wilcoxon Matched-Pairs SignedTest) se verifica la existencia de diferencias significativas entre las respuestas dadas para cada una de las treinta dimensiones, que definen el contenido de los informes de auditoría, por cada grupo consultado; además y para comparar las percepciones de los diferentes grupos y su significatividad, también se utiliza el "test de Mann-Whitney".

Conclusiones: Se rechaza la hipótesis nula y se concluye que tanto los contables como el "resto de usuarios" diferencian los distintos tipos de informes, además el "resto de usuarios" encuentra los diferentes tipos de informes más parecidos. Las divergencias de interpretación, entre los grupos encuestados, se centran en el significado dado a los informes "limpios" y a las "salvedades" que emiten los auditores, especialmente las salvedades por el "principio de empresa en funcionamiento" y con pequeñas empresas; otorgando mayor importancia, a dichas salvedades, los usuarios de la información contable que los propios contables. 


\section{Limitaciones:}

1. Una muestra muy reducida y "no aleatoria" que restringe la generalización de las conclusiones obtenidas.

2. La subjetividad asociada a las "dimensiones" empleadas en el estudio, así como el orden empleado en las 30 escalas utilizadas, con las diferentes "dimensiones", que puede dar lugar a un efecto "halo"36.

3. Los tipos de informes empleados no incluyen la amplia gama de "salvedades" que se pueden dar en la realidad.

4. Se pierde realismo en el experimento ya que se emplean informes de auditoría con párrafos estándar en los que las "salvedades" no aparecen cuantificadas.

\footnotetext{
${ }^{36}$ El denominado "efecto halo" supone que el orden en el que se efectúan las preguntas pueda afectar o condicionar las respuestas de los encuestados.
} 
2.3.1.8. Estudio empírico sobre el "gap de expectativas" con el informe de auditoría anglosajón, para comprobar la reacción de los usuarios a su ampliación a través de la SAS nº 600 (Innes, Brown y Hatherly 1997)

Objetivo: Verificar la existencia del "gap de expectativas", en el Reino Unido, con el modelo corto de informe de auditoría, y comprobar la repercusión que tiene sobre el "gap" la ampliación del contenido del informe a través de la norma de auditoría inglesa que lo desarrolla (SAS n $\mathrm{n}^{\mathrm{0}}$ 600), y que supone el desarrollo anglosajón de la norma n ${ }^{\circ} 58$ norteamericana.

Experimento: La investigación se desarrolla con auditores y con usuarios del informe de auditoría. Los auditores se seleccionan de manera aleatoria obteniéndose una muestra de 500, de los que responden 254 al cuestionario solicitado, lo que supone una tasa de respuesta del 51\%. Para el colectivo de usuarios se escogen 2 grupos de 70 estudiantes a tiempo parcial, de un master MBA de la Universidad de Edimburgo, todos ellos trabajadores con experiencia en las ramas comercial, financiera, de producción, y gubernamental. Con los estudiantes se realiza un "experimento de laboratorio", de manera que a un grupo se le entrega unas cuentas anuales ficticias con un informe de auditoría corto, mientras que al otro grupo se le entrega las mismas cuentas anuales pero con el modelo largo de informe de auditoría. Tanto a los auditores como a los usuarios del informe se les suministra un cuestionario en el que se les solicita que valoren, a través de una escala tipo "Likert" entre 1 y 7 puntos, una serie de afirmaciones y/o preguntas que definen los "atributos" característicos de la auditoría, los estados financieros y los auditores.

Metodología: Para recabar la información se utiliza una encuesta postal para los auditores, y una entrevista personal para los usuarios de los informes. 
Dicho cuestionario es probado previamente a su realización definitiva con 12 estudiantes, auditores y docentes. Para el análisis de los resultados se realiza un estudio exploratorio de los datos; así mediante el "test de la Chicuadrado" se comprueba la "normalidad" de la distribución, y gracias al "test de Bartlet" se verifica la "homogeneidad de las varianzas". Una vez constatada la "no normalidad" de los datos, y debido al carácter ordinal de los mismos, se utilizan técnicas no paramétricas aplicándose el “análisis de la varianza por rangos en un sentido de Kruskal-Wallis" con un grado de significatividad del 95\%; en aquellos casos en los que el test es significativo se aplica el "test de Wilcoxon-Mann-Whitney" para determinar el origen de las diferencias, entre los grupos encuestados, con un nivel de significación estadística del 95\%.

\section{Conclusiones:}

1. Se obtiene evidencia, para el caso de los informes cortos de auditoría, de que existe un "gap" en las expectativas entre usuarios y auditores.

2. Los resultados demuestran que la extensión del informe antiguo cambia las percepciones de los usuarios, de forma que el informe largo transmite mejor el propósito de la auditoria cerrando el "gap" con los auditores, y además aumenta la percepción de los usuarios en cuanto a la "calidad", el rigor empleado en el desarrollo de la auditoría, así como las percepciones en cuanto a la "utilidad", especialmente con relación al fraude.

3. Las posibles soluciones sugeridas por la profesión contable al "gap" pasan por un enfoque defensivo, basado en la educación de los usuarios, y un enfoque constructivo que pasa por ampliar las 
actividades que realiza el auditor para satisfacer las demandas de los usuarios.

\section{Limitaciones:}

1. Los estudiantes utilizados para el experimento se concentran en una misma área geográfica del Reino Unido, además son una aproximación "no realista" de los verdaderos usuarios de los servicios de auditoría.

2. El método empleado para recabar la información no es el mismo para los auditores que para los estudiantes, y además éstos últimos no tienen acceso al tipo de informe largo.

3. Los autores indican que se corre el riesgo de que el informe suministrado no haya sido leído en detalle y se trate como algo simbólico.

4. Debido al método de elección de la muestra los resultados no son generalizables. 


\subsubsection{INVESTIGACIONES MEDIANTE ENCUESTAS}

Dentro de los estudios realizados sobre los problemas de comprensión, del informe de auditoría, se incluyen aquellos que han empleado la metodología propia de áreas de conocimiento ajenas al ámbito contable, como el "marketing" y más concretamente la "investigación de mercados".

- Dillard y Jensen, 1983.

- Geiger, 1989.

- Miller, Reed y Strawser, 1990 y 1993. 
2.3.2.1. Estudio empírico sobre la posibilidad de retirada del informe de auditoría corto y su sustitución por un modelo largo que clarifique su lenguaje (Dillard y Jensen 1983)

Objetivo: El propósito de los autores no es otro que comprobar la reacción de los usuarios de los informes de auditoría ante los cambios en el modelo corto de informe, propuesto por el ASB norteamericano en su borrador de SAS, con la intención de verificar la visión que éstos grupos tienen sobre la función y responsabilidad del auditor.

Experimento: A raíz de que la CAR (Commission on Auditors' Responsibilities) norteamericana, perteneciente a AICPA, concluyera en su informe que la "comunicación" entre el auditor y los usuarios del servicio es insatisfactoria, a causa de las siguientes deficiencias: $1^{\circ}$. Un lenguaje estandarizado. $2^{\circ}$. Errores a la hora de expresar los mensajes más importantes. $3^{\circ}$. Terminología técnica que es ambigua y poco clara. $4^{\mathrm{o}}$. Error al comunicar, a través del informe, las responsabilidades del auditor, los autores han estudiado los resultados obtenidos por dicha comisión al enviar una encuesta de opinión a los diferentes grupos implicados en la auditoría; de forma que con las 453 respuestas recibidas, se proponen comprobar los puntos de vista de los distintos grupos y analizar las diferencias. Del conjunto de respuestas los autores se han centrado en las 388 recibidas de tres grupos: empresas de asesoramiento en contabilidad, empresas industriales e instituciones financieras, el resto de respuestas corresponden a firmas de auditores, académicos, asociaciones empresariales, Administración, etc.

Metodología: A los grupos encuestados se les suministra un borrador con el nuevo modelo de informe y se les solicita que den su opinión sobre si mejora 
o no el informe corto. Al ser "preguntas abiertas", los autores han realizado un estudio descriptivo en el que exponen y clasifican una primera reacción general al cambio en el modelo de informe, para los tres grupos, que viene determinada por la posibilidad de una "reacción general favorable"; una "reacción general desfavorable" motivada porque se debilite la opinión del auditor, sea confusa y poco clara, o sea innecesaria al no suponer mejoría; y la posibilidad de que no se pueda obtener una reacción discernible. Una vez valorada la primera impresión de los encuestados, se procede al análisis descriptivo de la reacción de los grupos a las propuestas específicas de cambio en el informe, de manera que se comprueba el grado de acuerdo (con tres posibilidades), el desacuerdo y una tercera opción cuando no se observa reacción alguna. Los cambios propuestos en el borrador se refieren: $1^{\circ}$. Eliminar la expresión "fairly". $2^{\circ}$. Añadir la expresión "razonable pero no absoluta garantía de errores materiales". $3^{\circ}$. Añadir en el informe que la formulación de las cuentas anuales es responsabilidad de los administradores. $4^{\circ}$. Eliminar la expresión de uniformidad al aplicar los PCGA. $5^{\circ}$. Añadir la expresión "application requires judgment" para indicar que el proceso de auditoría está sujeto al juicio profesional del auditor. $6^{\circ}$. Añadir la palabra "independiente" en el título del informe.

Posteriormente, y con la intención de simplificar y hacer más comparable los puntos de vista de los tres grupos analizados, se procede a realizar un "análisis tri-dimensional" de las respuestas obtenidas, para lo que se construye una figura tridimensional, en la que el eje $\mathrm{X}$ representa el porcentaje de acuerdo expresado para cada uno de los cambios propuestos, el eje $\mathrm{Y}$ el porcentaje de desacuerdo expresado para cada uno de los cambios propuestos, y el eje $\mathrm{Z}$ el porcentaje que expresa la "no reacción" para las modificaciones propuestas. 


\section{Conclusiones:}

1. El borrador de "informe largo" encuentra una clara oposición de los usuarios.

2. Las respuestas sugieren que asesorías contables, sociedades industriales e instituciones financieras reaccionan de forma diferente, ante los cambios propuestos en el informe, con relación a la razonable seguridad que aporta el informe, las responsabilidades de los administradores y la uniformidad al aplicar los PCGA.

3. La ambigüedad del "informe corto" no es solamente un problema de semántica, de forma que se concluye que existe más consenso entre los grupos sobre el modelo corto que sobre el borrador propuesto, que en teoría es menos ambiguo.

\section{Limitaciones:}

1. La muestra obtenida no es aleatoria y por tanto no es representativa del universo estudiado.

2. Al ser "preguntas abiertas" existe una gran variación en las mismas, de forma que el proceso de clasificación es una tarea complicada y subjetiva.

3. Las respuestas dadas no son anónimas, de forma que han sido preparadas para que se asocien a la entidad a la que están representando. 
2.3.2.2. Estudio empírico para verificar si el borrador del nuevo modelo de informe de auditoría norteamericano, del año 1988, consigue mejorar la comunicación entre el auditor y los usuarios de los estados financieros (Geiger 1989)

Objetivo: El autor pretende comprobar las reacciones de los colectivos relacionados con la labor auditora ante el borrador de la norma de auditoría SAS n $n^{\circ} 58$, emitida por el ASB perteneciente a AICPA norteamericano, por la que se modifica la redacción del informe de auditoría, para verificar si se han tenido en cuenta los cambios demandados por los usuarios.

Experimento: El ASB envía información postal con el borrador de la norma $\mathrm{n}^{\mathrm{o}} 58$ y solicita, a determinados auditores así como a todo el que se lo requiere de forma expresa, comentarios en torno a dicho borrador con la finalidad de obtener las opiniones de los auditores y usuarios sobre el nuevo modelo de informe. Posteriormente, el autor con las 183 respuestas obtenidas de diferentes colectivos, se encarga de establecer agrupaciones homogéneas y codifica la información de la que extrae una serie de conclusiones. Se establecen las siguientes agrupaciones: 123 auditores externos, 15 agencias gubernamentales de auditoría, 19 "filing corporations", 19 académicos, 3 abogados y asesores legales y 5 individuos no clasificados.

Metodología: Una vez tratados y depurados los datos, se limita a realizar un análisis descriptivo del grado de acuerdo o desacuerdo con los cambios propuestos por el ASB, y expone la información en términos porcentuales. 


\section{Conclusiones:}

1. Existe una mayoría de usuarios que está de acuerdo en la necesidad de un nuevo modelo de informe de auditoría.

2. El 74\% de los individuos se muestra de acuerdo en que el "lenguaje", utilizado en el borrador, se puede mejorar para clarificar los mensajes comunicados a través del informe.

\section{Limitaciones:}

1. La información se obtiene de cartas, con sugerencias sobre el borrador de la norma de auditoría, enviadas a la ASB y, por tanto, se trata de opiniones abiertas y sin homogeneidad ni sistematización alguna, de manera que el autor tiene que extraer la información y codificarla de forma muy subjetiva; siendo la técnica de investigación el "análisis de contenido" que requiere de categorías precisas y significativas de entrevistados.

2. Del análisis no se puede obtener una relación "causa-efecto" entre las respuestas obtenidas y la modificación que realiza la ASB sobre el borrador de norma.

3. Los individuos seleccionados no se pueden considerar representativos de ninguna población de usuarios de los informes y, por tanto, no se pueden hacer generalizaciones. 
2.3.2.3. Estudio empírico para verificar si el nuevo modelo de informe de auditoría norteamericano consigue disminuir el "gap" en la comunicación entre el auditor y los usuarios de los estados financieros (Miller, Reed y $\underline{\text { Strawser } 1990 \text { y } 1993)}$

Objetivo: El estudio trata de comprobar si la redacción del informe de auditoría largo, que establece la SAS $\mathrm{n}^{\mathrm{o}} 58$ norteamericana, y que viene a sustituir al "modelo corto" (vigente en USA entre 1948 y 1988 salvo por pequeñas modificaciones), consigue mejorar la comunicación entre los auditores y los usuarios del informe, para lo cual se investiga si el nuevo modelo de informe tiene mayor utilidad que el anterior para los responsables de la concesión de créditos en entidades financieras.

Experimento: Para llevar a cabo el estudio se obtiene una muestra de banqueros, de un directorio norteamericano (The Rand McNally Bankers Directory), a los que se les envía un cuestionario postal junto a dos modelos de informe de auditoría "limpios", tanto el antiguo como el nuevo. Se les solicita que contesten una batería de 23 preguntas, relativas a ambos informes, mediante una escala de 100 puntos. La información recabada permite contrastar las percepciones de banqueros de pequeñas entidades financieras con los pertenecientes a los grandes bancos.

Metodología: La información necesaria se obtiene mediante el envío de un cuestionario postal a los responsables de entidades financieras, y el análisis de los datos se realiza a través de un estudio de "diferencia de medias" entre los dos grupos entrevistados pertenecientes a pequeñas y grandes entidades financieras. 


\section{Conclusiones:}

1. La gran uniformidad de las respuestas dadas por los dos grupos de prestamistas, con relación al informe de auditoría de la SAS n $n^{\mathrm{o}} 58$, indica que se ha reducido el "gap de expectativas".

2. Se evidencia una mejora en la "comunicación" entre los usuarios y los auditores a través del nuevo informe, se mejora el conocimiento que se tiene sobre las responsabilidades tanto de los auditores como de los administradores.

3. El nuevo modelo de informe afecta en mayor medida a las "percepciones" que tienen los banqueros de pequeñas entidades, que a los de las grandes.

4. Para ambos grupos el nuevo modelo de informe es más comprensible y posee un mayor valor que el antiguo.

5. Se concluye que el nuevo modelo, aprobado por el ASB, ha tenido éxito en resolver problemas planteados tanto por la "Comisión Cohen" como por el resto profesionales y usuarios.

\section{Limitaciones:}

1. La subjetividad asociada a las expresiones utilizadas para valorar los dos modelos de informes.

2. Los autores no hacen referencia a la aleatoriedad o no del proceso de selección de la muestra. 
CAPÍTULO III

ESTUDIO EMPÍRICO NACIONAL SOBRE LA AUDITORÍA DE CUENTAS: FUNCIÓN, UTILIDAD Y COMPRENSIÓN DEL INFORME DE AUDITORÍA 


\subsection{OBJETIVO Y PLANTEAMIENTO DE HIPÓTESIS}

La investigación persigue contrastar las percepciones que tienen los diferentes colectivos, que participan de manera directa o indirecta en la auditoría de cuentas, sobre tres variables cualitativas que se pretenden medir: la "función" actual del auditor de cuentas, la "utilidad" que presta el servicio de auditoría y el grado de "comprensión" del informe del auditor. Concretamente, se quiere recabar información de los auditores de cuentas, directores de los departamentos de riesgos de entidades de crédito, directores financieros o gerentes de empresas y analistas de inversión pertenecientes a sociedades y agencias de valores. Para ello se ha elaborado una -encuesta postal- que contiene en su mayoría las mismas cuestiones para todos los colectivos. No obstante se incluyen preguntas específicas para alguna de las poblaciones objeto de estudio, que se formulan atendiendo a las características de cada grupo y por tanto no son extensibles al resto.

Del análisis de la información obtenida se pretende inferir las diferentes percepciones de los grupos para cada una de las variables, aplicadas en un ámbito nacional, y de las que se deriva lo que se conoce como "gap de expectativas", que viene siendo analizado desde hace más de dos décadas sobre todo en los países anglosajones, y más recientemente en España.

Además se quiere realizar un estudio descriptivo de la información adquirida, que sirva para conocer el estado actual de la profesión auditora, sus problemas y expectativas. Por ello la investigación tiene como finalidad conocer las necesidades que genera el ejercicio de la auditoría, para poder establecer pautas a seguir en la mejora de un servicio que demanda la sociedad y que debe ir actualizándose y adaptándose a los cambios sociales. 
Con la información derivada de la encuesta se pretende contrastar las siguientes variables cualitativas:

1. La "función" del servicio de auditoría, es decir la labor que tienen encomendada los auditores para con las empresas y los usuarios de su trabajo.

2. La "utilidad", tanto para la compañía auditada como para los terceros interesados, derivada del servicio que ofrecen los auditores de cuentas.

3. La "comprensión" de la exposición que hacen los auditores de su trabajo a través del informe de auditoría.

Las hipótesis nulas a contrastar quedan definidas, a saber:

- H01: Los auditores, sociedades auditadas, entidades de crédito (representadas por Bancos, Cajas de Ahorros y Cajas Rurales) y analistas financieros (representados por Agencias y Sociedades de Valores) muestran la misma percepción sobre la función que cumple el servicio de auditoría de cuentas.

Dentro de la primera hipótesis se ha considerado una subhipótesis que trata la problemática en torno a los "servicios multidisciplinares" que pueden prestar los auditores y que queda definida como:

- $\mathrm{H}_{011:}$ Los auditores y sociedades auditadas muestran la misma percepción sobre la posibilidad de que los 
auditores puedan prestar otros servicios distintos al de auditoría de cuentas.

- H02: Los auditores, sociedades auditadas, entidades de crédito (representadas por Bancos, Cajas de Ahorros y Cajas Rurales) y analistas financieros (representados por Agencias y Sociedades de Valores) muestran la misma percepción sobre la utilidad que presta la auditoría de cuentas.

A su vez esta segunda hipótesis se ha ampliado de manera concreta sobre dos colectivos, entidades de crédito y analistas financieros:

- $\mathrm{H}_{021}$ : Las entidades de crédito perciben que la información suministrada por el dictamen del auditor es relevante para la toma de sus decisiones de financiación.

- $\mathrm{H}_{022:}$ Los analistas financieros perciben que la información suministrada por el dictamen del auditor es relevante para la toma de sus decisiones de inversión.

- H03: Los auditores, sociedades auditadas, entidades de crédito (representadas por Bancos, Cajas de Ahorros y Cajas Rurales) y analistas financieros (representados por Agencias y Sociedades de Valores) muestran la misma percepción en cuanto a la comprensión del informe de auditoría de cuentas. 


\subsection{METODOLOGÍA EMPLEADA}

\subsubsection{DISEÑO MUESTRAL}

\subsubsection{Población objeto de estudio}

La encuesta va dirigida a cuatro colectivos diferentes pero bien delimitados, de una parte los auditores de cuentas, empresas que han sido auditadas, entidades de crédito que indirectamente se benefician de la labor del auditor y analistas financieros que, al igual que las entidades de crédito, son parte interesada en el servicio.

\section{Auditores}

La población de auditores aglutina a todos aquellos auditores de cuentas que pueden ejercer como tales en el conjunto del Estado Español; por ello son reconocidos oficialmente por el ICAC y, como consecuencia, aparecen en el "Registro Oficial de Auditores de Cuentas" (ROAC) que con periodicidad anual publica dicho Instituto. Así para el año objeto de estudio, se componía de:

Tabla $n^{\circ} 3$

Auditores inscritos en el ROAC en 1999

\begin{tabular}{|l|l|c|}
\hline \multicolumn{2}{|c|}{ AUDITORES } & Número \\
\hline \multirow{2}{*}{ Personas fisicas } & Ejercientes & 4.610 \\
\cline { 2 - 3 } & Ejercientes por cuenta ajena & 965 \\
\cline { 2 - 3 } & No ejercientes & 10.522 \\
\cline { 2 - 3 } & \multicolumn{1}{|c|}{ Subtotal Personas físicas } & 16.097 \\
\hline Sociedades & Ejercientes TOTAL AUDITORES & 17.027 \\
\hline
\end{tabular}

Fuente: ICAC, BOICAC nº41, marzo 2000. 
No obstante, del total se ha escogido como "marco muestral" aquellos auditores que realmente se dedican al ejercicio de la profesión, de manera que los auditores ejercientes durante el ejercicio 1999 se repartían como sigue:

Tabla $\mathrm{n}^{\mathrm{o}} 4$

Auditores individuales inscritos como ejercientes en el ROAC en 1999

\begin{tabular}{|c|c|c|}
\hline \multicolumn{2}{|c|}{ AUDITORES } & Número \\
\hline \multirow[t]{3}{*}{ Ejercientes por cuenta propia } & & \\
\hline & Con facturación & 1.860 \\
\hline & Sin facturación & 1.321 \\
\hline \multirow{2}{*}{$\begin{array}{c}\text { Socios de sociedades } \\
\text { no ejercientes a titulo individual }\end{array}$} & & 1.429 \\
\hline & ORES EJERCIENTES & 4.610 \\
\hline
\end{tabular}

Fuente: ICAC, BOICAC nº41, marzo 2000.

Aunque el "marco muestral" debía estar formado por 4.610 auditores ejercientes se ha tomado una cifra de 4.629 auditores, debido a que según los listados oficiales por provincias que publica el ICAC en el ROAC el número real de censados es éste último 37.

\section{Empresas}

Las sociedades objeto de estudio son todo tipo de empresas que, independientemente de su forma jurídica, se hayan sometido a la auditoría de sus cuentas anuales durante el ejercicio 1999, ya que el estudio busca la opinión de aquellas mercantiles que han recibido el servicio de auditoría. Así, y según consta en la información que suministra el ICAC, para dicho ejercicio, los trabajos realizados por los auditores se clasifican como:

\footnotetext{
${ }^{37}$ Aunque las estadísticas oficiales reconocidas en el BOICAC $\mathrm{n}^{\circ} 41$ hacen referencia a una cifra de 4.610 auditores, el número real que aparece con nombres y apellidos en el ROAC es de 4.629, por ello se ha tomado ésta última cifra para la selección aleatoria de los encuestados.
} 
Tabla $\mathrm{n}^{\mathrm{o}} 5$

Trabajos realizados en 1999 relacionados por Tipos de Auditoría

\begin{tabular}{|c|c|c|}
\hline TIPO & NÚMERO & $\%$ \\
\hline Auditoría obligatoria de cuentas anuales & 24.197 & 61 \\
\hline Auditoría voluntaria de cuentas anuales & 8.805 & 22 \\
\hline Otros trabajos obligatorios & 2.468 & 6 \\
\hline Otros trabajos voluntarios & 3.466 & 9 \\
\hline Información errónea o no aportada & 524 & 1 \\
\hline TOTAL DE TRABAJOS & 39.460 & 100 \\
\hline
\end{tabular}

Fuente: ICAC, BOICAC n²41, marzo 2000.

Del total de trabajos desempeñados por los auditores en 1999, componen la población objeto de la investigación los referidos a la "auditoría de cuentas anuales", que ascienden a 33.002, divididos en 24.197 auditorias obligatorias y 8.805 voluntarias.

A partir de una población inicial de 33.002 empresas se ha tratado de aproximar un "marco muestral" lo más representativo posible, y que viene delimitado de forma natural por la posibilidad de acceder a estos trabajos a través del Registro Mercantil donde las sociedades deben, cuando proceda, depositar sus cuentas anuales junto con el informe de auditoría. En este sentido se ha recurrido a una base de datos privada denominada "SABE" que recoge información de más del $90 \%$ de las sociedades que presentan sus cuentas anuales al Registro Mercantil.

Posteriormente, y partiendo del hecho que la cifra de 33.002 empresas puede incluir trabajos de auditoría de cuentas anuales realizados a la misma sociedad y, por tanto, que dicha cantidad no implica necesariamente que las empresas auditadas en el ejercicio 1999 asciendan a ese montante, se ha obtenido una base de datos con 23.664 empresas diferentes con sus cuentas anuales auditadas que forman, en principio, el "marco muestral". Sin 
embargo, la cifra real que se ha utilizado como marco ha sido de 15.960 empresas, de toda la geografía nacional, ya que la técnica de recogida de información para las empresas se ha realizado mediante el envío de la encuesta a través de fax, lo que deja reducido el "marco muestral" sólo a las empresas que tenían disponible este instrumento de comunicación.

\section{Entidades de Crédito}

La población de entidades de crédito que se incluye en la investigación, como parte interesada en la información que suministra el auditor para la toma de decisiones, es la formada por todas aquellas entidades o personas susceptibles de conceder cualquier tipo de financiación a las empresas auditadas. Aunque se desconoce la población real de este tipo de entidades, se ha obtenido un "marco muestral" que recoge todos los bancos, cajas de ahorros y cooperativas de crédito inscritos y reconocidos como tales por el Banco de España a través del "Registro Oficial de Entidades sujetas al control e inspección del Banco de España", publicado con fecha trece de noviembre de dos mil, que ascendía a la cantidad de 231 entidades: 88 bancos, 48 cajas de ahorros y 95 cajas rurales.

\section{Analistas Financieros}

Bajo la población de analistas financieros o analistas de inversiones se incluye todo tipo de persona o entidad que sea susceptible de utilizar la información, que provee el auditor a través del informe, en las decisiones de inversión, que lleva a cabo en su propio interés o en el de terceros, de forma profesional. Para representar dicho colectivo se ha recurrido a un "marco muestral" obtenido del listado publicado por la Comisión Nacional del Mercado de Valores en el "Registro Oficial de Sociedades y Agencias de 
Valores", que, con fecha 23 de noviembre de 2000, aglutinaba a 104 entidades.

\subsubsection{Muestra}

Una vez delimitado el universo a estudiar y los correspondientes marcos muestrales se ha procedido a realizar una selección de individuos a encuestar a través de un sistema de "muestreo aleatorio simple" para los grupos de auditores y empresas auditadas y, debido a lo escaso de los individuos que componen los marcos muestrales referentes a entidades de crédito y analistas de inversión, se ha procedido al envío de la encuesta a todos los sujetos de estos dos últimos grupos. Como paso previo a la determinación de los individuos que componen las muestras de cada una de las poblaciones, y en orden a obtener un porcentaje orientativo de respuestas a la encuesta, se ha realizado un "pre-test", con los grupos de empresas auditadas y auditores de cuentas, consistente en el envío de la encuesta a una selección de 50 empresas y 50 auditores, recibiéndose una tasa de respuesta del $29.5 \%$ para los auditores y del $17.9 \%$ para las empresas.

Los tamaños de las muestras se han determinado teniendo en cuenta los objetivos finales del análisis, los tamaños de las poblaciones, la división en estratos realizada, el tiempo disponible y la restricción presupuestaria como factor más relevante.

\section{Auditores}

Se ha tomado una "muestra aleatoria simple" de 1.500 auditores ejercientes, tanto de forma individual como mediante forma societaria y 
además se ha procedido a "estratificar ${ }^{38 "}$ la muestra, por comunidades autónomas, con la finalidad de obtener unos resultados lo más representativos en el conjunto del mercado nacional de auditoría.

Tabla $n^{\circ} 6$

Muestra de auditores estratificada por CCAA

\begin{tabular}{|l|c|c|c|c|}
\hline Comunidades Autónomas & $\begin{array}{c}\text { Auditores por } \\
\text { Comunidad }\end{array}$ & $\%$ & $\begin{array}{c}\text { Muestra por } \\
\text { Comunidad }\end{array}$ & $\%$ \\
\hline ANDALUCÍA & 566 & $12 \%$ & 183 & $12 \%$ \\
\hline ARAGÓN & 154 & $3 \%$ & 50 & $3 \%$ \\
\hline ASTURIAS & 127 & $3 \%$ & 41 & $3 \%$ \\
\hline BALEARES & 105 & $2 \%$ & 34 & $2 \%$ \\
\hline CANARIAS & 168 & $4 \%$ & 54 & $4 \%$ \\
\hline CANTABRIA & 62 & $1 \%$ & 20 & $1 \%$ \\
\hline CASTILLA LEÓN & 206 & $4 \%$ & 67 & $4 \%$ \\
\hline CASTILLA LA MANCHA & 104 & $2 \%$ & 34 & $2 \%$ \\
\hline CATALUNA & 817 & $18 \%$ & 265 & $18 \%$ \\
\hline CEUTA Y MELILLA & 8 & $0 \%$ & 3 & $0 \%$ \\
\hline EXTREMADURA & 70 & $2 \%$ & 23 & $2 \%$ \\
\hline GALICIA & 275 & $6 \%$ & 89 & $6 \%$ \\
\hline MADRID & 859 & $19 \%$ & 277 & $19 \%$ \\
\hline MURCIA & 144 & $3 \%$ & 47 & $3 \%$ \\
\hline NAVARRA & 107 & $2 \%$ & 35 & $2 \%$ \\
\hline RIOJA & 37 & $1 \%$ & 12 & $1 \%$ \\
\hline VALENCIA & 511 & $11 \%$ & 166 & $11 \%$ \\
\hline VASCO PAÍS & 309 & $7 \%$ & 100 & $7 \%$ \\
\hline & 4.629 & $100 \%$ & 1.500 & $100 \%$ \\
\hline
\end{tabular}

Una vez establecidos los "estratos" representativos de cada una de las autonomías, en el total del "marco muestral", se ha procedido a la asignación de un número aleatorio a cada uno de los auditores individuales así como sociedades que aparecen listadas en el ROAC para proceder, a través de la función de "análisis de datos" que incluye la orden de "generación de números aleatorios" de distribución uniforme, en la hoja de cálculo "EXCEL

\footnotetext{
${ }^{38}$ El método seguido de estratificación ha sido el "proporcional" o de "afijación proporcional", que como señalan Dillon et al. (1997) supone que el número de unidades seleccionadas dentro de cada estrato $\mathrm{h}$ es directamente proporcional al tamaño de la población del mismo, que equivale a decir que la fracción de muestreo $\mathrm{f}_{\mathrm{h}}=\mathrm{n}_{\mathrm{h}} / \mathrm{N}_{\mathrm{h}}$ es constante en todos los estratos, lo que conlleva que la fracción
} 
2000", a la obtención de la muestra de 1.500 auditores. Una vez estratificada, la misma se reparte tal y como aparece en la tabla $\mathrm{n}^{\circ} 6$.

\section{Empresas}

Se ha obtenido una "muestra aleatoria simple" de 2.000 sociedades auditadas, procediéndose a estratificar la muestra, por comunidades autónomas, con la finalidad de obtener unos resultados lo más representativos posibles de toda la geografía nacional.

Tabla $\mathrm{n}^{\circ} 7$

Muestra de empresas estratificada por CCAA

\begin{tabular}{|l|c|c|c|c|}
\hline Comunidades Autónomas & $\begin{array}{c}\text { Empresas por } \\
\text { Comunidad }\end{array}$ & $\begin{array}{c}\text { Muestra por } \\
\text { Comunidad }\end{array}$ & $\%$ \\
\hline ANDALUCÍA & 1.088 & $7 \%$ & 136 & $7 \%$ \\
\hline ARAGÓN & 491 & $3 \%$ & 62 & $3 \%$ \\
\hline ASTURIAS & 316 & $2 \%$ & 40 & $2 \%$ \\
\hline BALEARES & 252 & $2 \%$ & 32 & $2 \%$ \\
\hline CANARIAS & 404 & $3 \%$ & 51 & $3 \%$ \\
\hline CANTABRIA & 133 & $1 \%$ & 17 & $1 \%$ \\
\hline CASTILLA LEÓN & 510 & $3 \%$ & 64 & $3 \%$ \\
\hline CASTILLA LA MANCHA & 306 & $2 \%$ & 38 & $2 \%$ \\
\hline CATALUÑA & 4.776 & $30 \%$ & 598 & $30 \%$ \\
\hline CEUTA Y MELILLA & 26 & $0 \%$ & 3 & $0 \%$ \\
\hline EXTREMADURA & 122 & $1 \%$ & 15 & $1 \%$ \\
\hline GALICIA & 696 & $4 \%$ & 87 & $4 \%$ \\
\hline MADRID & 3.367 & $21 \%$ & 422 & $21 \%$ \\
\hline MURCIA & 403 & $3 \%$ & 51 & $3 \%$ \\
\hline NAVARRA & 299 & $2 \%$ & 37 & $2 \%$ \\
\hline RIOJA & 126 & $1 \%$ & 16 & $1 \%$ \\
\hline VALENCIA & 1.529 & $10 \%$ & 192 & $10 \%$ \\
\hline VASCO PAÍS & 1.116 & $7 \%$ & 140 & $7 \%$ \\
\hline & 15.960 & $100 \%$ & 2.000 & $100 \%$ \\
\hline
\end{tabular}

total de muestreo $\mathrm{f}=\mathrm{n} / \mathrm{N}$ es la fracción de cada uno de los estratos. De esta forma el número de individuos de cada estrato $\mathrm{n}_{\mathrm{h}}$ se calcula por: ${ }_{n h}=\left(\frac{N_{h}}{N}\right) n$ 
Una vez establecidos los "estratos", ver tabla $\mathrm{n}^{0} 7$, que representan cada una de las autonomías en el total del "marco muestral", se ha procedido a la asignación de un número aleatorio a cada una de las empresas para obtener, a través de la función de "análisis de datos" que incluye la orden de "generación de números aleatorios" de distribución uniforme, en la hoja de cálculo “EXCEL 2000”, una muestra de 2.000 individuos.

\section{Entidades de Crédito}

Para el caso de las entidades de crédito ya sean bancos, cajas de ahorros y cajas rurales, y debido a lo pequeño del "marco muestral" no se ha seleccionado una muestra sino que se ha procedido al envío de la encuesta a las 231 entidades que forman el conjunto.

\section{Analistas Financieros}

Al igual que sucede con las entidades de crédito, los escasos individuos que forman el "marco muestral" condicionan la consecución de una muestra representativa, por lo que se opta por el envío a las 104 sociedades y agencias de valores inscritas como tales en la CNMV.

\section{- Cálculo del "Error muestral”}

Para conseguir que las muestras obtenidas sean representativas de las poblaciones, de las que provienen, se han establecido los "niveles de confianza" y "errores muestrales permitidos", en las tablas que se exponen a continuación: 
Tabla $\mathrm{n}^{\circ} 8$

Cálculo del error muestral para las sociedades auditadas

\begin{tabular}{|c|c|}
\hline \multicolumn{2}{|l|}{ EMPRESAS } \\
\hline \multicolumn{2}{|c|}{ Valor Error muestral = } \\
\hline $\mathrm{n}=$ & 316 Muestra \\
\hline$p=$ & 50 probabilidad éxito \\
\hline$q=$ & 50 probabilidad error \\
\hline$N=$ & 15.960 marco muestral \\
\hline$z^{2}=$ & 4,0401 \\
\hline $\mathrm{NC}=$ & $95,50 \%$ nivel de confianza \\
\hline
\end{tabular}

Tabla $\mathrm{n}^{\circ} 9$

Cálculo del error muestral para los auditores

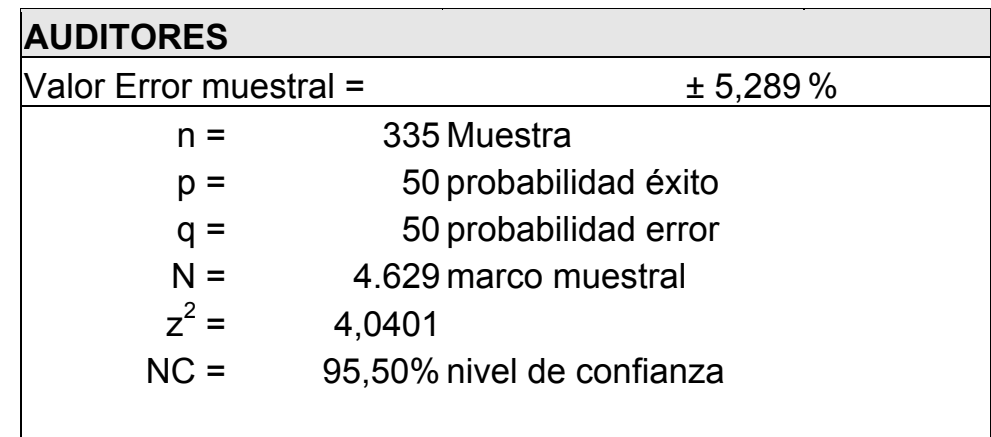

Tabla $n^{\circ} 10$

Cálculo del error muestral para las entidades de crédito

\begin{tabular}{|cc|}
\hline \multicolumn{2}{|l|}{ ENTIDADES DE CRÉDITO } \\
\hline Valor Error muestral $=$ & \\
\hline $\mathrm{n}=$ & $\mathbf{7 9}$ Muestra \\
$\mathrm{p}=$ & 50 probabilidad éxito \\
$\mathrm{q}=$ & 50 probabilidad error \\
$\mathrm{N}=$ & 231 marco muestral \\
$\mathrm{z}^{2}=$ & 2,7725 \\
$\mathrm{NC}=$ & $90,00 \%$ nivel de confianza \\
\end{tabular}


Tabla $n^{\circ} 11$

Cálculo del error muestral para las ag. y soc. de valores

\begin{tabular}{|cc|}
\hline AGENCIAS Y SOCIEDADES DE VALORES \\
\hline Valor Error muestral $=$ & $\pm 12,033 \%$ \\
\hline $\mathrm{n}=$ & 33 muestra \\
$\mathrm{p}=$ & 50 probabilidad éxito \\
$\mathrm{q}=$ & 50 probabilidad error \\
$\mathrm{N}=$ & 104 marco muestral \\
$\mathrm{z}^{2}=$ & 2,7725 \\
$\mathrm{NC}=$ & $90,00 \%$ nivel de confianza \\
\hline
\end{tabular}

\subsubsection{Fuente de datos}

Las fuentes que han servido para elaborar los correspondientes marcos muestrales de cada grupo son:

1. Auditores: El conjunto de los inscritos en el "Registro Oficial de Auditores de Cuentas (ROAC)" publicado anualmente por el Instituto de Contabilidad y Auditoría de Cuentas (ICAC). No obstante, para realizar el pretest, que se remite por fax, la información se ha obtenido de los auditores que aparecen publicados en la "Guía de páginas amarillas" que mantiene la empresa Telefónica a través de su página en Internet.

2. Empresas: El conjunto de sociedades auditadas ha sido obtenido de una base de datos privada denominada "Sistema de Análisis de Balances Españoles" (SABE), y elaborada por las sociedades Bureau Van Dijk e Informa, S.A.

3. Entidades de Crédito: La información relativa a bancos, cajas de ahorros y cooperativas de crédito procede del "Registro Oficial de 
Entidades sujetas al control e inspección del Banco de España", publicadas a través de la página "web" de dicho organismo. Como se produce un segundo envío, a través de fax, la información necesaria se obtiene de la base de datos de "Las 5.000 mayores empresas españolas", publicada por la revista "Actualidad Económica" en su número extra 2.210 de octubre-noviembre de 2000.

4. Analistas Financieros: Los datos relativos a sociedades y agencias de valores provienen del listado publicado por la Comisión Nacional del Mercado de Valores (CNMV) a través del "Registro Oficial de Sociedades y Agencias de Valores", que puede consultarse en la dirección de Internet de la citada Institución. Debido a que se produce un segundo envío, a través de fax, la información necesaria se recaba de la base de datos de "Las 5.000 mayores empresas españolas", publicada por la revista "Actualidad Económica" en su número extra 2.210 de octubrenoviembre de 2000.

\subsubsection{Fechas de circularización y recogida de datos}

Debido a los diferentes métodos utilizados para la obtención de la información, las fechas de envío y recogida de datos se han desarrollado como se detalla a continuación:

- Empresas: En cuanto al "pretest", se les envía por fax el día 6 de febrero de 2000, recibiéndose respuestas durante los 15 días siguientes. La encuesta definitiva se comienza a mandar, a cada una de las comunidades autónomas por orden alfabético, el día 20 de febrero con la Comunidad 
Andaluza, y se concluye con el País Vasco el día 12 de marzo. Como no es posible remitir con éxito todos los cuestionarios, el día 13 de marzo, se procede a intentar un nuevo giro de aquellos que no llegan a su destino y se termina con fecha 22 del mismo mes. Por último, se realiza un segundo reenvío, tanto de los girados con éxito sin respuesta como de los que no se han llegado a remitir, que se inicia el día 24 de abril y finaliza el día 7 de mayo de 2000.

- Auditores: La circularización al grupo de auditores de cuentas ejercientes, que se realiza mediante correo ordinario, se inicia el día 19 de marzo y finaliza el día 25 de abril.

- Entidades de crédito y analistas financieros: La remisión del cuestionario postal, a estos dos grupos, se inicia el día 12 de abril y se concluye el 16 del mismo mes. No obstante se ha procedido a un segundo reenvío por fax entre los días 9 y 14 de mayo de 2000.

\subsubsection{Técnica de recogida de la información}

Se ha recurrido a dos técnicas distintas para recabar la información necesaria para el estudio, de una parte se ha utilizado el "envío mediante fax" y de otra parte el "envío postal". Para las empresas auditadas se usa exclusivamente el fax, para los auditores sólo el envío postal y tanto para las entidades de crédito como para los analistas se combina el envío por correo con el apoyo del fax. Los resultados de la remisión, que son muy satisfactorios ${ }^{39}$, se muestran en la tabla $\mathrm{n}^{\mathrm{0}} 12$.

\footnotetext{
${ }^{39}$ Como indican Dillon et al. (1997), en el caso de encuestas "en frío", es decir en aquellas en las que se envía el cuestionario a un grupo de encuestados que no se ha comprometido previamente a participar, no es lógico esperar que el porcentaje de respuestas supere el 10-20\%. Además en estudios similares como el realizado por García Benau et al. (1993) se obtiene una tasa de respuesta del $15.25 \%$, lo que implica que el porcentaje de éxito alcanzado en las respuestas es muy satisfactorio.
} 
Tabla $n^{\circ} 12$

Tasa de Respuestas recibidas

\begin{tabular}{|l|c|c|c|c|c|}
\hline $\begin{array}{c}\text { Grupos } \\
\text { Encuestados }\end{array}$ & $\begin{array}{c}\text { Muestra } \\
\text { a enviar }\end{array}$ & $\begin{array}{c}\text { Remitidos } \\
\text { con éxito }\end{array}$ & Devueltos & $\begin{array}{c}\text { Respuestas } \\
\text { recibidas }\end{array}$ & $\begin{array}{c}\text { \% de respuesta } \\
\text { s/remitidos con } \\
\text { éxito }\end{array}$ \\
\hline Empresas & 2.000 & 1.365 & n.p. ${ }^{40}$ & 316 & $23.15 \%$ \\
\hline Auditores & 1.500 & 1.401 & 99 & 335 & $23.91 \%$ \\
\hline $\begin{array}{l}\text { Entidades } \\
\text { Crédito }\end{array}$ & 231 & 229 & 2 & 79 & $34.50 \%$ \\
\hline $\begin{array}{l}\text { Analistas } \\
\text { Financieros }\end{array}$ & 104 & 103 & 1 & 33 & $32.04 \%$ \\
\hline \multicolumn{1}{|c|}{ TOTAL } & 3.835 & 3.098 & 102 & 763 & $24.63 \%$ \\
\hline
\end{tabular}

\subsubsection{Representante de las entidades encuestadas}

Las personas a las que se ha dirigido la encuesta han sido, para cada unos de los grupos, las siguientes:

1. Auditores: de manera personalizada ya fueran personas físicas o jurídicas; en el último caso, y debido a que algunas de las sociedades tienen sedes en diferentes comunidades, se ha dirigido la encuesta al "administrador" de cada una de las sucursales, para evitar duplicidades en el envío.

2. Empresas: la encuesta realizada a las sociedades auditadas se ha remitido al "director financiero".

3. Entidades de crédito: el cuestionario de entidades de crédito ha sido enviado a las sedes centrales y concretamente al "departamento de riesgos" encargado de la concesión de financiación a las empresas. 
4. Analistas financieros: para las sociedades y agencias de valores, se ha mandado el cuestionario a la atención del "gerente" como responsable de la firma.

\subsubsection{7. Ámbito de aplicación}

El ámbito de aplicación de la encuesta es "nacional", ya que se persigue que los resultados de la investigación sean representativos de todo el Estado Español. No obstante y por el proceso de estratificación de la muestra se han querido obtener resultados que sean comparables "a nivel regional".

\subsubsection{ELABORACIÓN DEL CUESTIONARIO}

Se han preparado cuatro cuestionarios (véanse Anexos 25, 26 y 27) en función del grupo objetivo encuestado, que fundamentalmente coinciden en sus preguntas pero que, también, incluyen preguntas específicas para los diversos colectivos. En este sentido se han agrupado en los siguientes bloques:

I - Datos personales: bloque que contiene preguntas sobre la situación personal y profesional del encuestado, y que es común para los cuatro grupos entrevistados.

II - Función de la auditoría: que incluye preguntas relativas al propósito que cumple el servicio de auditoría de cuentas. Este apartado recoge las mismas preguntas para auditores y empresas, aunque algunas

\footnotetext{
${ }^{40} \mathrm{Al}$ realizarse el envío a las empresas mediante fax, no se ha producido ninguna devolución, sino que por diversos problemas como errores en el número de teléfono, que la línea comunicara o por cortes en el envío no se ha llegado a remitir todas las encuestas.
} 
menos para entidades financieras y analistas financieros, debido a que se han insertado tres preguntas, sobre la problemática en torno a los servicios multidisciplinares que presta el auditor, sólo para los dos primeros grupos.

III - Utilidad de la auditoría: en el tercer bloque de preguntas se trata el tema de la relevancia que tiene el trabajo del auditor para la toma de decisiones, siendo comunes las preguntas para los cuatro grupos salvo una, que sólo va dirigida a empresas y auditores, debido a problemas de espacio físico en la encuesta.

IV - Comprensión del informe de auditoría: en este apartado se incluyen dos preguntas relativas a los problemas de comprensión que se pueden generar con el informe del auditor y que son comunes para los cuatro grupos.

V - Decisiones de financiación: las cuatro preguntas que contiene esta parte, por razones obvias, se dirigen exclusivamente para el grupo encuestado de entidades de crédito, ya que se les interroga sobre la importancia que tiene el trabajo del auditor para la toma de decisiones de concesión de créditos a empresas.

VI - Decisiones de inversión: por último, en el sexto bloque se relacionan tres cuestiones relativas a la incidencia del trabajo del auditor sobre la toma de decisiones de inversión que llevan a cabo los analistas financieros. 


\subsubsection{Preparación de las preguntas}

Una vez definidas las "variables-objetivo" que se pretenden medir, entre los grupos encuestados, se ha pasado a preparar las cuestiones que sirven para realizar la toma de información que se necesita; para ello se han empleado como referente aquellas que ya han servido con éxito en otras investigaciones similares ${ }^{41}$, y además se ha contado en todo momento con la colaboración de auditores ejercientes y docentes.

Las preguntas se han redactado en "formato cerrado", para conseguir facilitar al encuestado su respuesta, salvo tres de ellas en las que se solicita se informe sobre la edad, los años de experiencia profesional y el puesto en la entidad, con la finalidad de que el entrevistado sea efectivamente la persona a la que va dirigida la encuesta. La respuesta a las cuestiones se ha suministrado mediante una "escala tipo Likert42" graduada entre 1 "total desacuerdo" y 5 "total acuerdo", salvo en el caso de dos preguntas que, aún siendo en "formato cerrado", no se han definido con dicha escala al no adecuarse la misma a las posibilidades de respuesta.

A continuación se hace referencia a los estudios que han servido de base para la inclusión de las distintas preguntas en cada uno de los bloques del cuestionario:

Bloque I - Datos personales -, el primer bloque recoge información sobre la edad, sexo, experiencia profesional, puesto en la empresa, y nivel de estudios de los encuestados, de manera que la información es útil para poder clasificar a los individuos de cada una de las poblaciones objetivo.

\footnotetext{
${ }^{41}$ Según indica Rojas Tejada et al. (1998) utilizar preguntas que hayan sido empleadas con éxito en otras encuestas asegura mayor fiabilidad y mejor comunicación de los resultados.
} 
Bloque II - Función de la Auditoría -, en el segundo bloque se incluyen preguntas sobre la "función" del auditor, que han sido utilizadas por otros investigadores, con una redacción que no tiene por qué ser igual en cuanto a su forma pero sí en cuanto al fondo, tal y como se expone:

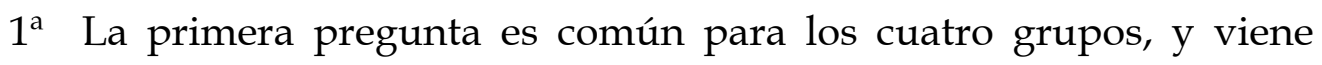
referida a la responsabilidad del auditor. Ya aparece en estudios previos como los desarrollados por Beck (1973), Humphrey, Moizer y Turley (1993), García Benau et al. (1993) y Herrador Alcaide (2000).

$2^{\text {a }}$ La segunda cuestión, que también es la misma para todos los encuestados, versa sobre el propósito de la auditoría de cuentas anuales; además ha sido probada previamente por Innes, Brown y Hatherly (1997).

$3^{\mathrm{a}}$ La tercera pregunta interroga a todos los colectivos sobre los estados contables que son auditados, es utilizada en los estudios de Miller, Reed y Strawser (1990 y 1993).

$4^{\mathrm{a}}$ La cuarta requiere a todos los grupos que se pronuncien sobre la naturaleza del juicio profesional que emite el auditor. Se incluye en estudios como los de Bailey, Bylinski y Shields (1983) y Miller, Reed y Strawser (1990 y 1993).

$5^{\mathrm{a}}$ La quinta pregunta alude a lo que los diferentes colectivos esperan del trabajo del auditor. Utilizada por Beck (1973), Bailey, Bylinski y Shields (1983), Nair y Rittenberg (1987), García Benau et al. (1993), Humphrey, Moizer y Turley (1993) y Innes, Brown y Hatherly (1997).

${ }^{42}$ Como señala Sarabia Sánchez et al. (1999) el uso de la escala Likert tiene las ventajas de que son 
$6^{\mathrm{a}}$ La sexta pregunta, exclusivamente para dos grupos, hace referencia a los servicios multidisciplinares que prestan los auditores. Recogida previamente por Miller, Reed y Strawser (1990 y 1993), Humphrey, Moizer y Turley (1993), García Benau et al. (1993) y Herrador Alcaide (2000).

$7^{\mathrm{a}}$ El séptimo punto, sólo para los grupos de empresas auditadas y auditores, también aborda los servicios multidisciplinares que prestan los auditores. Empleada por Libby (1979), Holt y Moizer (1990), Humphrey, Moizer y Turley (1993), García Benau et al. (1993) y Innes, Brown y Hatherly (1997).

$8^{\text {a }}$ El octavo tema, únicamente para empresas y auditores, trata el importante tema de la responsabilidad del auditor al informar sobre ilegalidades. Desarrollada en Humphrey, Moizer y Turley (1993), García Benau et al. (1993), el Informe MARC (1996), el "Libro Blanco" del IACJC (1997) y Herrador Alcaide (2000).

$9^{a}$ La novena cuestión interroga sobre la existencia de insatisfacción entre los encuestados sobre la función de la auditoría. Tratada en el Informe MARC (1996) y el “Libro Blanco” del IACJC (1997).

Bloque III - Utilidad de la auditoría -, la tercera parte de la encuesta incluye cuestiones relativas a la "utilidad" asociada al servicio de auditoría de cuentas, y las preguntas versan sobre los temas siguientes:

$10^{\text {a }}$ Para el grupo de empresas y auditores constituye la décima cuestión, sin embargo para entidades financieras y analistas es la

escalas fáciles de entender y de construir además de tener validez y fiabilidad alta. 
número siete. En ésta se trata sobre diferentes puntos relacionados con la relevancia del informe y la utilidad del servicio. Tratado por Beck (1973), Miller, Reed y Strawser (1990 y 1993), Humphrey, Moizer y Turley (1993), García Benau et al. (1993), el Informe MARC (1996) y Herrador Alcaide (2000).

$11^{\mathrm{a}}$ La pregunta undécima se realiza sólo a auditores y sociedades, y se les encuesta sobre los terceros interesados en el trabajo del auditor.

$12^{\mathrm{a}}$ La cuestión número doce de auditores y sociedades, que equivale a la octava para los otros dos colectivos, versa sobre la utilidad del trabajo del auditor en la toma de decisiones de gestión por la empresa. Las investigaciones que han preguntado de forma similar son las de Libby (1979), Bailey, Bylinski y Shields (1983), Nair y Rittenberg (1987), Mayper, Welker y Wiggins (1988), Robertson (1988), Holt y Moizer (1990), Miller, Reed y Strawser (1990 y 1993), Humphrey, Moizer y Turley (1993), García Benau et al. (1993), Innes, Brown y Hatherly (1997) y Herrador Alcaide (2000).

$13^{\mathrm{a}}$ La decimotercera pregunta de la encuesta de auditores y sociedades se corresponde con la novena de los analistas y entidades financieras, en ella se hace mención a la necesidad o no de que el auditor amplíe su cometido. Son cuestiones ya tratadas en el Informe MARC (1996) y Herrador Alcaide (2000).

Bloque IV - Comprensión del informe -, en el cuarto apartado de la encuesta se encuentran preguntas relativas al "grado de comprensión" del informe que elabora y emite el auditor como resultado de su trabajo. 
$14^{\mathrm{a}}$ En la decimocuarta pregunta para auditores y empresas que equivale a la décima para los demás encuestados, se pregunta sobre la cantidad de informes de auditoría leídos por los encuestados y sirve como "pregunta de control", para verificar que se conozca realmente el dictamen que emite el auditor.

$15^{\mathrm{a}}$ En esta cuestión se aborda el problema de la comprensión del informe por el lenguaje técnico, problemas de redacción, etc. Tema tratado en Dillar y Jensen (1983), Mayper, Welker y Wiggins (1988), Miller, Reed y Strawser (1990 y 1993), Informe MARC (1996), Innes, Brown y Hatherly (1997) y Herrador Alcaide (2000).

Bloque V - Decisiones de financiación -, la quinta parte de la encuesta se destina únicamente a entidades de crédito para captar la percepción que tienen, las personas encargadas de la concesión de préstamos a las empresas, sobre la relevancia del informe del auditor y el tipo de opinión que emite.

$16^{\text {a }}$ Se corresponde con la pregunta decimosegunda de la encuesta a entidades financieras, en la que se les solicita expresen su grado de acuerdo sobre si el informe es o no fundamental para obtener determinados servicios de dichas entidades.

$17^{\text {a }}$ La siguiente cuestión se refiere al tipo de información que las entidades de financiación consideran más importante al conceder un préstamo. Recogida en los estudios de Libby (1979), Firth (1980), Mayper, Nair y Rittenberg (1987) y Welker y Wiggins (1988). 
$18^{\mathrm{a}}$ La pregunta decimocuarta de las entidades financieras cuestiona la relevancia del tipo de opinión del informe sobre las decisiones de financiación. Planteada por Firth (1980) y Geiger (1992).

$19^{a}$ La última interrogante que se plantea a bancos, cajas de ahorros y cooperativas de crédito, viene referida al grado de trascendencia de las distintas "salvedades" que se incluyen en los informes. Tema investigado previamente por Libby (1979), Nair y Rittenberg (1987) y Mayper, Welker y Wiggins (1988).

Bloque VI - Decisiones de inversión -, el bloque final de la encuesta se dirige exclusivamente a sociedades y agencias de valores con la intención de contrastar la relevancia del trabajo del auditor en las "decisiones de inversión" que éstas realizan.

$20^{\mathrm{a}}$ En la pregunta duodécima de analistas se plantea la importancia del informe frente a otro tipo de información a la hora de invertir.

$21^{\mathrm{a}}$ En la siguiente se alude a la importancia de la opinión del auditor sobre la decisión y cuantía de la inversión.

$22^{a}$ Para finalizar se exponen los distintos tipos de "salvedades" para valorar su incidencia en la toma de decisiones de los inversores. Tratado en Bailey, Bylinski y Shields (1983) y Innes, Brown y Hatherly (1997). 


\subsubsection{Pretest}

Durante el proceso de preparación del cuestionario, que ha sido dilatado, se ha contado con la experiencia profesional de auditores de cuentas ejercientes, así como de profesionales relacionados con la banca y el mercado bursátil, también se ha contado con las recomendaciones de profesores universitarios de las áreas relacionadas con cada uno de los colectivos objeto de estudio. Una vez preparada la encuesta se ha realizado un "pretest" que ha servido, fundamentalmente, para observar aquellas preguntas que podían plantear problemas por su redacción o exposición, como, también, para obtener un índice orientativo de la "tasa de respuesta esperada" para la encuesta definitiva que sirviera como información relevante al estudiar el tamaño de la muestra.

El "pretest" se ha realizado exclusivamente con los grupos de auditores y empresas auditadas, debido a que para las poblaciones de entidades de crédito y agencias y sociedades de valores, por ser muy reducidas, se estimó oportuno no realizar un "muestreo aleatorio" sino enviarlo a la totalidad de los individuos. Para el caso de los auditores se ha tomado una "muestra no aleatoria" de 44 casos, a los que se les remite la encuesta a través de fax cuyos números se obtienen de la "Guía Páginas Amarillas" publicada por la empresa Telefónica en Internet, recibiéndose 13 respuestas que suponen una tasa de respuesta del 29.5\%. En el caso de empresas auditadas la selección se realiza de forma aleatoria con 106 individuos, a los que se les envía el cuestionario mediante números de fax obtenidos de la base de datos "SABE", de ellos se reciben de conformidad 19 que implican una tasa de respuesta del $17.9 \%$. 


\subsubsection{Documentación remitida al encuestado}

A los diferentes grupos encuestados se les ha enviado la siguiente documentación, en función del procedimiento empleado para la recogida de datos:

- En los casos en que se ha utilizado el fax, se ha remitido una primera hoja de portada, además se ha adjuntado una segunda hoja con una "carta de presentación" en la que se expone el motivo de la investigación (véase Anexos 23 y 24), firmada por el doctorando con el visto bueno del director, para finalizar con la "encuesta" en dos hojas.

- En los casos que se ha remitido la encuesta mediante correo ordinario, se incluye la misma "carta de presentación" junto a la "encuesta" en una hoja a dos caras y un sobre franqueado para devolver.

\subsubsection{Fiabilidad del cuestionario}

Para verificar la fiabilidad del cuestionario, entendiéndola como consistencia interna, es decir, como coherencia y estabilidad cuando las mismas cuestiones se aplican varias veces a la hora de medir las variables cualitativas de la "función de la auditoría de cuentas", la "utilidad del servicio de auditoría", la "comprensión del informe", para los cuatro grupos encuestados (empresas auditadas, auditores de cuentas, entidades financieras y analistas financieros), así como la "relevancia del informe" para las decisiones de financiación e inversión que toman las entidades financieras y las agencias y sociedades de valores, se ha aplicado el modelo de 
consistencia interna desarrollado por Cronbach, en 1951, y conocido por "Método alfa de Cronbach"3".

Así una vez aplicado el "análisis de la fiabilidad" se han obtenido los siguientes resultados:

- Para el primer bloque, que agrupa las cuestiones sobre la "función" del auditor, se ha obtenido un valor de " $\alpha=0.7677$ ".

- Con el segundo bloque, que aglutina las preguntas relativas a la "utilidad" del servicio que presta el auditor, se consigue un valor de “ $\alpha=0.7098 "$.

- El tercer bloque incluye cuestiones relativas a la "comprensión" del informe que emite el auditor, para el que se obtiene un valor de " $\alpha=$ $0.1287^{\prime \prime}$.

- Para el cuarto bloque, que recoge las preguntas sobre las "decisiones de financiación" que toman las entidades de crédito, se ha obtenido un valor de " $\alpha=0.8488$ ".

- El quinto bloque incluye las cuestiones que miden la relevancia del informe de auditoría en las “decisiones de inversión”, que adoptan las agencias y sociedades de valores, para las que se ha estimado un valor de " $\alpha=0.7977$ ".

\footnotetext{
${ }^{43} \mathrm{La}$ fórmula que define el coeficiente alfa se concreta como $\alpha=\frac{N \bar{p}}{1+\bar{p}(N-1)}$ donde $N$ es el número de cuestiones planteadas y $\bar{p}$ es la media de la correlación entre ítems, tomando $\alpha$ valores entre 0 y 1 ,
} 
De los valores de fiabilidad obtenidos se puede concluir que, en general, el cuestionario tiene una consistencia interna aceptable ${ }^{44}$, salvo en el caso del bloque relativo a la “comprensión" del informe de auditoría para el que se obtiene un valor pequeño que señala una coherencia interna baja, siendo indicativo de que el número de cuestiones empleadas para medir la comprensión del informe se ha quedado escaso y que las correlaciones entre las cuestiones son reducidas.

\subsubsection{METODOLOGÍA EMPLEADA EN EL ANÁLISIS DE DATOS}

\subsubsection{Grabación y Validación de la información}

Una vez recogida la información, la misma ha sido grabada manual y directamente en una hoja especialmente preparada para la encuesta, donde se han predefinido las "variables" y sus posibles valores a través del programa estadístico "SPSS (Statistical Package for the Social Sciencies) versión 10.0". Una vez procesada la información, con el fin de evitar errores humanos, se ha realizado en primer lugar un "control estadístico de rangos", para cada variable, con el fin de detectar valores anómalos que han sido corregidos, además y mediante selección aleatoria se ha verificado una muestra de cada uno de los grupos objeto de estudio, siendo los fallos encontrados despreciables.

En cuanto al problema de los "casos perdidos", es decir, aquellas cuestiones no respondidas por los encuestados, ya sea de manera deliberada

de forma que cuanto mayor es su valor más consistencia interna tiene la escala.

44 Según señala Sarabia et al. (1999), considerando las recomendaciones de Nunnally (1987) y Peterson (1994), se suele considerar un valor de alfa igual a 0.7 como el nivel mínimo para investigación preliminar, 0.8 para investigación básica y 0.9 para investigación aplicada. No obstante otros autores como Camacho Rosales (2000) indica que un valor de alfa de 0.67 implica un coeficiente de fiabilidad moderadamente alto. 
o por desconocimiento, se han considerado despreciables estadísticamente por su bajo número e influencia en los resultados obtenidos.

\subsubsection{Técnicas empleadas en la exploración de datos}

Para comenzar el análisis de los datos obtenidos en la encuesta se ha realizado un estudio exploratorio mediante la aplicación de "estadística descriptiva" a través de la exposición con tablas y gráficos, estadísticos básicos y frecuencias de la información sobre las características específicas de las poblaciones objeto de estudio.

\subsubsection{Técnicas empleadas en el análisis avanzado de datos}

Una vez realizado un estudio descriptivo de la información recogida se ha pasado a la "contrastación de las hipótesis" planteadas, mediante las técnicas estadísticas que la doctrina contable ha utilizado en estudios similares, además se ha procedido a la ampliación con otras técnicas que han servido para una mejor interpretación y obtención de conclusiones relevantes.

En primer lugar se ha verificado la "normalidad" de las distribuciones con la prueba de "Kolmogorov-Smirnov" que, para cada una de las muestras del estudio (auditores, empresas, entidades de crédito y sociedades y agencias de valores), compara la función de distribución acumulada de las variables a estudiar con la "distribución normal", con la finalidad de contrastar si las observaciones podrían razonablemente proceder de la mencionada "distribución normal". En el caso de que se obtuviera que alguna de las muestras se comporta siguiendo una "distribución normal" se ha realizado una segunda prueba, aún más restrictiva, que consiste en aplicar 
el procedimiento de "Kolmogorov-Smirnov" con un nivel de significación de "Lillefors", para ratificar la normalidad o no de las distribuciones.

La finalidad de comprobar la "normalidad" o no de las distribuciones muestrales no ha sido otra que la de determinar el tipo de pruebas estadísticas aplicables para la verificación de las hipótesis, de manera que la "no normalidad" debiera conducir al empleo de unas pruebas u otras, teniendo en cuenta que determinados autores llegan a utilizar pruebas paramétricas ${ }^{45}$, para los casos que se verifica la normalidad de las distribuciones, aún cuando las variables analizadas son de "naturaleza ordinal".

La contrastación de las percepciones que los encuestados muestran se ha llevado a cabo mediante la aplicación del "análisis de la varianza en un sentido de una clasificación por rangos de Kruskal-Wallis", dicha prueba ofrece un contraste no paramétrico para comprobar si más de dos muestras independientes pertenecen a diferentes poblaciones. Mientras la prueba " $\mathrm{U}$ de Mann Whitney" se ha empleado para valorar la significatividad estadística de la diferencia entre los valores medios obtenidos de dos muestras independientes.

Una vez realizados los "test no paramétricos", y siguiendo la metodología de estudios previos, se han aplicado "test paramétricos", como el "análisis de la varianza en un sentido" (ANOVA) para más de dos muestras, así como la "prueba T" para dos muestras independientes, con el

\footnotetext{
${ }^{45}$ Mayper et al. (1988) emplean junto a pruebas no paramétricas como el test de Mann-Whitney otras paramétricas como la $T^{2}$ de Hotelling, la prueba t para parejas. Holt y Moizer (1990) emplean junto a la prueba de Mann-Whitney el test tanto paramétrico como no paramétrico de los Rangos de Wilcoxon. Kelly et al. (1989) utilizan junto al test de Kruskal-Wallis las pruebas paramétricas de la $t$ de student así como la ANOVA. Bailey et al. (1983) utilizan la prueba para escalas de intervalo-razón ANOVA en el caso de variables ordinales, al igual que Carcello et al. (1992). No obstante y al ser la mayoría de
} 
fin de corroborar o no los resultados obtenidos anteriormente. Las pruebas post-hoc de "Tukey" y "Tamhane" se han empleado para comprobar el origen de las diferencias intergrupos. Por último, se ha desarrollado un "análisis factorial46" con la finalidad de condensar la información en aquellos factores que mejor definen cada una de las variables estudiadas.

\subsubsection{LIMITACIONES DEL ESTUDIO}

- Debido al escaso "marco muestral" de los grupos de entidades de crédito y agencias y sociedades de valores, y a pesar de obtener unos porcentajes de respuesta elevados, el "error muestral" es excesivo sobre todo en el caso del grupo de analistas de inversiones, a su vez el "nivel de confianza" establecido para ambos grupos es bajo.

- Los resultados obtenidos para el grupo de sociedades y agencias de valores no son generalizables al conjunto de analistas financieros.

- El "marco muestral" representativo de la población de empresas auditadas se queda reducido en exceso, debido al método empleado en la recogida de la información.

- Como es característico en todas las "investigaciones de opinión", las cuestiones empleadas para medir las variables objeto de estudio conllevan un cierto grado de subjetividad, que ha sido limitado por el empleo de preguntas que habían sido utilizadas en estudios previos con éxito para medir lo mismo.

\footnotetext{
variables que se miden de naturaleza ordinal, deben aplicarse pruebas no paramétricas como señalan numerosos autores, véase Dillon et al. (1997), Sarabia et al. (1999) y Ato García (1991).

${ }^{46}$ Hair et al. (1999) señalan que "a la hora de resumir los datos, con el análisis factorial se obtiene unas dimensiones subyacentes que, cuando son interpretadas y comprendidas, describen los datos con un número de conceptos mucho más reducido que las variables individuales originales".
} 
- Las preguntas no han sido contestadas siempre por los individuos a quienes iba dirigida la encuesta $y$, por tanto, los resultados pueden no ser siempre válidos.

- La baja fiabilidad del cuestionario para una de las hipótesis puede condicionar la validez de la contrastación de la variable cualitativa "comprensión del informe de auditoría", pero nunca las conclusiones obtenidas para cada una de las cuestiones de forma individualizada. 


\subsection{ANÁLISIS DE LOS RESULTADOS}

\subsubsection{ANÁLISIS DESCRIPTIVO}

Una primera aproximación a los datos ha consistido en realizar un "análisis descriptivo" de los rasgos principales que caracterizan los diferentes grupos encuestados.

En la tabla $\mathrm{n}^{\circ} 13$ se muestran las respuestas totales obtenidas para cada una de las poblaciones estudiadas, así el total de encuestas recibidas ya sea mediante fax o por correo asciende a 763, de las que 316 corresponden a empresas auditadas, 335 provienen de auditores tanto personas físicas como jurídicas, 79 son cuestionarios de entidades de crédito y 33 de agencias y sociedades de valores.

Tabla $\mathrm{n}^{\mathrm{o}} 13$

Número de Encuestas recibidas por Grupos de Estudio

\begin{tabular}{|l|c|c|c|}
\hline \multicolumn{1}{|c|}{ Grupos de estudio } & Frecuencia & Porcentaje & $\begin{array}{c}\text { Porcentaje } \\
\text { acumulado }\end{array}$ \\
\hline Empresas & 316 & $41.4 \%$ & 41.4 \\
Auditores & 335 & $43.9 \%$ & 85.3 \\
Entidades de crédito & 79 & $10.4 \%$ & 95.7 \\
Agencias y sociedades de valores & 33 & $4.3 \%$ & 100.0 \\
\hline \multicolumn{2}{|c|}{ Total } & 763 & $100.0 \%$ \\
\hline
\end{tabular}

En términos porcentuales el grupo más representado es el de auditores de cuentas con el $43.9 \%$ (ver gráfico $\mathrm{n}^{\mathrm{o}} 1$ ), seguido por el grupo de empresas con el $41.4 \%$, las entidades de crédito con el $10.4 \%$ y el grupo de agencias y sociedades de valores con el $4.3 \%$, que puede parecer bajo pero que en términos relativos supone una tasa de respuesta muy alta del $31.7 \%$, sobre el total de agencias y sociedades de valores circularizadas que ascendía 
a 104. Del mismo modo las 79 respuestas remitidas por bancos, cajas de ahorros y cajas rurales suponen $10.4 \%$ del total en términos absolutos, pero en términos relativos implica una "tasa de éxito" del 34.19\%.

Gráfico $n^{\circ} 1$

Respuestas recibidas en términos porcentuales

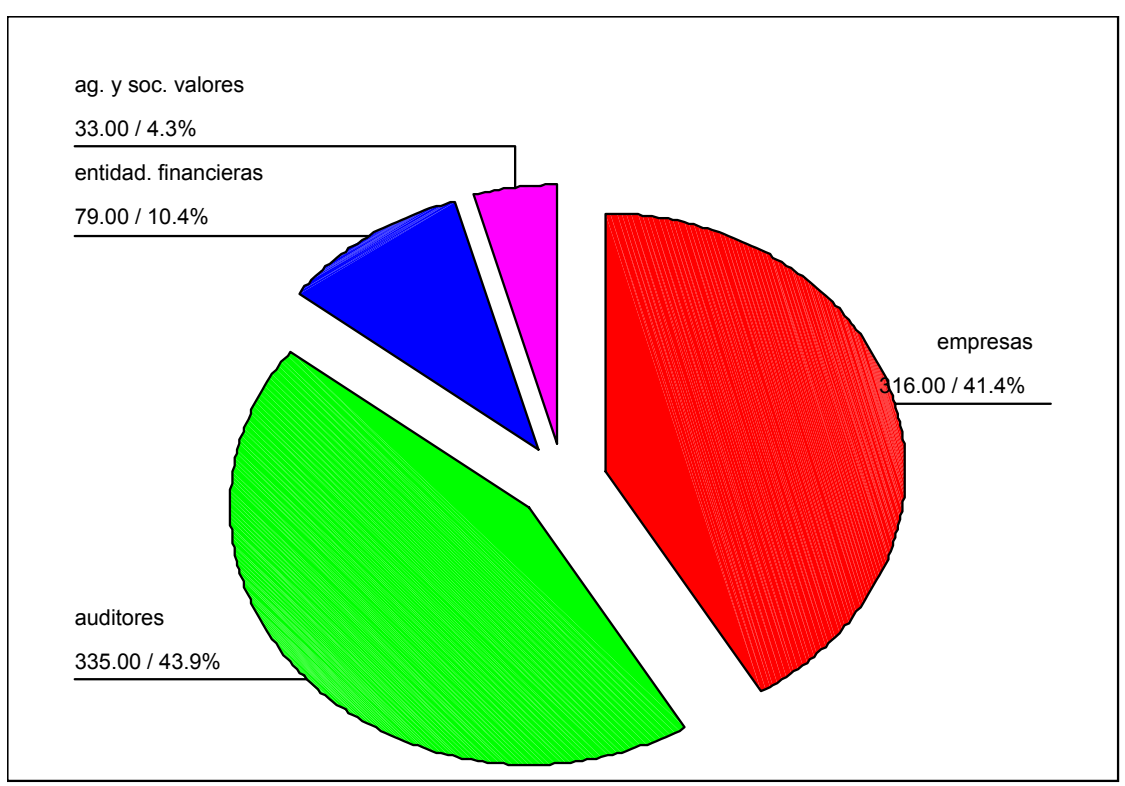

En cuanto al grado de respuesta por Comunidades Autónomas como se observa, tanto en la tabla $n^{\circ} 14$ como en el gráfico $n^{\circ} 2$, el número mayor de cuestionarios se ha recibido de Cataluña con 155 respuestas, pertenecientes a todos los grupos que se estudian, seguido de la Comunidad de Madrid con 152, Valencia con 88, Andalucía con 78, País Vasco con 52, Castilla-León con 45, Galicia con 39, Murcia con 27, Aragón con 26, Asturias con 25, Navarra con 13, Castilla-La Mancha con 11, Cantabria y la Rioja con 10, Baleares, Canarias y Extremadura con 9, mientras que no se ha recibido contestación alguna ni de Ceuta ni de Melilla, aunque su representación en el conjunto es poco significativa. Del total de encuestas han resultado "inclasificables" 5 cuestionarios por no disponer de dicha información. 
Tabla ${ }^{\circ} 14$

Número de Respuestas recibidas por CCAA

\begin{tabular}{|c|c|c|}
\hline CCAA & Frecuencia & Porcentaje \\
\hline Andalucía & 78 & $10.2 \%$ \\
\hline Aragón & 26 & $3.4 \%$ \\
\hline Asturias & 25 & $3.3 \%$ \\
\hline Baleares & 9 & $1.2 \%$ \\
\hline Canarias & 9 & $1.2 \%$ \\
\hline Cantabria & 10 & $1.3 \%$ \\
\hline Castilla León & 45 & $5.9 \%$ \\
\hline Castilla la Mancha & 11 & $1.4 \%$ \\
\hline Cataluña & 155 & $20.3 \%$ \\
\hline Extremadura & 9 & $1.2 \%$ \\
\hline Galicia & 39 & $5.1 \%$ \\
\hline Madrid & 152 & $19.9 \%$ \\
\hline Murcia & 27 & $3.5 \%$ \\
\hline Navarra & 13 & $1.7 \%$ \\
\hline La Rioja & 10 & $1.3 \%$ \\
\hline Valencia & 88 & $11.5 \%$ \\
\hline País Vasco & 52 & $6.8 \%$ \\
\hline \multirow{3}{*}{$\begin{array}{c}\text { Subtotal } \\
\text { Casos perdidos } \\
\text { TOTAL }\end{array}$} & 758 & $99.3 \%$ \\
\hline & 5 & $0.7 \%$ \\
\hline & 763 & $100.0 \%$ \\
\hline
\end{tabular}

Gráfico $n^{\circ} 2$

Respuestas recibidas por CCAA



Dentro del grupo de auditores se ha distinguido entre aquellos que ejercen de forma individual frente a las sociedades de auditoría, en términos 
absolutos, tal y como se refleja en el gráfico $n^{\circ} 3$, se han recibido respuestas de 234 auditores individuales y de 100 sociedades.

Gráfico n 3

Número de cuestionarios de auditores según su forma jurídica

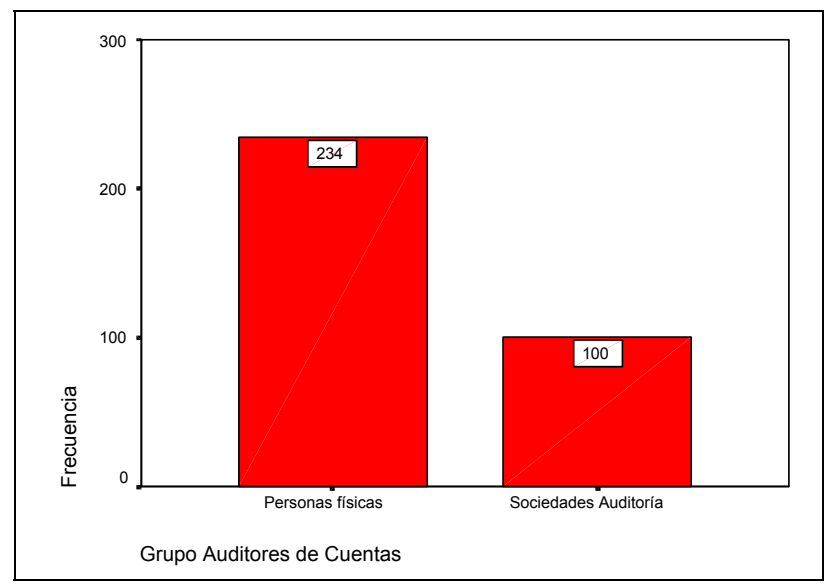

Para el caso de las entidades de crédito, que se han subclasificado atendiendo a la forma jurídica de las mismas, ya fueran Bancos, Cajas de Ahorros o Cajas Rurales, el número de cuestionarios recibidos ha sido de 19 procedentes de bancos, 26 de cajas de ahorros y 34 de cajas rurales.

Gráfico n ${ }^{\circ} 4$ Número de cuestionarios de entidades de crédito según su forma jurídica

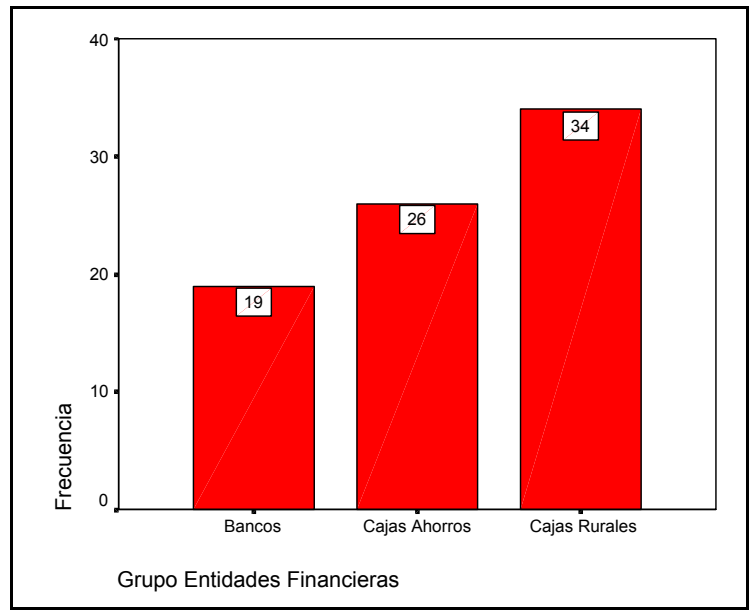


En cuanto al grupo de analistas financieros, representados por las agencias y sociedades de valores, se observa en el gráfico $n^{\circ} 5$, que el número de encuestas recibidas es de 14 de agencias de valores y 17 de sociedades.

Gráfico $n^{\circ} 5$

Número de encuestas de ag. y soc. de valores según su forma jurídica

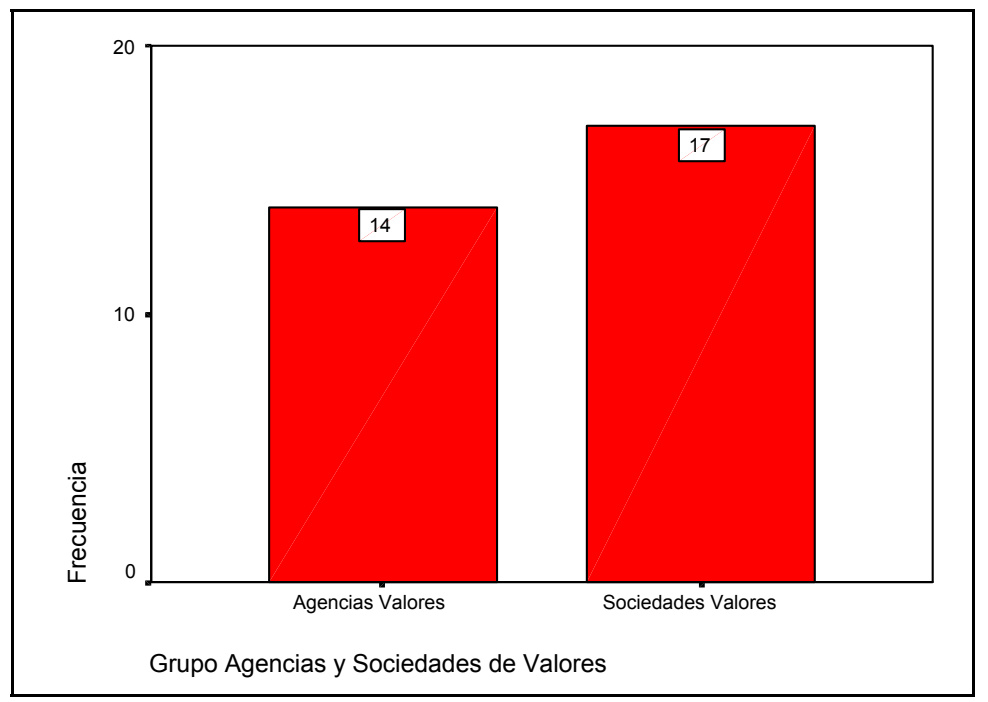

Como se refleja en la tabla $n^{\circ} 15$ la mayoría de encuestados son de sexo masculino, ya que aparecen 644 hombres frente a 92 mujeres, y en valores porcentuales suponen el $87.5 \%$ del total.

Tabla $n^{\circ} 15$

Sexo de los encuestados por grupos de estudio

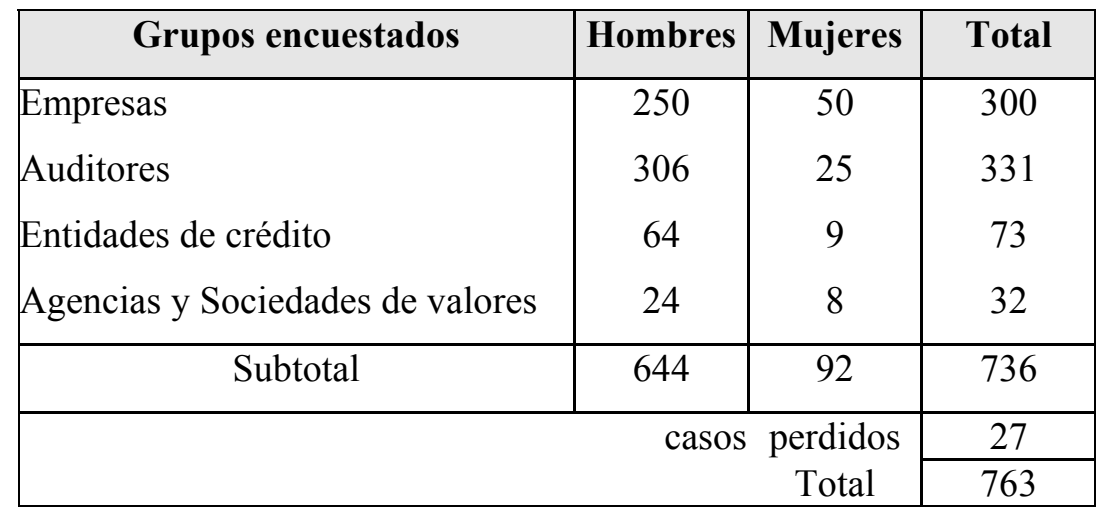


Tabla $\mathrm{n}^{\mathrm{o}} 16$

Edad de los encuestados por grupos de estudio

\begin{tabular}{|c|c|c|c|c|c|}
\hline \multirow{2}{*}{ Grupos de estudio } & \multicolumn{4}{|c|}{ Edad (en años) } & \multirow{2}{*}{ Total } \\
\hline & $20<X \# 30$ & $30<X \# 40$ & $40<X \# 50$ & $\mathbf{5 0}<\mathrm{X}$ & \\
\hline Empresas & 38 & 122 & 87 & 56 & 303 \\
\hline Auditores & 10 & 78 & 120 & 120 & 328 \\
\hline Entidades de crédito & 4 & 28 & 33 & 12 & 77 \\
\hline Agencias y soc. de valores & 4 & 11 & 10 & 7 & 32 \\
\hline Subtotal & 56 & 239 & 250 & 195 & 740 \\
\hline \multicolumn{5}{|c|}{ casos perdidos } & 23 \\
\hline & & & \multicolumn{2}{|c|}{ Total } & 763 \\
\hline
\end{tabular}

Como se observa, en la tabla $n^{0} 16$, la mayor parte de los encuestados se encuentra en una franja de edad comprendida entre los 30 y 50 años, cuyo montante asciende a 489 individuos del total.

Tabla $n^{\circ} 17$

Experiencia profesional de los encuestados por grupos de estudio

\begin{tabular}{|c|c|c|c|c|c|}
\hline \multirow{2}{*}{ Grupos de estudio } & \multicolumn{4}{|c|}{ Experiencia profesional (en años) } & \multirow{2}{*}{ Total } \\
\hline & $1<X \# 5$ & $5<X \# 10$ & $10<X \# 20$ & $20<X$ & \\
\hline Empresas & 35 & 71 & 116 & 81 & 303 \\
\hline Auditores & 37 & 73 & 158 & 60 & 328 \\
\hline Entidades de crédito & 5 & 14 & 26 & 32 & 77 \\
\hline Agencias y soc. de valores & 2 & 6 & 15 & 9 & 32 \\
\hline Subtotal & 79 & 164 & 315 & 182 & 740 \\
\hline \multicolumn{5}{|c|}{ casos perdidos } & 23 \\
\hline & & & \multicolumn{2}{|c|}{ Total } & 763 \\
\hline
\end{tabular}

Según se aprecia, en la tabla $n^{\circ} 17$, la mayoría de encuestados posee una experiencia profesional que oscila entre 10 y 20 años, donde se 
encuentran 315 casos; a continuación aparecen 182 individuos cuya experiencia supera los veinte años.

En la tabla $\mathrm{n}^{\mathrm{o}} 18$ se ha detallado el puesto desempeñado por las personas que han contestado la encuesta, clasificadas por grupos de estudio y bajo ocho posibilidades según fuera: director financiero, gerente, contable, auditor, en diferentes puestos, y analista tanto de riesgos como financiero.

Tabla $\mathrm{n}^{\mathrm{o}} 18$

Puesto desempeñado por el encuestado por grupos de estudio

\begin{tabular}{|c|c|c|c|c|c|}
\hline \multirow[b]{2}{*}{ Puesto de trabajo } & \multicolumn{4}{|c|}{ Grupos encuestados } & \multirow[b]{2}{*}{ Total } \\
\hline & Empresas & Auditores & \begin{tabular}{|c|} 
Entidades \\
Financieras
\end{tabular} & $\begin{array}{l}\text { Ag. y Soc. } \\
\text { de Valores }\end{array}$ & \\
\hline Director financiero & 201 & & & 5 & 206 \\
\hline Director gerente & 41 & & & 7 & 48 \\
\hline Contable & 25 & & & 2 & 27 \\
\hline Auditor individual & & 130 & & & 130 \\
\hline Auditor administrador & & 70 & & & 70 \\
\hline Auditor socio & & 75 & & & 75 \\
\hline Analista de riesgos & & & 47 & & 47 \\
\hline Analista de inversión & & & & 4 & 4 \\
\hline Otros & 19 & 3 & 28 & 11 & 61 \\
\hline Subtotal & 286 & 278 & 75 & 29 & 668 \\
\hline & & & \multirow{2}{*}{\multicolumn{2}{|c|}{$\begin{array}{c}\text { casos perdidos } \\
\text { Total }\end{array}$}} & 95 \\
\hline & & & & & 763 \\
\hline
\end{tabular}

Del total de las 763 encuestas recibidas han sido clasificadas 668, contabilizándose 95 casos perdidos porque no se ha rellenado dicho campo. Dentro de la opción de otros empleos se han tenido que incluir 61 individuos con puestos tan dispares como: "director de impuestos", "consejero delegado", "auditor interno", "director de planificación", "auxiliar administrativo", "director de control de gestión", etc. 
Tabla $\mathrm{n}^{\mathrm{o}} 19$

Nivel de estudios por grupos encuestados

\begin{tabular}{|c|c|c|c|c|c|}
\hline \multirow[b]{2}{*}{ Grupos de estudio } & \multicolumn{4}{|c|}{ Nivel de Estudios } & \multirow[b]{2}{*}{ Total } \\
\hline & $\begin{array}{c}\text { Estudios } \\
\text { primarios }\end{array}$ & Bachiller-Fp & \begin{tabular}{|c|} 
Estudios \\
Univ. grado \\
medio
\end{tabular} & \begin{tabular}{|c|} 
Estudios \\
Univ. grado \\
superior \\
\end{tabular} & \\
\hline Empresas & 4 & 38 & 55 & 196 & 293 \\
\hline Auditores & 2 & 4 & 43 & 276 & 325 \\
\hline Entidades de crédito & 1 & 6 & 11 & 55 & 73 \\
\hline Agencias y soc. de valores & - & 2 & 2 & 29 & 33 \\
\hline Subtotal & 7 & 50 & 111 & 556 & 724 \\
\hline \multicolumn{5}{|c|}{$\begin{array}{c}\text { casos perdidos } \\
\text { Total }\end{array}$} & $\begin{array}{c}39 \\
763\end{array}$ \\
\hline
\end{tabular}

En la tabla $n^{0} 19$ se muestra el nivel de formación de los encuestados por grupos de estudio, y se puede observar que la gran mayoría de los individuos se caracteriza por tener "estudios universitarios" de grado superior 556, o medio 111, frente a 57 que no los han cursado. Tanto en valores absolutos como relativos el grupo de auditores es el que obtiene una mayor tasa de profesionales cualificados con estudios universitarios con el 98.1\%, seguido de agencias y sociedades de valores con el 93.3\%, entidades financieras con el $90.4 \%$ y por último las sociedades auditadas con el $85.6 \%$.

En el cuadro siguiente se aprecian los 202 individuos encuestados con "estudios de postgrado", frente a 543 que no los tienen, encontrándose 18 casos que aparecen sin valor y se consideran perdidos.

Tabla $n^{\circ} 20$

Estudios de postgrado por grupos de estudio

\begin{tabular}{|c|c|c|c|}
\hline \multirow{2}{*}{ Grupos de estudio } & \multicolumn{2}{|c|}{ Estudios de Postgrado } & \multirow{2}{*}{ Total } \\
\hline & si & no & \\
\hline Empresas & 75 & 229 & 304 \\
\hline Auditores & 93 & 239 & 332 \\
\hline Entidades de crédito & 21 & 55 & 76 \\
\hline Agencias y soc. de valores & 13 & 20 & 33 \\
\hline Subtotal & 202 & 543 & 745 \\
\hline & \multirow{2}{*}{\multicolumn{2}{|c|}{$\begin{array}{r}\text { casos perdidos } \\
\text { Total }\end{array}$}} & 18 \\
\hline & & & 763 \\
\hline
\end{tabular}




\subsubsection{CONTRASTACIÓN DE LAS HIPÓTESIS}

\subsubsection{Primera hipótesis}

- Aplicación del test de Kolmogorov-Smirnov para la hipótesis $H_{01}$

Lo primero que se ha realizado han sido las pruebas de "normalidad" de las distribuciones, que muestran los diferentes grupos de estudio, para cada uno de los ítems, y para ello se ha aplicado el test de "KolmogorovSmirnov" 47 en función de la hipótesis a contrastar.

La hipótesis nula que se ha planteado en primer lugar se define como:

$\mathrm{H}_{01}$ : Los auditores, sociedades auditadas, entidades de crédito (representadas por Bancos, Cajas de Ahorros y Cajas Rurales) y analistas financieros (representados por Agencias y Sociedades de Valores) muestran la misma percepción sobre la función que cumple el servicio de auditoría de cuentas.

Para contrastar dicha hipótesis se han empleado las respuestas realizadas entre las cuestiones primera y quinta de las cuatro encuestas preparadas para los diferentes grupos de estudio.

Las pruebas de "Kolmogorov-Smirnov", que se incluyen en los Anexos, se han estructurado recogiendo en la primera columna las cuestiones planteadas a los cuatro grupos encuestados, el número de

${ }^{47}$ Como señala Daniel (1999: 723) en la prueba de bondad de ajuste de Kolmogorov-Smirnov se efectúa una comparación entre alguna función teórica de distribución acumulativa (en este caso se toma la distribución Normal) $\mathrm{F}_{T}(\mathrm{x})$, y una función muestral de distribución acumulativa $\mathrm{F}_{M}(\mathrm{x})$. La diferencia entre ambas distribuciones se mide con el estadístico D que se define como la máxima 
respuestas válidas, las "medias" y "desviaciones típicas" de las distribuciones, el valor del estadístico definido por "Kolmogorov-Smirnov" y la "significatividad".

Como se desprende del Anexo 1 ninguno de los constructos empleados, para medir la función que los diferentes grupos asignan al auditor de cuentas, se comporta para el caso de las empresas con "normalidad".

Al igual que para el grupo de empresas, con el de auditores se observa que aplicando la prueba de "normalidad" se obtiene que ninguno de los ítems planteados sigue dicha distribución, tal y como se aprecia al revisar la columna de los valores que toma la "significatividad asintótica bilateral" que aparece en el Anexo 2.

El Anexo 3 se estructura como los anteriores, y también muestra que, para el caso del grupo entidades financieras (Bancos, Cajas de Ahorros y Cajas Rurales), tampoco se cumple la condición de "normalidad" de las distribuciones, como se comprueba al observar la columna de la significatividad.

A diferencia de los grupos anteriores, para el caso de las agencias y sociedades de valores, se advierte, según el Anexo 4, que para determinados ítems se cumple la condición de "normalidad" en la distribución, concretamente para el caso de las cuestiones sobre la responsabilidad del auditor para detectar fraudes e irregularidades, sobre la seguridad que aporta el auditor en relación a la solvencia de la situación financiera, la

distancia vertical entre $\mathrm{F}_{M}(\mathrm{x})$ y $\mathrm{F}_{T}(\mathrm{x})$, es decir $D=\sup \left|F_{M}(x)-F_{T}(x)\right| n$, donde $\mathrm{n}$ es el tamaño de la muestra. Dicha prueba puede utilizarse con muestras de cualquier tamaño. 
adecuación de la gestión de la empresa y la seguridad sobre la vida futura de la misma. Para el resto de cuestiones sigue sin cumplirse la condición de "normalidad" en las distribuciones.

Una vez que se verifica la "no normalidad" de las distribuciones con la prueba de "Kolmogorov-Smirnov" no tiene sentido aplicar la corrección de "Lilliefors"48", sobre "normalidad en la distribución", puesto que es aún más restrictiva.

- Aplicación del test de Kruskal-Wallis para la hipótesis $H_{01}$

La etapa siguiente ha consistido en el contraste de la primera hipótesis mediante la prueba no paramétrica de "Kruskal-Wallis ${ }^{49}$ ", que se utiliza para los casos de más de dos muestras independientes, con la finalidad de comprobar si varias muestras proceden de la misma población. La prueba " $\mathrm{H}$ de Kruskal-Wallis" es una extensión de la prueba “U de Mann-Whitney”, y es el análogo no paramétrico del "análisis de la varianza de un factor", para detectar las diferencias en la localización de las distribuciones. La prueba " $\mathrm{H}$ de Kruskal-Wallis" supone que no existe una ordenación a priori de las $k$ poblaciones de las cuales se extraen las muestras.

Como señala Newbold (1997: 525) el contraste de “Kruskal-Wallis se utilizará cuando el investigador tenga fundadas sospechas que la población objeto de estudio tenga una distribución marcadamente diferente de la

48 Ato García (1991) indica que la prueba de Lilliefors no es sino una modificación de la de Kolmogorov-Smirnov que se emplea como test de "normalidad" cuando los valores de la media y varianza de una población son desconocidos.

${ }^{49}$ El estadístico H de Kruskal-Wallis queda definido de la siguiente manera: $H=\frac{12}{n(n+1)} \sum_{i=1}^{K} \frac{R_{i}^{2}}{n_{i}}-3(n+1)$, donde $\mathrm{n}_{1}, \mathrm{n}_{2}, \ldots, \mathrm{n}_{\mathrm{k}}$ son muestras independientes de $\mathrm{K}$ poblaciones $\mathrm{y} \mathrm{n}$ es el número total de observaciones muestrales, siendo $\mathrm{R}_{1}, \mathrm{R}_{2}, \ldots, \mathrm{R}_{\mathrm{k}}$, las sumas de los rangos para las $\mathrm{K}$ muestras. Newbold (1997: 526) indica que el contraste será válido para muestras de al menos cinco observaciones para cada población. 
distribución normal", por ello que su aplicación sea la más adecuada para contrastar la diferencia o no de percepciones en los cuatro grupos encuestados (la hipótesis nula a contrastar se basa en suponer que las medias de las cuatro poblaciones son iguales), una vez verificada la "no normalidad" de las distribuciones de empresas, auditores, entidades financieras y agencias y sociedades de valores.

\section{Tabla $n^{\circ} 21$}

Prueba de Kruskal-Wallis para los grupos encuestados ( $1^{\text {a }}$ hipótesis)

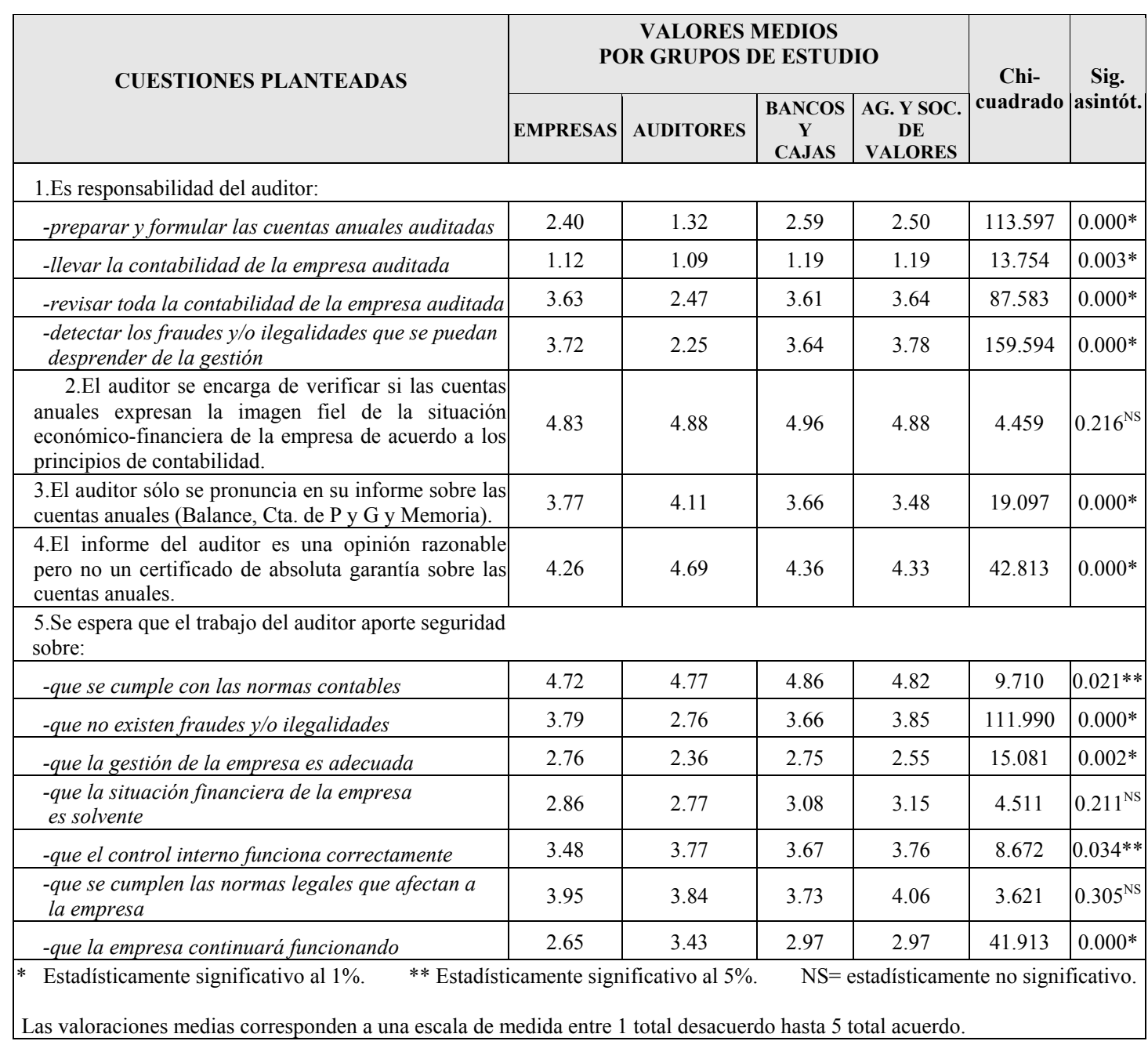


Según se desprende de la tabla $n^{0} 21$, se pueden realizar las siguientes afirmaciones:

- Se producen diferencias estadísticamente significativas, entre los cuatro grupos, en relación con sus percepciones sobre la responsabilidad que tiene el auditor de "preparar y formular las cuentas anuales" que audita, aunque todos los grupos se muestran en desacuerdo con que ésta sea una misión del auditor. Al aplicar la prueba de "Mann-Whitney dos a dos" se confirma que los auditores están mucho más cerca del total desacuerdo que el resto de grupos. Al mismo resultado llegan Kelly y Mohrweis (1989), para el caso de inversores e instituciones financieras, Bailey, Bylinski y Shields (1983), así como Miller et al. (1990).

- Existen diferencias significativas entre los grupos sobre la responsabilidad del auditor en torno a la "llevanza de la contabilidad" de la empresa sometida a auditoría de cuentas, no obstante todos se muestran en desacuerdo con que le corresponda al auditor dicha labor.

- Se observa que se dan diferencias, estadísticamente significativas, en lo relativo a que sea papel del auditor "revisar toda la contabilidad" de la empresa auditada, de forma que tanto compañías auditadas, entidades financieras como agencias y sociedades de valores se posicionan de acuerdo con que ésa sea misión del auditor, mientras los auditores expresan que están en desacuerdo con que deban hacerlo. 
- Al igual que en la pregunta anterior los auditores estiman que no les corresponde a ellos detectar los "fraudes e irregularidades" que se desprenden de la gestión, mientras el resto de grupos opinan lo contrario, siendo dichas diferencias de percepción significativas desde el punto de vista estadístico. Sin embargo en el estudio, a escala nacional, llevado a cabo por García Benau et al. (1993), los auditores se manifiestan de acuerdo con que les corresponda asegurarse que se detectan todos los fraudes importantes, al igual que sucede en el Reino Unido, según se comprueba en la investigación de Humphrey, Moizer y Turley (1993). Por otra parte, el estudio de Beck (1973) corrobora los resultados obtenidos, con un grupo de accionistas australianos, en el sentido de que se espera del auditor que detecte los fraudes e irregularidades que se originen en la gestión de la empresa. Miller et al. (1990) obtienen el mismo resultado para el colectivo de entidades financieras.

- Todos los grupos están de acuerdo en que el auditor se pronuncia, en su informe, sólo sobre las cuentas anuales, mostrando las diferencias un $1 \%$ de significatividad estadística; además el test de "MannWhitney por parejas" indica que los auditores muestran un mayor grado de acuerdo que empresas, entidades financieras y agencias y sociedades de valores.

- Aparecen diferencias significativas en cuanto a la afirmación que señala que el informe del auditor es una "opinión razonable pero no un certificado de absoluta garantía" sobre las cuentas anuales. Al estudiar las diferencias de medias, dos a dos, se comprueba que los auditores son los que muestran un mayor grado de acuerdo con dicha 
afirmación, en contraposición a las empresas que son las que menos acuerdo demuestran.

- De igual modo se producen diferencias significativas en relación con que la labor del auditor aporte seguridad sobre las siguientes cuestiones: cumplimiento de las normas contables, inexistencia de fraudes e ilegalidades, que la gestión sea adecuada, que el control interno funcione correctamente y que la empresa continuará funcionando. Todos los encuestados se muestran de acuerdo en que aporta seguridad acerca del "cumplimiento de las normas contables" y sobre el "correcto funcionamiento del control interno", alcanzando los mismos resultados que Humphrey, Moizer y Turley (1993) y García Benau et al. (1993). Sin embargo, los auditores se muestran en desacuerdo sobre que deban aportar seguridad de que no existan "fraudes e ilegalidades" frente al acuerdo del resto de grupos. Además, tanto las empresas, las entidades financieras como los analistas indican su desacuerdo, aunque en los dos últimos casos muy leve, con que se espere del auditor que aporte seguridad de que la "empresa continuará funcionando" mientras los auditores indican su acuerdo. No obstante, este resultado contradice lo conseguido por García Benau et al. (1993) en España, y Humphrey, Moizer y Turley (1993) en el Reino Unido, debido a que los grupos encuestados de directores financieros y usuarios manifestaban que el papel del auditor debe asegurar que no se duda de la viabilidad futura de la empresa. Además todos los grupos expresan su desacuerdo con que se espere del auditor que aporte seguridad de que la gestión es adecuada, sin embargo Beck (1973) llega al resultado contrario. 
Los resultados expuestos conducen a "rechazar" la primera hipótesis nula de igualdad de percepciones entre los grupos en relación con la función que tienen asignada los auditores de cuentas.

- Aplicación del análisis de la varianza $a^{50}$ en un sentido para la hipótesis $H_{01}$

Para corroborar los resultados obtenidos para la primera hipótesis, con la aplicación de la prueba no paramétrica de "Kruskal-Wallis", se ha desarrollado el test paramétrico del "análisis de la varianza en un sentido ${ }^{51}$ " que se emplea para contrastar la hipótesis nula de que las medias, de más de dos grupos independientes, son iguales.

Al aplicar la prueba ANOVA se consigue ratificar la significatividad estadística de las diferencias señaladas mediante el test no paramétrico de "Kruskal-Wallis", excepto en el caso de las preguntas que cuestionan la responsabilidad del auditor de llevar la contabilidad de la empresa auditada y aquella que versa sobre la expectativa de seguridad que aporta su trabajo con relación a si se cumple con las normas contables, tal y como se aprecia en el Anexo 17. Posteriormente se han realizado dos pruebas "post-hoc" en

${ }^{50}$ El contraste de hipótesis para el análisis de la varianza de un factor se define como: partiendo de varias muestras aleatorias independientes con $\mathrm{n}_{1}, \mathrm{n}_{2}, \ldots, \mathrm{n}_{\mathrm{k}}$ observaciones procedentes de $\mathrm{K}$ poblaciones. Sea $n$ el tamaño muestral total de manera que $n=n_{1}+n_{2}+\ldots+n_{k}$, se definen los cuadrados medios como:

- $\quad$ dentro de los grupos $\mathrm{CMD}=\mathrm{SCD} / \mathrm{n}-\mathrm{K}$

- $\quad$ entre grupos $\mathrm{CMG}=\mathrm{SCG} / \mathrm{K}-1$

La hipótesis nula a contrastar será que las $\mathrm{K}$ medias poblacionales son iguales $\mathrm{H}_{0}: \mathrm{u}_{1}=\mathrm{u}_{2}=\ldots=\mathrm{u}_{\mathrm{k}}$ Un contraste al nivel de significación $\alpha$ quedará determinado por la siguiente regla de decisión: rechazar $\mathrm{H}_{0}$ : si CMG / CMD $>\mathrm{F}_{\mathrm{K}-1, \mathrm{n}-\mathrm{K}, \alpha}$

donde $\mathrm{F}_{\mathrm{K}-1, \mathrm{n}-\mathrm{K}, \alpha}$ es aquel número para el que $\mathrm{P}\left(\mathrm{F}_{\mathrm{K}-1, \mathrm{n}-\mathrm{K}}>\mathrm{F}_{\mathrm{K}-1, \mathrm{n}-\mathrm{K}, \alpha}\right)$ y la variable aleatoria $\mathrm{F}_{\mathrm{K}-1, \mathrm{n}-\mathrm{K}}$ sigue una distribución F con (K-1) grados de libertad en el numerador y (n-K) grados de libertad en el denominador. Donde CMD es el cuadrado medio dentro de los grupos, CMG es el cuadrado medio entre grupos, SCD es la suma de cuadrados dentro de los grupos y SCG es la suma de cuadrados entre grupos. Véase Newbold (1997).

${ }^{51}$ Aunque las variables que se miden son ordinales y, por tanto, lo determinante en la aceptación o no de las hipótesis son las pruebas no paramétricas, se ha seguido la metodología utilizada en estudios similares por otros autores que en la mayoría de casos ratifican los resultados obtenidos con las pruebas no paramétricas mediante la aplicación de pruebas paramétricas, véase los estudios de Kelly et al. (1989), Bailey et al. (1983) y Carcello et al. (1992). 
función de la "homogeneidad o no de varianzas" que marca la prueba de "Levene", así en los casos de igualdad de varianzas se ha aplicado la prueba "HSD de Tukey" mientras que en el caso contrario se ha utilizado la prueba de "Tamhane". De la prueba de "Tukey" se deriva, respecto a la cuestión sobre si se espera del trabajo del auditor que aporte seguridad de que no existen "fraudes e irregularidades", que las diferencias significativas se producen entre dos grupos, los auditores por un lado y el resto de encuestados por otro, formado, este último, tanto por empresas como por entidades financieras y sociedades y agencias de valores. Respecto de la cuestión sobre la seguridad que aporta el auditor con relación a la "continuidad de la empresa", la diferencia estadística se produce únicamente entre auditores y empresas.

Por otra parte al aplicar la prueba de "Tamhane" se confirma que las diferencias que se encuentran en las preguntas, sobre si es responsabilidad del auditor "preparar y formular las cuentas anuales" auditadas, "revisar toda la contabilidad" de la empresa auditada y detectar los "fraudes e ilegalidades derivados de la gestión", se originan entre dos grupos de un lado los auditores y de otro el resto de los encuestados. Además las diferencias que se observan en la afirmación, que expresa que el auditor sólo se pronuncia en su informe sobre las cuentas anuales, son debidas sólo a los grupos de empresas y auditores.

- Análisis pormenorizado con el grupo de empresas para la hipótesis $H_{01}$

Una vez contrastada la primera hipótesis, se ha llevado a cabo un estudio "intragrupo" de las respuestas recibidas de las empresas sometidas a auditoría. 
Tabla $n^{\circ} 22$

Prueba de Kruskal-Wallis para las empresas agrupadas por CCAA (1 ${ }^{\text {a }}$ hipótesis)

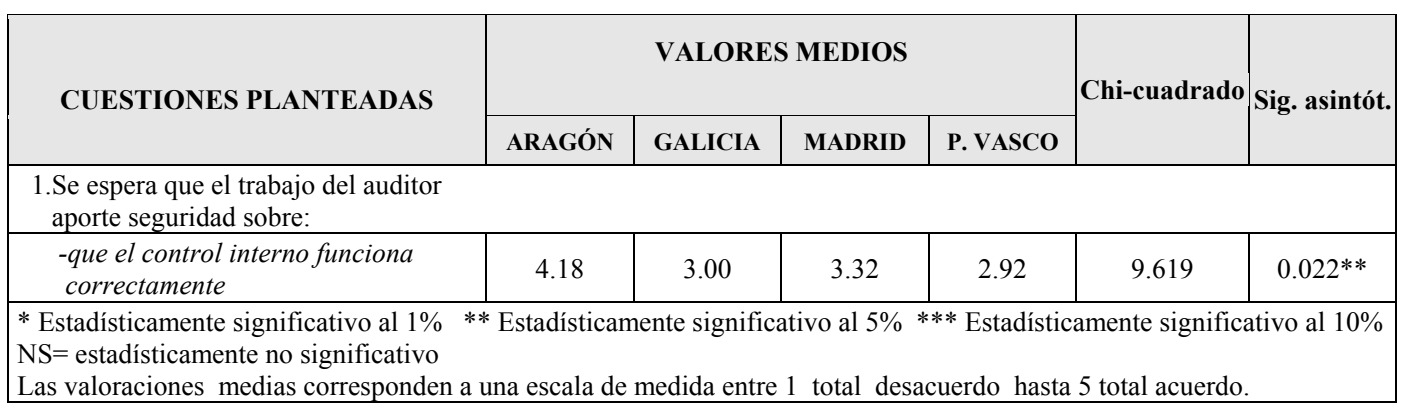

Al aplicar el test de "Kruskal-Wallis" y la "U de Mann-Whitney" se obtiene que las empresas auditadas procedentes de la Comunidad de Aragón son las que manifiestan un mayor acuerdo en atribuir a la labor del auditor que aporte seguridad sobre que "el control interno funcione correctamente"; en sentido contrario se pronuncian las empresas del País Vasco, que no están de acuerdo con esta premisa. Los empresarios gallegos se mantienen en una posición neutra según la cual no expresan ni acuerdo ni desacuerdo con dicha afirmación.

Según se aprecia en la tabla $n^{0} 23$, el grado de acuerdo con las afirmaciones indicadas, en general, se incrementa conforme aumenta la experiencia profesional de los encuestados, en el caso de las empresas, de manera que los que acreditan más de 20 años de experiencia profesional manifiestan mayores cotas de acuerdo que aquellos que poseen una corta experiencia. 
Tabla $n^{\circ} 23$ Prueba de Mann-Whitney ${ }^{52}$

para las empresas agrupadas por la experiencia profesional ( $1^{\text {a }}$ hipótesis)

\begin{tabular}{|c|c|c|c|c|}
\hline \multirow{2}{*}{ CUESTIONES PLANTEADAS } & \multicolumn{2}{|c|}{$\begin{array}{l}\text { VALORES MEDIOS DE AÑOS DE } \\
\text { EXPERIENCIA PROFESIONAL }\end{array}$} & \multirow{2}{*}{$\begin{array}{l}\text { U de Mann- } \\
\text { Whitney }\end{array}$} & \multirow{2}{*}{ Sig. asintót. } \\
\hline & $1<\mathrm{X} \# 5$ & $20<X$ & & \\
\hline $\begin{array}{l}\text { 1.El auditor se encarga de verificar si las cuentas } \\
\text { anuales expresan la imagen fiel de la situación } \\
\text { económico-financiera de la empresa de acuerdo a } \\
\text { los principios de contabilidad. }\end{array}$ & 4.57 & 4.90 & 1124 & $0.001 *$ \\
\hline $\begin{array}{l}\text { 2.El auditor sólo se pronuncia en su informe sobre } \\
\text { las cuentas anuales (Balance, Cta. de P y G y } \\
\text { Memoria). }\end{array}$ & 3.40 & 3.89 & 1123.5 & $0.061 * * *$ \\
\hline $\begin{array}{l}\text { 3.El informe del auditor es una opinión razonable } \\
\text { pero no un certificado de absoluta garantía sobre las } \\
\text { cuentas anuales. }\end{array}$ & 3.79 & 4.28 & 1006.5 & $0.022 * *$ \\
\hline \multicolumn{5}{|l|}{$\begin{array}{l}\text { 4.Se espera que el trabajo del auditor aporte } \\
\text { seguridad sobre: }\end{array}$} \\
\hline -que se cumple con las normas contables & 4.57 & 4.81 & 1146 & $0.021 * *$ \\
\hline $\begin{array}{l}\text {-que se cumplen las normas legales que afectan a } \\
\text { la empresa }\end{array}$ & 3.71 & 4.20 & 1034 & $0.018 * *$ \\
\hline \multicolumn{5}{|c|}{$\begin{array}{l}\text { * Estadísticamente significativo al } 1 \% \quad * * \text { Estadísticamente significativo al } 5 \% * * * \text { Estadísticamente significativo al } 10 \% \\
\text { NS = estadísticamente no significativo } \\
\text { Las valoraciones medias corresponden a una escala de medida entre } 1 \text { total desacuerdo hasta } 5 \text { total acuerdo. }\end{array}$} \\
\hline
\end{tabular}

Tabla n 24 Prueba de Mann-Whitney

para las empresas agrupadas por el nivel de estudios ( $1^{\text {a }}$ hipótesis)

\begin{tabular}{|c|c|c|c|c|}
\hline \multirow{2}{*}{ CUESTIONES PLANTEADAS } & \multicolumn{2}{|c|}{$\begin{array}{l}\text { VALORES MEDIOS } \\
\text { POR NIVEL DE ESTUDIOS }\end{array}$} & \multirow{2}{*}{$\begin{array}{l}\text { U de Mann- } \\
\text { Whitney }\end{array}$} & \multirow{2}{*}{ Sig. asintót. } \\
\hline & Bachiller-Fp & $\begin{array}{c}\text { Estudios } \\
\text { universitarios de } \\
\text { grado superior }\end{array}$ & & \\
\hline \multicolumn{5}{|l|}{ 1.Es responsabilidad del auditor: } \\
\hline $\begin{array}{l}\text {-revisar toda la contabilidad de la empresa } \\
\text { auditada }\end{array}$ & 4.08 & 3.55 & 2912 & $0.028 * *$ \\
\hline $\begin{array}{l}\text {-detectar los fraudes y/o ilegalidades que se } \\
\text { puedan desprender de la gestión }\end{array}$ & 4.14 & 3.61 & 2756.5 & $0.016^{* *}$ \\
\hline $\begin{array}{l}\text { 2.El auditor se encarga de verificar si las } \\
\text { cuentas anuales expresan la imagen fiel de la } \\
\text { situación económico-financiera de la empresa de } \\
\text { acuerdo a los principios de contabilidad. }\end{array}$ & 4.68 & 4.90 & 3363.5 & $0.046^{* *}$ \\
\hline \multicolumn{5}{|l|}{$\begin{array}{l}\text { 3. Se espera que el trabajo del auditor aporte } \\
\text { seguridad sobre: }\end{array}$} \\
\hline -que no existen fraudes y/o ilegalidades & 4.29 & 3.63 & 2435.5 & $0.001 *$ \\
\hline -que la gestión de la empresa es adecuada & 3.42 & 2.57 & 2489.5 & $0.001 *$ \\
\hline \multicolumn{5}{|c|}{$\begin{array}{l}\text { * Estadísticamente significativo al } 1 \% * * \text { Estadísticamente significativo al } 5 \% * * * \text { Estadísticamente significativo al 10\% } \\
\mathrm{NS}=\text { estadísticamente no significativo }\end{array}$} \\
\hline
\end{tabular}

${ }^{52}$ Según señala Newbold (1997) partiendo de dos muestras aleatorias independientes de tamaños $\mathrm{n}_{1} \mathrm{y}$ $\mathrm{n}_{2}$ de dos poblaciones, si se juntan las observaciones muestrales y se les adjudican sus rangos, representando mediante $\mathrm{R}_{1}$ la suma de los rangos de la primera población, el estadístico de contraste definido por Mann $y$ Whitney queda: $U=n_{1} n_{2}+\frac{n_{1}\left(n_{1}+1\right)}{2}-R_{1}$ 
Los responsables de empresas que han cursado estudios de bachillerato o formación profesional revelan un mayor grado de acuerdo, que los que poseen estudios universitarios, en relación con que sea responsabilidad del auditor "revisar toda la contabilidad" de la empresa auditada, así como detectar los "fraudes e irregularidades" que se pueden derivar de la gestión de la sociedad. Además los universitarios con carreras superiores se manifiestan en desacuerdo con que se espere del trabajo del auditor que aporte seguridad sobre que "la gestión de la empresa sea adecuada", por el contrario los que tienen estudios de bachillerato o formación profesional se muestran de acuerdo.

- Análisis pormenorizado con el grupo de auditores para la hipótesis $H_{01}$

Se ha realizado un análisis más exhaustivo dentro del colectivo de auditores diferenciando dos grupos, el compuesto por los auditores ejercientes a título individual y las sociedades de auditoría.

Tabla $\mathrm{n}^{\mathrm{o}} 25$

Prueba de Mann-Whitney para los auditores según la forma jurídica ( $1^{\mathrm{a}}$ hipótesis)

\begin{tabular}{|c|c|c|c|c|}
\hline \multirow{2}{*}{ CUESTIONES PLANTEADAS } & \multicolumn{2}{|c|}{ VALORES MEDIOS } & \multirow{2}{*}{$\begin{array}{l}\text { U de } \\
\text { Mann-Whitney }\end{array}$} & \multirow{2}{*}{ Sig. asintót } \\
\hline & $\begin{array}{c}\text { AUDITORES } \\
\text { INDIVIDUALES }\end{array}$ & $\begin{array}{l}\text { SOCIEDADES } \\
\text { DE } \\
\text { AUDITORÍA }\end{array}$ & & \\
\hline $\begin{array}{l}\text { 1.El auditor sólo se pronuncia en su informe sobre las } \\
\text { cuentas anuales (Balance, Cta. de P y G y Memoria). }\end{array}$ & 4.06 & 4.22 & 10247.5 & $0.096 * * *$ \\
\hline \multicolumn{5}{|l|}{$\begin{array}{l}\text { 2.Se espera que el trabajo del auditor aporte seguridad } \\
\text { sobre: }\end{array}$} \\
\hline -que la empresa continuará funcionando & 3.30 & 3.72 & 9357.5 & $0.007^{*}$ \\
\hline \multicolumn{5}{|c|}{$\begin{array}{l}* \text { Estadísticamente significativo al 1\% ** Estadísticamente significativo al 5\%*** Estadísticamente significativo al } 10 \% \\
\text { NS= estadísticamente no significativo }\end{array}$} \\
\hline
\end{tabular}

Del conjunto de cuestiones, sobre la primera hipótesis planteada, sólo se han encontrado diferencias estadísticamente significativas en dos de ellas: 
- Las sociedades de auditoría muestran un mayor acuerdo, que los auditores personas físicas, en relación con que el auditor "sólo se pronuncia en su informe sobre las cuentas anuales".

- De igual manera los auditores que ejercen bajo la forma jurídica de sociedad manifiestan un mayor grado de acuerdo con que los usuarios del servicio esperan que el trabajo del auditor aporte seguridad sobre que la "empresa continuará funcionando".

Analizando los valores medios de las respuestas de auditores, por comunidades autónomas, se observan cuatro cuestiones cuyas diferencias son estadísticamente significativas.

\section{Tabla $n^{0} 26$}

Prueba de Kruskal-Wallis para los auditores agrupados por CCAA ( $1^{\text {a }}$ hipótesis $)$

\begin{tabular}{|c|c|c|c|c|c|c|}
\hline \multirow{2}{*}{ CUESTIONES PLANTEADAS } & \multicolumn{4}{|c|}{ VALORES MEDIOS } & \multirow{2}{*}{$\begin{array}{c}\text { Chi- } \\
\text { cuadrado }\end{array}$} & \multirow{2}{*}{$\begin{array}{l}\text { Sig. } \\
\text { asintót. }\end{array}$} \\
\hline & ANDALUCÍA & CATALUÑ̃ & MADRID & VALENCIA & & \\
\hline $\begin{array}{l}\text { 1.El auditor se encarga de verificar si las cuentas } \\
\text { anuales expresan la imagen fiel de la situación } \\
\text { económico-financiera de la empresa de acuerdo a } \\
\text { los principios de contabilidad. }\end{array}$ & 4.73 & 4.98 & 4.88 & 4.83 & 11.313 & $0.010 *$ \\
\hline $\begin{array}{l}\text { 2.El auditor sólo se pronuncia en su informe sobre } \\
\text { las cuentas anuales (Balance, Cta. de P y G y } \\
\text { Memoria). }\end{array}$ & 3.88 & 4.21 & 4.24 & 4.34 & 8.518 & $0.036 * *$ \\
\hline \multicolumn{7}{|l|}{$\begin{array}{l}\text { 3.Se espera que el trabajo del auditor aporte } \\
\text { seguridad sobre: }\end{array}$} \\
\hline -que la gestión de la empresa es adecuada & 2.17 & 2.62 & 2.09 & 2.54 & 6.657 & $0.084 * * *$ \\
\hline -que la empresa continuará funcionando & 3.33 & 3.87 & 3.33 & 3.03 & 4.096 & $0.026 * *$ \\
\hline \multicolumn{7}{|c|}{$\begin{array}{l}* \text { Estadísticamente significativo al } 1 \% * * \text { Estadísticamente significativo al } 5 \% * * * \text { Estadísticamente significativo al } 10 \% \\
\text { NS= estadísticamente no significativo } \\
\text { Las valoraciones medias corresponden a una escala de medida entre } 1 \text { total desacuerdo hasta } 5 \text { total acuerdo. }\end{array}$} \\
\hline
\end{tabular}

En la tabla $\mathrm{n}^{\mathrm{o}} 26$ se observa que se producen diferencias estadísticamente significativas, por CCAA, respecto a que el auditor se encargue de "verificar la imagen fiel", a que "sólo se pronuncie en el informe sobre las cuentas anuales", a que su trabajo aporte seguridad acerca de que "la gestión es adecuada" y a que "la empresa continuará funcionando". 
Además al aplicar la prueba de "Mann-Whitney" se obtiene que los auditores catalanes revelan un menor desacuerdo, que los andaluces, con relación a que se espere del auditor que aporte seguridad sobre que "la gestión de la empresa es adecuada", y un mayor grado de acuerdo respecto al resto de cuestiones planteadas.

Tabla $n^{\circ} 27$ Prueba de Kruskal-Wallis

para los auditores agrupados por la experiencia profesional ( $1^{\mathrm{a}}$ hipótesis $)$

\begin{tabular}{|c|c|c|c|c|c|c|}
\hline \multirow{2}{*}{ CUESTIONES PLANTEADAS } & \multicolumn{4}{|c|}{$\begin{array}{l}\text { VALORES MEDIOS DE AÑOS DE } \\
\text { EXPERIENCIA PROFESIONAL }\end{array}$} & \multirow{2}{*}{$\begin{array}{c}\text { Chi- } \\
\text { cuadrado }\end{array}$} & \multirow{2}{*}{$\begin{array}{l}\text { Sig. } \\
\text { asintót. }\end{array}$} \\
\hline & $1<\mathrm{X} \# \mathbf{5}$ & $5<X \# 10$ & $10<X \# 20$ & $20<X$ & & \\
\hline \multicolumn{7}{|l|}{$\begin{array}{l}\text { 1.Se espera que el trabajo del auditor aporte } \\
\text { seguridad sobre: }\end{array}$} \\
\hline -que la gestión de la empresa es adecuada & 2.73 & 2.38 & 2.35 & 2.14 & 6.255 & $0.10 * * *$ \\
\hline $\begin{array}{l}\text {-que el control interno funciona } \\
\text { correctamente }\end{array}$ & 3.78 & 3.53 & 3.73 & 4.09 & 8.524 & $0.036 * *$ \\
\hline \multicolumn{7}{|c|}{$\begin{array}{l}* \text { Estadísticamente significativo al 1\% ** Estadísticamente significativo al } 5 \% * * * \text { Estadísticamente significativo al } 10 \% \\
\mathrm{NS}=\text { estadísticamente no significativo } \\
\text { Las valoraciones medias corresponden a una escala de medida entre } 1 \text { total desacuerdo hasta } 5 \text { total acuerdo. }\end{array}$} \\
\hline
\end{tabular}

Tal y como se aprecia en la tabla $n^{0} 27$, y corrobora la prueba de "Mann-Whitney por parejas", los auditores con una experiencia profesional superior a 20 años expresan mayor desacuerdo, con que se espere del trabajo del auditor que aporte seguridad sobre que "la gestión de la empresa es adecuada", que los auditores más noveles. Del mismo modo son los auditores, con mayor antigüedad profesional, los que manifiestan mayor grado de acuerdo con que les corresponda aportar seguridad sobre que "el control interno de las sociedades funcione correctamente", que aquellos con una experiencia laboral menor o igual a cinco años.

Según se deduce de los resultados, de la tabla $n^{0} 28$, los auditores con edades comprendidas entre los 20 y 30 años se manifiestan de acuerdo con el hecho de que una de las responsabilidades del auditor es "revisar toda la contabilidad" de la empresa auditada, mientras los auditores con edades superiores a la treintena se manifiestan en desacuerdo. 
Tabla $n^{\circ} 28$

Prueba de Kruskal-Wallis para los auditores agrupados por la edad ( $1^{\text {a }}$ hipótesis)

\begin{tabular}{|c|c|c|c|c|c|c|}
\hline \multirow{2}{*}{ CUESTIONES PLANTEADAS } & \multicolumn{4}{|c|}{ VALORES MEDIOS DE EDAD } & \multirow{2}{*}{$\begin{array}{c}\text { Chi- } \\
\text { cuadrado }\end{array}$} & \multirow{2}{*}{$\begin{array}{l}\text { Sig. } \\
\text { asintót }\end{array}$} \\
\hline & $20<\mathrm{X} \# \mathbf{3 0}$ & $30<x \# 40$ & $40<\mathrm{X} \# \mathbf{5 0}$ & $\mathbf{5 0}<\mathbf{X}$ & & \\
\hline \multicolumn{7}{|l|}{ 1.Es responsabilidad del auditor: } \\
\hline $\begin{array}{l}\text {-revisar toda la contabilidad de la empresa } \\
\text { auditada }\end{array}$ & 3.22 & 2.13 & 2.09 & 2.97 & 22.601 & $0.000^{*}$ \\
\hline \multicolumn{7}{|l|}{$\begin{array}{l}\text { 2.Se espera que el trabajo del auditor aporte } \\
\text { seguridad sobre: }\end{array}$} \\
\hline $\begin{array}{l}\text {-que se cumplen las normas legales que } \\
\text { afectan a la empresa }\end{array}$ & 4.20 & 3.55 & 3.89 & 3.99 & 7.849 & $0.049 * *$ \\
\hline
\end{tabular}

Tabla $n^{\circ} 29$

Prueba de Mann-Whitney para auditores según el nivel de estudios ( $1^{\text {a }}$ hipótesis)

\begin{tabular}{|c|c|c|c|c|}
\hline \multirow{2}{*}{ CUESTIONES PLANTEADAS } & \multicolumn{2}{|c|}{ VALORES MEDIOS } & \multirow{2}{*}{$\begin{array}{c}\text { U de } \\
\text { Mann-Whitney }\end{array}$} & \multirow{2}{*}{ Sig. asintót. } \\
\hline & \begin{tabular}{|c|}
$\begin{array}{c}\text { Estudios } \\
\text { universitarios de } \\
\text { grado medio }\end{array}$ \\
\end{tabular} & \begin{tabular}{|c|} 
Estudios \\
universitarios de \\
grado superior
\end{tabular} & & \\
\hline $\begin{array}{l}\text { 1.El auditor se encarga de verificar si las cuentas } \\
\text { anuales expresan la imagen fiel de la situación } \\
\text { económico-financiera de la empresa de acuerdo a los } \\
\text { principios de contabilidad. }\end{array}$ & 4.98 & 4.86 & 5444.5 & $0.086 * * *$ \\
\hline \multicolumn{5}{|l|}{$\begin{array}{l}\text { 2.Se espera que el trabajo del auditor aporte seguridad } \\
\text { sobre: }\end{array}$} \\
\hline -que no existen fraudes y/o ilegalidades & 3.12 & 2.72 & 4848.5 & $0.063 * * *$ \\
\hline -que la gestión de la empresa es adecuada & 2.74 & 2.31 & 4748.5 & $0.044 * *$ \\
\hline \multicolumn{5}{|c|}{ * Estadísticamente significativo al 1\% $* *$ Estadísticamente significativo al 5\% *** Estadísticamente significativo al $10 \%$} \\
\hline \multicolumn{5}{|c|}{ Las valoraciones medias corresponden a una escala de medida entre 1 total desacuerdo hasta 5 total acuerdo. } \\
\hline
\end{tabular}

Como se observa, en la tabla $\mathrm{n}^{0} 29$, los auditores con formación universitaria de grado medio se manifiestan con un muy leve acuerdo sobre que se espera que su trabajo aporte seguridad respecto a la inexistencia de "fraudes y/o ilegalidades", frente al desacuerdo que apuntan los auditores con estudios universitarios superiores. 
Tabla $n^{\circ} 30$

Prueba de Mann-Whitney para auditores por estudios de postgrado ( $1^{\text {a }}$ hipótesis)

\begin{tabular}{|c|c|c|c|c|}
\hline \multirow{2}{*}{ CUESTIONES PLANTEADAS } & \multicolumn{2}{|c|}{ VALORES MEDIOS } & \multirow{2}{*}{$\begin{array}{c}\text { U de } \\
\text { Mann-Whitney }\end{array}$} & \multirow{2}{*}{ Sig. asintót. } \\
\hline & $\begin{array}{c}\text { Sin estudios de } \\
\text { postgrado }\end{array}$ & \begin{tabular}{|c|}
$\begin{array}{c}\text { Con estudios de } \\
\text { postgrado }\end{array}$ \\
\end{tabular} & & \\
\hline \multicolumn{5}{|l|}{$\begin{array}{l}\text { 1.Se espera que el trabajo del auditor aporte seguridad } \\
\text { sobre: }\end{array}$} \\
\hline -que la situación financiera de la empresa es solvente & 2.66 & 3.00 & 9109.5 & $0.043 * *$ \\
\hline \multicolumn{5}{|c|}{$\begin{array}{l}* \text { Estadísticamente significativo al } 1 \% * * \text { Estadísticamente significativo al } 5 \% * * * \text { Estadísticamente significativo al } 10 \% \\
\text { NS= estadísticamente no significativo } \\
\text { Las valoraciones medias corresponden a una escala de medida entre } 1 \text { total desacuerdo hasta } 5 \text { total acuerdo. }\end{array}$} \\
\hline
\end{tabular}

Los auditores sin estudios de postgrado se manifiestan en desacuerdo con que se espere de su trabajo que aporte seguridad sobre que "la empresa es solvente", mientras los que sí tienen este tipo de formación no se muestran ni en acuerdo ni en desacuerdo.

- Análisis pormenorizado con el grupo de entidades de crédito para la hipótesis $H_{01}$

A continuación se ha llevado a cabo un análisis pormenorizado, del grupo formado por entidades de crédito, para destacar las diferencias significativas que se han encontrado atendiendo a determinadas cualidades de los individuos encuestados.

Tabla no 31 Prueba de Kruskal-Wallis

para las entidades de crédito agrupadas por CCAA ( $1^{\text {a }}$ hipótesis)

\begin{tabular}{|c|c|c|c|c|c|}
\hline \multirow{2}{*}{ CUESTIONES PLANTEADAS } & \multicolumn{3}{|c|}{ VALORES MEDIOS } & \multirow{2}{*}{$\begin{array}{c}\text { Chi- } \\
\text { cuadrado }\end{array}$} & \multirow{2}{*}{ Sig. asintót. } \\
\hline & ANDALUCÍA & MADRID & VALENCIA & & \\
\hline $\begin{array}{l}\text { 1.El auditor sólo se pronuncia en su informe } \\
\text { sobre las cuentas anuales (Balance, Cta. de P y G y } \\
\text { Memoria). }\end{array}$ & 3.45 & 4.19 & 2.81 & 7.865 & $0.020 * *$ \\
\hline \multicolumn{6}{|l|}{$\begin{array}{l}\text { 2.Se espera que el trabajo del auditor aporte } \\
\text { seguridad sobre: }\end{array}$} \\
\hline -que el control interno funciona correctamente & 3.18 & 3.37 & 4.33 & 20.491 & $0.008 *$ \\
\hline $\begin{array}{l}\text {-que se cumplen las normas legales que afectan a } \\
\text { la empresa }\end{array}$ & 3.45 & 3.38 & 4.38 & 20.491 & $0.055 * * *$ \\
\hline \multicolumn{6}{|c|}{$\begin{array}{l}\text { * Estadísticamente significativo al } 1 \% * * \text { Estadísticamente significativo al } 5 \% * * * \text { Estadísticamente significativo al } 10 \% \\
\text { NS= estadísticamente no significativo } \\
\text { Las valoraciones medias corresponden a una escala de medida entre } 1 \text { total desacuerdo hasta } 5 \text { total acuerdo. }\end{array}$} \\
\hline
\end{tabular}


Mientras los directivos de las entidades financieras con sede social en las Comunidades de Andalucía o Madrid manifiestan su acuerdo con que el auditor de cuentas "sólo se pronuncie en su informe sobre las cuentas anuales", los responsables de la Comunidad Valenciana expresan su desacuerdo.

Tabla $n^{\circ} 32$ Prueba de Kruskal-Wallis para las entidades de crédito agrupadas por la experiencia profesional $\left(1^{\mathrm{a}}\right.$ hipótesis $)$

\begin{tabular}{|c|c|c|c|c|c|c|}
\hline \multirow{2}{*}{ CUESTIONES PLANTEADAS } & \multicolumn{4}{|c|}{$\begin{array}{l}\text { VALORES MEDIOS DE AÑOS DE } \\
\text { EXPERIENCIA PROFESIONAL }\end{array}$} & \multirow{2}{*}{$\begin{array}{l}\text { Chi- } \\
\text { cuadrado }\end{array}$} & \multirow{2}{*}{ Sig. asintót. } \\
\hline & $1<\mathrm{X} \# \mathbf{5}$ & $5<X \# 10$ & $10<X \# 20$ & $20<X$ & & \\
\hline \multicolumn{7}{|l|}{ 1.Es responsabilidad del auditor: } \\
\hline $\begin{array}{l}\text { - preparar y formular las cuentas anuales } \\
\text { auditadas }\end{array}$ & 2.00 & 1.64 & 3.24 & 2.60 & 8.363 & $0.039 * *$ \\
\hline $\begin{array}{l}\text { 2.El auditor se encarga de verificar si las } \\
\text { cuentas anuales expresan la imagen fiel de la } \\
\text { situación económico-financiera de la empresa de } \\
\text { acuerdo a los principios de contabilidad. }\end{array}$ & 4.60 & 5.00 & 4.96 & 5.00 & 19.021 & $0.000^{*}$ \\
\hline \multicolumn{7}{|l|}{$\begin{array}{l}\text { 3. Se espera que el trabajo del auditor aporte } \\
\text { seguridad sobre: }\end{array}$} \\
\hline -que la gestión de la empresa es adecuada & 1.60 & 2.00 & 3.08 & 3.00 & 11.198 & $0.011 * *$ \\
\hline $\begin{array}{l}\text {-que la situación financiera de la empresa es } \\
\text { solvente }\end{array}$ & 2.40 & 2.36 & 3.46 & 3.19 & 6.314 & $0.097 * * *$ \\
\hline -que el control interno funciona correctamente & 3.40 & 2.93 & 3.96 & 3.81 & 6.979 & $0.073 * * *$ \\
\hline $\begin{array}{l}\text {-que se cumplen las normas legales que afectan } \\
\text { a la empresa }\end{array}$ & 2.40 & 3.07 & 4.12 & 3.91 & 10.012 & $0.018 * *$ \\
\hline \multicolumn{7}{|c|}{$\begin{array}{l}* \text { Estadísticamente significativo al 1\% } \quad * * \text { Estadísticamente significativo al } 5 \% \quad * * * \text { Estadísticamente significativo al } 10 \% \\
\mathrm{NS}=\text { estadísticamente no significativo }\end{array}$} \\
\hline
\end{tabular}

La mayoría de los responsables de las entidades financieras encuestadas manifiestan su desacuerdo con atribuir al auditor la responsabilidad de "preparar y formular las cuentas anuales auditadas" salvo en el caso de aquellos gestores, con una experiencia profesional dentro del intervalo de 10 y 20 años, que indican su acuerdo. Además aquellos directivos cuya experiencia no supera los diez años apuntan su desacuerdo sobre que se espere del auditor que aporte seguridad en relación con que "la situación financiera de la empresa sea solvente", mientras que los de mayor experiencia profesional se pronuncian en sentido inverso. 
Según se aprecia, en la tabla $n^{\circ} 33$, los encuestados pertenecientes a entidades financieras con estudios universitarios de grado medio expresan su acuerdo con que se espere del auditor que aporte seguridad sobre que "la gestión es adecuada", que "la situación financiera es solvente" y que "la empresa continuará funcionando", sin embargo aquellos gestores que poseen estudios superiores se manifiestan en desacuerdo.

Tabla no 33 Prueba de Mann-Whitney

para las entidades de crédito agrupadas por el nivel de estudios ( $1^{\mathrm{a}}$ hipótesis)

\begin{tabular}{|c|c|c|c|c|}
\hline \multirow{2}{*}{ CUESTIONES PLANTEADAS } & \multicolumn{2}{|c|}{$\begin{array}{l}\text { VALORES MEDIOS } \\
\text { POR NIVEL DE ESTUDIOS }\end{array}$} & \multirow{2}{*}{$\begin{array}{l}\text { U de Mann- } \\
\text { Whitney }\end{array}$} & \multirow[t]{2}{*}{ Sig. asintót. } \\
\hline & $\begin{array}{c}\text { Estudios } \\
\text { universitarios de } \\
\text { grado medio } \\
\end{array}$ & \begin{tabular}{|c|} 
Estudios \\
universitarios de \\
grado superior \\
\end{tabular} & & \\
\hline $\begin{array}{l}\text { 1.El auditor sólo se pronuncia en su informe } \\
\text { sobre las cuentas anuales (Balance, Cta. de P y G y } \\
\text { Memoria). }\end{array}$ & 3.09 & 3.95 & 209.000 & $0.090 * * *$ \\
\hline \multicolumn{5}{|l|}{$\begin{array}{l}\text { 3. Se espera que el trabajo del auditor aporte } \\
\text { seguridad sobre: }\end{array}$} \\
\hline -que no existen fraudes y/o ilegalidades & 4.36 & 3.40 & 159.000 & $0.011 * *$ \\
\hline -que la gestión de la empresa es adecuada & 3.90 & 2.47 & 111.000 & $0.002 *$ \\
\hline $\begin{array}{l}\text {-que la situación financiera de la empresa es } \\
\text { solvente }\end{array}$ & 4.55 & 2.67 & 90.000 & $0.000 *$ \\
\hline $\begin{array}{l}\text {-que se cumplen las normas legales que afectan a } \\
\text { la empresa }\end{array}$ & 4.45 & 3.55 & 174.000 & $0.021 * *$ \\
\hline -que la empresa continuará funcionando & 3.80 & 2.73 & 158.000 & $0.030 * *$ \\
\hline
\end{tabular}

- Análisis pormenorizado con el grupo de agencias y sociedades de valores para la hipótesis $H_{01}$

Según se observa, en la tabla $n^{\circ} 34$, y se comprueba al aplicar el test de "Mann-Whitney", los encuestados del grupo de sociedades y agencias de valores con una experiencia profesional superior a los 20 años manifiestan un mayor grado de acuerdo, que aquellos con una antigüedad menor o igual a los 10 años, sobre si corresponde al auditor detectar los "fraudes e irregularidades que se deriven de la gestión", así como sobre que su informe aporte seguridad acerca del "cumplimiento de las normas vigentes". 
Tabla n ${ }^{\circ} 34$ Prueba de Mann-Whitney para agencias y soc. de valores agrupadas por la experiencia profesional ( $1^{\text {a }}$ hipótesis)

\begin{tabular}{|c|c|c|c|c|}
\hline \multirow{2}{*}{ CUESTIONES PLANTEADAS } & \multicolumn{2}{|c|}{$\begin{array}{l}\text { VALORES MEDIOS DE AÑOS DE } \\
\text { EXPERIENCIA PROFESIONAL }\end{array}$} & \multirow{2}{*}{$\begin{array}{l}\text { U de Mann- } \\
\text { Whitney }\end{array}$} & \multirow{2}{*}{ Sig. asintót. } \\
\hline & $5<X \# 10$ & $20<X$ & & \\
\hline \multicolumn{5}{|l|}{ 1.Es responsabilidad del auditor: } \\
\hline $\begin{array}{l}\text {-detectar los fraudes e irregularidades que se } \\
\text { puedan desprender de la gestión }\end{array}$ & 3.17 & 4.33 & 11.500 & $0.056 * * *$ \\
\hline \multicolumn{5}{|l|}{$\begin{array}{l}\text { 2.Se espera que el trabajo del auditor aporte } \\
\text { seguridad sobre: }\end{array}$} \\
\hline $\begin{array}{l}\text {-que se cumplen las normas legales que afectan a } \\
\text { la empresa }\end{array}$ & 3.33 & 4.67 & 9.000 & $0.022 * *$ \\
\hline \multicolumn{5}{|c|}{$\begin{array}{l}* \text { Estadísticamente significativo al } 1 \% * * \text { Estadísticamente significativo al } 5 \% * * * \text { Estadísticamente significativo al } 10 \% \\
\text { NS= estadísticamente no significativo } \\
\text { Las valoraciones medias corresponden a una escala de medida entre } 1 \text { total desacuerdo hasta } 5 \text { total acuerdo. }\end{array}$} \\
\hline
\end{tabular}

\subsection{Desglose de la primera hipótesis}

La hipótesis nula que se ha desglosado de la primera, sobre la "función" del auditor, se ha planteado como:

$\mathrm{H}_{011}$ Los auditores y sociedades auditadas muestran la misma percepción sobre la posibilidad de que los auditores puedan prestar otros servicios distintos al de auditoría de cuentas.

- Aplicación del test de Kolmogorov-Smirnov para la hipótesis $H_{011}$

Se han realizado las pruebas de "normalidad" de las distribuciones que muestran los diferentes grupos de estudio, para ello se ha aplicado el test de "Kolmogorov-Smirnov", con la finalidad de determinar que prueba se debe aplicar para contrastar la hipótesis.

Atendiendo a los resultados obtenidos para el grupo de empresas al realizar la prueba de "Kolmogorov-Smirnov" se aprecia, en el Anexo 15, que ninguno de los ítems analizados se comportan según una distribución 
normal. Como sucede en el caso de las empresas, para el grupo de auditores continúa sin cumplirse la condición de "normalidad", según recoge el Anexo 16.

- Aplicación del test de Mann-Whitney para la hipótesis $H_{011}$

Una vez verificada la "no normalidad" de ninguna de las variables analizadas, para los dos grupos que se han estudiado, se ha procedido ha contrastar la diferencia de percepciones entre auditores y empresas mediante la aplicación de la prueba estadística de la "U de Mann-Whitney" que, como indica Spiegel (1991: 412), es la prueba adecuada cuando lo que se quiere es "decidir si hay o no diferencia entre las muestras, o sea, si proceden o no de una misma población".

Tabla $\mathrm{n}^{\mathrm{o}} 35$

Prueba de Mann-Whitney para empresas y auditores $\left(1^{\mathrm{a}} \cdot 1^{\mathrm{o}}\right.$. hipótesis)

\begin{tabular}{|c|c|c|c|c|}
\hline \multirow{2}{*}{ CUESTIONES PLANTEADAS } & \multicolumn{2}{|c|}{$\begin{array}{c}\text { VALORES MEDIOS } \\
\text { POR GRUPOS DE ESTUDIO }\end{array}$} & \multirow{2}{*}{$\begin{array}{c}\text { U de } \\
\text { Mann-Whitney }\end{array}$} & \multirow{2}{*}{ Sig. asintót. } \\
\hline & EMPRESAS & AUDITORES & & \\
\hline \multicolumn{5}{|l|}{$\begin{array}{l}\text { 1. ¿Está de acuerdo en que los auditores puedan prestar } \\
\text { otros servicios aparte de la auditoría de cuentas a las } \\
\text { empresas que auditan? }\end{array}$} \\
\hline -teneduría de libros y llevanza de contabilidad & 1.95 & 1.53 & 42754 & $0.000^{*}$ \\
\hline -asesoría fiscal & 3.08 & 3.53 & 43635 & $0.000^{*}$ \\
\hline -asesoría legal & 3.02 & 3.37 & 45159 & $0.002 *$ \\
\hline -consultoría de empresas & 3.18 & 3.75 & 40239 & $0.000 *$ \\
\hline -asesoría de inversiones y financiera & 2.65 & 3.26 & 40382 & $0.000 *$ \\
\hline -implantación de sistemas de calidad & 2.73 & 3.80 & 31023 & $0.000^{*}$ \\
\hline -auditoría medioambiental & 2.84 & 3.77 & 33730 & $0.000^{*}$ \\
\hline -auditoría de prevención de riesgos laborales & 2.70 & 3.69 & 33131 & $0.000 *$ \\
\hline -implantación de sistemas informáticos & 2.51 & 3.38 & 35285 & $0.000^{*}$ \\
\hline -servicios de tasaciones y peritajes & 2.53 & 3.35 & 36028 & $0.000 *$ \\
\hline -servicios de selección de personal & 2.41 & 3.22 & 36299 & $0.000^{*}$ \\
\hline -asesoramiento en auditoría interna & 3.77 & 3.90 & 46806 & $0.012 * *$ \\
\hline $\begin{array}{l}\text { 2. ¿Está de acuerdo en que los auditores puedan prestar } \\
\text { otros servicios aparte de la auditoría de cuentas a las } \\
\text { empresas que no auditan? }\end{array}$ & 4.21 & 4.84 & 35087 & $0.000^{*}$ \\
\hline
\end{tabular}


De los resultados obtenidos, en la tabla $n^{\circ} 35$, con el test de "MannWhitney", se desprenden las siguientes conclusiones:

- Ambos grupos, tanto empresas como auditores, se muestran en desacuerdo con que los auditores puedan prestar servicios de "llevanza de la contabilidad" a las empresas que auditan, manifestando un importante grado de desacuerdo.

- Los dos colectivos, empresas y auditores, señalan su acuerdo con que los auditores puedan realizar servicios de "asesoría fiscal", "legal" y “consultoría de empresas" a las sociedades que están auditando, sin embargo el grado de acuerdo es muy pequeño especialmente para el caso de las compañías. Tanto Humphrey, Moizer y Turley (1993) 53 como García Benau et al. (1993) contrastan en sus investigaciones que tanto auditores, directores financieros como otros usuarios manifiestan su desacuerdo con el hecho de que el auditor no pueda ofrecer servicios de asesoramiento a sus clientes. En este sentido Herrador Alcaide (2000) comprueba que las sociedades de auditoría madrileñas consideran que la prestación de otros trabajos profesionales, para el cliente de auditoría, no afecta a su independencia.

- De igual forma se producen diferencias estadísticamente significativas para los servicios, en los que las empresas muestran su desacuerdo frente al acuerdo de auditores, de "asesoría financiera y de inversiones", "implantación de sistemas de calidad", "auditoría medioambiental" y de "prevención de riesgos laborales",

\footnotetext{
${ }^{53}$ Del grupo de usuarios, en el estudio de Humphrey, Moizer y Turley (1993), sólo los periodistas especializados en economía muestran su desacuerdo con que se presten servicios de asesoramiento a los clientes de auditoría.
} 
"implantación de sistemas informáticos", "servicios de tasaciones y peritajes" y "servicios de selección de personal".

- Tanto auditores como empresas auditadas se muestran de acuerdo con que los auditores externos puedan asesorar a las empresas auditadas en "auditoría interna".

- Ambos grupos manifiestan un alto grado de acuerdo con que los auditores pueden prestar "otros servicios" a empresas que no son clientes de auditoría externa o de cuentas anuales.

De las conclusiones expresadas se obtiene suficiente evidencia para "rechazar" la hipótesis nula $\left(\mathrm{H}_{011}\right)$, en torno a la igualdad de percepciones en la prestación de servicios adicionales a la propia auditoría.

- Aplicación del test T para la hipótesis $H_{011}$

Para corroborar los resultados obtenidos con la aplicación de la prueba no paramétrica de "Mann-Whitney" se ha realizado el "test paramétrico T", para dos muestras independientes, de manera que los hallazgos alcanzados son los mismos salvo en el caso de la cuestión relativa al "asesoramiento en auditoría interna", ya que con dicha prueba la diferencia, entre grupos, no es estadísticamente significativa, según se observa en el Anexo 20.

- Análisis pormenorizado con el grupo de empresas para la hipótesis $H_{011}$

Como se distingue, en la tabla $\mathrm{n}^{\circ} 36$, se produce un claro acuerdo entre las empresas de las distintas comunidades sobre determinados servicios que el auditor puede prestar de forma adicional a su cliente de auditoría; en este 
sentido los responsables andaluces están de acuerdo con que los auditores puedan prestar servicios como "consultoría", "asesoría de inversiones y financiera", de "calidad" o en "auditoría interna"; frente a esta postura las empresas catalanas, madrileñas y valencianas manifiestan su desacuerdo con que se suministren, en concreto, los servicios de "asesoría de inversiones y financiera" y de "calidad", a los propios clientes de auditoría. Además las empresas valencianas tampoco están de acuerdo en que se presten servicios de "consultoría".

Tabla $n^{\circ} 36$

Prueba de Kruskal-Wallis para las empresas agrupadas por CCAA (1 $1^{\mathrm{a}} \cdot 1^{\mathrm{o}}$. hipótesis)

\begin{tabular}{|c|c|c|c|c|c|c|}
\hline \multirow{2}{*}{ CUESTIONES PLANTEADAS } & \multicolumn{4}{|c|}{ VALORES MEDIOS } & \multirow{2}{*}{$\begin{array}{c}\text { Chi- } \\
\text { cuadrado }\end{array}$} & \multirow{2}{*}{ Sig. asintót. } \\
\hline & ANDALUCÍA & CATALUÑa & MADRID & VALENCIA & & \\
\hline \multicolumn{7}{|c|}{$\begin{array}{l}\text { 1. ¿Está de acuerdo en que los auditores puedan } \\
\text { prestar otros servicios aparte de la auditoría de } \\
\text { cuentas a las empresas que auditan? }\end{array}$} \\
\hline -consultoría de empresas & 4.07 & 3.05 & 3.03 & 2.74 & 9.483 & $0.024 * *$ \\
\hline -asesoría de inversiones y financiera & 3.60 & 2.48 & 2.47 & 2.44 & 9.580 & $0.022 * *$ \\
\hline -implantación de sistemas de calidad & 3.60 & 2.51 & 2.89 & 2.62 & 8.192 & $0.042 * *$ \\
\hline -asesoramiento en auditoría interna & 4.64 & 3.78 & 3.79 & 3.66 & 9.494 & $0.023^{* *}$ \\
\hline \multicolumn{7}{|c|}{$\begin{array}{l}\text { * Estadísticamente significativo al 1\% } * * \text { Estadísticamente significativo al } 5 \% * * * \text { Estadísticamente significativo al 10\% } \\
\mathrm{NS}=\text { estadísticamente no significativo }\end{array}$} \\
\hline
\end{tabular}

Tabla ${ }^{\circ} 37$ Prueba de Mann-Whitney

para las empresas agrupadas por los estudios de postgrado $\left(1^{\mathrm{a}} .1^{\mathrm{o}}\right.$. hipótesis)

\begin{tabular}{|c|c|c|c|c|}
\hline \multirow{2}{*}{ CUESTIONES PLANTEADAS } & \multicolumn{2}{|c|}{ VALORES MEDIOS } & \multirow{2}{*}{$\begin{array}{c}\text { U de } \\
\text { Mann-Whitney }\end{array}$} & \multirow{2}{*}{$\begin{array}{l}\text { Sig. } \\
\text { asintót. }\end{array}$} \\
\hline & $\begin{array}{c}\text { Sin estudios de } \\
\text { postgrado }\end{array}$ & $\begin{array}{c}\text { Con estudios de } \\
\text { postgrado }\end{array}$ & & \\
\hline \multicolumn{5}{|c|}{$\begin{array}{l}\text { 1. ¿Está de acuerdo en que los auditores puedan prestar } \\
\text { otros servicios aparte de la auditoría de cuentas a las } \\
\text { empresas que auditan? }\end{array}$} \\
\hline - asesoría fiscal & 3.19 & 2.68 & 6905.5 & $0.009 *$ \\
\hline -asesoría legal & 3.11 & 2.68 & 7111 & $0.025 * *$ \\
\hline -consultoría de empresas & 3.26 & 2.77 & 6949.5 & $0.013^{*}$ \\
\hline -auditoría medioambiental & 2.92 & 2.57 & 7320 & $0.070 * * *$ \\
\hline \multicolumn{5}{|c|}{$\begin{array}{l}* \text { Estadísticamente significativo al } 1 \% * * \text { Estadísticamente significativo al } 5 \% * * * \text { Estadísticamente significativo al } 10 \% \\
\text { NS= estadísticamente no significativo } \\
\text { Las valoraciones medias corresponden a una escala de medida entre } 1 \text { total desacuerdo hasta } 5 \text { total acuerdo. }\end{array}$} \\
\hline
\end{tabular}


Los directivos de empresas con estudios de postgrado muestran su desacuerdo con que se presten servicios accesorios de "asesoría fiscal", "legal", "consultoría" y "auditoría medioambiental"; por el contrario los que carecen de dichos estudios se manifiestan de acuerdo, salvo para el caso de "auditoría medioambiental".

- Análisis pormenorizado con el grupo de auditores para la hipótesis $H_{011}$

\section{Tabla $\mathrm{n}^{\mathrm{o}} 38$}

Prueba de Kruskal-Wallis para los auditores agrupados por CCAA (1ª 1 . hipótesis)



Mientras los auditores de las comunidades aragonesa y gallega se manifiestan en una posición neutra sobre que el auditor pueda asesorar a sus clientes de auditoría en la "implantación de sistemas de calidad", los de las comunidades madrileña y vasca se muestran de acuerdo, especialmente los de esta última.

Se produce una diferencia, significativa estadísticamente, entre auditores con estudios universitarios de grado medio y los de grado superior; de manera que mientras los primeros se manifiestan en desacuerdo con que se presten a las empresas auditadas servicios adicionales de "asesoría de inversiones y financiera" los segundos opinan lo contrario. 
Tabla n 39 Prueba de Mann-Whitney

para los auditores agrupados por el nivel de estudios $\left(1^{\mathrm{a}} \cdot 1^{\mathrm{o}}\right.$. hipótesis)

\begin{tabular}{|c|c|c|c|c|}
\hline \multirow{2}{*}{ CUESTIONES PLANTEADAS } & \multicolumn{2}{|c|}{$\begin{array}{c}\text { VALORES MEDIOS } \\
\text { POR NIVEL DE ESTUDIOS }\end{array}$} & \multirow[t]{2}{*}{$\begin{array}{l}\text { U de Mann- } \\
\text { Whitney }\end{array}$} & \multirow{2}{*}{ Sig. asintót } \\
\hline & $\begin{array}{c}\text { Estudios } \\
\text { universitarios de } \\
\text { grado medio }\end{array}$ & $\begin{array}{c}\text { Estudios } \\
\text { universitarios de } \\
\text { grado superior }\end{array}$ & & \\
\hline \multicolumn{5}{|l|}{$\begin{array}{l}\text { 1. ¿Está de acuerdo en que los auditores puedan } \\
\text { prestar otros servicios aparte de la auditoría de cuentas } \\
\text { a las empresas que auditan? }\end{array}$} \\
\hline -consultoría de empresas & 3.44 & 3.81 & 5003.5 & $0.087^{* * *}$ \\
\hline -asesoría de inversiones y financiera & 2.88 & 3.32 & 4960.5 & $0.091 * * *$ \\
\hline $\begin{array}{l}\text { 2. ¿Está de acuerdo en que los auditores puedan } \\
\text { prestar otros servicios aparte de la auditoría de cuentas } \\
\text { a las empresas que no auditan? }\end{array}$ & 4.60 & 4.87 & 5078.5 & $0.014 * *$ \\
\hline
\end{tabular}

Tabla ${ }^{\circ} 40$

Prueba de Kruskal-Wallis para los auditores agrupados por la edad (1 $1^{\mathrm{a}} .1$. hipótesis)

\begin{tabular}{|c|c|c|c|c|c|c|}
\hline \multirow{2}{*}{ CUESTIONES PLANTEADAS } & \multicolumn{4}{|c|}{ VALORES MEDIOS DE EDAD } & \multirow{2}{*}{$\begin{array}{c}\text { Chi- } \\
\text { cuadrado }\end{array}$} & \multirow{2}{*}{$\begin{array}{l}\text { Sig. } \\
\text { asintót. }\end{array}$} \\
\hline & $20<X \# \mathbf{X}$ & $30<\mathrm{X} \# \mathbf{4 0}$ & $40<X$ \#50 & $\mathbf{5 0}<\mathbf{X}$ & & \\
\hline \multicolumn{7}{|c|}{$\begin{array}{l}\text { 1. ¿Está de acuerdo con que los auditores } \\
\text { puedan prestar otros servicios aparte de la } \\
\text { auditoría de cuentas a las empresas que } \\
\text { auditan? }\end{array}$} \\
\hline -asesoría legal & 4.10 & 3.74 & 3.36 & 3.12 & 9.909 & $0.019 * *$ \\
\hline -asesoría de inversiones y financiera & 3.90 & 3.72 & 3.27 & 2.92 & 13.136 & $0.004 *$ \\
\hline -implantación de sistemas de calidad & 3.56 & 4.21 & 3.71 & 3.68 & 6.470 & $0.091^{* * *}$ \\
\hline -auditoría medioambiental & 3.00 & 4.25 & 3.69 & 3.63 & 9.935 & $0.019 * *$ \\
\hline $\begin{array}{l}\text {-auditoría de prevención de riesgos } \\
\text { laborales }\end{array}$ & 2.80 & 4.16 & 3.56 & 3.65 & 9.514 & $0.023 * *$ \\
\hline -implantación de sistemas informáticos & 3.30 & 3.83 & 3.27 & 3.24 & 7.478 & $0.058 * * *$ \\
\hline \multicolumn{7}{|c|}{$\begin{array}{l}\text { * Estadísticamente significativo al } 1 \% * * \text { Estadísticamente significativo al } 5 \% * * * \text { Estadísticamente significativo al } 10 \% \\
\text { NS= estadísticamente no significativo }\end{array}$} \\
\hline
\end{tabular}

Según se observa, en la tabla $\mathrm{n}^{\circ} 40$, sobre la posibilidad de prestar otros servicios aparte de la auditoría, para el caso de servicios de "asesoría de inversiones y financiera" los auditores con edades comprendidas entre 20 y 50 años manifiestan su acuerdo; una vez superada dicha edad se muestra un muy leve desacuerdo. Respecto a ofrecer, además, “auditoría de prevención 
de riesgos laborales", mientras los auditores mayores de 30 años expresan su acuerdo los más jóvenes indican su desacuerdo.

\subsubsection{Segunda hipótesis}

La hipótesis nula que se ha planteado en segundo lugar se define como:

$\mathrm{H}_{02}$ : Los auditores, sociedades auditadas, entidades de crédito (representadas por Bancos, Cajas de Ahorros y Cajas Rurales) y analistas financieros (representados por Agencias y Sociedades de Valores) muestran la misma percepción sobre la utilidad que presta la auditoría de cuentas.

Se han realizado las pruebas de "normalidad" de las distribuciones que muestran los diferentes grupos de estudio, para ello se ha aplicado el test de "Kolmogorov-Smirnov", con la finalidad de determinar que prueba es más conveniente practicar para contrastar la hipótesis.

- Aplicación del test de Kolmogorov-Smirnov para la hipótesis $\mathrm{H}_{02}$

Como se observa en el Anexo 5, la prueba de "Kolmogorov-Smirnov" para el grupo de empresas auditadas indica que ninguno de los ítems propuestos, para medir la "utilidad" de la auditoría, se comporta siguiendo una distribución normal.

Al igual que para el grupo de sociedades, en el caso de los auditores tampoco se obtiene que las distribuciones estudiadas se comporten según la "normal", tal y como se comprueba en el Anexo 6 al observar la columna relativa al nivel de "significatividad asintótica bilateral". 
En el caso del grupo representado por bancos, cajas de ahorros y cajas rurales sólo uno de los ítems, el último, sigue una distribución normal, mientras que el resto no se comporta "normalmente" según se refleja en el Anexo 7.

De la tabla que aparece en el Anexo 8 se deriva que para la mayoría de los casos, con el grupo de agencias y sociedades de valores, se verifica la "normalidad" de las distribuciones, por ello se ha pasado a realizar el mismo test pero con la restricción de "Lilliefors", que como señala Ato García (1991: 194) "se emplea como prueba de normalidad cuando los valores de la media y varianza de una población son desconocidos". Una vez practicado el test de "Lilliefors" (véase Anexo 9) se contrasta que las distribuciones de los casos, para el grupo de agencias y sociedades de valores, tampoco siguen distribuciones normales y, por tanto, dicha prueba rebate la "normalidad" verificada en el contraste anterior.

- Aplicación del test de Kruskal-Wallis para la hipótesis $\mathrm{H}_{02}$

La etapa siguiente, una vez comprobada la "no normalidad" de las distribuciones de los ítems que sirven para valorar la "utilidad de la auditoría" de cuentas, para cada uno de los grupos analizados, consiste en contrastar la segunda hipótesis aplicando el test de "Kruskal-Wallis" que, como indica Newbold (1997), se debe emplear cuando se sospeche que las distribuciones de las poblaciones objeto de estudio son diferentes a la "normal". 
Tabla $n^{\circ} 41$

Prueba de Kruskal-Wallis para los grupos encuestados (2a hipótesis)

\begin{tabular}{|c|c|c|c|c|c|c|}
\hline \multirow{2}{*}{ CUESTIONES PLANTEADAS } & \multicolumn{4}{|c|}{$\begin{array}{l}\text { VALORES MEDIOS } \\
\text { POR GRUPOS DE ESTUDIO }\end{array}$} & \multirow{2}{*}{$\begin{array}{c}\text { Chi- } \\
\text { cuadrado }\end{array}$} & \multirow{2}{*}{$\begin{array}{l}\text { Sig. } \\
\text { asintót. }\end{array}$} \\
\hline & EMPRESAS & AUDITORES & \begin{tabular}{|c|} 
BANCOS \\
Y \\
CAJAS
\end{tabular} & \begin{tabular}{|c|} 
AG. Y SOC. \\
DE \\
VALORES
\end{tabular} & & \\
\hline \multicolumn{7}{|l|}{$\begin{array}{l}\text { 1. Exprese su grado de acuerdo con las siguientes } \\
\text { afirmaciones: }\end{array}$} \\
\hline $\begin{array}{l}\text {-las cuentas anuales muestran la imagen real de las } \\
\text { empresas }\end{array}$ & 3.75 & 3.35 & 3.31 & 3.61 & 20.617 & $0.000^{*}$ \\
\hline $\begin{array}{l}\text {-la auditoría aporta fiabilidad a las cuentas anuales } \\
\text { de las empresas }\end{array}$ & 4.36 & 4.63 & 4.35 & 4.42 & 29.536 & $0.000^{*}$ \\
\hline $\begin{array}{l}\text {-la auditoría aporta "valor añadido" a la sociedad } \\
\text { auditada }\end{array}$ & 3.58 & 4.21 & 3.74 & 3.48 & 58.588 & $0.000^{*}$ \\
\hline -el coste de la auditoría está justificado & 3.28 & 4.44 & 3.53 & 2.97 & 186.632 & $0.000 *$ \\
\hline $\begin{array}{l}\text {-la auditoría se realiza exclusivamente por ser una } \\
\text { obligación legal }\end{array}$ & 2.98 & 3.12 & 2.78 & 2.91 & 5.575 & $0.134^{\mathrm{NS}}$ \\
\hline -la auditoría es un servicio de interés público & 3.41 & 4.14 & 3.68 & 3.61 & 59.259 & $0.000 *$ \\
\hline $\begin{array}{l}\text {-la opinión que emite el auditor es completamente } \\
\text { independiente }\end{array}$ & 3.82 & 4.36 & 3.69 & 3.21 & 76.618 & $0.000 *$ \\
\hline $\begin{array}{l}\text {-la opinión del auditor conlleva un alto grado de } \\
\text { subjetividad }\end{array}$ & 2.64 & 2.42 & 2.50 & 2.70 & 8.551 & $0.036^{* *}$ \\
\hline \multicolumn{7}{|l|}{$\begin{array}{l}\text { 2. Exprese su grado de acuerdo con las siguientes } \\
\text { afirmaciones: }\end{array}$} \\
\hline $\begin{array}{l}\text {-las cuentas anuales aportan información para la } \\
\text { toma de decisiones }\end{array}$ & 3.45 & 3.91 & 4.04 & 3.73 & 25.831 & $0.000 *$ \\
\hline $\begin{array}{l}\text {-el informe del auditor aporta información adicional } \\
\text { para la toma de decisiones }\end{array}$ & 3.09 & 3.70 & 3.66 & 3.18 & 41.423 & $0.000 *$ \\
\hline $\begin{array}{l}\text {-la carta de recomendaciones aporta información } \\
\text { adicional para la gestión }\end{array}$ & 3.54 & 4.17 & 3.75 & 3.52 & 62.053 & $0.000 *$ \\
\hline $\begin{array}{l}\text {-el informe es útil para determinar si la empresa es } \\
\text { financieramente viable }\end{array}$ & 3.13 & 3.24 & 3.48 & 3.06 & 6.158 & $0.104^{\mathrm{NS}}$ \\
\hline $\begin{array}{l}\text {-un informe limpio aporta información más relevante } \\
\text { que uno con salvedades }\end{array}$ & 2.63 & 2.32 & 2.90 & 2.64 & 14.003 & $0.003 *$ \\
\hline
\end{tabular}

Del cuadro anterior se deducen los resultados que siguen:

- Existen diferencias estadísticamente significativas, entre los grupos, en relación con la expresión que indica que "las cuentas anuales muestran la imagen real de las empresas", no obstante tanto unos como otros se manifiestan de acuerdo con dicha afirmación. Miller et al. (1990) llegan a la misma conclusión con el colectivo de entidades financieras. 
- De igual forma se producen diferencias significativas en cuanto a que la auditoría aporte "fiabilidad" a las cuentas anuales de las empresas, sin embargo tanto empresas, auditores, entidades financieras como analistas muestran un elevado grado de acuerdo en la cuestión; comprobándose con la prueba de "Mann-Whitney" que los auditores expresan mayor grado de acuerdo que las empresas auditadas. Beck (1973) obtiene el mismo resultado, en Australia, para un grupo de accionistas. En este sentido Herrador Alcaide (2000) señala que los auditores de la Comunidad de Madrid consideran que el informe de auditoría añade mucha "credibilidad" a las cuentas anuales.

- En el mismo sentido "de acuerdo" se pronuncian todos los grupos cuando se les pregunta sobre si la auditoría de cuentas aporta "valor añadido" a la sociedad, evidenciando el test que se dan diferencias de percepciones estadísticamente significativas; además los auditores revelan un mayor grado de acuerdo que las sociedades con el hecho de que la auditoría aporte "valor añadido", según se desprende de la prueba de "diferencia de medias por parejas". Las investigaciones de Humphrey, Moizer y Turley (1993) y García Benau et al. (1993) llegan al mismo resultado al constatar que todos los grupos encuestados están de acuerdo en que la auditoría es beneficiosa.

- Las empresas, auditores y entidades de crédito se muestran de acuerdo con que "el coste de auditoría se encuentre justificado", produciéndose diferencias dentro de ese grado de acuerdo que son significativas. Por contra, el grupo de agencias y sociedades de valores no se manifiesta de acuerdo con que el coste de la auditoría se encuentre justificado. 
- Todos los grupos encuestados se manifiestan de acuerdo con el hecho de que la auditoría de cuentas sea considerada como un "servicio de interés público", habiéndose comprobado que el grupo de auditores presenta un mayor grado de acuerdo que las empresas, según ratifica la prueba de "Mann-Whitney", y constatando que las diferencias entre grupos son significativas. En el mismo sentido se pronuncian los estudios empíricos realizados por García Benau et al. (1993) y Humphrey, Moizer y Turley (1993), salvo, en ésta última investigación, donde los grupos de analistas de inversiones y periodistas, especializados en economía, se manifiestan de manera neutra los primeros y en desacuerdo los segundos.

- Existe común acuerdo sobre que "la opinión que emite el auditor es completamente independiente", siendo las diferencias estadísticamente significativas, y mostrado el "test de contraste de medias dos a dos" que el grupo de auditores es el que manifiesta un mayor acuerdo, seguido del grupo de empresas y en último lugar de sociedades y agencias de valores. Los resultados coinciden con García Benau et al. (1993) y Humphrey, Moizer y Turley (1993), salvo, en éste último estudio, para los grupos de analistas de inversiones y periodistas especializados en economía, que se manifiestan de manera neutra los primeros y en desacuerdo los segundos. El estudio realizado por Beck (1973), en Australia, refleja que la mayoría de accionistas esperan del auditor que sea completamente independiente de la dirección de la empresa.

- Todos los grupos se revelan en desacuerdo con la afirmación que indica que "la opinión del auditor conlleva un alto grado de subjetividad", produciéndose diferencias estadísticamente 
significativas entre los grupos. Kelly y Mohrweis (1989) obtienen el mismo resultado con inversores y entidades financieras en Estados Unidos.

- Al aplicar la prueba de "Mann-Whitney por parejas", se observa que, las entidades financieras, aparecen como el grupo que presenta un mayor grado de acuerdo sobre que "las cuentas anuales aporten información para la toma de decisiones", estando todos los grupos en acuerdo y siendo las diferencias significativas como señala la tabla $n^{\circ}$ 41.

- Los grupos de auditores, entidades financieras, analistas y empresas se muestran de acuerdo sobre que el "informe del auditor aporte información adicional para la toma de decisiones", no obstante el grado de acuerdo es bajo o muy bajo para el caso de empresas y agencias y sociedades de valores.

- Todos los encuestados se manifiestan de acuerdo con que la "carta de recomendaciones" suponga información adicional para la gestión, además las diferencias, entre grupos, son significativas desde el punto de vista estadístico.

- Por último, todos los grupos se muestran en desacuerdo con el hecho de que un informe "limpio" aporte más información que uno con "salvedades". Robertson (1988) obtiene en su experimento que los analistas financieros conceden más credibilidad y se muestran más satisfechos cuando los informes contienen salvedades que en caso contrario. 
Con los resultados obtenidos se puede concluir "rechazando" la hipótesis nula que mantenía igualdad de percepciones, entre los grupos, sobre la "utilidad" que implica el servicio de auditoría de cuentas.

- Aplicación del análisis de la varianza en un sentido para la hipótesis $H_{02}$

Para ratificar los resultados obtenidos para la segunda hipótesis, con la aplicación de la prueba no paramétrica de "Kruskal-Wallis", se ha desarrollado el test paramétrico del "análisis de la varianza en un sentido".

Al aplicar la prueba ANOVA se consiguen los mismos resultados y se corroboran las diferencias señaladas mediante el test no paramétrico, de "Kruskal-Wallis", excepto en el caso de la afirmación que hace referencia a que "la opinión del auditor conlleva un alto grado de subjetividad" como se refleja en el Anexo 18. Posteriormente se han realizado dos pruebas "posthoc", en función de la "homogeneidad o no de varianzas" que marca la prueba de "Levene", así en los casos de igualdad de varianzas se ha aplicado la prueba "HSD de Tukey" mientras que en el caso contrario se ha utilizado la prueba de "Tamhane", para comprobar el origen de las diferencias intergrupos.

Al practicar la prueba de "Tukey" se observa que en las afirmaciones donde se recoge que, "las cuentas anuales muestran la imagen real de las empresas", el "informe aporta información adicional para la toma de decisiones" y un "informe limpio aporta más información que uno con salvedades"; las diferencias apreciadas son debidas a las distintas percepciones entre auditores, empresas y entidades financieras pero no con agencias y sociedades de valores. 
Del test de "Tamhane" se deriva que en las cuestiones relacionadas con que "la auditoría aporta valor añadido" a la sociedad auditada, que "el coste de la auditoría este justificado", que "la auditoría sea un servicio de interés público" y que "la carta de recomendaciones aporte información adicional para la gestión", las diferencias estadísticas se producen entre dos grupos, el grupo de auditores por una parte y el resto de encuestados por otra.

- Análisis pormenorizado con el grupo de empresas para la hipótesis $\mathrm{H}_{02}$

Tabla $n^{\circ} 42$

Prueba de Mann-Whitney para las empresas agrupadas por sexo (2a hipótesis)

\begin{tabular}{|c|c|c|c|c|}
\hline \multirow[t]{2}{*}{ CUESTIONES PLANTEADAS } & \multicolumn{2}{|c|}{ VALORES MEDIOS } & \multirow{2}{*}{$\begin{array}{c}\text { U de } \\
\text { Mann- } \\
\text { Whitney }\end{array}$} & \multirow{2}{*}{$\begin{array}{l}\text { Sig. asintót. } \\
\text { (bilateral) }\end{array}$} \\
\hline & HOMBRE & MUJER & & \\
\hline \multicolumn{5}{|l|}{$\begin{array}{l}\text { 1. Exprese su grado de acuerdo con las siguientes } \\
\text { afirmaciones: }\end{array}$} \\
\hline -la auditoría es un servicio de interés público & 3.52 & 2.85 & 4069 & $0.001 *$ \\
\hline $\begin{array}{l}\text {-la opinión del auditor conlleva un alto grado de } \\
\text { subjetividad }\end{array}$ & 2.70 & 2.34 & 4705 & $0.037 * *$ \\
\hline $\begin{array}{l}\text {-las cuentas anuales aportan información para la } \\
\text { toma de decisiones }\end{array}$ & 3.38 & 3.73 & 4898.5 & $0.078 * * *$ \\
\hline
\end{tabular}

Como se desprende de la tabla $\mathrm{n}^{\mathrm{O}} 42$, mientras los responsables de las empresas encuestadas de sexo masculino se manifiestan de acuerdo con que la auditoría es un "servicio de interés público", los responsables de sexo femenino lo hacen en desacuerdo.

La variable relativa al "nivel de estudios" es especialmente útil para determinadas cuestiones; según la tabla $n^{\circ} 43$ los encuestados con preparación a nivel de bachillerato o formación profesional muestran un leve acuerdo con que "la opinión del auditor es bastante subjetiva", por el contrario los universitarios, tanto de grado medio como de grado superior, no están de acuerdo con dicha afirmación. Sucede lo mismo cuando se les 
solicita que opinen sobre si "un informe limpio aporta más información que uno con salvedades", así mientras los que presentan un nivel de formación más bajo muestran su acuerdo los universitarios se pronuncian en desacuerdo.

Tabla no 43 Prueba de Kruskal-Wallis

para las empresas agrupadas por el nivel de estudios ( $2^{a}$ hipótesis)

\begin{tabular}{|c|c|c|c|c|c|}
\hline \multirow{2}{*}{ CUESTIONES PLANTEADAS } & \multicolumn{3}{|c|}{$\begin{array}{l}\text { VALORES MEDIOS } \\
\text { POR NIVEL DE ESTUDIOS }\end{array}$} & \multirow{2}{*}{$\begin{array}{l}\text { Chi- } \\
\text { cuadrado }\end{array}$} & \multirow{2}{*}{$\begin{array}{l}\text { Sig. } \\
\text { asintót }\end{array}$} \\
\hline & $\begin{array}{c}\text { Bachiller } \\
\text {-Fp }\end{array}$ & \begin{tabular}{|c|}
$\begin{array}{c}\text { Estudios } \\
\text { universitarios de } \\
\text { grado medio }\end{array}$ \\
\end{tabular} & \begin{tabular}{|c|} 
Estudios \\
universitarios de \\
grado superior
\end{tabular} & & \\
\hline \multicolumn{6}{|l|}{$\begin{array}{l}\text { 1. Exprese su grado de acuerdo con las siguientes } \\
\text { afirmaciones: }\end{array}$} \\
\hline $\begin{array}{l}\text {-la auditoría aporta "valor añadido" a la sociedad } \\
\text { auditada }\end{array}$ & 3.45 & 4.17 & 3.46 & 15.470 & $0.000 *$ \\
\hline $\begin{array}{l}\text {-la opinión del auditor conlleva un alto grado de } \\
\text { subjetividad }\end{array}$ & 3.13 & 2.89 & 2.47 & 13.979 & $0.001 *$ \\
\hline $\begin{array}{l}\text {-las cuentas anuales aportan información para la } \\
\text { toma de decisiones }\end{array}$ & 3.95 & 3.31 & 3.41 & 6.018 & $0.049 * *$ \\
\hline $\begin{array}{l}\text {-el informe del auditor aporta información } \\
\text { adicional para la toma de decisiones }\end{array}$ & 3.49 & 2.93 & 3.04 & 5.013 & $0.08 * * *$ \\
\hline $\begin{array}{l}\text {-el informe es útil para determinar si la empresa es } \\
\text { financieramente viable }\end{array}$ & 3.61 & 3.06 & 3.05 & 7.730 & $0.021 * *$ \\
\hline $\begin{array}{l}\text {-un informe limpio aporta información más } \\
\text { relevante que uno con salvedades }\end{array}$ & 3.27 & 2.79 & 2.41 & 9.166 & $0.010^{*}$ \\
\hline \multicolumn{6}{|c|}{$\begin{array}{l}\text { * Estadísticamente significativo al } 1 \% * * \text { Estadísticamente significativo al } 5 \% * * * \text { Estadísticamente significativo al } 10 \% \\
\text { NS }=\text { estadísticamente no significativo }\end{array}$} \\
\hline
\end{tabular}

En la tabla $\mathrm{n}^{\mathrm{o}} 44$ se aprecia, y verifica con la prueba de "MannWhitney por parejas", que aquellos responsables de empresas con experiencia profesional superior a veinte años presentan un mayor grado de acuerdo que los que se encuentran en el intervalo con menor antigüedad laboral, en cuanto a que "las cuentas anuales muestren la imagen real de las empresas", que la auditoría aporte "fiabilidad", "valor añadido", así como con que "la opinión que emite el auditor sea independiente". Además los que poseen una experiencia que oscila entre 1 y 10 años manifiestan un leve desacuerdo con que "el coste de la auditoría esté justificado" mientras que los de experiencia mayor muestran su acuerdo. Adicionalmente cuando la mayoría de los encuestados se muestra en desacuerdo con que "la opinión lleve aparejada un alto grado de subjetividad", el grupo que tiene una 
experiencia profesional entre 5 y 10 años mantiene una posición indiferente o neutra.

Tabla n ${ }^{\circ} 44$ Prueba de Kruskal-Wallis

para las empresas agrupadas por la experiencia profesional ( $2^{\mathrm{a}}$ hipótesis)

\begin{tabular}{|c|c|c|c|c|c|c|}
\hline \multirow{2}{*}{ CUESTIONES PLANTEADAS } & \multicolumn{4}{|c|}{$\begin{array}{l}\text { VALORES MEDIOS DE AÑOS DE } \\
\text { EXPERIENCIA PROFESIONAL }\end{array}$} & \multirow{2}{*}{$\begin{array}{c}\text { Chi- } \\
\text { cuadrado }\end{array}$} & \multirow{2}{*}{$\begin{array}{l}\text { Sig. } \\
\text { asintót. }\end{array}$} \\
\hline & $1<\mathrm{X} \# \mathbf{5}$ & $5<X \# 10$ & $10<\mathbf{X} \# \mathbf{2 0}$ & $20<X$ & & \\
\hline \multicolumn{7}{|l|}{$\begin{array}{l}\text { 1. Exprese su grado de acuerdo con las siguientes } \\
\text { afirmaciones: }\end{array}$} \\
\hline $\begin{array}{l}\text {-las cuentas anuales muestran la imagen real de } \\
\text { las empresas }\end{array}$ & 3.56 & 3.59 & 3.68 & 4.00 & 8.662 & $0.034 * *$ \\
\hline $\begin{array}{l}\text {-la auditoría aporta fiabilidad a las cuentas } \\
\text { anuales de las empresas }\end{array}$ & 4.21 & 4.09 & 4.41 & 4.54 & 11.565 & $0.009^{*}$ \\
\hline $\begin{array}{l}\text {-la auditoría aporta "valor añadido" a la sociedad } \\
\text { auditada }\end{array}$ & 3.32 & 3.43 & 3.58 & 3.86 & 8.300 & $0.40^{* *}$ \\
\hline -el coste de la auditoría está justificado & 2.94 & 2.97 & 3.34 & 3.67 & 16.752 & $0.001^{*}$ \\
\hline -la auditoría es un servicio de interés público & 3.03 & 3.35 & 3.35 & 3.68 & 7.706 & $0.52 * * *$ \\
\hline $\begin{array}{l}\text {-la opinión que emite el auditor es completamente } \\
\text { independiente }\end{array}$ & 3.59 & 3.51 & 3.84 & 4.11 & 12.653 & $0.005^{*}$ \\
\hline $\begin{array}{l}\text {-la opinión del auditor conlleva un alto grado de } \\
\text { subjetividad }\end{array}$ & 2.50 & 3.07 & 2.48 & 2.57 & 11.438 & $0.010^{*}$ \\
\hline $\begin{array}{l}\text {-la carta de recomendaciones aporta } \\
\text { información adicional para la gestión }\end{array}$ & 3.52 & 3.28 & 3.49 & 3.80 & 9.420 & $0.024 * *$ \\
\hline
\end{tabular}

- Análisis pormenorizado con el grupo de auditores para la hipótesis $H_{02}$

Tabla ${ }^{\circ} 45$

Prueba de Kruskal-Wallis para los auditores agrupados por CCAA (2 $2^{\mathrm{a}}$ hipótesis)

\begin{tabular}{|c|c|c|c|c|c|c|}
\hline \multirow{2}{*}{ CUESTIONES PLANTEADAS } & \multicolumn{4}{|c|}{ VALORES MEDIOS } & \multirow{2}{*}{$\begin{array}{c}\text { Chi- } \\
\text { cuadrado }\end{array}$} & \multirow{2}{*}{$\begin{array}{l}\text { Sig. } \\
\text { asintót. }\end{array}$} \\
\hline & ANDALUCÍA & CATALUÑ̃A & MADRID & VALENCIA & & \\
\hline \multicolumn{7}{|l|}{$\begin{array}{l}\text { 1. Exprese su grado de acuerdo con las siguientes } \\
\text { afirmaciones: }\end{array}$} \\
\hline $\begin{array}{l}\text {-la auditoría se realiza exclusivamente por ser } \\
\text { una obligación legal }\end{array}$ & 3.28 & 2.83 & 2.90 & 3.57 & 9.021 & $0.029 * *$ \\
\hline $\begin{array}{l}\text {-las cuentas anuales aportan información para } \\
\text { la toma de decisiones }\end{array}$ & 3.78 & 4.00 & 4.19 & 3.54 & 6.481 & $0.09 * * *$ \\
\hline \multicolumn{7}{|c|}{$\begin{array}{l}* \text { Estadísticamente significativo al } 1 \% * * \text { Estadísticamente significativo al } 5 \% * * * \text { Estadísticamente significativo al } 10 \% \\
\mathrm{NS}=\text { estadísticamente no significativo } \\
\text { Las valoraciones medias corresponden a una escala de medida entre } 1 \text { total desacuerdo hasta } 5 \text { total acuerdo. }\end{array}$} \\
\hline
\end{tabular}

Los auditores pertenecientes a las Comunidades Andaluza y Valenciana se manifiestan de acuerdo con que la auditoría de cuentas la solicitan las empresas como consecuencia de una "obligación legal", mientras 
que los auditores procedentes de las Comunidades Catalana y Madrileña indican su desacuerdo con dicha idea.

- Análisis pormenorizado con el grupo de entidades de crédito para la hipótesis $\mathrm{H}_{02}$

Como se observa, en la tabla $\mathrm{n}^{\circ} 46$, una mayor parte de los directivos de entidades financieras encuestados se manifiestan en desacuerdo con que la auditoría de cuentas se realice por ser una "obligación legal"; no obstante el grupo de individuos cuya experiencia profesional se encuentra entre 5 y 10 años se pronuncia en sentido opuesto, es decir, expresando su acuerdo con esta motivación.

Tabla $n^{\circ} 46$ Prueba de Kruskal-Wallis para las entidades de crédito agrupadas por la experiencia profesional ( $2^{\mathrm{a}}$ hipótesis)

\begin{tabular}{|c|c|c|c|c|c|c|}
\hline \multirow{2}{*}{ CUESTIONES PLANTEADAS } & \multicolumn{4}{|c|}{$\begin{array}{l}\text { VALORES MEDIOS DE AÑOS DE } \\
\text { EXPERIENCIA PROFESIONAL }\end{array}$} & \multirow{2}{*}{$\begin{array}{c}\text { Chi- } \\
\text { cuadrado }\end{array}$} & \multirow{2}{*}{$\begin{array}{c}\text { Sig. } \\
\text { asintót. }\end{array}$} \\
\hline & $1<X$ \# 5 & $5<X \# 10$ & $10<X \# 20$ & $20<X$ & & \\
\hline \multicolumn{7}{|l|}{$\begin{array}{l}\text { 1. Exprese su grado de acuerdo con las siguientes } \\
\text { afirmaciones: }\end{array}$} \\
\hline $\begin{array}{l}\text {-la auditoría se realiza exclusivamente por } \\
\text { ser una obligación legal }\end{array}$ & 1.80 & 3.21 & 2.58 & 2.91 & 6.954 & $0.073 * * *$ \\
\hline
\end{tabular}

- Análisis pormenorizado con el grupo de agencias y sociedades de valores para la hipótesis $H_{02}$

Tabla no 47 Prueba de Kruskal-Wallis para las agencias y soc. de valores agrupadas por la experiencia profesional ( $2^{\mathrm{a}}$ hipótesis)

\begin{tabular}{|c|c|c|c|c|c|}
\hline \multirow{2}{*}{ CUESTIONES PLANTEADAS } & \multicolumn{3}{|c|}{$\begin{array}{l}\text { VALORES MEDIOS DE AÑOS } \\
\text { DE EXPERIENCIA } \\
\text { PROFESIONAL }\end{array}$} & \multirow{2}{*}{ Chi-cuadrado } & \multirow{2}{*}{ Sig. asintót. } \\
\hline & $5<X \# 10$ & $10<\mathrm{X} \# \mathbf{2 0}$ & $\mathbf{2 0}<\mathbf{X}$ & & \\
\hline \multicolumn{6}{|l|}{$\begin{array}{l}\text { 1. Exprese su grado de acuerdo con las siguientes } \\
\text { afirmaciones: }\end{array}$} \\
\hline -el coste de la auditoría está justificado & 3.83 & 2.60 & 3.11 & 4.680 & $0.096 * * *$ \\
\hline $\begin{array}{l}\text {-la auditoría se realiza exclusivamente por ser una } \\
\text { obligación legal }\end{array}$ & 2.50 & 2.47 & 3.78 & 5.270 & $0.072 * * *$ \\
\hline \multicolumn{6}{|c|}{$\begin{array}{l}* \text { Estadísticamente significativo al } 1 \% * * \text { Estadísticamente significativo al } 5 \% * * * \text { Estadísticamente significativo al } 10 \% \\
\mathrm{NS}=\text { estadísticamente no significativo } \\
\text { Las valoraciones medias corresponden a una escala de medida entre } 1 \text { total desacuerdo hasta } 5 \text { total acuerdo. }\end{array}$} \\
\hline
\end{tabular}


Los encuestados, representantes de agencias y sociedades de valores, que cuentan con una experiencia profesional entre 10 y 20 años, en el ámbito financiero, expresan su desacuerdo con que el coste que soportan las empresas auditadas esté justificado, mientras el resto de los encuestados se manifiestan de acuerdo. Adicionalmente puede decirse que los encuestados que poseen una experiencia entre 5 y 20 años no están de acuerdo con que la auditoría se realice exclusivamente por ser una "obligación legal"; finalmente los que tienen una experiencia de más de 20 años opinan lo contrario, es decir, estiman que, en efecto, la auditoría se lleva a cabo por constituir una obligación que la ley impone a las empresas.

Tabla $n^{\circ} 48$ Prueba de Mann-Whitney para las sociedades y ag. de valores agrupadas por estudios de postgrado ( $2^{\mathrm{a}}$ hipótesis $)$

\begin{tabular}{|c|c|c|c|c|}
\hline \multirow{2}{*}{ CUESTIONES PLANTEADAS } & \multicolumn{2}{|c|}{ VALORES MEDIOS } & \multirow{2}{*}{$\begin{array}{c}\text { U de } \\
\text { Mann-Whitney }\end{array}$} & \multirow{2}{*}{ Sig. asintót. } \\
\hline & $\begin{array}{c}\text { Sin estudios de } \\
\text { postgrado }\end{array}$ & $\begin{array}{c}\text { Con estudios de } \\
\text { postgrado }\end{array}$ & & \\
\hline \multicolumn{5}{|l|}{$\begin{array}{l}\text { 1. Exprese su grado de acuerdo con las siguientes } \\
\text { afirmaciones: }\end{array}$} \\
\hline $\begin{array}{l}\text {-las cuentas anuales muestran la imagen real de } \\
\text { las empresas }\end{array}$ & 4.00 & 3.00 & 66 & $0.014 * *$ \\
\hline $\begin{array}{l}\text {-la auditoría aporta fiabilidad a las cuentas } \\
\text { anuales de las empresas }\end{array}$ & 4.70 & 4.00 & 73 & $0.017 * *$ \\
\hline $\begin{array}{l}\text {-la opinión que emite el auditor es completamente } \\
\text { independiente }\end{array}$ & 3.55 & 2.69 & 74.5 & $0.034 * *$ \\
\hline $\begin{array}{l}\text {-la carta de recomendaciones aporta } \\
\text { información adicional para la gestión }\end{array}$ & 3.85 & 3.00 & 81.5 & $0.064 * * *$ \\
\hline \multicolumn{5}{|c|}{$\begin{array}{l}* \text { Estadísticamente significativo al } 1 \% * * \text { Estadísticamente significativo al } 5 \% * * * \text { Estadísticamente significativo al } 10 \% \\
\text { NS= estadísticamente no significativo }\end{array}$} \\
\hline
\end{tabular}

Según se aprecia, en la tabla $n^{\circ} 48$, los encuestados sin estudios de postgrado se pronuncian bastante de acuerdo con que "las cuentas anuales reflejen la imagen real de las empresas", mientras que los que poseen estudios de postgrado se mantienen en una posición neutra. Adicionalmente los que no tienen estudios posteriores a los universitarios, también se manifiestan de acuerdo con que "la opinión que emite el auditor en su informe es completamente independiente", por el contrario los que si poseen este tipo de formación se muestran en desacuerdo. 
Tabla ${ }^{\circ} 49$ Prueba de Mann-Whitney

para las agencias y soc. de valores agrupadas por sexo ( $2^{\mathrm{a}}$ hipótesis)

\begin{tabular}{|c|c|c|c|c|}
\hline \multirow{2}{*}{ CUESTIONES PLANTEADAS } & \multicolumn{2}{|c|}{ VALORES MEDIOS } & \multirow{2}{*}{$\begin{array}{l}\text { U de Mann- } \\
\text { Whitney }\end{array}$} & \multirow{2}{*}{$\begin{array}{l}\text { Sig. asintót. } \\
\text { (bilateral) }\end{array}$} \\
\hline & HOMBRE & MUJER & & \\
\hline \multicolumn{5}{|l|}{$\begin{array}{l}\text { 1. Exprese su grado de acuerdo con las siguientes } \\
\text { afirmaciones: }\end{array}$} \\
\hline $\begin{array}{l}\text {-el informe del auditor aporta información } \\
\text { adicional para la toma de decisiones }\end{array}$ & 3.00 & 3.88 & 57.5 & $0.075 * * *$ \\
\hline $\begin{array}{l}\text {-la carta de recomendaciones aporta } \\
\text { información adicional para la gestión }\end{array}$ & 3.29 & 4.25 & 48.5 & $0.032 * *$ \\
\hline
\end{tabular}

Se producen diferentes percepciones, estadísticamente significativas, entre los responsables de agencias y sociedades de valores, en función del sexo de los encuestados; en este sentido cuando el encuestado es varón mantiene una posición neutra sobre si "el informe del auditor aporta información adicional para la toma de decisiones", mientras que los responsables de sexo femenino expresan su acuerdo. Además las mujeres manifiestan un mayor acuerdo que los hombres sobre que "la carta de recomendaciones aporte información adicional para la gestión".

\subsection{Desglose de la segunda hipótesis}

A su vez esta segunda hipótesis se ha desglosado en otras dos, que se han planteado sólo para las entidades financieras y las agencias y sociedades de valores:

- H021: Las entidades de crédito (representadas por bancos, cajas de ahorros y rurales) perciben que la información suministrada por el dictamen del auditor es relevante para la toma de sus decisiones de concesión de créditos. 
- $\mathrm{H}_{022:}$ Los analistas de inversiones (representados por sociedades y agencias de valores) perciben que la información suministrada por el dictamen del auditor es relevante para la toma de sus decisiones de inversión.

- Aplicación del test de Kolmogorov-Smirnov para la hipótesis $H_{021}$

Para contrastar las dos hipótesis nulas, $\mathrm{H}_{021}$ y $\mathrm{H}_{022}$, se ha empleado el test de "Kolmogorov-Smirnov" sobre aquellas cuestiones planteadas exclusivamente para cada uno de los dos grupos que participan en cada una de las dos hipótesis.

De la tabla $\mathrm{n}^{0} 50$ se extraen los siguientes resultados para el grupo de entidades financieras compuesto por bancos, cajas de ahorros y cajas rurales:

- En la primera cuestión se observa que las entidades financieras muestran un elevado grado de acuerdo, estadísticamente significativo, con el hecho de que consideran "imprescindible" la presentación del informe de auditoría para que la empresa sometida a auditoría pueda obtener una línea de crédito, un préstamo a corto y largo plazo, una línea de descuento comercial y un aval bancario.

- Cuando se les pregunta a las entidades financieras sobre cual es la información más relevante al conceder un préstamo a las empresas, éstas expresan un mayor acuerdo con que es aquella que se deriva de la Central de Riesgos del Banco de España, seguida del conocimiento personal, las cuentas anuales y el informe de auditoría. No obstante, también se muestran de acuerdo con que sea relevante, al conceder financiación, la información que se desprende de "tener buenas 
referencias", de las declaraciones tributarias y del acceso a bases de datos privadas. Sensu contrario Herrador Alcaide (2000) contrasta que, para el grupo de auditores de la Comunidad de Madrid, el informe de auditoría no es un instrumento que oriente las decisiones de los agentes económicos como ocurre con las entidades de crédito.

\section{Tabla $\mathrm{n}^{\circ} 50$}

Prueba de Kolmogorov-Smirnov para las entidades de crédito (hipótesis $2^{\mathrm{a}} .1^{\mathrm{o}}$.)

\begin{tabular}{|c|c|c|c|c|c|}
\hline \multirow[b]{2}{*}{ CUESTIONES PLANTEADAS } & \multirow[b]{2}{*}{$\mathbf{N}$} & \multicolumn{2}{|c|}{ Parámetros normales ${ }^{\mathrm{a}, \mathrm{b}}$} & \multirow{2}{*}{\begin{tabular}{c|}
$Z$ de \\
Kolmogorov- \\
Smirnov
\end{tabular}} & \multirow{2}{*}{$\begin{array}{l}\text { Sig. asintót. } \\
\text { (bilateral) }\end{array}$} \\
\hline & & Media & $\begin{array}{l}\text { Desviación } \\
\text { típica }\end{array}$ & & \\
\hline \multicolumn{6}{|l|}{$\begin{array}{l}\text { 1. La presentación del informe de auditoría es } \\
\text { imprescindible para que se presten servicios, a una } \\
\text { empresa obligada a auditarse, en el caso de: }\end{array}$} \\
\hline -conceder una línea de crédito & 78 & 4.27 & 1.00 & 2.811 & $0.000 *$ \\
\hline -conceder un préstamo a corto plazo & 78 & 4.17 & 1.02 & 2.579 & $0.000^{*}$ \\
\hline -conceder un préstamo a largo plazo & 78 & 4.38 & 0.97 & 3.226 & $0.000 *$ \\
\hline -abrir una línea de descuento comercial & 78 & 3.97 & 1.01 & 2.128 & $0.000^{*}$ \\
\hline -conceder un aval bancario & 78 & 4.13 & 1.06 & 2.373 & $0.000 *$ \\
\hline \multicolumn{6}{|l|}{$\begin{array}{l}\text { 2. La información más relevante al conceder un } \\
\text { préstamo se obtiene de: }\end{array}$} \\
\hline -el informe de auditoría & 78 & 3.68 & 0.99 & 2.030 & $0.001 *$ \\
\hline -la central de riesgos & 78 & 4.18 & 0.82 & 2.229 & $0.000^{*}$ \\
\hline -bases de datos privadas & 78 & 3.42 & 1.09 & 1.677 & $0.007 *$ \\
\hline -conocimiento personal & 75 & 4.15 & 0.88 & 2.025 & $0.001 *$ \\
\hline -declaraciones tributarias & 75 & 3.47 & 1.03 & 1.801 & $0.003 *$ \\
\hline -cuentas anuales & 78 & 3.97 & 0.90 & 2.026 & $0.001 *$ \\
\hline -tener buenas referencias & 78 & 3.44 & 1.03 & 1.678 & $0.007 *$ \\
\hline \multicolumn{6}{|l|}{ 3. Exprese su acuerdo con las siguientes afirmaciones: } \\
\hline $\begin{array}{l}\text {-el tipo de opinión influye en la decisión de } \\
\text { conceder el préstamo }\end{array}$ & 78 & 4.03 & 0.91 & 2.279 & $0.000^{*}$ \\
\hline $\begin{array}{l}\text {-el tipo de opinión influye en la decisión de la } \\
\text { cuantía a prestar }\end{array}$ & 78 & 3.36 & 1.22 & 2.227 & $0.000^{*}$ \\
\hline \multicolumn{6}{|l|}{$\begin{array}{l}\text { 4. El tipo de salvedades que más pueden influir en su } \\
\text { decisión al conceder un préstamo son: }\end{array}$} \\
\hline -incertidumbres en cuanto a la vida de la empresa & 78 & 4.69 & 0.61 & 3.970 & $0.000^{*}$ \\
\hline -por incumplimiento de principios contables & 78 & 3.47 & 0.88 & 1.989 & $0.001 *$ \\
\hline -incertidumbres fiscales & 78 & 3.67 & 0.82 & 2.079 & $0.000 *$ \\
\hline -por valoración de activos & 78 & 3.90 & 0.80 & 2.715 & $0.000^{*}$ \\
\hline -por incumplimiento de normas legales & 78 & 3.81 & 0.87 & 2.246 & $0.000^{*}$ \\
\hline -por limitaciones al alcance & 78 & 3.73 & 0.86 & 2.101 & $0.000 *$ \\
\hline $\begin{array}{l}\text {-por relaciones con empresas del grupo o } \\
\text { asociadas }\end{array}$ & 77 & 3.69 & 0.88 & 2.073 & $0.000^{*}$ \\
\hline \multicolumn{6}{|l|}{$\begin{array}{l}\text { a. La distribución de contraste es la normal } \\
\text { b. Se han calculado a partir de los datos }\end{array}$} \\
\hline
\end{tabular}


- Los bancos, cajas de ahorros y cajas rurales expresan un alto grado de acuerdo con el hecho de que el tipo de opinión ("favorable", "con salvedades", "desfavorable" o "denegada") que emite el auditor, en su dictamen, influye en sus "decisiones de concesión de préstamos". De igual modo se manifiestan de acuerdo, aunque en menor medida, con el hecho de que el tipo de opinión del auditor influye en "la cuantía del préstamo a conceder". Al mismo resultado llega Geiger (1992) contrastando, en Estados Unidos, que el informe afecta a las decisiones de financiación. En el estudio de Herrador Alcaide (2000) los auditores, también, muestran su acuerdo con que las "opiniones calificadas" aportan información relevante para las entidades de crédito. Sin embargo, Libby (1979) concluyó señalando lo contrario.

- Por último se les solicita que señalen el "tipo de salvedades" que más puede influir en la decisión de conceder financiación a las empresas, mostrando un mayor acuerdo con que son aquellas que ponen de manifiesto la existencia de "incertidumbres en cuanto a la vida de la sociedad", seguidas de las "salvedades por errores de valoración de activos", "incumplimiento de normas legales", "limitaciones al alcance", por "relaciones con empresas del grupo", "incertidumbres fiscales" y por "incumplimiento de principios contables". Firth (1980) logra el mismo resultado, para el Reino Unido, al contrastar que las salvedades por incertidumbre en cuanto al "principio de empresa en funcionamiento" y por la "valoración de activos" son las más relevantes al conceder préstamos a las empresas.

Con los resultados obtenidos se concluye "aceptando" la hipótesis nula $\left(\mathrm{H}_{021}\right) \mathrm{y}$, por tanto, asumiendo que las entidades financieras perciben 
que la información suministrada por el dictamen del auditor es relevante para la toma de sus decisiones de concesión de créditos.

- Aplicación del test T para la hipótesis $H_{021}$

Para corroborar los resultados estadísticos obtenidos con la prueba no paramétrica, se ha realizado el "test paramétrico de la $\mathrm{T}$ " que comprueba si las medias son significativamente diferentes de la distribución normal. Como se aprecia, en la tabla del Anexo 21, los hallazgos alcanzados son exactamente los mismos que con la prueba no paramétrica de "KolmogorovSmirnov".

- Aplicación del test de Kolmogorov-Smirnov para la hipótesis $H_{022}$

De los datos de la tabla $n^{\circ} 51$ se deducen los siguientes resultados:

- Para las agencias y sociedades de valores la información más relevante al realizar una inversión se obtiene al llevar a cabo un "análisis fundamental" seguido del "análisis técnico" y el "conocimiento personal".

- Las agencias y sociedades de valores se manifiestan de acuerdo con que el tipo de opinión que emite el auditor ejerce influencia en sus "decisiones de inversión" en las empresas, con un nivel de significación estadística del 10\%. Según se desprende del estudio de Herrador Alcaide (2000) los auditores también muestran su acuerdo con que las "opiniones calificadas" aportan información relevante para los inversores. 
- También se muestran de acuerdo con el hecho de que aquellas salvedades que tienen mayor relevancia sobre sus decisiones de inversión son por este orden, "las incertidumbres en cuanto a la vida de la compañía", las referidas a la "valoración de activos", por "incumplimiento de normas legales", "incumplimiento de principios contables", "incertidumbres fiscales", por "relaciones con empresas del grupo y asociadas" y por "limitaciones al alcance".

\section{Tabla $n^{0} 51$}

Prueba de Kolmogorov-Smirnov para las agencias y soc. de valores (hipótesis $2^{\mathrm{a}} \cdot 2^{\circ}$ )

\begin{tabular}{|c|c|c|c|c|c|}
\hline \multirow{2}{*}{ CUESTIONES PLANTEADAS } & \multirow{2}{*}{$\mathbf{N}$} & \multicolumn{2}{|c|}{$\begin{array}{l}\text { Parámetros } \\
\text { normales }^{\mathrm{a}, \mathrm{b}}\end{array}$} & \multirow{2}{*}{$\begin{array}{l}\text { Z de } \\
\text { Kolmogorov- } \\
\text { Smirnov }\end{array}$} & \multirow{2}{*}{$\begin{array}{l}\text { Sig. asintót. } \\
\text { (bilateral) }\end{array}$} \\
\hline & & Media & $\begin{array}{c}\text { Desviación } \\
\text { típica }\end{array}$ & & \\
\hline \multicolumn{6}{|l|}{$\begin{array}{l}\text { 1. La información más relevante al realizar una } \\
\text { inversión se obtiene de: }\end{array}$} \\
\hline -realizar un análisis técnico & 32 & 3.69 & 1.09 & 1.345 & $0.054 * * *$ \\
\hline -realizar un análisis fundamental & 31 & 4.10 & 0.75 & 1.275 & $0.077 * * *$ \\
\hline -el informe de auditoría & 32 & 2.81 & 1.06 & 1.043 & $0.226^{\mathrm{NS}}$ \\
\hline -la central de riesgos & 31 & 3.29 & 1.07 & 1.102 & $0.176^{\mathrm{NS}}$ \\
\hline -bases de datos privadas & 31 & 2.97 & 1.05 & 0.985 & $0.287^{\mathrm{NS}}$ \\
\hline -conocimiento personal & 30 & 3.63 & 0.89 & 1.606 & $0.012 * *$ \\
\hline -declaraciones tributarias & 31 & 2.68 & 1.11 & 1.189 & $0.118^{\mathrm{NS}}$ \\
\hline -cuentas anuales & 32 & 3.66 & 0.90 & 1.193 & $0.116^{\mathrm{NS}}$ \\
\hline -tener buenas referencias & 32 & 3.16 & 0.99 & 1.085 & $0.190^{\mathrm{NS}}$ \\
\hline \multicolumn{6}{|l|}{ 2. Exprese su acuerdo con las siguientes afirmaciones: } \\
\hline $\begin{array}{l}\text {-el tipo de opinión influye en la decisión de } \\
\text { invertir o no en una empresa }\end{array}$ & 32 & 3.81 & 1.00 & 1.305 & $0.066 * * *$ \\
\hline -el tipo de opinión influye en la cuantía a invertir & 32 & 3.41 & 1.24 & 1.040 & $0.229^{\mathrm{NS}}$ \\
\hline \multicolumn{6}{|l|}{$\begin{array}{l}\text { 3. El tipo de salvedades que más pueden influir en su } \\
\text { decisión de inversión son: }\end{array}$} \\
\hline -incertidumbres en cuanto a la vida de la empresa & 32 & 4.31 & 0.82 & 1.868 & $0.002 *$ \\
\hline -por incumplimiento de principios contables & 32 & 3.78 & 0.94 & 1.404 & $0.039 * *$ \\
\hline -incertidumbres fiscales & 32 & 3.75 & 0.92 & 1.846 & $0.002 *$ \\
\hline -por valoración de activos & 32 & 4.06 & 0.62 & 1.818 & $0.003^{*}$ \\
\hline -por incumplimiento de normas legales & 32 & 3.84 & 0.92 & 1.265 & $0.081 * * *$ \\
\hline -por limitaciones al alcance & 31 & 3.52 & 1.00 & 1.487 & $0.024 * *$ \\
\hline $\begin{array}{l}\text {-por relaciones con empresas del grupo o } \\
\text { asociadas }\end{array}$ & 32 & 3.59 & 1.07 & 1.718 & $0.005^{*}$ \\
\hline \multicolumn{6}{|l|}{$\begin{array}{l}\text { a. La distribución de contraste es la normal } \\
\text { b. Se han calculado a partir de los datos }\end{array}$} \\
\hline \multicolumn{6}{|c|}{$\begin{array}{l}\text { * Estadísticamente significativo al 1\%. ** Estadísticamente significativo al 5\%.*** Estadísticamente significativo al } 10 \% \\
\text { NS= estadísticamente no significativo. }\end{array}$} \\
\hline
\end{tabular}


Con los resultados de la prueba se concluye "aceptando" la hipótesis nula $\left(\mathrm{H}_{022}\right)$, para un nivel de significación estadística del 10\%, y, por tanto, asumiendo que las sociedades y agencias de valores perciben que la información suministrada por el dictamen del auditor es relevante para la toma de sus decisiones de inversión.

- Aplicación del test $T$ para la hipótesis $H_{022}$

Para corroborar los resultados estadísticos obtenidos, con la prueba no

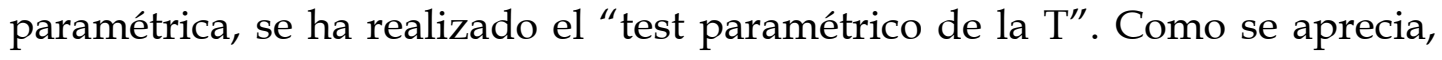
en la tabla del Anexo 22, al aplicar la prueba paramétrica se consiguen los mismos resultados que con el test de "Kolmogorov-Smirnov", salvo en el caso de la expresión que indica que "la información más relevante al realizar una inversión se obtiene de las cuentas anuales", así como en el caso de la que señala que "el tipo de opinión del informe influye en la cuantía a invertir", para las que la "prueba $T$ " muestra que las diferencias son estadísticamente significativas cuando no lo eran con la prueba no paramétrica.

\subsubsection{Tercera hipótesis}

La hipótesis nula que se ha planteado en tercer lugar se define como:

H03: Los auditores, sociedades auditadas, entidades de crédito (representadas por Bancos, Cajas de Ahorros y Cajas Rurales) y analistas financieros (representados por Agencias y Sociedades de Valores) muestran la misma percepción en cuanto a la comprensión del informe de auditoría de cuentas. 
- Aplicación del test de Kolmogorov-Smirnov para la hipótesis $\mathrm{H}_{03}$

Se han realizado las pruebas de "normalidad" de las distribuciones que muestran los diferentes grupos, para ello se ha aplicado el test de "Kolmogorov-Smirnov", con la finalidad de determinar que prueba se debe llevar a cabo para contrastar la hipótesis tercera.

En el Anexo 10 se observa que, ninguna de las variables empleadas para valorar la "comprensión" del informe de auditoría, se comporta como una "distribución normal" en el caso de las empresas sujetas a auditoría.

Para el caso de los auditores se puede comprobar, según se refleja en el Anexo 11, que tampoco se siguen distribuciones normales al aplicar el test definido por "Kolmogorov-Smirnov".

Tanto para los grupos de empresas auditadas como de auditores, se verifica, mediante el mismo test, que en el caso de las entidades financieras tampoco los ítems analizados se comportan siguiendo una "distribución estadística normal" (Anexo 12).

En cuanto al grupo representado por agencias y sociedades de valores se advierte, en el Anexo 13, que en determinados casos se cumple la condición de "normalidad", concretamente en las expresiones 3, 5, 6 y 7, de forma que para corroborar dicha "normalidad" se ha aplicado el test de "Lilliefors" al desconocerse los parámetros poblacionales.

Mediante la prueba de "Lillefors" se contrasta la "no normalidad" de ninguna de las distribuciones que con el test de "Kolmogorov-Smirnov" sí aparecían como "normales", según se refleja en el Anexo 14. 
- Aplicación del test de Kruskal-Wallis para la hipótesis $H_{03}$

Una vez verificada la "no normalidad" de ninguna de las variables analizadas, y siguiendo el procedimiento empleado con las demás hipótesis, la prueba utilizada para contrastar la tercera hipótesis nula es la de "KruskalWallis".

De los resultados obtenidos, en la tabla $n^{0} 52$, al aplicar el test no paramétrico de “Kruskal-Wallis”, se puede reseñar lo siguiente:

- Tanto las empresas que son auditadas, como auditores, entidades de crédito y sociedades y agencias de valores muestran diferentes percepciones, significativas desde punto de vista estadístico, sobre el hecho de que "las salvedades incluidas en el informe del auditor son comprensibles", no obstante todos los grupos encuestados opinan que dichas salvedades son comprensibles.

- También se producen diferencias significativas en cuanto a la percepción que se tiene sobre que "el lenguaje empleado en el informe sea muy técnico", de forma que auditores y agencias y sociedades de valores se revelan de acuerdo con que dicho lenguaje es muy técnico, mientras empresas auditadas y entidades financieras muestran su desacuerdo con que se produzca una excesiva tecnificación de la redacción.

- Todos los grupos señalan su acuerdo con que realiza "una redacción de las salvedades excesivamente escueta". 
- Se observa un acuerdo general en torno a que "el propósito de la auditoría esté claramente expresado en el informe", coincidiendo con las conclusiones del estudio realizado por Kelly y Mohrweis (1989) con inversores y bancos en Estados Unidos.

Tabla $n^{\circ} 52$

Prueba de Kruskal-Wallis para los grupos encuestados ( $3^{\text {a }}$ hipótesis)

\begin{tabular}{|c|c|c|c|c|c|c|}
\hline \multirow{2}{*}{ CUESTIONES PLANTEADAS } & \multicolumn{4}{|c|}{$\begin{array}{c}\text { VALORES MEDIOS } \\
\text { POR GRUPOS DE ESTUDIO }\end{array}$} & \multirow{2}{*}{$\begin{array}{c}\text { Chi- } \\
\text { cuadrado }\end{array}$} & \multirow{2}{*}{$\begin{array}{l}\text { Sig. } \\
\text { asintót. }\end{array}$} \\
\hline & EMPRESAS & AUDITORES & $\begin{array}{c}\text { BANCOS } \\
\text { Y } \\
\text { CAJAS }\end{array}$ & \begin{tabular}{|} 
AG. Y SOC. \\
DE \\
VALORES
\end{tabular} & & \\
\hline \multicolumn{7}{|l|}{$\begin{array}{l}\text { 1. Exprese su grado de acuerdo con las siguientes } \\
\text { afirmaciones: }\end{array}$} \\
\hline $\begin{array}{l}\text {-la redacción del informe del auditor está } \\
\text { excesivamente estandarizada }\end{array}$ & 4.14 & 3.84 & 4.06 & 4.09 & 3.544 & $0.315^{\mathrm{NS}}$ \\
\hline $\begin{array}{l}\text {-las salvedades que se incluyen en el informe } \\
\text { son comprensibles }\end{array}$ & 3.79 & 3.82 & 3.60 & 3.28 & 11.196 & $0.011 * *$ \\
\hline $\begin{array}{l}\text {-el lenguaje utilizado en el informe de auditoría } \\
\text { es muy técnico }\end{array}$ & 2.93 & 3.71 & 2.83 & 3.15 & 73.937 & $0.000^{*}$ \\
\hline $\begin{array}{l}\text {-se realiza una redacción de las salvedades } \\
\text { excesivamente escueta }\end{array}$ & 3.46 & 3.27 & 3.60 & 3.55 & 7.121 & $0.068 * * *$ \\
\hline $\begin{array}{l}\text {-el propósito de la auditoría está claramente } \\
\text { expresado en el informe }\end{array}$ & 3.83 & 4.05 & 3.88 & 3.55 & 15.187 & $0.002 *$ \\
\hline $\begin{array}{l}\text {-el informe es un adecuado medio de } \\
\text { comunicación con los usuarios }\end{array}$ & 3.12 & 3.29 & 2.95 & 3.30 & 7.807 & $0.050 * *$ \\
\hline $\begin{array}{l}\text {-el lenguaje utilizado en el informe de auditoría } \\
\text { es ambiguo }\end{array}$ & 2.53 & 2.63 & 2.92 & 2.94 & 11.035 & $0.012 * *$ \\
\hline -la opinión que emite el auditor es comprensible & 3.87 & 3.90 & 3.86 & 3.48 & 6.023 & $0.110^{\mathrm{NS}}$ \\
\hline \multicolumn{7}{|c|}{$\begin{array}{l}\text { * Estadísticamente significativo al 1\%. }{ }^{* *} \text { Estadísticamente significativo al 5\%. }{ }^{* * *} \text { Estadísticamente significativo al } 10 \% \text {. } \\
\mathrm{NS}=\text { estadísticamente no significativo. }\end{array}$} \\
\hline 1 & & & & & & \\
\hline
\end{tabular}

- Los grupos de empresas, auditores y analistas de inversión se muestran de acuerdo con que "el informe de auditoría sea un adecuado medio de comunicación" con los usuarios, aunque dicho acuerdo sea en un grado pequeño; cuando el grupo de entidades financieras manifiesta un cierto desacuerdo, también muy leve. Este resultado contradice las conclusiones que obtienen Robertson (1988) y Mayper et al. (1988), ya que según sus estudios los mensajes que se comunican a través del informe no son recibidos de manera adecuada por los usuarios. En este sentido, Geiger (1989) constata que los 
usuarios se muestran partidarios de una modificación del lenguaje que mejore la comunicación.

- Todos los grupos señalan su desacuerdo con que "el lenguaje empleado en el informe de auditoría es ambiguo", produciéndose diferencias entre grupos que son estadísticamente significativas, y presentando las empresas un mayor grado de desacuerdo que las entidades financieras y las agencias y sociedades de valores, como indica la prueba de "Mann-Whitney por parejas".

Con los resultados expuestos se puede concluir "rechazando" la tercera hipótesis nula planteada sobre la igualdad de percepciones en torno a la comprensión de los informes de auditoría.

Tabla $n^{\circ} 53$

$\mathrm{N}^{\mathrm{o}}$ de informes leídos por grupos de estudio

\begin{tabular}{|c|c|c|c|c|c|}
\hline \multirow{2}{*}{ Grupos de estudio } & \multicolumn{4}{|c|}{$\mathbf{N}^{0}$ de informes leídos } & \multirow{2}{*}{ Total } \\
\hline & ninguno & $X<25$ & $25 ＃ X$ \# 100 & $100<X$ & \\
\hline Empresas & 0 & 99 & 132 & 73 & 305 \\
\hline Auditores & 0 & 12 & 90 & 227 & 329 \\
\hline Entidades de crédito & 0 & 10 & 20 & 45 & 75 \\
\hline Agencias y soc. de valores & 0 & 4 & 16 & 13 & 33 \\
\hline Subtotal & 0 & 125 & 258 & 358 & 742 \\
\hline \multicolumn{5}{|c|}{ casos perdidos } & 21 \\
\hline \multicolumn{5}{|c|}{ Total } & 763 \\
\hline
\end{tabular}

Para evitar que en este epígrafe contestaran personas que no hubieran leído ningún informe se establece una "pregunta de control" que evalúa el número de dictámenes a los que se ha tenido acceso; como se observa, en la tabla $\mathrm{n}^{0} 53$, todos los individuos encuestados han accedido al informe del auditor. 
- Aplicación del análisis de la varianza en un sentido para la hipótesis $\mathrm{H}_{03}$

Siguiendo la metodología anterior y para ratificar los resultados obtenidos para la tercera hipótesis, con la aplicación de la prueba no paramétrica de "Kruskal-Wallis", se ha desarrollado el test paramétrico del "análisis de la varianza en un sentido".

Al aplicar la prueba "ANOVA" se consiguen los mismos resultados que corroboran las diferencias señaladas mediante el test no paramétrico de "Kruskal-Wallis", salvo en el caso de la expresión que indica que "la redacción del informe está excesivamente estandarizada", ya que con el test paramétrico las diferencias que se encuentran sí son estadísticamente significativas como se refleja en el Anexo 19. Posteriormente se han realizado dos pruebas "post-hoc" en función de la "homogeneidad o no de varianzas" que marca la prueba de "Levene", así en los casos de igualdad de varianzas se ha aplicado el test "HSD de Tukey" mientras que en el caso contrario se ha utilizado la prueba de "Tamhane".

De la prueba "HSD de Tukey" se deriva que las diferencias que se producen en cuanto a "la comprensión de las salvedades" que emite el auditor en su informe, se dan entre dos grupos distintos, el formado por las agencias y sociedades de valores por un lado y el constituido por empresas y auditores por otro. Mientras que en lo relativo a que "el lenguaje empleado sea muy técnico", las diferencias se producen entre un grupo compuesto por entidades financieras y empresas y otro formado por los auditores. 
- Análisis pormenorizado con el grupo de empresas para la hipótesis $\mathrm{H}_{03}$

La variable "edad de los encuestados" actúa como discriminante del grado de acuerdo con que responden los responsables de las empresas, así según se aprecia, en la tabla $\mathrm{n}^{\circ} 54$, en general, como se comprueba comparando las medias por parejas, a medida que aumenta la edad de los individuos se eleva su grado de acuerdo con que "las salvedades del informe del auditor sean comprensibles" y con el hecho de que "el propósito de la auditoría se encuentre claramente expresado en el informe", adicionalmente la prueba de "Mann-Whitney dos a dos" confirma que los mayores de 50 años manifiestan un mayor acuerdo que los más jóvenes, sobre que la opinión que emite el auditor sea comprensible.

\section{Tabla $n^{0} 54$}

Prueba de Kruskal-Wallis para las empresas agrupadas por la edad ( $3^{\text {a }}$ hipótesis)

\begin{tabular}{|c|c|c|c|c|c|c|}
\hline \multirow{2}{*}{ CUESTIONES PLANTEADAS } & \multicolumn{4}{|c|}{ VALORES MEDIOS DE EDAD } & \multirow{2}{*}{$\begin{array}{c}\text { Chi- } \\
\text { cuadrado }\end{array}$} & \multirow{2}{*}{$\begin{array}{l}\text { Sig. } \\
\text { asintót. }\end{array}$} \\
\hline & $20<X \# 30$ & $30<X \# 40$ & $40<X$ \#50 & $50<X$ & & \\
\hline \multicolumn{7}{|l|}{$\begin{array}{l}\text { 1. Exprese su grado de acuerdo con las siguientes } \\
\text { afirmaciones: }\end{array}$} \\
\hline $\begin{array}{l}\text {-las salvedades que se incluyen en el informe son } \\
\text { comprensibles }\end{array}$ & 3.57 & 3.67 & 3.93 & 4.05 & 10.995 & $0.012 * *$ \\
\hline $\begin{array}{l}\text {-el propósito de la auditoría está claramente } \\
\text { expresado en el informe }\end{array}$ & 3.61 & 3.61 & 4.01 & 4.17 & 16.430 & $0.001 *$ \\
\hline -la opinión que emite el auditor es comprensible & 3.74 & 3.66 & 3.94 & 4.28 & 19.875 & $0.000^{*}$ \\
\hline \multicolumn{7}{|c|}{$\begin{array}{l}\text { * Estadísticamente significativo al } 1 \% \quad * * \text { Estadísticamente significativo al } 5 \% \text { *** Estadísticamente significativo al } 10 \% \\
\mathrm{NS}=\text { estadísticamente no significativo } \\
\text { Las valoraciones medias corresponden a una escala de medida entre } 1 \text { total desacuerdo hasta } 5 \text { total acuerdo. }\end{array}$} \\
\hline
\end{tabular}

Una parte importante de los encuestados pertenecientes a empresas auditadas se pronuncian en desacuerdo con que "el lenguaje utilizado en el informe sea muy técnico", sin embargo aquellos que poseen una experiencia profesional entre 10 y 20 años muestran un leve acuerdo. De igual modo como se observa en la tabla $\mathrm{n}^{0} 55$, y constata con la prueba de "MannWhitney por parejas", los individuos cuya experiencia sobrepasa los 20 años 
manifiestan mayor acuerdo que los noveles, sobre que "el propósito de la auditoría esté claramente expresado en el informe" y que "la opinión del auditor sea comprensible".

Tabla $n^{\circ} 55$ Prueba de Kruskal-Wallis

para las empresas agrupadas por la experiencia profesional ( $3^{\mathrm{a}}$ hipótesis)

\begin{tabular}{|c|c|c|c|c|c|c|}
\hline \multirow{2}{*}{ CUESTIONES PLANTEADAS } & \multicolumn{4}{|c|}{$\begin{array}{l}\text { VALORES MEDIOS DE AÑOS DE } \\
\text { EXPERIENCIA PROFESIONAL }\end{array}$} & \multirow{2}{*}{$\begin{array}{c}\text { Chi- } \\
\text { cuadrado }\end{array}$} & \multirow{2}{*}{ Sig. asintót. } \\
\hline & $1<\mathrm{X} \# 5$ & $5<X \# 10$ & $10<X \# 20$ & $20<X$ & & \\
\hline \multicolumn{7}{|l|}{$\begin{array}{l}\text { 1. Exprese su grado de acuerdo con las siguientes } \\
\text { afirmaciones: }\end{array}$} \\
\hline $\begin{array}{l}\text {-la redacción del informe del auditor está } \\
\text { excesivamente estandarizada }\end{array}$ & 4.09 & 4.02 & 4.08 & 4.34 & 6.921 & $0.074 * * *$ \\
\hline $\begin{array}{l}\text {-las salvedades que se incluyen en el informe } \\
\text { son comprensibles }\end{array}$ & 3.58 & 3.56 & 3.81 & 4.11 & 15.422 & $0.001 *$ \\
\hline $\begin{array}{l}\text {-el lenguaje utilizado en el informe de auditoría } \\
\text { es muy técnico }\end{array}$ & 2.82 & 2.71 & 3.13 & 2.86 & 6.372 & $0.095^{* * *}$ \\
\hline $\begin{array}{l}\text {-el propósito de la auditoría está claramente } \\
\text { expresado en el informe }\end{array}$ & 3.48 & 3.76 & 3.80 & 4.16 & 12.585 & $0.006^{*}$ \\
\hline -la opinión que emite el auditor es comprensible & 3.64 & 3.68 & 3.79 & 4.27 & 21.675 & $0.000^{*}$ \\
\hline
\end{tabular}

- Análisis pormenorizado con el grupo de auditores para la hipótesis $\mathrm{H}_{03}$

Tabla $\mathrm{n}^{\circ} 56$

Test de Kruskal-Wallis para los auditores agrupados por CCAA ( $3^{\mathrm{a}}$ hipótesis)

\begin{tabular}{|c|c|c|c|c|c|c|}
\hline \multirow{2}{*}{ CUESTIONES PLANTEADAS } & \multicolumn{4}{|c|}{ VALORES MEDIOS } & \multirow{2}{*}{$\begin{array}{c}\text { Chi- } \\
\text { cuadrado }\end{array}$} & \multirow{2}{*}{ Sig. asintót. } \\
\hline & ARAGÓN & GALICIA & MADRID & P. VASCO & & \\
\hline \multicolumn{7}{|l|}{$\begin{array}{l}\text { 1. Exprese su grado de acuerdo con las siguientes } \\
\text { afirmaciones: }\end{array}$} \\
\hline $\begin{array}{l}\text {-la redacción del informe del auditor está } \\
\text { excesivamente estandarizada }\end{array}$ & 4.00 & 4.30 & 3.76 & 3.41 & 6.348 & $0.096^{* * *}$ \\
\hline $\begin{array}{l}\text {-las salvedades que se incluyen en el informe son } \\
\text { comprensibles }\end{array}$ & 4.00 & 3.60 & 4.00 & 3.45 & 6.323 & $0.097 * * *$ \\
\hline $\begin{array}{l}\text {-el propósito de la auditoría está claramente } \\
\text { expresado en el informe }\end{array}$ & 4.50 & 3.40 & 4.19 & 3.82 & 10.556 & $0.014^{* *}$ \\
\hline $\begin{array}{l}\text {-el lenguaje utilizado en el informe de auditoría es } \\
\text { ambiguo }\end{array}$ & 3.17 & 3.00 & 2.27 & 2.59 & 7.269 & $0.064 * * *$ \\
\hline
\end{tabular}

Analizando las respuestas de los auditores, por comunidades autónomas, se distingue que mientras los auditores de Aragón señalan un 
leve acuerdo con que "el lenguaje utilizado en el informe es ambiguo" y los gallegos se mantienen en una postura neutra, los auditores madrileños y vascos manifiestan su desacuerdo con la mencionada ambigüedad del lenguaje.

- Análisis pormenorizado con el grupo de entidades de crédito para la hipótesis $\mathrm{H}_{03}$

Según se deriva de la tabla $n^{\circ} 57$ los directivos de entidades financieras, que poseen una experiencia profesional superior a veinte años, indican su acuerdo sobre que "el lenguaje del informe del auditor es muy técnico", por el contrario los de menor experiencia expresan su desacuerdo.

Tabla $n^{\circ} 57$ Prueba de Kruskal-Wallis para las

entidades de crédito agrupadas por la experiencia profesional ( $3^{\mathrm{a}}$ hipótesis)

\begin{tabular}{|c|c|c|c|c|c|}
\hline \multirow{2}{*}{ CUESTIONES PLANTEADAS } & \multicolumn{3}{|c|}{$\begin{array}{l}\text { VALORES MEDIOS DE AÑOS DE } \\
\text { EXPERIENCIA PROFESIONAL }\end{array}$} & \multirow{2}{*}{$\begin{array}{l}\text { Chi- } \\
\text { cuadrado }\end{array}$} & \multirow{2}{*}{ Sig. asintót. } \\
\hline & $5<\mathrm{X} \# 10$ & $10<X \# 20$ & $\mathbf{2 0}<\mathrm{X}$ & & \\
\hline \multicolumn{6}{|l|}{$\begin{array}{l}\text { 1. Exprese su grado de acuerdo con las siguientes } \\
\text { afirmaciones: }\end{array}$} \\
\hline $\begin{array}{l}\text {-el lenguaje utilizado en el informe de auditoría es } \\
\text { muy técnico }\end{array}$ & 2.43 & 2.62 & 3.22 & 7.687 & $0.021 * *$ \\
\hline \multicolumn{6}{|c|}{$\begin{array}{l}\text { * Estadísticamente significativo al 1\% } \\
\text { NS }=\text { estadísticamente no significativo }\end{array}$} \\
\hline
\end{tabular}

- Análisis pormenorizado con el grupo de agencias y sociedades de valores para la hipótesis $\mathrm{H}_{03}$

Tabla n 58 Prueba de Kruskal-Wallis

para las ag. y soc. de valores agrupadas por la edad ( $3^{\text {a }}$ hipótesis)

\begin{tabular}{|c|c|c|c|c|c|}
\hline \multirow{2}{*}{ CUESTIONES PLANTEADAS } & \multicolumn{3}{|c|}{$\begin{array}{l}\text { VALORES MEDIOS DE AÑOS DE } \\
\text { EDAD }\end{array}$} & \multirow{2}{*}{$\begin{array}{c}\text { Chi- } \\
\text { cuadrado }\end{array}$} & \multirow{2}{*}{ Sig. asintót. } \\
\hline & $30<x \# 40$ & $40<\mathrm{X} \# \mathbf{5 0}$ & $\mathbf{5 0}<\mathbf{X}$ & & \\
\hline \multicolumn{6}{|l|}{$\begin{array}{l}\text { 1. Exprese su grado de acuerdo con las siguientes } \\
\text { afirmaciones: }\end{array}$} \\
\hline $\begin{array}{l}\text {-el propósito de la auditoría está claramente } \\
\text { expresado en el informe }\end{array}$ & 3.91 & 3.80 & 2.86 & 4.821 & $0.090 * * *$ \\
\hline \multicolumn{6}{|c|}{$\begin{array}{l}\text { * Estadísticamente significativo al } 1 \% * * \text { Estadísticamente significativo al } 5 \% * * * \text { Estadísticamente significativo al } 10 \% \\
\text { NS= estadísticamente no significativo } \\
\text { Las valoraciones medias corresponden a una escala de medida entre } 1 \text { total desacuerdo hasta } 5 \text { total acuerdo. }\end{array}$} \\
\hline
\end{tabular}


El personal encuestado en agencias y sociedades de valores con una edad superior a 50 años expresa su desacuerdo con que "el propósito de la auditoría quede claramente reflejado en el informe", mientras que los de edades inferiores muestran su acuerdo.

\subsubsection{ANÁLISIS ADICIONAL}

Junto a la contrastación de hipótesis se ha realizado un análisis adicional con la información obtenida. Se ha comprobado si las diferencias de medias entre los cuatro grupos encuestados son significativas en relación con cuestiones que interrogan a los individuos sobre "si existe insatisfacción con el servicio de auditoría de cuentas", así como sobre preguntas referidas a una posible "extensión de la función del auditor".

De la tabla $\mathrm{n}^{\circ} 59$ se pueden extraer las siguientes conclusiones:

- Tanto los representantes de las sociedades auditadas como de las entidades financieras $y$ sociedades $y$ agencias de valores se manifiestan a favor de que el auditor se pronuncie en su informe sobre "la detección de fraudes e irregularidades", por el contrario los auditores encuestados se muestran en desacuerdo, siendo las diferencias estadísticamente significativas al 1\%. En el estudio de Herrador Alcaide (2000) se observa que los auditores madrileños mantienen una postura neutra sobre la posibilidad de ampliar la información sobre el fraude.

- Las entidades financieras seguidas de las empresas se muestran de acuerdo con que el auditor amplíe su trabajo y pueda pronunciarse en 
su informe sobre "la eficacia de la gestión empresarial", de la compañía que audita, sin embargo los auditores señalan su desacuerdo, mientras que el grupo de agencias y sociedades de valores no se muestra ni en desacuerdo ni en acuerdo.

Tabla $n^{\circ} 59$

Prueba de Kruskal-Wallis para los grupos encuestados (adicional)

\begin{tabular}{|c|c|c|c|c|c|c|}
\hline \multirow{2}{*}{ CUESTIONES PLANTEADAS } & \multicolumn{4}{|c|}{$\begin{array}{c}\text { VALORES MEDIOS } \\
\text { POR GRUPOS DE ESTUDIO }\end{array}$} & \multirow{2}{*}{$\begin{array}{c}\text { Chi- } \\
\text { cuadrado }\end{array}$} & \multirow{2}{*}{ Sig. asintót. } \\
\hline & EMPRESAS & AUDITORES & \begin{tabular}{|} 
BANCOS \\
Y \\
CAJAS \\
\end{tabular} & \begin{tabular}{|l|} 
AG. Y SOC. \\
DE \\
VALORES \\
\end{tabular} & & \\
\hline \multicolumn{7}{|l|}{$\begin{array}{l}\text { 1. Ampliaría el trabajo del auditor de manera que le } \\
\text { permitiera pronunciarse, en su informe, de } \\
\text { manera expresa sobre: }\end{array}$} \\
\hline -la detección de fraudes e irregularidades & 3.80 & 2.67 & 3.94 & 4.13 & 115.878 & $0.000 *$ \\
\hline -la eficacia de la gestión empresarial & 3.22 & 2.54 & 3.75 & 3.03 & 59.580 & $0.000 *$ \\
\hline -la evolución futura de la sociedad & 3.12 & 2.65 & 3.73 & 2.97 & 41.431 & $0.000 *$ \\
\hline -el control interno de la empresa & 3.77 & 3.49 & 4.14 & 4.19 & 24.851 & $0.000^{*}$ \\
\hline -la rentabilidad de la empresa & 3.16 & 2.67 & 3.58 & 3.22 & 36.321 & $0.000 *$ \\
\hline -la solvencia de la empresa & 3.48 & 2.97 & 4.00 & 4.06 & 53.766 & $0.000 *$ \\
\hline $\begin{array}{l}\text { 2. Existe un sentimiento de insatisfacción en los } \\
\text { usuarios, sobre el propósito y objetivos que viene } \\
\text { a cumplir la auditoría de cuentas. }\end{array}$ & 2.83 & 3.18 & 2.76 & 3.27 & 17.148 & $0.001 *$ \\
\hline
\end{tabular}

- El grupo de bancos, cajas de ahorros y cooperativas de crédito expresa su acuerdo con el hecho de que el auditor haga mención expresa en su informe sobre "la evolución futura de la sociedad", el colectivo de las empresas muestra un acuerdo muy escaso, y tanto el grupo de auditores como en menor medida el de analistas de inversión apunta su desacuerdo con ésta medida. Sin embargo, Herrador Alcaide (2000) indica que los auditores madrileños se decantan por una posición neutra sobre la posibilidad de ampliar la información sobre la continuidad de la vida empresarial.

- Todos los grupos se posicionan de acuerdo, siendo las diferencias intergrupos significativas estadísticamente, con que el informe haga 
hincapié de manera expresa en "el control interno de la sociedad auditada". Adicionalmente los grupos de analistas y entidades financieras manifiestan un mayor grado de acuerdo que los auditores, que también lo expresan pero de forma menor, según se desprende al aplicar la prueba de "Mann-Whitney dos a dos". Sin embargo, Herrador Alcaide (2000) apunta que los auditores de la Comunidad de Madrid se manifiestan en una posición neutra sobre la posibilidad de ampliar la información sobre el control interno.

- La mayoría de colectivos, a excepción de los auditores, está de acuerdo con que el informe contenga alusión a "la rentabilidad de la sociedad auditada".

- Al estudiar las medias por parejas se obtiene que el grupo de sociedades y agencias de valores, proseguido de entidades financieras y empresas, pone de manifiesto su acuerdo con que el auditor incluya en el informe referencia a "la solvencia de la sociedad auditada"; sin embargo los auditores de cuentas se muestran reacios a esta medida, siendo, en todo caso, las diferencias de percepciones estadísticamente significativas.

- Cuando se les pregunta sobre si existe "un sentimiento de insatisfacción sobre el propósito y objetivos que viene a cumplir la auditoría de cuentas", tanto analistas como auditores se manifiestan de acuerdo, mientras empresas y entidades financieras lo hacen en sentido contrario.

A los grupos de auditores y empresas auditadas se les ha solicitado que indicaran que colectivos consideran que exigen se auditen las cuentas 
anuales, como forma de corroborar la importancia que muy variados intereses muestran por la verificación externa.

Como se aprecia, en la tabla $\mathrm{n}^{0} 60$, tanto los auditores como las sociedades auditadas estiman que los colectivos que exigen las cuentas anuales revisadas por un auditor son, en su mayoría, los accionistas, así como las entidades de crédito. En el caso de las empresas también 179 casos frente a 131 se muestran a favor de que la Administración Pública es otra parte interesada que requiere de la auditoría contable.

\section{Tabla $n^{\circ} 60$}

Colectivos interesados en el servicio de auditoría

\begin{tabular}{|l|c|c|c|c|}
\hline \multirow{2}{*}{ CUESTIONES PLANTEADAS } & \multicolumn{2}{|c|}{ EMPRESAS } & \multicolumn{2}{c|}{ AUDITORES } \\
\cline { 2 - 5 } & SI & NO & SI & NO \\
\hline $\begin{array}{l}\text { 1. Señale quién exige las cuentas anuales de } \\
\text { las empresas auditadas: }\end{array}$ & 262 & 48 & 303 & 29 \\
\hline -Accionistas & 45 & 265 & 44 & 288 \\
\hline -Clientes & 243 & 67 & 256 & 76 \\
\hline -Entidades financieras & 73 & 237 & 55 & 277 \\
\hline -Compañias de seguros & 67 & 243 & 93 & 239 \\
\hline -Proveedores & 179 & 131 & 154 & 178 \\
\hline -Administración pública & 122 & 188 & 125 & 207 \\
\hline -Analistas financieros & 28 & 281 & 50 & 282 \\
\hline -Personal de la empresa & & & &
\end{tabular}

\subsubsection{Análisis Factorial}

Se ha llevado a cabo un "análisis factorial" para cada una de las variables principales analizadas en los diferentes bloques de la encuesta (función, utilidad y comprensión), con la finalidad de tratar de obtener un pequeño grupo de factores que poseyeran un amplio poder explicativo y fuesen los más representativos de cada una de las variables principales, sin que de los resultados obtenidos se haya podido definir de manera satisfactoria factores de agrupación entre los diferentes ítems. 
CONCLUSIONES 
1. Con los resultados obtenidos se rechaza la hipótesis nula de igualdad de percepciones, entre sociedades auditadas, entidades de crédito, agencias y sociedades de valores y auditores, en relación con la "función" que tienen asignada los auditores.

\subsection{Análisis conjunto:}

- Todos los grupos encuestados indican que no es labor del auditor de cuentas ni "la preparación y formulación de las cuentas anuales", ni "la llevanza material de la contabilidad" de las empresas auditadas. De igual modo, se obtiene un común acuerdo con que el auditor "sólo se pronuncia en su informe sobre las cuentas anuales" y sobre que su "opinión profesional es un juicio razonable pero no un certificado de absoluta garantía" sobre las mismas cuentas.

- Se produce un acuerdo general sobre que el auditor con su trabajo aporta seguridad en relación con que "se cumple con las normas contables" que afectan a las sociedades, y sobre que "el control interno funciona correctamente". Se obtiene un desacuerdo general sobre que sea labor del auditor aportar seguridad acerca de que "la gestión de la empresa es adecuada".

- Tanto entidades de crédito, empresas auditadas como agencias y sociedades de valores señalan que no esperan de la labor del auditor que "aporte seguridad sobre la continuidad de la compañía", mientras que los auditores opinan lo contrario. 
- Existe una percepción errónea sobre la "función" del auditor respecto a que:

- Sea función del auditor "revisar toda la contabilidad" de la empresa auditada, de forma que tanto compañías auditadas, entidades de crédito como agencias y sociedades de valores se posicionan de acuerdo con que esa sea misión del auditor

- Le corresponda al auditor "detectar los fraudes e irregularidades" que se desprenden de la gestión, mostrando su acuerdo compañías auditadas, entidades de crédito y agencias y sociedades de valores.

- El trabajo del auditor "aporte seguridad" sobre si "la situación financiera de la entidad auditada es solvente".

1.2. Análisis pormenorizado:

Empresas:

- En función de la comunidad autónoma de pertenencia, las empresas reflejan posturas enfrentadas respecto a las funciones asignadas al auditor, así mientras los responsables de las Comunidades de Madrid y Aragón si que esperan que el auditor aporte seguridad sobre que "el control interno funciona adecuadamente", los empresarios del País Vasco se manifiestan en desacuerdo, mientras que los gallegos se mantienen en una postura intermedia. 
- Cuanta mayor "experiencia profesional" demuestran los encuestados, representantes de las empresas auditadas, mayor es la comprensión de los objetivos que tiene encomendados el auditor.

- Se observa que cuanto mayor es "el nivel de formación" de los encuestados mejor entendimiento existe sobre la responsabilidad del auditor de cuentas.

Auditores:

- Los auditores andaluces, catalanes, madrileños y valencianos reflejan posturas similares en cuanto al cometido inherente a su labor.

- Cuanta mayor "experiencia profesional" demuestran los auditores mayor es su grado de desacuerdo con que tengan que evaluar que "la gestión de la empresa es adecuada".

- Los auditores más jóvenes, concretamente aquellos con edades comprendidas entre los 20 y 30 años, se manifiestan de acuerdo con que sea misión suya "revisar la totalidad de la contabilidad" de la empresa auditada, mientras los mayores de 30 años se pronuncian en desacuerdo.

Entidades de Crédito:

- La comunidad de procedencia de las entidades de crédito sirve como factor discriminante al valorar determinados atributos asociados con la "función" del auditor de cuentas; así mientras que los encuestados procedentes de Madrid o Andalucía manifiestan su acuerdo con que 
"el auditor sólo se pronuncia en su informe sobre las cuentas anuales", los valencianos se muestran en desacuerdo.

- Los responsables de bancos, cajas de ahorros y cajas rurales con una "experiencia profesional" dentro del intervalo entre 10 y 20 años indican su acuerdo con que sea responsabilidad del auditor "preparar y formular las cuentas anuales auditadas".

- Aquellos directivos de banca cuya "experiencia profesional" supera los diez años señalan su acuerdo sobre que se espere del auditor que aporte seguridad en relación con que "la situación financiera de la empresa sea solvente"; además los que poseen una experiencia entre uno y cinco años manifiestan su desacuerdo con que el auditor sea responsable de verificar que se cumplen "las normas legales que afectan a la empresa auditada".

- Los encuestados procedentes de entidades de crédito con estudios universitarios superiores manifiestan una mayor comprensión de las "funciones" asignadas al auditor que aquellos que poseen estudios universitarios pero de grado medio.

Los resultados obtenidos llevan a concluir que tanto las sociedades que son auditadas como las entidades de crédito y agencias y sociedades de valores conocen razonablemente el propósito principal que guía la labor del auditor de cuentas, pese a que se tengan percepciones erróneas de forma puntual en cuanto a la detección de fraudes e irregularidades, en cuanto a que su trabajo implique la revisión de la totalidad de la contabilidad que se audita, así como que se espere que el auditor dictamine sobre la solvencia financiera de la empresa. 
La formación y la experiencia profesional se revelan como factores discriminantes a la hora de comprender la función del auditor, así, en general, cuanta mayor experiencia y cualificación existe mejor se capta la finalidad de la auditoría de cuentas anuales.

2. Con los resultados obtenidos se rechaza la hipótesis que sostiene igualdad de percepciones, entre auditores y empresas auditadas, respecto a la problemática de los "servicios multidisciplinares" que presta el auditor.

\subsection{Análisis conjunto:}

- Los auditores y sociedades, sujetas a auditoría de cuentas anuales, muestran un elevado grado de desacuerdo con que los auditores puedan realizar la "llevanza de la contabilidad" de las empresas que auditan.

- Ni las sociedades auditadas ni los auditores encuentran inconveniente el hecho de que los profesionales de la auditoría puedan realizar servicios de "asesoría fiscal, legal y consultoría de empresas", a las sociedades que están auditando.

- Las empresas muestran su desacuerdo frente al acuerdo de auditores, con que estos últimos puedan prestar servicios de "asesoría financiera y de inversiones", "implantación de sistemas de calidad", "auditoría medioambiental y de prevención de riesgos laborales", "implantación de sistemas informáticos", "servicios de tasaciones y peritajes" y "servicios de selección de personal". 
- Tanto auditores como empresas auditadas se muestran de acuerdo con que, los primeros, puedan asesorar a las empresas en "auditoría interna".

- Ambos grupos manifiestan un alto grado de acuerdo con que los auditores pueden prestar "otros servicios", a empresas que no son clientes de auditoría externa.

2.2. Análisis pormenorizado:

Empresas:

- Se comprueba que la Comunidad Autónoma de procedencia de las empresas es un factor importante en la apreciación que manifiestan los encuestados sobre los "servicios multidisciplinares". En este sentido los responsables andaluces están de acuerdo en que los auditores puedan prestar servicios como "consultoría", "asesoría de inversiones y financiera", "de calidad" o en "auditoría interna"; frente a esta postura las empresas catalanas, madrileñas y valencianas manifiestan su desacuerdo con que se suministren, en concreto, los servicios de "asesoría de inversiones y financiera" y "de calidad" a los propios clientes de auditoría. Además las empresas valencianas tampoco están de acuerdo en que se presten servicios de "consultoría".

- El que los directivos de las empresas entrevistadas hayan recibido "formación de postgrado" supone un factor discriminante de las diferentes percepciones en cuanto a los servicios multidisciplinares. Así, los directivos de empresas con estudios de postgrado muestran su 
desacuerdo con que se presten servicios accesorios de "asesoría fiscal", "legal", "consultoría" y "auditoría medioambiental"; por el contrario los que carecen de dichos estudios se manifiestan de acuerdo, salvo para el caso de "auditoría medioambiental".

Auditores:

- Mientras los auditores de las Comunidades Aragonesa y Gallega se manifiestan en una posición neutra sobre que el auditor pueda asesorar a sus clientes de auditoría en "la implantación de sistemas de calidad", los de las Comunidades Madrileña y Vasca se muestran de acuerdo, especialmente los de esta última.

- Las características de "edad" de los auditores así como los "estudios universitarios" se manifiestan como factores relevantes a la hora de estudiar las respuestas ante la problemática de servicios multidisciplinares; de manera que mientras los universitarios de grado medio se manifiestan en desacuerdo con que se presten a las empresas auditadas servicios adicionales de "asesoría de inversiones y financiera" los de grado superior opinan lo contrario. Adicionalmente, y para el mismo tipo de servicios, los auditores con edades comprendidas entre 20 y 50 años manifiestan su acuerdo, una vez superada dicha edad se muestra un muy leve desacuerdo. Respecto a ofrecer, además, "auditoría de prevención de riesgos laborales", mientras los auditores mayores de 30 años expresan su acuerdo, los más jóvenes indican su desacuerdo.

De los resultados alcanzados se deriva que mientras los auditores no aprecian inconveniente alguno en prestar "servicios adicionales" al de 
auditoría de cuentas tanto a las empresas que auditan como a las que no auditan, los encuestados representantes de las sociedades auditadas no manifiestan su acuerdo con que se presten otros servicios a las empresas que al mismo tiempo son clientes de auditoría salvo en el caso de "asesoramiento en auditoría interna, fiscal, legal y consultoría". No obstante los empresarios no ponen inconveniente alguno en que se presten "servicios accesorios" en aquellas sociedades no auditadas.

3. Con los resultados obtenidos se rechaza la hipótesis nula de igualdad de percepciones en torno a la "utilidad" que aporta el servicio de auditoría de cuentas.

3.1. Análisis conjunto:

- Todos los colectivos encuestados se manifiestan de acuerdo con el hecho de que "las cuentas anuales expresen la imagen real de las empresas".

- Tanto empresas, auditores, entidades de crédito como agencias y sociedades de valores se muestran de acuerdo, siendo los auditores los que presentan un mayor grado de acuerdo, con que la auditoría aporta "fiabilidad" a las cuentas anuales y "valor añadido" a la sociedad auditada.

- Las empresas, auditores y entidades de crédito se revelan de acuerdo con que "el coste de auditoría se encuentre justificado"; sensu contrario, el grupo de agencias y sociedades de valores no está de acuerdo con que el coste de la auditoría se encuentre justificado. 
- Se obtiene común acuerdo con el hecho de que la auditoría de cuentas sea considerada como un servicio de "interés público" y con que la opinión del auditor sea completamente "independiente".

- Todos los grupos analizados se manifiestan en desacuerdo con que la opinión del auditor conlleva un alto grado de "subjetividad".

- La totalidad de los encuestados indica su acuerdo con que "las cuentas anuales aportan información para la toma de decisiones"; en este sentido, también, se produce común acuerdo con el hecho de que "el informe del auditor conlleve información adicional para la toma de decisiones", así como con que "la carta de recomendaciones aporte información adicional para la gestión". No obstante tanto empresas como agencias y sociedades de valores manifiestan un grado de acuerdo muy bajo con el hecho de que el dictamen del auditor aporte información adicional para la toma de decisiones.

- Todos los grupos se muestran en desacuerdo con que un informe "limpio" aporte más información que uno con "salvedades".

\subsection{Análisis pormenorizado:}

Empresas:

- Mientras los responsables encuestados para las empresas de sexo masculino se manifiestan de acuerdo con que la auditoría es un servicio de "interés público", las responsables de sexo femenino se expresan en desacuerdo. 
- Los encuestados con preparación de bachillerato o formación profesional señalan un leve acuerdo con que "la opinión del auditor es bastante subjetiva", por el contrario los universitarios tanto de grado medio como superior no están de acuerdo con dicha afirmación. Sucede lo mismo cuando se les solicita que opinen sobre si "un informe limpio aporta más información que uno con salvedades", en este sentido mientras los que presentan un nivel de formación más bajo muestran su acuerdo, los universitarios se pronuncian en desacuerdo.

- Los responsables de empresas encuestados que poseen una experiencia que oscila entre 1 y 10 años manifiestan un leve desacuerdo con que "el coste de la auditoría esté justificado", mientras que los de experiencia mayor muestran su acuerdo.

Auditores:

- El hecho de pertenecer a una u otra Comunidad Autónoma supone opiniones contrapuestas en cuanto a que "la auditoría se realice exclusivamente por ser una obligación legal"; así los auditores pertenecientes a las Comunidades Andaluza y Valenciana se manifiestan de acuerdo con que la auditoría de cuentas la solicitan las empresas como consecuencia de que sea una obligación legal, mientras que los auditores procedentes de las Comunidades Catalana y Madrileña indican su desacuerdo con dicha idea. 
Entidades de Crédito:

- Una mayor parte de los directivos de entidades financieras encuestados se manifiestan en desacuerdo con que "la auditoría de cuentas se realice, exclusivamente, por ser una obligación legal", no obstante el grupo de individuos cuya experiencia profesional se encuentra entre 5 y 10 años se pronuncia en sentido opuesto, es decir, expresando su acuerdo.

Agencias y Sociedades de Valores:

- Los representantes de agencias y sociedades de valores encuestados que cuentan con una experiencia profesional entre 10 y 20 años, en el ámbito financiero, expresan su desacuerdo con que "el coste que soportan las empresas auditadas esté justificado", mientras el resto de encuestados se manifiesta de acuerdo. Además aquellos que poseen una experiencia profesional entre 5 y 20 años señalan su desacuerdo con que "la auditoría se realice exclusivamente por ser una obligación legal", en tanto los que mantienen una experiencia de más de 20 años opinan lo contrario.

- Adicionalmente los que no tienen estudios posteriores a los universitarios, también se manifiestan de acuerdo con que "la opinión que emite el auditor en su informe es completamente independiente", por el contrario los que si poseen este tipo de formación se muestran en desacuerdo.

En términos generales, se percibe que la auditoría de cuentas reporta utilidad y es beneficiosa tanto para la empresa auditada como para los 
terceros interesados en el juicio profesional del auditor, no sólo aporta "fiabilidad" sino que también es "relevante para la toma de decisiones". Además se percibe una buena imagen del auditor como profesional "independiente" y "objetivo", al tiempo que su labor es vista como una actividad de "interés público" que no sólo beneficia a las partes contratantes.

4. Con los resultados obtenidos se concluye aceptando las hipótesis nulas que asumen la "relevancia" del informe de auditoría en las "decisiones de concesión de créditos", por entidades de crédito, y en las "decisiones de inversión" realizadas por agencias y sociedades de valores.

- Tanto bancos como cajas de ahorros y cooperativas de crédito manifiestan un elevado grado de acuerdo con el hecho de que consideran imprescindible la presentación del informe de auditoría para que la empresa sometida a auditoría pueda obtener una "línea de crédito", "un préstamo a corto y largo plazo", una "línea de descuento comercial" y un "aval bancario".

- Las entidades de crédito se posicionan de acuerdo con que la información más relevante al conceder un préstamo es la que se deriva de la "Central de Riesgos del Banco de España", seguida del "conocimiento personal", las "cuentas anuales" y el "informe de auditoría"; además también es relevante "tener buenas referencias", tener acceso a las "declaraciones tributarias" y a las "bases de datos privadas".

- Los bancos, cajas de ahorros y cajas rurales expresan un alto grado de acuerdo con el hecho de que el tipo de opinión (favorable, con salvedades, desfavorable o denegada) que emite el auditor, en su 
dictamen, influye en sus decisiones de concesión de préstamos. De igual modo se manifiestan de acuerdo, aunque en menor medida, con el hecho de que "el tipo de opinión del auditor influye en la cuantía del préstamo a conceder".

- Las salvedades que más pueden influir en la decisión de conceder financiación son aquellas que ponen de manifiesto "incertidumbres en cuanto a la vida de la sociedad", seguidas de "salvedades por errores de valoración de activos", "incumplimiento de normas legales", "limitaciones al alcance", "por relaciones con empresas del grupo", "incertidumbres fiscales" y por "incumplimiento de principios contables".

- Según acuerdan las agencias y sociedades de valores la información más relevante al realizar una inversión se obtiene al llevar a cabo un "análisis fundamental" seguido del "análisis técnico" y el "conocimiento personal".

- Las agencias y sociedades de valores se manifiestan de acuerdo con que "el tipo de opinión que emite el auditor influye en la decisión de invertir" o no en una empresa.

- Los analistas de inversiones (representados por agencias y sociedades de valores) se muestran de acuerdo con que las "salvedades" que tienen mayor relevancia sobre sus decisiones de inversión son por este orden las que se refieren a: "incertidumbres en cuanto a la vida de la compañía", "valoración de activos", "incumplimiento de normas legales", "incumplimiento de principios contables", "incertidumbres 
fiscales", "relaciones con empresas del grupo y asociadas" y "limitaciones al alcance".

De lo expuesto se extrae que tanto los representantes de entidades de crédito como de sociedades y agencias de valores consideran relevante la información contenida en el dictamen para sus decisiones de inversión y de concesión de créditos, hasta el punto que puede condicionar su postura en cuanto a conceder financiación o invertir en una compañía, así como en la cuantía a prestar. El tipo de salvedad que se aprecia como más relevante para la toma de decisiones, de ambos colectivos, es la que pone en duda la continuidad de la explotación, seguida de la salvedad por valoración de activos y por incumplimiento de normas legales.

5. Con los resultados observados se concluye rechazando la hipótesis que asume la igualdad de percepciones en torno a la "comprensión" del informe de auditoría.

\subsection{Análisis conjunto:}

- Tanto las empresas que son auditadas, como auditores, entidades de crédito y sociedades y agencias de valores se muestran de acuerdo con el hecho de que "las salvedades incluidas en los informes del auditor son comprensibles".

- Los auditores y agencias y sociedades de valores se manifiestan de acuerdo con que "el lenguaje empleado en el informe es muy técnico", mientras que las empresas auditadas y las entidades de crédito opinan lo contrario. 
- Todos los grupos manifiestan su acuerdo con que se realiza "una redacción de las salvedades excesivamente escueta".

- Existe un acuerdo generalizado sobre que "el propósito de la auditoría esté claramente expresado en el informe".

- El grupo de empresas, auditores y analistas de inversión se muestran de acuerdo con que "el informe de auditoría sea un adecuado medio de comunicación con los usuarios"; las entidades de crédito, por su parte, se mantienen en una postura intermedia.

- Todos los grupos señalan su desacuerdo con que "el lenguaje empleado en el informe de auditoría es ambiguo".

\subsection{Análisis pormenorizado:}

Empresas:

- A medida que aumenta la edad de los individuos se eleva su grado de acuerdo con que "las salvedades del informe del auditor son comprensibles" y con el hecho de que "el propósito de la auditoría se encuentre claramente expresado en el informe", adicionalmente los mayores de 40 años son los que manifiestan un mayor acuerdo sobre que "la opinión que emite el auditor sea comprensible".

- El incremento de la experiencia profesional lleva aparejado un mayor acuerdo sobre que "el propósito de la auditoría esté claramente expresado en el informe" y que "la opinión del auditor sea comprensible". 
Auditores:

- Analizando las respuestas de los auditores por comunidades autónomas se observa que mientras los auditores de Aragón señalan un mínimo acuerdo con que "el lenguaje utilizado en el informe es ambiguo" y los gallegos se mantienen en una postura neutra, los auditores madrileños y vascos manifiestan su desacuerdo con la mencionada ambigüedad del lenguaje.

Entidades de Crédito:

- Los directivos de entidades de crédito que poseen una experiencia profesional superior a veinte años señalan su acuerdo con que "el lenguaje del informe del auditor es muy técnico", por el contrario los de menor experiencia expresan su desacuerdo que aumenta conforme la experiencia profesional se reduce.

Agencias y Sociedades de Valores:

- El personal encuestado en agencias y sociedades de valores con una edad superior a 50 años expresa su desacuerdo con que "el propósito de la auditoría quede claramente reflejado en el informe", mientras que los de edades inferiores muestran su acuerdo.

De los resultados obtenidos se desprende que el actual modelo de informe de auditoría refleja adecuadamente el propósito de la auditoría, con un lenguaje comprensible, aunque se le critica el uso de expresiones muy técnicas, una redacción excesivamente estandarizada y unas salvedades muy escuetas. 
6. Resultados observados en relación con posibles modificaciones de la "función" actual del auditor:

- Tanto los representantes de las sociedades auditadas como de entidades de crédito y sociedades y agencias de valores se manifiestan a favor de que el auditor se pronuncie en su informe de manera expresa sobre la detección de "fraudes e irregularidades", por el contrario los auditores encuestados se muestran en desacuerdo.

- Las entidades de crédito y las empresas se muestran de acuerdo con que el auditor amplíe su trabajo y pueda pronunciarse en su informe sobre la "eficacia de la gestión empresarial", de la compañía que audita, sin embargo los auditores señalan su desacuerdo, y las agencias y sociedades de valores se manifiestan en una posición indistinta.

- El grupo de bancos, cajas de ahorro y cooperativas de crédito así como el colectivo de sociedades auditadas manifiestan su acuerdo con el hecho de que el auditor haga mención expresa en su informe sobre "la evolución futura de la sociedad", y tanto el grupo de auditores como en menor medida el de analistas de inversión apuntan su desacuerdo con ésta medida.

- Todos los grupos se posicionan de acuerdo con que el informe haga hincapié de manera expresa en "el control interno de la sociedad auditada". 
- La mayoría de colectivos, a excepción de los auditores, está de acuerdo con que el informe de auditoría se refiera a la "rentabilidad" de la sociedad auditada.

- Los grupos de sociedades y agencias de valores, entidades de crédito y empresas ponen de manifiesto su acuerdo con que el auditor incluya en el informe alguna referencia a la "solvencia" de la sociedad auditada, sin embargo los auditores de cuentas se muestran reacios a esta medida.

- Cuando se les pregunta sobre si existe un "sentimiento de insatisfacción" sobre el propósito y objetivos que viene a cumplir la auditoría de cuentas, tanto analistas como auditores se manifiestan de acuerdo, mientras que las empresas y las entidades de crédito lo hacen en sentido contrario.

- Tanto empresarios como auditores confirman que colectivos tan variados como los accionistas, clientes, entidades de crédito, compañías de seguros, proveedores, Administración Pública, analistas financieros y personal de las empresas se muestran interesados en el trabajo del auditor.

En las opiniones vertidas por los usuarios encuestados se aprecia un acuerdo general con que el auditor debe incorporar información, en su dictamen, que facilite la toma de decisiones; frente a esto la postura que sostienen los auditores es la contraria, al reaccionar oponiéndose a cualquier modificación de sus funciones actuales. 
Del conjunto de la encuesta se deduce que los auditores se encuentran "sensibilizados" con la trascendencia social del trabajo que prestan, así como preocupados por satisfacer a sus clientes, hasta el punto de que piensan que existe un sentimiento de insatisfacción hacia su labor que no aprecian la mayoría de usuarios. 
BIBLIOGRAFÍA 


\section{BIBLIOGRAFÍA}

ACTUALIDAD ECONÓMICA: Las cinco mil mayores empresas, $\mathrm{n}^{0}$ 2.157, octubre 1999, pp. 25-31.

ACCOUNTING AND REVIEW SERVICES COMMITTEE (ARSC): Compilación y Revisión de Estados Financieros (SSARS-1), AR-100, BAILEY, L. y HOLZMANN, O.J.: Guía de Auditoría, Harcourt Brace, Madrid, 1998.

ALCARRIA JAIME, J.: "Estudio sobre los informes de auditoría en empresas no cotizadas", Partida Doble, $\mathrm{n}^{\circ}$ 83, noviembre 1997, pp. 72-83.

ALDERMAN, C. W.: "An Empirical Analysis of the Impact of Uncertainty Qualifications on the Market Risk Components", Accounting and Business Research, autumn 1979, pp. 258-266.

ALMELA DÍEZ, B.: La auditoría de cuentas en el marco de la reforma mercantil, Ed. ICAC, Madrid, 1996.

- “Novedades en auditoría”, partida Doble, no 107, enero 2000, pp. 76-83.

AMERICAN INSTITUTE OF CERTIFIED PUBLIC ACCOUNTANTS (AICPA): Auditing Concepts Committee: "Report of the Committee on Basic Auditing Concepts", The Accounting Review, Vol. 47, Supplement 1972.

- Commission on Auditor's Responsibilities (Cohen Commission), Report, Conclusion and Recommendations, New York, 1978.

ARANA GONDRA, F.J. y LASSO DE LA VEGA J.: "El dictamen del Auditor en el ámbito de la información económica", III Congreso Nacional del ICJC, Barcelona, marzo 1977, pp. 133-195.

ASOCIACIÓN ESPAÑOLA DE CONTABILIDAD Y ADMINISTRACIÓN DE EMPRESAS (AECA): Marco conceptual para la Información Financiera, Serie Principios Contables, Madrid, 1999.

ATO GARCÍA, M.: Investigación en ciencias del comportamiento, Ed. D-M, Murcia, 1991.

AUDITING PRACTICES BOARD (APB): Auditors' Reports on Financial Statements, Statement of Auditing Standards (SAS) nº 600, Londres, 1993. 
AUDITING STANDARDS BOARD (ASB): Codificación de Procedimientos y Normas de Auditoría, Statements on Auditing Standards (SAS) $\mathrm{n}^{\circ} 1$, BAILEY, L. y HOLZMANN, O.J.: Guía de Auditoría, Harcourt Brace, Madrid, 1998.

- Informes sobre Estados Financieros Auditados, Statements on Auditing Standards (SAS) $\mathrm{n}^{\mathrm{o}}$ 58, BAILEY, L. y HOLZMANN, O.J.: Guía de Auditoría, Harcourt Brace, Madrid, 1998.

- Statements on Auditing Standards (SAS) no 83 amends AU sec. 310 Relationship between the auditor's appointment and planning.

- Statements on Standards for Attestation Engagements (SSAE) $n^{0} 7$ amends SSAE $\mathrm{n}^{\mathrm{o}} 1$ Attestation Standards AT sec. 100.

BAILEY, K.E., BYLINSKI, J.H. y SHIELDS, M.D.: "Effects of Audit Report Wording Changes on the Perceived Message", Journal of Accounting Research, Vol. 21, n 2, autumn 1983, pp. 355-370.

BAILEY, W.T.: “The effects of Audit Reports on Chartered Financial Analysts' Perceptions of the Sources of Financial-Statement and AuditReport Messages", The Accounting Review, Vol. LVI, n 4, October 1981, pp. 882-896.

- "An appraisal of Research Designs Used to Investigate the Information Content of Audit Reports", The Accounting Review, Vol. LVII, $\mathrm{n}^{\mathrm{o}}$ 1, January 1982, pp. 141-146.

BALL, R., WALKER, R.G. y WHITTRED, G.P.: “Audit Qualifications and Share Prices", Abacus, June 1979, pp. 23-34.

BANKS, D.W. y KINNEY, W.R.: "Loss Contingency Reports and Stock Prices: An Empirical Study", Lournal of Accounting Research, Vol. 20, spring 1982, pp. 240-254.

BASKIN, E.F.: "The Communicative Effectiveness of Consistency Exceptions", The Accounting Review, January 1972, pp. 38-51.

BECK, G.W.: "The Role of the Auditor in Modern Society: an empirical appraisal", Accounting and Business Review, spring 1973, pp. 117-123.

BERTHOLDT, R.H.: "Discussion of The Impact of Uncertainty Reporting on the Loan Decision", Iournal of Accounting Research, Vol.17, supplement 1979, pp. 58-63. 
BROMAGE, M.C.: Los informes de auditoría y su técnica de redacción, $2^{\text {a }}$ Edición, Ediciones Deusto S.A., Bilbao, 1989.

BROWN, P. y WALTER, T.: "Fifty Betas", Lournal of the Australian Society of Security Analysts, October 1974.

CABAL GARCÍA, E.: La utilidad del informe de auditoría con especial referencia a su impacto en el mercado bursátil, Tesis Doctoral, Universidad de Oviedo, Oviedo, 2000a.

- "La efectividad comunicativa del informe de auditoría medida a través de su impacto en el mercado bursátil", Estudios Financieros, no 209-210, agosto-septiembre 2000b, pp. 123-178.

- "Realidad y expectativas en torno al informe de auditoría de cuentas anuales: aspectos normativos, problemas y posibles soluciones", Revista Técnica, $3^{\mathrm{a}}$ Época, $\mathrm{n}^{\mathrm{o}} 17,2000 \mathrm{c}$, pp. 14-37.

CAMACHO ROSALES, J.: Estadística con SPSS para Windows, Ed. Ra-Ma, Madrid, 2000.

CAÑADAS MOLINA, E. y GONZÁLEZ QUINTANA M.J.: “El tratamiento de la uniformidad en el informe de auditoría", Técnica Contable, abril 2000, pp. 311-320.

CAÑIBANO CALVO, L.: Curso de auditoría contable, $4^{\mathrm{a}}$ Edición, Ediciones Pirámide S.A., Madrid, 1996.

CAÑIBANO CALVO, L. y CASTRILLO, L.: “La independencia de los auditores", Armonización de los servicios de auditoría en la U.E.: posición actual y futura de España - II Jornada de Trabajo sobre Auditoría Contable ASEPUC, Cantabria, junio 1997, pp. 51-70.

CARCELlO, J., H. HERMANSON, R., T. McGRATH, N.: “Audit Quality Attributes: The Perceptions of Audit Partners, Preparers, and Financial Statement Users", Auditing: A Journal of Practice $\mathcal{E}$ Theory, Vol. 11, no1, spring 1992, pp. 1-15.

CARRO ARANA, M.: “El auditor en el ámbito concursal: hacia una coordinación entre la reforma proyectada de la Ley Concursal y la Ley de Auditoría de Cuentas", Armonización de los servicios de auditoría en la U.E.: posición actual y futura de España - II Jornada de Trabajo sobre Auditoría Contable ASEPUC, Cantabria, junio 1997, pp. 189-196. 
CASALS CREUS, R., GASSÓ VILAFRANCA, J.M., y SORIA SENDRA, C.: Fundamentos de Auditoría, 4a Edición, Ed. IACJC, Madrid, 1998.

CASANOVAS PARELlA, I.: El Marco Legal de la Auditoría en España, Ed. Estudios Financieros, Madrid, 1996.

CHOW, C.W. y RICE, S.J.: “Qualified Audit Opinions and Share Prices - An Investigation", Auditing: A Journal of Practice $\mathcal{E}$ Theory, Vol. 1, $\mathrm{n}^{\mathrm{o}} 2$, winter 1982, pp. 35-53.

COBO GONZÁLEZ, A.: "Reflexiones sobre la independencia de los auditores", Armonización de los servicios de auditoría en la U.E.: posición actual y futura de España - II Jornada de Trabajo sobre Auditoría Contable ASEPUC, Cantabria, junio 1997, pp. 197-200.

COMISIÓN DE GOBIERNO DE LAS SOCIEDADES: "Informe final sobre la Comisión de Gobierno de las Sociedades. Informe Hampel”, BOICAC, $\mathrm{n}^{\circ}$ 35, 1998, pp. 31-61.

COMISIÓN DE LA UNIÓN EUROPEA: "Comunicación de la Comisión Relativa a la Auditoría Legal en la Unión Europea: el Camino a Seguir", BOICAC, n 34, 1998, pp. 209-219.

- “Función, Posición y Responsabilidad civil del Auditor Legal en la Unión Europea - Libro Verde", BOICAC, n 27, 1996, pp. 23-48.

- “Estudio sobre la Función, Posición y Responsabilidad del Auditor Estatutario en la Unión Europea - Informe MARC", $\underline{B O I C A C}, \mathrm{n}^{\circ}$ 27, 1996, pp. 49-132.

COMISIÓN DE OPERACIONES DE BOLSA Y COMPAÑÍA NACIONAL DE AUDITORES DE CUENTAS: "Informe del Grupo de Trabajo sobre Deontología de los Auditores de Cuentas en las Sociedades que Emiten Títulos Negociables en los Mercados de Valores - Informe Le Portz", BOICAC, $\mathrm{n}^{\mathrm{o}} 17$, julio 1993, pp. 55-80.

CRASWELL, A.T.: "Studies of the information content of qualified audit reports", Journal of Business, Finance \& Accounting, spring 1985, pp. 93115.

CRONBACH, L.J.: "Coefficient Alpha and the Internal Structure of Test", Psycometrika, no 16, September 1951, pp. 297-334.

DANIEL, W.W.: Bioestadística, 3ª Edición, Ed. Uteha, México, 1999. 
DASSEN, R.J.M.: Audit quality: an empirical study of the attributes and determinants of audit quality perceptions, Landgraff: Drukkerij Groenvelt BV, 1995.

DE AGUSTÍN MELENDRO, J.A. y GIRONELLA MASGRAU, E.: “Otros trabajos que pueden realizar los economistas auditores", Papeles de Auditoría, no 7, marzo 1999, pp. 20-29.

DEL BRÍO GONZÁLEZ, E.B.: “Efecto de las salvedades de los informes de auditoría sobre el precio de las acciones en la Bolsa de Madrid", Revista Española de Financiación y Contabilidad, Vol. XXVII, n 94, enero-marzo 1998, pp. 129-170.

DIDIS, S.K.: “Communicating Audit Results", Internal Auditor, October 1997, pp. 36-38.

DÍEZ GARCÍA, J.L.: "Presente y Futuro de la Auditoría", Papeles de Auditoría, $\mathrm{n}^{\mathrm{o}}$ 7, marzo 1999, pp. 16-17.

DILLARD, J.F. y JENSEN, D.L.: “The Auditor's Report: An Analysis of Opinion", The Accounting Review, Vol. LVIII, n 4, October 1983, pp. 787798.

DILLON, W.R., MADDEN, T.J. y FIRTLE, N.H.: La investigación de mercados en un entorno de marketing, $3^{\text {a }}$ Edición, McGraw-Hill, Madrid, 1997.

DODD, P., et al.: "Qualified audit opinions and stock prices", Iournal of Accounting and Economics, Vol. 6, 1984, pp. 3-38.

DODD, P. y WARNER, J.: “On corporate governance, a study of proxy contest", Journal of Financial Economics, no 11, 1983, pp. 401-438.

DOPUCH, N., HOLTHAUSEN, R.W. y LEFTWICH, R.W.: "Predicting Audit Qualifications with Financial and Market Variables", The Accounting Review, Vol. LXII, n 3 , julio 1987, pp. 431-54.

DURÁNDEZ ADEVA, A.: "La auditoría: orígenes, evolución y futuro", $\underline{\text { Alta }}$ Dirección, no 101, 1982, pp. 29-34.

- “Las relaciones entre abogados y auditores", Papeles de Auditoría, no 8, octubre 1999, pp. 9-11. 
ELLIOTT, J.A.: “Subject to Audit Opinions and Abnormal Security Returns Outcomes and Ambiguities", Journal of Accounting Research, Vol. 20, n 2, autumn 1982, pp. 617-638.

ELLIOT, R.K., JACOBSON, P.D.: “The Auditor's Standard Report: The Last Word or in Need of Change?", Journal of Accountancy, February 1987, pp. 72-78.

EXPANSIÓN: “Andersen Consulting consigue separarse de Arthur; pero tendrá que cambiar de nombre", Año XV, no 4261, 8 de agosto 2000, pp. 3-5.

FERNÁNDEZ, M.: “El parlamento deja pendiente la reforma de la Ley de Auditoría para la próxima legislatura", Expansión, Año XV, n ${ }^{\circ} 4127,2$ marzo 2000, pág. 58.

- "Las compañías norteamericanas prefieren a sus auditoras para recibir servicios de consultoría", Expansión, Año XV, n 4197, 25 mayo 2000, pág. 69.

- “La agenda del nuevo ICAC", Expansión, Año XV, n 4335, noviembre 2000.

FERNÁNDEZ PEÑA, E.: "Hacia la auditoría contemporánea", Revista Técnica, IACJC, $3^{\mathrm{a}}$ Época, $\mathrm{n}^{\mathrm{o}} 3$, 1993, pp. 60-69.

FERNÁNDEZ PIRLA, J.M.: “La nueva ordenación legal de la contabilidad y

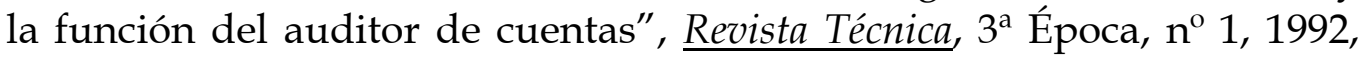
pp. 7-13.

FEROZ, E.H., PARK, K. y PASTENA, V.S.: “The Financial and Market Effects of the SEC's Accounting and Auditing Enforcement Releases", Lournal of Accounting Research, Vol. 29, Supplement 1991, pp. 107-129.

FIRTH, M.: "Qualified Audit Reports: Their Impact On Investment Decisions", The Accounting Review, Vol. LIII, n 3, julio 1978, pp. 642-650.

- "A note on the impact of audit qualifications on lending and credit decisions", Journal of Banking and Finance, n 4, 1980, pp. 257-267.

FISKE J. y HARTLEY, J.: Reading Televisión, Londres, 1980, citado por Kotler, P.: Dirección de Marketing, 8ª Edición, Prentice Hall, Madrid, 1996. 
GAFFNEY, M.A. y LYNN, S.A.: "A comparison of the perceptions of auditors and analysts about municipal audit reports", Financial Accountability \& Management, Vol. 7, spring 1991, pp. 35-56.

GALLIZO, J.L. y D'SILVA A.: “Expectativas de la auditoría: posición del auditor", VIII Congreso de AECA, Tomo I, Sevilla, septiembre 1995, pp. $217-41$.

GARCÍA BENAU, M.A.: "El debate internacional sobre el gap de expectativas en auditoría", Armonización de los servicios de auditoría en la U.E.: posición actual y futura de España - II Jornada de Trabajo sobre Auditoría Contable ASEPUC, Cantabria, junio 1997, pp. 149-78.

GARCÍA BENAU, M.A., et al.: "La calidad del servicio de auditoría: Los auditores vistos por sus clientes", Revista Española de Financiación y Contabilidad, Vol. XXVIII, $\mathrm{n}^{\mathrm{o}}$ 102, octubre-diciembre 1999, pp. 1005-1041.

GARCÍA BENAU, M.A., HUMPHREY, C., MOIZER, P. y TURLEY, S.: La auditoría y sus expectativas: los casos de España y del Reino Unido, Ed. ICAC, Madrid, 1993.

GARCÍA BENAU, M.A. y PUCHETA MARTINEZ, M.C.: “¿Comprenden los usuarios el informe de auditoría?", Técnica Contable, marzo 2001, pp. 177194.

GARCÍA BENAU, M.A., RUÍZ BARBADILLO, E. y VICO MARTÍNEZ, A.: Análisis de la estructura del mercado de servicios de auditoría en España, Ed. ICAC, Madrid, 1998.

GARCÍA BENAU, M.A. y UCIEDA ARCAS, J.L.: “Cómo acercar la auditoría a los requerimientos de la sociedad", Partida Doble, $\mathrm{n}^{\circ}$ 66, abril 1996, pp. 60-64.

GARCÍA BENAU, M.A. y VICO MARTÍNEZ, A.: “Un análisis internacional del contenido de los informes de auditoría: de los informes cortos a los informes largos", VIII Congreso de AECA, Tomo I, Sevilla, septiembre 1995, pp. 461-77.

- "Tendencias internacionales en la elaboración de los informes de auditoría", Técnica Contable, no 565, enero 1996, pp. 4-20.

GARCÍA DELGADO, S.: reseña tesis doctoral sobre "la importancia relativa en la auditoría financiera", AECA, octubre-diciembre 1994, citado por Urías Valiente y Blasco Lang “El procedimiento de elaboración de 
normas técnicas de auditoría y los informes de auditoría de cuentas anuales: algunas reflexiones a propósito de su posible reforma", II Jornada de Auditoría Contable-Asepuc, Cantabria, junio 1997, pp. 117148.

GARCÍA LUENGO, R.B. et al.: Código de Comercio y Otras Normas Mercantiles, Aranzadi Editorial, Pamplona, septiembre 1999.

GARCÍA ORDAZ, M. y MARTÍNEZ LÓPEZ, F.J.: "Implantación de un sistema de calidad total en la función contable de una empresa multinacional: aplicación de las normas de gestión ISO 9000", VIII Congreso AECA, Tomo II, Sevilla, septiembre 1995, pp. 273-291.

GEIGER, M.A.: "The New Audit Report: An Analysis of Exposure Draft Comments", Auditing: A Journal of Practice $\mathcal{E}$ Theory, Vol. 8, n², spring 1989, pp. 40-63.

- "Audit disclosures of consistency: an analysis of loan officer reaction to SAS 58", Advances in Accounting, Vol. 10, 1992, pp. 77-90.

GIBSON, K.M., PANY, K. y SMITH, S.H.: “Do We Understand Each Other?", Journal of Accountancy, enero 1998, pp. 53-59.

GIRONELLA MASGRAU, E. y GASSÓ VILAFRANCA, J.M.: "La auditoría externa y su filosofía", Alta Dirección, $\mathrm{n}^{\circ}$ 65, 1976.

GLOECK, J.D. y JAGER, H.: "The audit expectation gap in the republic of South Africa", Working Paper, School of Accountancy University of Pretoria.

GÓMEZ AGUILAR, N., LARRÁN JORGE, M. y RUÍZ BARBADILLO, E.: "Informe de auditoría y relevancia de la información contable en los mercados de capitales", X Congreso de AECA, Zaragoza, septiembre 1999.

GÓMEZ CIRIA, A.: “La armonización de los servicios de auditoría en la Unión Europea", Armonización de los servicios de auditoría en la U.E.: posición actual y futura de España - II Jornada de Trabajo sobre Auditoría Contable ASEPUC, Cantabria, junio 1997, pp. 7-11.

GONZALO ANGULO, J.A.: “La auditoría, una profesión en la encrucijada de los noventa", Revista Española de Financiación y Contabilidad, Vol. XXIV, $\mathrm{n}^{\circ}$ 84, abril-junio 1995, pp. 595-629. 
GOXÉNS DUCH, A.: “Un antecedente de la auditoría de las sociedades anónimas", Técnica Contable, enero 1985, pág. 19.

GRINAKER, R.L. y BARR, B.B.: Auditoría el examen de los estados financieros, Cia. Editorial Continental S.A., México, 1982.

GUY, D.M. y SULLIVAN J.D.: "The expectation gap auditing standards", Journal of Accountancy, Vol. 165, n 4, April 1988, pp. 36-46.

HAIR, J.F., ANDERSON, R.E., TATHAM, R.L. y BLACK, W.C.: Análisis Multivariante, $5^{\text {a }}$ Edición, Prentice Hall Iberia, Madrid, 1999.

HATHERLY, D., INNES, J. y BROWN, T.: “The Expanded Audit Report - An Empirical Investigation", Accounting and Business Research, Vol. 21, no 84, 1991, pp. 311-319.

HATHERLY, D.J. y SKUSE, P.C.: “Audit Reports” incluido en Current Issues in Auditing, 2a Edición, Paul Chapman Publishing Ltd., Londres, 1991.

HERRADOR ALCAIDE, T.C.: El informe de auditoría financiera de las cuentas anuales como conclusión y objetivo del trabajo del auditor: un estudio empírico para la Comunidad Autónoma de Madrid, Tesis Doctoral, Universidad Nacional de Educación a Distancia, Madrid, 2000.

HOLMES, A.W.: Principios básicos de auditoría, Cía. Editorial Continental S.A. (CECSA), México, 1978.

HOLT, G. y MOIZER, P.: "The Meaning of Audit Reports", Accounting and Business Research, Vol. 20, no 78, 1990, pp. 111-121.

HUMPHREY, C.: "Audit Expectations", incluido en Current Issues in Auditing, 2a Edición, Paul Chapman Publishing Ltd., Londres, 1991.

HUMPHREY, C., MOIZER, P. y TURLEY, S.: “The audit expectations gap in Britain: an empirical investigation", Accounting and Business Research, Vol. 23, summer 1993, pp. 395-411.

ILLESCAS ORTIZ, R.: Enciclopedia Jurídica Básica, Vol. I, $1^{\mathrm{a}}$ edición, Ed. Civitas, Madrid, 1995.

INNES, J., BROWN, T. y HATHERLY, D.: "The expanded audit report - a research study within the development of SAS 600", Accounting, Auditing E Accountability Journal, Vol. 10, n 5, 1997, pp. 702-717. 
INSTITUTO DE AUDITORES CENSORES JURADOS DE CUENTAS (IACJC): Libro Blanco de la auditoría de cuentas en España, Edita IACJC, Madrid, 1997.

- "Nueve de cada diez auditores desean la unificación de las Corporaciones" (encuesta septiembre 1999), El auditor-IACJC, $\mathrm{n}^{\circ} 4$, enero 2000, pp. 2-5.

- "Conclusiones de las diferentes ponencias, mesas redondas y panel internacional del XII Congreso Nacional del IACJC de España en octubre

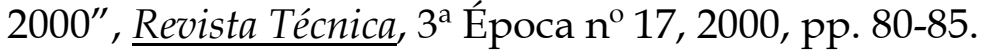

- “El informe de auditoría. La situación actual y perspectivas de futuro en un entorno global", El auditor-IACJC, n' 7 septiembre 2000, pp. 125-156.

INTERNATIONAL FEDERATION OF ACCOUNTANTS (IFAC): Objetivo y Principios Básicos de la Auditoría de los Estados Financieros, Norma Internacional de Auditoría $\mathrm{n}^{\circ}$ 200, traducido por TUA PEREDA, J. y GONZALO ANGULO, J.A., Madrid, 1999.

- Auditoría limitada de los estados financieros, Norma Internacional de Auditoría $\mathrm{n}^{\circ}$ 910, traducido por TUA PEREDA, J. y GONZALO ANGULO, J.A., Madrid, 1999.

- Encargos de aplicar determinados procedimientos acordados con el cliente, Norma Internacional de Auditoría $\mathrm{n}^{\circ}$ 920, traducido por TUA PEREDA, J. y GONZALO ANGULO, J.A., Madrid, 1999.

- Compromiso de elaborar información financiera, Norma Internacional de Auditoría $\mathrm{n}^{\circ}$ 930, traducido por TUA PEREDA, J. y GONZALO ANGULO, J.A., Madrid, 1999.

INSTITUTO DE CONTABILIDAD Y AUDITORIA DE CUENTAS (ICAC): Anuario del Registro Oficial de Auditores de Cuentas, Madrid, 1999.

- Resolución, de 28 de marzo de 1990, por la que se publican las Normas Técnicas de Auditoría, BOICAC, nº 1, marzo 1990.

- Resolución, de 19 de enero de 1991, por la que se publican las Normas Técnicas de Auditoría, BOICAC, nº 4, enero 1991.

- Resolución, de 1 de diciembre de 1994, por la que se modifican los apartados 1.4.3, 3.2.4. b) y 3.9.3 de las Normas Técnicas de Auditoría, BOICAC, no 19, diciembre 1994. 
- Normativa sobre Auditoría de Cuentas en España, Ed. ICAC, Madrid, 1997.

- Resolución, de 16 de junio de 1999, por la que se hace pública la Norma Técnica de Auditoría sobre "Contrato de auditoría o Carta de Encargo", BOICAC, $\mathrm{n}^{\circ} 38$, junio 1999.

- Situación de la auditoría en España, BOICAC, nº 41, marzo 2000.

- Resolución, de 15 de junio de 2000, por la que se hace pública la Norma Técnica de Auditoría sobre "Errores e Irregularidades", BOICAC, $\mathrm{n}^{\circ} 42$, junio 2000.

- Resolución, de 16 de junio de 2000, por la que se hace pública la Norma Técnica de Auditoría sobre "Cumplimiento de la normativa aplicable a la entidad auditada", BOICAC, $\mathrm{n}^{\circ}$ 42, junio 2000.

INSTITUTE OF CHARTERED ACCOUNTANTS IN IRELAND (ICAI): ICAI response to review group on auditing, October 2000.

JARNE JARNE, J.I., LAIINEZ GADEA, J.A. y CALLAO GASTÓN, S.: "Análisis Internacional de la Calidad de la Auditoría empresarial", La Contabilidad y la Auditoría ante los próximos retos, VIII Encuentro de ASEPUC, Alicante, 1998, pp. 683-704.

JONES, F.L.: "The Information Content of the Auditor's Going Concern Evaluation", Journal of Accounting and Public Policy, Vol. 15, 1996, pp.1-27.

KELLY, A.S. y MOHRWEIS, L.C.: "Bankers' and Investors' Perceptions of the Auditor's Role in Financial Statement Reporting: the Impact of SAS no58", Auditing: A journal of Practice \& Theory, Vol. 9, n 1, 1989, pp. 87-97.

$\mathrm{KOH}$, H.C. y WOO, E.: "The expectation gap in auditing", Managerial Auditing Journal, $\mathrm{n}^{\mathrm{o}} 13$, marzo 1998, pp. 147-154.

KOHLER, E.L.: Auditoría, introducción a la práctica de la contaduría pública, 11 Edición, Editorial Diana S.A., México, 1982.

KOTLER, P.: Dirección de Marketing, 8a Edición, Prentice Hall, Madrid, 1996.

LANDSITTEL, D.L.: “The Auditor's standard report: the last word or in need of change", Journal of Accountancy, February 1987, pp. 80-84.

LARRIBA DÍAZ-ZORITA, A.: Plan General de Contabilidad, 4a Edición, Ed. IACJC, Madrid, 1999. 
LARRIBA DÍAZ-ZORITA, A. y GONZALO ANGULO, J.A.: “La responsabilidad social del auditor", Revista Técnica, no 9, 1996, pp. 4-29.

LIBBY, R.: "The Impact of Uncertainty Reporting on the Loan Decision", Journal of Accounting Research, Vol.17, supplement 1979a, pp. 35-71.

- "Bankers' and Auditors' Perceptions of the Message Communicated by the Audit Report", Lournal of Accounting Research, Vol. 17, nº 1 , spring 1979b, pp. 99-122.

LIGGIO, C.D.: "The expectation gap: the accountant's Waterloo", Lournal of Contemporary Business, $\mathrm{n}^{\circ}$ 3, primavera 1974, pp. 27-44.

LÓPEZ CASUSO, A.: "Auditoría, independencia y objetividad", Revista Técnica, $3^{a}$ Época, nº 7, 1995, pp. 68-75.

- Normas de Auditoría, como interpretarlas para su aplicación, Ed. IACJC, Madrid, 1995.

LÓPEZ HERNÁNDEZ, A.M., NAVARRO GALERA, A. y MAZA VERA, P.: Normativa Básica de Contabilidad y Auditoría de Cuentas, Ed. Comares, Granada, septiembre 1996.

LOUDDER, M.L. et al.: "The Information Content of Audit Qualifications", Auditing: A Journal of Practice $\mathcal{E}$ Theory, Vol. 11, no 1, spring 1992, pp. 6982.

LUENGO MULET, P.: -Reflexiones sobre la Auditoría de Cuentas- en Ensayos y Estudios Contables en homenaje a D. Enrique Fernández Peña, D. Rafael Muñoz-Yusta Marcos y D. Melecio Riesco Escudero, Ed. ICAC, Madrid, 1997.

LLULL GILET, A. y PERELLÓ JULIÁ, M.: "El auditor de cuentas y los sistemas de gestión y auditoría medioambientales", Revista Técnica, $3^{\text {a }}$ Época $n^{\circ} 17,2000$, pp. 52-67.

MALLO RODRÍGUEZ, C.: "La auditoría estratégica de gestión dentro de la regulación legal de la auditoría de cuentas", Papeles de Auditoría, REA, $\mathrm{n}^{\circ}$ 9, junio 2000, pp. 19-26.

MARKOVITZ, H.: Portfolio selection: efficient diversification of investment, Wiley, New York, 1959. 
MAYPER, A.G., WELKER, R.B., y WIGGINS, C.E.: “Accounting and review services: perceptions of the message within the CPA'S report", Advances in Accounting, Vol. 6, 1988, pp. 219-232.

MELUMAD, N.D. y ZIV, A.: “A Theorical Examination of the Market Reaction to Auditor's Qualifications", Journal of Accounting Research, Vol. 35, n² 2, Autumn 1997, pp. 239-256.

MILLER, J.R., REED, S.A., STRAWSER, R.H.: “The new auditor's report: Will it close the expectations gap in communications?", The CPA Journal, May 1990, pp. 68-72.

- "Bank Loan Officers' Perceptions of the New Audit Report", Accounting Horizons, Vol. 7, n 1, march 1993, pp. 39-52.

MOIZER, P.: “Lo ultimo en la investigación del mercado de auditoría”, The European Accounting Review, n 1, 1992, pp. 333-348.

MÚRIA ALBIOL, J. y GIL SAURA, R.: Preparación, Tabulación y Análisis de Encuestas para Directivos, Ed. ESIC, Madrid, 1998.

NAIR, R.D., RITTENBERG, L.E.: "Messages Perceived from Audit, Review, and Compilation Reports: Extension to More Diverse Groups", Auditing: A Journal of Practice E Theory, Vol. 7, n¹, fall 1987, pp. 15-38.

NEWBOLD, P.: Estadística para los negocios y la economía, $4^{\text {a }}$ Edición, Ed. Prentice Hall, Madrid, 1998.

ORTA PÉREZ, M.: Una Propuesta de Marco Conceptual de la Auditoría de Cuentas Anuales, Ed. ICAC, Madrid, 1996.

OSGOOD, C.E., SUCI, G.J. y TANNEBAUM, P.H.: The measurement of meaning, University of Illinois Press, 1957.

PACHECO CAÑETE, M.: Régimen Legal de la Auditoría de Cuentas y Responsabilidad de los Auditores, Ed. Consejo Económico y Social (CES), Madrid, junio 2000.

PEDREIRA PEREZ, R.: “Auditoría de cuentas y administración financiera", incluido en el volumen Ensayos sobre Auditoría en homenaje a Manuel Mier Menes, IACJC, Madrid, 1997.

PEREDA SIGÜENZA, J.M.: Manual de Auditoría y Cuentas Anuales, Editorial Centro de Estudios Ramón Areces S.A., Madrid, 1991. 
PEREDA SIGÜENZA, J.M. y ALVARADO RIQUELME, M.: “La independencia del auditor: propuestas de modificación de la normativa", Partida Doble, $\mathrm{n}^{\circ} 110$, abril 2000, pp. 80-91.

PRADO LORENZO, J.M.: “La Norma de auditoría sobre la aplicación del principio de Empresa en Funcionamiento: Consideraciones de los

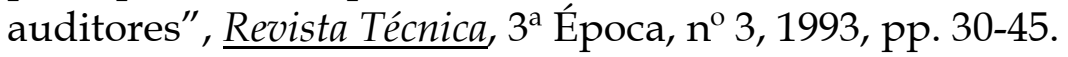

PRADO LORENZO, J.M. y GONZALEZ BRAVO, Mª I.: Auditoría: ¿hacia dónde caminar?, La Contabilidad y la Auditoría ante los próximos retos, VIII Encuentro de ASEPUC, Alicante, 1998, pp. 861- 878.

POLO Y SÁNCHEZ CALERO, citados por ARANA GONDRA, F.J. y LASSO DE LA VEGA J.: “El dictamen del Auditor en el ámbito de la información económica", III Congreso Nacional IACJC, Barcelona, marzo 1977, pp. 137-138.

PORTER, B.: "An empirical study of the audit expectation-performance gap", Accounting and Business Research, $\mathrm{n}^{\circ} 24$, invierno 1993, pp. 49-68.

REAL ACADEMIA ESPAÑOLA: Diccionario de la Lengua Española, Ed. Espasa Calpe, 21ª Edición, Madrid, 1992.

REGISTRO DE ECONOMISTAS AUDITORES (REA): “Búsqueda de soluciones y Propuestas de futuro", Papeles de Auditoría, no 4, enero 1997, pp. 3-4.

- "Propuestas del REA al Libro Verde", Papeles de Auditoría, n 4, enero 1997, pp. 21-22.

- "Acercando la auditoría a la sociedad", Papeles de Auditoría, no 6, junio 1998, pp. 2-4.

ROBERTSON, J.C.: “Analysts' Reactions to Auditors' Messages in Qualified Reports", Accounting Horizons, June 1988, pp. 82-89.

ROJAS TEJADA, A.J., FERNÁNDEZ PRADOS, J.S. y PÉREZ MELÉNDEZ, C.: Investigar Mediante Encuestas: fundamentos teóricos y aspectos prácticos, Ed. Síntesis Psicología, Madrid, 1998.

RUÍZ BARBADILLO, E.: Los objetivos del informe de auditoría, Ed. ICAC, Madrid 1997. 
- "Dimensiones informativas y objetivos del informe de auditoría", Revista de Contabilidad, Vol. 1, nº 2, julio-diciembre 1998, pp. 129-152.

RUÍZ BARBADILLO, E. y GÓMEZ AGUILAR, Ma .N.: "La actitud de la profesión ante las expectativas de auditoría", Armonización de los servicios de auditoría en la U.E.: posición actual y futura de España - II Jornada de Trabajo sobre Auditoría Contable ASEPUC, Cantabria, junio 1997, pp. 221-233.

RUÍZ BLANCO, S.: “Responsabilidad, formación e independencia. Las normas de la profesión en España: una perspectiva histórica", IX Congreso de AECA, Tomo I, Sevilla, septiembre 1997, pp. 1125-1145.

SAMUELSON, P.A. y NORDHAUS, W.D.: Economía, $12^{\mathrm{a}}$ edición, McGrawHill, México, 1988.

SÁNCHEZ FERNÁNDEZ DE VALDERRAMA, J.L.: Teoría y Práctica de la Auditoría I - Concepto y Metodología, Ed. Pirámide, Madrid, 1997.

SÁNCHEZ SEGURA, A.: "El informe de auditoría: alcance, significado y evidencia empírica", Revista Española de Financiación y Contabilidad, Vol. XXVIII, n 2, octubre-diciembre 1999, pp. 1163-1167.

SANTESMASES MESTRE, M.: Marketing Conceptos y Estrategias, Ed. Pirámide, Madrid, 1998.

SARABIA SÁNCHEZ, F.J. et al.: Metodología para la investigación en marketing y dirección de empresas, Ed. Pirámide, Madrid, 1999.

SCHIFFMAN, L.G. y KANUK, L.L.: Comportamiento del Consumidor, 5a Edición, Prentice Hall, México, 1997.

SCHULTZ, J.J.: "Discussion of The Impact of Uncertainty Reporting on the Loan Decision", Iournal of Accounting Research, Vol.17, supplement 1979, pp. 64-71.

SEGOVIA SAN JUAN, A.I.: “El comité de auditoría desde una perspectiva de agencia", La Contabilidad y la Auditoría ante los próximos retos, VIII Encuentro de ASEPUC, Alicante, 1998, pp. 905-917.

SHARPE, W.F.: "A simplified model for portfolio analysis", Management Science, January 1963, pp. 377-392. 
SIERRA MOLINA, G. y ORTA PÉREZ, M.: “Una responsabilidad básica del auditor: el control de calidad", Armonización de los servicios de auditoría en la U.E.: posición actual y futura de España - II Jornada de Trabajo sobre Auditoría Contable ASEPUC, Cantabria, junio 1997, pp. 71116.

SPIEGEL, M.R.: Estadística, 2a Edición, McGraw-Hill, Madrid, 1991.

SUÁREZ SUÁREZ, A.S.: La Moderna Auditoría. Un análisis conceptual y metodológico, 1ªdición, McGraw-Hill, Madrid, 1991.

TWEEDIE, D.P.: “Fraud - Managements' and Auditors' Responsibility for its Prevention and Detection", incluido en Current Issues in Auditing, $2^{\mathrm{a}}$ Edición, Paul Chapman Publishing Ltd., Londres, 1991.

URÍAS VALIENTE, J.: Auditoría Financiera, Tebar Flores, Madrid, 1987.

- El objetivo de relevancia en el informe del auditor independiente, ICAC, Madrid, 1990.

URÍAS VALIENTE, J. y BLASCO LANG, J.J.: “El procedimiento de elaboración de normas técnicas de auditoría y los informes de auditoría de cuentas anuales: algunas reflexiones a propósito de su posible reforma", Armonización de los servicios de auditoría en la U.E.: posición actual y futura de España - II Jornada de Trabajo sobre Auditoría Contable ASEPUC, Cantabria, junio 1997, pp. 117-148.

VARA ARRIBAS, R.: “Propuestas Europeas al 'gap de expectativas': del Informe Cadbury al Libro Verde", IX Congreso de AECA, Tomo I, septiembre 1997, pp. 821-843.

VELA PASTOR, M. y MARCO GRANELL, A.: "La Auditoría en el Mundo", Alta Dirección, no 101, 1982, pp. 9-16.

VERGÉS MAMÉ, E.: "Servicios relacionados con la auditoría que no constituyen trabajo de auditoría de cuentas", Revista Técnica, no 14, 1998, pp. 16-25.

- "Medidas de seguridad de los ficheros que contengan datos de carácter personal”, El Auditor-IACIC, n 5, abril 2000, pp. 2-8.

VICO MARTÍNEZ, A.: "La independencia aparente del auditor en el contexto del gap de expectativas", Armonización de los servicios de auditoría en la U.E.: posición actual y futura de España - II Jornada de 
Trabajo sobre Auditoría Contable ASEPUC, Cantabria, junio 1997, pp. 227-233.

VIDAL HERNÁNDEZ-MORA, J.A.: "El debate internacional sobre el gap de expectativas en auditoría", Armonización de los servicios de auditoría en la U.E.: posición actual y futura de España - II Jornada de Trabajo sobre Auditoría Contable ASEPUC, Cantabria, junio 1997, pp. 235-239.

WANDEN-BERGHE LOZANO, J.L. y TRIGUEROS PINA, J.A.: “Conflicto terminológico en auditoría y propuesta de clasificación", Técnica Contable, $n^{\mathrm{o}}$ 569, mayo 1996, pp. 327-342.

WHITTINGTON, O.R. y PANY, K.: Auditoría un Enfoque Integral, 12a Edición, Ed. McGraw-Hill, Bogotá, 2000.

WILKERSON, J.E.: "Selecting Experimental and Comparison Samples for Use in Studies of Auditor Reporting Decisions", Journal of Accounting research, Vol. 25, spring 1987, pp. 161-167.

WILLINGHAM, J.J.: “Discussant's response to relationship of auditing standards to detection of fraud", The CPA Journal, April 1975, pp. 18-21.

YUBERO HERMOSA, P.: "La utilidad de los informes de auditoría", IV Jornada de Auditoría Contable de ASEPUC, Madrid, 2001, pp. 179-192. 


\section{LEGISLACIÓN}




\section{LEGISLACIÓN}

- LEY de 17 de julio de 1951, de Régimen Jurídico de las Sociedades Anónimas.

- LEY 8/1980, de 10 de marzo, por la que se aprueba el Estatuto de los Trabajadores.

- LEY 13/1980, de 31 de marzo, General de la Cultura Física y del Deporte.

- LEY 19/1988, de 12 de julio, de Auditoría de Cuentas (BOE nº169, de 15 de julio [RCL 1988, 1538]).

- LEY 2/1995, de 23 de marzo, de Sociedades de Responsabilidad Limitada.

- LEY 7/1995, de 21 de junio, de la Generalidad de Cataluña.

- LEY 31/1995, de 8 de noviembre, de Prevención de Riesgos Laborales.

- LEY 15/1999, de 13 de diciembre, de Protección de datos de carácter personal.

- REAL DECRETO 1506/1967, de 30 de junio, por el que se aprueba el Reglamento de la Bolsa de Comercio.

- REAL DECRETO 871/1977, de 26 de abril, sobre el Estatuto Profesional de los Economistas, Profesores y Peritos Mercantiles.

- REAL DECRETO 302/1989, de 17 de marzo, por el que se aprueba el estatuto y la estructura orgánica del ICAC, modificado por el REAL DECRETO 1784/2000, de 27 de octubre.

- REAL DECRETO 1636/1990, de 20 de diciembre, por el que se aprueba el Reglamento que desarrolla la Ley 19/1988, de 12 de julio, de Auditoría de Cuentas (BOE $\mathrm{n}^{\circ} 308$, de 25 de diciembre).

- REAL DECRETO 572/1997, de 18 de abril, por el que se revisan los límites contables de los artículos 181 y 190 del TRLSA, aprobado por el Real Decreto Legislativo 1564/1989, de 22 de diciembre.

- REAL DECRETO 39/1997, de 17 de enero, por el que se aprueba el Reglamento de los servicios de Prevención de Riesgos Laborales. 
- REAL DECRETO 994/1999, de 11 de junio, por el que se aprueba el Reglamento de medidas de seguridad de los ficheros automatizados que contengan datos de carácter personal.

- REAL DECRETO LEGISLATIVO 1564/1989, de 22 de diciembre, por el que se aprueba el Texto Refundido de la Ley de Sociedades Anónimas (BOE $\mathrm{n}^{\circ} 310$ de 27 de diciembre; rect. $\mathrm{BOE} \mathrm{n}^{\circ} 28$, de 1 de febrero de 1990).

- REGLAMENTO 1836/93, de 29 de junio, del Consejo de la Unión Europea por el que se permite que las empresas del sector industrial se adhieran con carácter voluntario a un sistema comunitario de gestión y auditoría medioambientales (DOCE $n^{\circ}$ L 168, de 10-7-93). 


\section{ANEXO 1}

Prueba de Kolmogorov-Smirnov para la 1ª hipótesis (Grupo de Empresas)

\begin{tabular}{|c|c|c|c|c|c|}
\hline \multirow{2}{*}{ CUESTIONES PLANTEADAS } & \multirow{2}{*}{$\mathbf{N}$} & \multicolumn{2}{|c|}{$\begin{array}{l}\text { Parámetros } \\
\text { normales }^{\text {a, b }}\end{array}$} & \multirow{2}{*}{$\begin{array}{l}\text { Z de } \\
\text { Kolmogorov- } \\
\text { Smirnov }\end{array}$} & \multirow{2}{*}{$\begin{array}{l}\text { Sig. asintót. } \\
\text { (bilateral) }\end{array}$} \\
\hline & & Media & $\begin{array}{c}\text { Desviación } \\
\text { típica }\end{array}$ & & \\
\hline \multicolumn{6}{|l|}{ 1.Es responsabilidad del auditor: } \\
\hline -preparar y formular las cuentas anuales auditadas & 312 & 2.40 & 1.63 & 5.422 & $0.000 *$ \\
\hline -llevar la contabilidad de la empresa auditada & 309 & 1.12 & 0.47 & 9.077 & $0.000^{*}$ \\
\hline -revisar toda la contabilidad de la empresa auditada & 313 & 3.63 & 1.51 & 4.572 & $0.000^{*}$ \\
\hline $\begin{array}{l}\text {-detectar los fraudes y/o ilegalidades que se puedan } \\
\text { desprender de la gestión }\end{array}$ & 312 & 3.72 & 1.47 & 4.875 & $0.000^{*}$ \\
\hline $\begin{array}{l}\text { 2.El auditor se encarga de verificar si las cuentas } \\
\text { anuales expresan la imagen fiel de la situación } \\
\text { económico-financiera de la empresa de acuerdo a los } \\
\text { principios de contabilidad: }\end{array}$ & 315 & 4.83 & 0.57 & 9.044 & $0.000^{*}$ \\
\hline $\begin{array}{l}\text { 3.El auditor sólo se pronuncia en su informe sobre las } \\
\text { cuentas anuales (Balance, Cta. de P y G y Memoria): }\end{array}$ & 313 & 3.77 & 1.39 & 4.527 & $0.000^{*}$ \\
\hline $\begin{array}{l}\text { 4.El informe del auditor es una opinión razonable pero } \\
\text { no un certificado de absoluta garantía sobre las } \\
\text { cuentas anuales. }\end{array}$ & 313 & 4.26 & 1.11 & 5.753 & $0.000^{*}$ \\
\hline \multicolumn{6}{|l|}{$\begin{array}{l}\text { 5.Se espera que el trabajo del auditor aporte seguridad } \\
\text { sobre: }\end{array}$} \\
\hline -que se cumple con las normas contables & 315 & 4.72 & 0.53 & 8.136 & $0.000^{*}$ \\
\hline -que no existen fraudes y/o ilegalidades & 313 & 3.79 & 1.20 & 3.690 & $0.000 *$ \\
\hline -que la gestión de la empresa es adecuada & 314 & 2.76 & 1.41 & 2.867 & $0.000 *$ \\
\hline $\begin{array}{l}\text {-que la situación financiera de la empresa } \\
\text { es solvente }\end{array}$ & 312 & 2.86 & 1.45 & 2.882 & $0.000^{*}$ \\
\hline -que el control interno funciona correctamente & 315 & 3.48 & 1.33 & 3.337 & $0.000 *$ \\
\hline $\begin{array}{l}\text {-que se cumplen las normas legales que afectan a } \\
\text { la empresa }\end{array}$ & 313 & 3.95 & 1.15 & 4.147 & $0.000^{*}$ \\
\hline -que la empresa continuará funcionando & 312 & 2.65 & 1.50 & 3.669 & $0.000^{*}$ \\
\hline \multicolumn{6}{|l|}{$\begin{array}{l}\text { a. La distribución de contraste es la normal } \\
\text { b. Se han calculado a partir de los datos }\end{array}$} \\
\hline $\begin{array}{c}* \text { Estadísticamente significativo al } 1 \% . * * \text { Estadística } \\
\text { Las valoraciones medias corresponden a una escal }\end{array}$ & $\mathrm{si}$ & ivo & o. $\mathrm{NS}=\mathrm{e}$ & ísticamente & $\begin{array}{l}\text { ignificativo. } \\
\text { uerdo. }\end{array}$ \\
\hline
\end{tabular}




\section{ANEXO 2}

Prueba de Kolmogorov-Smirnov para la $1^{\text {a }}$ hipótesis (Grupo de Auditores)

\begin{tabular}{|c|c|c|c|c|c|}
\hline \multirow[b]{2}{*}{ CUESTIONES PLANTEADAS } & \multirow[b]{2}{*}{$\mathbf{N}$} & \multicolumn{2}{|c|}{ Parámetros normales ${ }^{\mathrm{a}, \mathrm{b}}$} & \multirow{2}{*}{$\begin{array}{c}\text { Z de } \\
\text { Kolmogorov- } \\
\text { Smirnov }\end{array}$} & \multirow{2}{*}{$\begin{array}{l}\text { Sig. asintót. } \\
\text { (bilateral) }\end{array}$} \\
\hline & & Media & $\begin{array}{c}\text { Desviación } \\
\text { típica }\end{array}$ & & \\
\hline \multicolumn{6}{|l|}{ 1.Es responsabilidad del auditor: } \\
\hline -preparar y formular las cuentas anuales auditadas & 327 & 1.32 & 0.91 & 9.029 & $0.000 *$ \\
\hline -llevar la contabilidad de la empresa auditada & 323 & 1.09 & 0.56 & 9.556 & $0.000 *$ \\
\hline -revisar toda la contabilidad de la empresa auditada & 327 & 2.47 & 1.63 & 5.215 & $0.000 *$ \\
\hline $\begin{array}{l}\text {-detectar los fraudes y/o ilegalidades que se puedan } \\
\text { desprender de la gestión }\end{array}$ & 330 & 2.25 & 1.36 & 4.760 & $0.000^{*}$ \\
\hline $\begin{array}{l}\text { 2.El auditor se encarga de verificar si las cuentas } \\
\text { anuales expresan la imagen fiel de la situación } \\
\text { económico-financiera de la empresa de acuerdo a los } \\
\text { principios de contabilidad: }\end{array}$ & 335 & 4.88 & 0.42 & 9.538 & $0.000^{*}$ \\
\hline $\begin{array}{l}\text { 3.El auditor sólo se pronuncia en su informe sobre las } \\
\text { cuentas anuales (Balance, Cta. de P y G y Memoria): }\end{array}$ & 331 & 4.11 & 1.30 & 5.884 & $0.000 *$ \\
\hline $\begin{array}{l}\text { 4.El informe del auditor es una opinión razonable pero } \\
\text { no un certificado de absoluta garantía sobre las } \\
\text { cuentas anuales. }\end{array}$ & 331 & 4.69 & 0.73 & 8.595 & $0.000^{*}$ \\
\hline \multicolumn{6}{|l|}{$\begin{array}{l}\text { 5.Se espera que el trabajo del auditor aporte seguridad } \\
\text { sobre: }\end{array}$} \\
\hline -que se cumple con las normas contables & 332 & 4.77 & 0.67 & 8.831 & $0.000 *$ \\
\hline -que no existen fraudes y/o ilegalidades & 331 & 2.76 & 1.24 & 3.427 & $0.000^{*}$ \\
\hline -que la gestión de la empresa es adecuada & 330 & 2.36 & 1.28 & 3.547 & $0.000^{*}$ \\
\hline $\begin{array}{l}\text {-que la situación financiera de la empresa } \\
\text { es solvente }\end{array}$ & 326 & 2.77 & 1.37 & 3.204 & $0.000 *$ \\
\hline -que el control interno funciona correctamente & 332 & 3.77 & 1.26 & 3.999 & $0.000^{*}$ \\
\hline $\begin{array}{l}\text {-que se cumplen las normas legales que afectan a } \\
\text { la empresa }\end{array}$ & 332 & 3.84 & 1.19 & 4.030 & $0.000^{*}$ \\
\hline -que la empresa continuará funcionando & 330 & 3.43 & 1.43 & 3.322 & $0.000^{*}$ \\
\hline $\begin{array}{l}\text { a. La distribución de contraste es la normal } \\
\text { b. Se han calculado a partir de los datos }\end{array}$ & & & & & \\
\hline
\end{tabular}




\section{ANEXO 3}

Prueba de Kolmogorov-Smirnov para $1^{\text {a }}$ hipótesis (Grupo de Entidades de Crédito)






\section{ANEXO 4}

Prueba de Kolmogorov-Smirnov para $1^{\mathrm{a}}$ hipótesis (Grupo de Ag. y Soc. de valores)

\begin{tabular}{|c|c|c|c|c|c|}
\hline \multirow{2}{*}{ CUESTIONES PLANTEADAS } & \multirow[b]{2}{*}{$\mathbf{N}$} & \multicolumn{2}{|c|}{ Parámetros normales ${ }^{\mathrm{a}, \mathrm{b}}$} & \multirow{2}{*}{\begin{tabular}{|c|}
$\begin{array}{l}Z \text { de } \\
\text { Kolmogorov- } \\
\text { Smirnov }\end{array}$ \\
\end{tabular}} & \multirow{2}{*}{$\begin{array}{l}\text { Sig. asintót } \\
\text { (bilateral) }\end{array}$} \\
\hline & & Media & $\begin{array}{c}\text { Desviación } \\
\text { típica }\end{array}$ & & \\
\hline \multicolumn{6}{|l|}{ 1.Es responsabilidad del auditor: } \\
\hline -preparar y formular las cuentas anuales auditadas & 32 & 2.50 & 1.72 & 1.743 & $0.005^{*}$ \\
\hline -llevar la contabilidad de la empresa auditada & 32 & 1.19 & 0.47 & 2.820 & $0.000 *$ \\
\hline -revisar toda la contabilidad de la empresa auditada & 33 & 3.64 & 1.43 & 1.458 & $0.029 * *$ \\
\hline $\begin{array}{l}\text {-detectar los fraudes y/o ilegalidades que se puedan } \\
\text { desprender de la gestión }\end{array}$ & 32 & 3.78 & 1.13 & 1.152 & $0.140^{\mathrm{NS}}$ \\
\hline $\begin{array}{l}\text { 2.El auditor se encarga de verificar si las cuentas } \\
\text { anuales expresan la imagen fiel de la situación } \\
\text { económico-financiera de la empresa de acuerdo a los } \\
\text { principios de contabilidad. }\end{array}$ & 33 & 4.88 & 0.55 & 3.029 & $0.000^{*}$ \\
\hline $\begin{array}{l}\text { 3.El auditor sólo se pronuncia en su informe sobre las } \\
\text { cuentas anuales (Balance, Cta. de P y G y Memoria). }\end{array}$ & 33 & 3.48 & 1.39 & 1.467 & $0.027 * *$ \\
\hline $\begin{array}{l}\text { 4.El informe del auditor es una opinión razonable pero } \\
\text { no un certificado de absoluta garantía sobre las } \\
\text { cuentas anuales. }\end{array}$ & 33 & 4.33 & 1.02 & 1.832 & $0.002 *$ \\
\hline \multicolumn{6}{|l|}{$\begin{array}{l}\text { 5.Se espera que el trabajo del auditor aporte seguridad } \\
\text { sobre: }\end{array}$} \\
\hline -que se cumple con las normas contables & 33 & 4.82 & 0.39 & 2.855 & $0.000 *$ \\
\hline -que no existen fraudes y/o ilegalidades & 33 & 3.85 & 1.09 & 1.424 & $0.035^{* *}$ \\
\hline -que la gestión de la empresa es adecuada & 33 & 2.55 & 1.46 & 1.098 & $0.179^{\mathrm{NS}}$ \\
\hline $\begin{array}{l}\text {-que la situación financiera de la empresa } \\
\text { es solvente }\end{array}$ & 33 & 3.15 & 1.42 & 1.061 & $0.210^{\mathrm{NS}}$ \\
\hline -que el control interno funciona correctamente & 33 & 3.76 & 1.03 & 1.491 & $0.023 * *$ \\
\hline $\begin{array}{l}\text {-que se cumplen las normas legales que afectan a } \\
\text { la empresa }\end{array}$ & 33 & 4.06 & 1.06 & 1.360 & $0.049^{* *}$ \\
\hline -que la empresa continuará funcionando & 33 & 2.97 & 1.59 & 1.121 & $0.162^{\mathrm{NS}}$ \\
\hline \multicolumn{6}{|l|}{$\begin{array}{l}\text { a. La distribución de contraste es la normal } \\
\text { b. Se han calculado a partir de los datos }\end{array}$} \\
\hline $\begin{array}{l}* \text { Estadísticamente significativo al } 1 \% \text {. ** Estadís } \\
\text { Las valoraciones medias corresponden a una esca }\end{array}$ & & & $\mathrm{NS}=\mathrm{e}$ & & ificativo. \\
\hline
\end{tabular}




\section{ANEXO 5}

Prueba de Kolmogorov-Smirnov para la $2^{\text {a }}$ hipótesis (Grupo de Empresas)

\begin{tabular}{|c|c|c|c|c|c|}
\hline \multirow{2}{*}{ CUESTIONES PLANTEADAS } & \multirow[b]{2}{*}{$\mathbf{N}$} & \multicolumn{2}{|c|}{ Parámetros normales $^{\mathrm{a}, \mathrm{b}}$} & \multirow{2}{*}{$\begin{array}{c}Z \text { de } \\
\text { Kolmogorov- } \\
\text { Smirnov }\end{array}$} & \multirow{2}{*}{$\begin{array}{l}\text { Sig. asintót. } \\
\text { (bilateral) }\end{array}$} \\
\hline & & Media & $\begin{array}{c}\text { Desviación } \\
\text { típica }\end{array}$ & & \\
\hline \multicolumn{6}{|l|}{$\begin{array}{l}\text { 1. Exprese su grado de acuerdo con las siguientes } \\
\text { afirmaciones: }\end{array}$} \\
\hline $\begin{array}{l}\text {-las cuentas anuales muestran la imagen real de las } \\
\text { empresas }\end{array}$ & 307 & 3.75 & 1.12 & 3.613 & $0.000^{*}$ \\
\hline $\begin{array}{l}\text {-la auditoría aporta fiabilidad a las cuentas anuales } \\
\text { de las empresas }\end{array}$ & 310 & 4.36 & 0.80 & 5.354 & $0.000 *$ \\
\hline $\begin{array}{l}\text {-la auditoría aporta "valor añadido" a la sociedad } \\
\text { auditada }\end{array}$ & 309 & 3.58 & 1.21 & 3.550 & $0.000^{*}$ \\
\hline -el coste de la auditoría está justificado & 310 & 3.28 & 1.21 & 3.275 & $0.000^{*}$ \\
\hline $\begin{array}{l}\text {-la auditoría se realiza exclusivamente por ser una } \\
\text { obligación legal }\end{array}$ & 310 & 2.98 & 1.36 & 2.445 & $0.000 *$ \\
\hline -la auditoría es un servicio de interés público & 309 & 3.41 & 1.30 & 2.924 & $0.000 *$ \\
\hline $\begin{array}{l}\text {-la opinión que emite el auditor es completamente } \\
\text { independiente }\end{array}$ & 310 & 3.82 & 1.10 & 3.559 & $0.000^{*}$ \\
\hline $\begin{array}{l}\text {-la opinión del auditor conlleva un alto grado de } \\
\text { subjetividad }\end{array}$ & 308 & 2.64 & 1.15 & 2.936 & $0.000^{*}$ \\
\hline \multicolumn{6}{|l|}{ 2. Exprese su acuerdo con las siguientes afirmaciones: } \\
\hline $\begin{array}{l}\text {-las cuentas anuales aportan información para la } \\
\text { toma de decisiones }\end{array}$ & 306 & 3.45 & 1.30 & 3.604 & $0.000^{*}$ \\
\hline $\begin{array}{l}\text {-el informe del auditor aporta información adicional } \\
\text { para la toma de decisiones }\end{array}$ & 303 & 3.09 & 1.28 & 3.075 & $0.000^{*}$ \\
\hline $\begin{array}{l}\text {-la carta de recomendaciones aporta información } \\
\text { adicional para la gestión }\end{array}$ & 301 & 3.54 & 1.14 & 3.729 & $0.000^{*}$ \\
\hline $\begin{array}{l}\text {-el informe es útil para determinar si la empresa es } \\
\text { financieramente viable }\end{array}$ & 302 & 3.13 & 1.22 & 2.894 & $0.000^{*}$ \\
\hline $\begin{array}{l}\text {-un informe limpio aporta información más relevante } \\
\text { que uno con salvedades }\end{array}$ & 300 & 2.63 & 1.48 & 3.268 & $0.000^{*}$ \\
\hline \multicolumn{6}{|l|}{$\begin{array}{l}\text { a. La distribución de contraste es la normal } \\
\text { b. Se han calculado a partir de los datos }\end{array}$} \\
\hline * Estadísticamente significativo al 1\%. ** Estadístic & ente & ativo a & $\mathrm{NS}=$ est & amente no sig & gnificativo. \\
\hline
\end{tabular}




\section{ANEXO 6}

\section{Prueba de Kolmogorov-Smirnov para la 2a hipótesis (Grupo de Auditores)}

\begin{tabular}{|c|c|c|c|c|c|}
\hline \multirow[b]{2}{*}{ CUESTIONES PLANTEADAS } & \multirow[b]{2}{*}{$\mathbf{N}$} & \multicolumn{2}{|c|}{ Parámetros normales $^{\mathrm{a}, \mathrm{b}}$} & \multirow{2}{*}{$\begin{array}{c}\mathrm{Z} \text { de } \\
\text { Kolmogorov- } \\
\text { Smirnov }\end{array}$} & \multirow{2}{*}{$\begin{array}{l}\text { Sig. asintót. } \\
\text { (bilateral) }\end{array}$} \\
\hline & & Media & $\begin{array}{l}\text { Desviación } \\
\text { típica }\end{array}$ & & \\
\hline \multicolumn{6}{|l|}{$\begin{array}{l}\text { 1. Exprese su grado de acuerdo con las siguientes } \\
\text { afirmaciones: }\end{array}$} \\
\hline $\begin{array}{l}\text {-las cuentas anuales muestran la imagen real de las } \\
\text { empresas }\end{array}$ & 324 & 3.35 & 1.26 & 3.130 & $0.000^{*}$ \\
\hline $\begin{array}{l}\text {-la auditoría aporta fiabilidad a las cuentas anuales } \\
\text { de las empresas }\end{array}$ & 331 & 4.63 & 0.64 & 7.533 & $0.000^{*}$ \\
\hline $\begin{array}{l}\text {-la auditoría aporta "valor añadido" a la sociedad } \\
\text { auditada }\end{array}$ & 329 & 4.21 & 0.98 & 5.546 & $0.000^{*}$ \\
\hline -el coste de la auditoría está justificado & 331 & 4.44 & 0.88 & 6.895 & $0.000 *$ \\
\hline $\begin{array}{l}\text {-la auditoría se realiza exclusivamente por ser una } \\
\text { obligación legal }\end{array}$ & 331 & 3.12 & 1.23 & 3.441 & $0.000 *$ \\
\hline -la auditoría es un servicio de interés público & 330 & 4.14 & 1.04 & 4.903 & $0.000^{*}$ \\
\hline $\begin{array}{l}\text {-la opinión que emite el auditor es completamente } \\
\text { independiente }\end{array}$ & 330 & 4.36 & 0.89 & 6.397 & $0.000 *$ \\
\hline $\begin{array}{l}\text {-la opinión del auditor conlleva un alto grado de } \\
\text { subjetividad }\end{array}$ & 330 & 2.42 & 1.28 & 3.948 & $0.000 *$ \\
\hline \multicolumn{6}{|l|}{ 2. Exprese su acuerdo con las siguientes afirmaciones: } \\
\hline $\begin{array}{l}\text {-las cuentas anuales aportan información para la } \\
\text { toma de decisiones }\end{array}$ & 330 & 3.91 & 1.18 & 4.531 & $0.000^{*}$ \\
\hline $\begin{array}{l}\text {-el informe del auditor aporta información adicional } \\
\text { para la toma de decisiones }\end{array}$ & 325 & 3.70 & 1.22 & 3.580 & $0.000^{*}$ \\
\hline $\begin{array}{l}\text {-la carta de recomendaciones aporta información } \\
\text { adicional para la gestión }\end{array}$ & 331 & 4.17 & 0.99 & 5.006 & $0.000 *$ \\
\hline $\begin{array}{l}\text {-el informe es útil para determinar si la empresa es } \\
\text { financieramente viable }\end{array}$ & 328 & 3.24 & 1.24 & 3.149 & $0.000^{*}$ \\
\hline $\begin{array}{l}\text {-un informe limpio aporta información más relevante } \\
\text { que uno con salvedades }\end{array}$ & 329 & 2.32 & 1.42 & 4.698 & $0.000^{*}$ \\
\hline \multicolumn{6}{|l|}{$\begin{array}{l}\text { a. La distribución de contraste es la normal } \\
\text { b. Se han calculado a partir de los datos }\end{array}$} \\
\hline
\end{tabular}




\section{ANEXO 7}

Prueba de Kolmogorov-Smirnov para la 2a hipótesis (Grupo Entidades de Crédito)

\begin{tabular}{|c|c|c|c|c|c|}
\hline \multirow[b]{2}{*}{ CUESTIONES PLANTEADAS } & \multirow[b]{2}{*}{$\mathbf{N}$} & \multicolumn{2}{|c|}{ Parámetros normales ${ }^{\mathrm{a}, \mathrm{b}}$} & \multirow{2}{*}{$\begin{array}{l}\text { Z de } \\
\text { Kolmogorov- } \\
\text { Smirnov }\end{array}$} & \multirow{2}{*}{$\begin{array}{l}\text { Sig. asintót. } \\
\text { (bilateral) }\end{array}$} \\
\hline & & Media & $\begin{array}{l}\text { Desviación } \\
\text { típica }\end{array}$ & & \\
\hline \multicolumn{6}{|l|}{$\begin{array}{l}\text { 1. Exprese su grado de acuerdo con las siguientes } \\
\text { afirmaciones: }\end{array}$} \\
\hline $\begin{array}{l}\text {-las cuentas anuales muestran la imagen real de las } \\
\text { empresas }\end{array}$ & 77 & 3.31 & 1.05 & 1.848 & $0.002 *$ \\
\hline $\begin{array}{l}\text {-la auditoría aporta fiabilidad a las cuentas anuales } \\
\text { de las empresas }\end{array}$ & 77 & 4.35 & 0.70 & 2.315 & $0.000 *$ \\
\hline $\begin{array}{l}\text {-la auditoría aporta "valor añadido" a la sociedad } \\
\text { auditada }\end{array}$ & 77 & 3.74 & 0.95 & 2.140 & $0.000 *$ \\
\hline -el coste de la auditoría está justificado & 77 & 3.53 & 0.97 & 1.890 & $0.002 *$ \\
\hline $\begin{array}{l}\text {-la auditoría se realiza exclusivamente por ser una } \\
\text { obligación legal }\end{array}$ & 77 & 2.78 & 1.13 & 1.648 & $0.009^{*}$ \\
\hline -la auditoría es un servicio de interés público & 77 & 3.68 & 1.12 & 1.744 & $0.005^{*}$ \\
\hline $\begin{array}{l}\text {-la opinión que emite el auditor es completamente } \\
\text { independiente }\end{array}$ & 77 & 3.69 & 0.99 & 2.053 & $0.000^{*}$ \\
\hline $\begin{array}{l}\text {-la opinión del auditor conlleva un alto grado de } \\
\text { subjetividad }\end{array}$ & 76 & 2.50 & 1.01 & 1.993 & $0.001 *$ \\
\hline \multicolumn{6}{|l|}{ 2. Exprese su acuerdo con las siguientes afirmaciones: } \\
\hline $\begin{array}{l}\text {-las cuentas anuales aportan información para la } \\
\text { toma de decisiones }\end{array}$ & 77 & 4.04 & 0.90 & 2.412 & $0.000 *$ \\
\hline $\begin{array}{l}\text {-el informe del auditor aporta información adicional } \\
\text { para la toma de decisiones }\end{array}$ & 77 & 3.66 & 1.08 & 2.042 & $0.000^{*}$ \\
\hline $\begin{array}{l}\text {-la carta de recomendaciones aporta información } \\
\text { adicional para la gestión }\end{array}$ & 76 & 3.75 & 0.95 & 1.903 & $0.001 *$ \\
\hline $\begin{array}{l}\text {-el informe es útil para determinar si la empresa es } \\
\text { financieramente viable }\end{array}$ & 77 & 3.48 & 1.01 & 2.126 & $0.000^{*}$ \\
\hline $\begin{array}{l}\text {-un informe limpio aporta información más relevante } \\
\text { que uno con salvedades }\end{array}$ & 77 & 2.90 & 1.46 & 1.319 & $0.062^{\mathrm{NS}}$ \\
\hline \multicolumn{6}{|l|}{$\begin{array}{l}\text { a. La distribución de contraste es la normal } \\
\text { b. Se han calculado a partir de los datos }\end{array}$} \\
\hline \multicolumn{6}{|c|}{$\begin{array}{l}* \text { Estadísticamente significativo al 1\%. ** Estadísticamente significativo al } 5 \% . \quad \text { NS= estadísticamente no significativo. } \\
\text { Las valoraciones medias corresponden a una escala de medida entre } 1 \text { total desacuerdo hasta } 5 \text { total acuerdo. }\end{array}$} \\
\hline
\end{tabular}




\section{ANEXO 8}

Prueba de Kolmogorov-Smirnov para la $2^{\mathrm{a}}$ hipótesis (Grupo Soc. y Ag. valores)

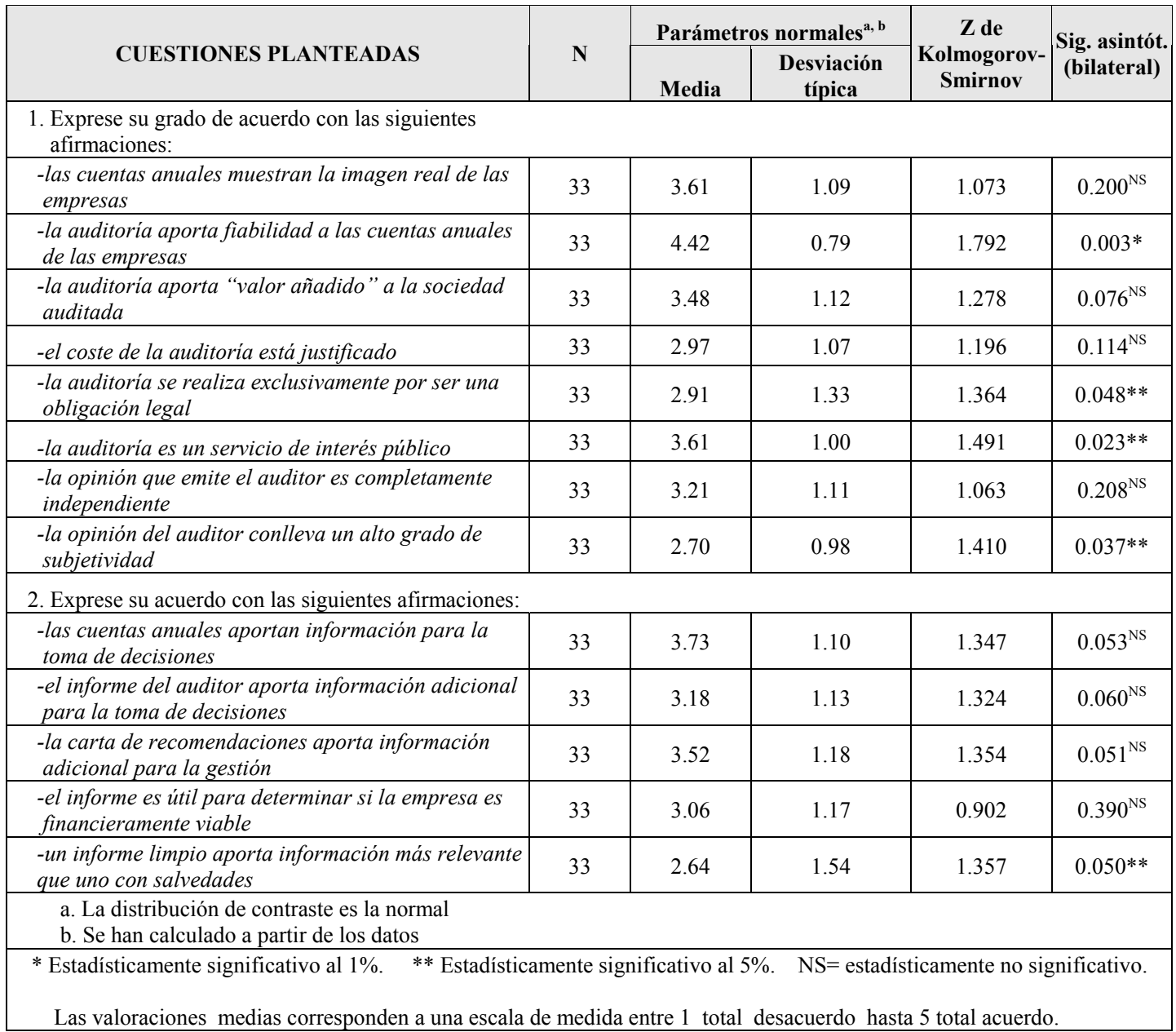




\section{ANEXO 9}

Prueba de Lilliefors para la $2^{\mathrm{a}}$ hipótesis (Grupo Soc. y Ag. valores)

\begin{tabular}{|c|c|c|}
\hline CUESTIONES PLANTEADAS & \begin{tabular}{c|} 
Estadístico \\
Kolmogorov- $^{\mathrm{a}}$ \\
Smirnov $^{\mathrm{a}}$ \\
\end{tabular} & $\begin{array}{l}\text { Sig. asintót. } \\
\text { (bilateral) }\end{array}$ \\
\hline \multicolumn{3}{|l|}{$\begin{array}{l}\text { 1. Exprese su grado de acuerdo con las siguientes } \\
\text { afirmaciones: }\end{array}$} \\
\hline $\begin{array}{l}\text {-las cuentas anuales muestran la imagen real de las } \\
\text { empresas }\end{array}$ & 0.187 & $0.005^{*}$ \\
\hline $\begin{array}{l}\text {-la auditoría aporta fiabilidad a las cuentas anuales } \\
\text { de las empresas }\end{array}$ & 0.312 & $0.000 *$ \\
\hline $\begin{array}{l}\text {-la auditoría aporta "valor añadido" a la sociedad } \\
\text { auditada }\end{array}$ & 0.222 & $0.000^{*}$ \\
\hline -el coste de la auditoría está justificado & 0.208 & $0.001 *$ \\
\hline $\begin{array}{l}\text {-la auditoría se realiza exclusivamente por ser una } \\
\text { obligación legal }\end{array}$ & 0.237 & $0.000^{*}$ \\
\hline -la auditoría es un servicio de interés público & 0.260 & $0.000 *$ \\
\hline $\begin{array}{l}\text {-la opinión que emite el auditor es completamente } \\
\text { independiente }\end{array}$ & 0.185 & $0.006^{*}$ \\
\hline $\begin{array}{l}\text {-la opinión del auditor conlleva un alto grado de } \\
\text { subjetividad }\end{array}$ & 0.246 & $0.000^{*}$ \\
\hline \multicolumn{3}{|l|}{$\begin{array}{l}\text { 2. Exprese su grado de acuerdo con las siguientes } \\
\text { afirmaciones: }\end{array}$} \\
\hline $\begin{array}{l}\text {-las cuentas anuales aportan información para la } \\
\text { toma de decisiones }\end{array}$ & 0.234 & $0.000 *$ \\
\hline $\begin{array}{l}\text {-el informe del auditor aporta información adicional } \\
\text { para la toma de decisiones }\end{array}$ & 0.231 & $0.000 *$ \\
\hline $\begin{array}{l}\text {-la carta de recomendaciones aporta información } \\
\text { adicional para la gestión }\end{array}$ & 0.236 & $0.000^{\wedge *}$ \\
\hline $\begin{array}{l}\text {-el informe es útil para determinar si la empresa es } \\
\text { financieramente viable }\end{array}$ & 0.157 & $0.038 * *$ \\
\hline $\begin{array}{l}\text {-un informe limpio aporta información más relevante } \\
\text { que uno con salvedades }\end{array}$ & 0.236 & $0.000^{*}$ \\
\hline \multicolumn{3}{|l|}{ a. Corrección de la significación de Lilliefors } \\
\hline $\begin{array}{l}\text { * Estadísticamente significativo al 1\%. } \\
* * \text { Estadísticamente significativo al } 5 \% \text {. } \\
\text { NS= estadísticamente no significativo. }\end{array}$ & & \\
\hline
\end{tabular}




\section{ANEXO 10}

Prueba de Kolmogorov-Smirnov para la $3^{\text {a }}$ hipótesis (Grupo de Empresas)

\begin{tabular}{|c|c|c|c|c|c|}
\hline \multirow{2}{*}{ CUESTIONES PLANTEADAS } & \multirow[b]{2}{*}{$\mathbf{N}$} & \multicolumn{2}{|c|}{ Parámetros normales $^{\mathrm{a}, \mathrm{b}}$} & \multirow{2}{*}{$\begin{array}{l}\text { Z de } \\
\text { Kolmogorov- } \\
\text { Smirnov }\end{array}$} & \multirow{2}{*}{$\begin{array}{l}\text { Sig. asintót. } \\
\text { (bilateral) }\end{array}$} \\
\hline & & Media & $\begin{array}{c}\text { Desviación } \\
\text { típica }\end{array}$ & & \\
\hline \multicolumn{6}{|l|}{$\begin{array}{l}\text { 1. Exprese su grado de acuerdo con las siguientes } \\
\text { afirmaciones: }\end{array}$} \\
\hline $\begin{array}{l}\text {-la redacción del informe del auditor está } \\
\text { excesivamente estandarizada }\end{array}$ & 303 & 4.14 & 0.93 & 4.559 & $0.000^{*}$ \\
\hline $\begin{array}{l}\text {-las salvedades que se incluyen en el informe son } \\
\text { comprensibles }\end{array}$ & 306 & 3.79 & 0.99 & 4.151 & $0.000^{*}$ \\
\hline $\begin{array}{l}\text {-el lenguaje utilizado en el informe de auditoría es } \\
\text { muy técnico }\end{array}$ & 305 & 2.93 & 1.22 & 2.881 & $0.000^{*}$ \\
\hline $\begin{array}{l}\text {-se realiza una redacción de las salvedades } \\
\text { excesivamente escueta }\end{array}$ & 302 & 3.46 & 1.07 & 3.141 & $0.000^{*}$ \\
\hline $\begin{array}{l}\text {-el propósito de la auditoría está claramente } \\
\text { expresado en el informe }\end{array}$ & 303 & 3.83 & 1.11 & 3.572 & $0.000 *$ \\
\hline $\begin{array}{l}\text {-el informe es un adecuado medio de comunicación } \\
\text { con los usuarios }\end{array}$ & 301 & 3.12 & 1.16 & 3.063 & $0.000^{*}$ \\
\hline $\begin{array}{l}\text {-el lenguaje utilizado en el informe de auditoría es } \\
\text { ambiguo }\end{array}$ & 303 & 2.53 & 1.10 & 3.353 & $0.000^{*}$ \\
\hline -la opinión que emite el auditor es comprensible & 305 & 3.87 & 0.95 & 4.216 & $0.000 *$ \\
\hline \multicolumn{6}{|l|}{$\begin{array}{l}\text { a. La distribución de contraste es la normal } \\
\text { b. Se han calculado a partir de los datos }\end{array}$} \\
\hline \multicolumn{6}{|c|}{$\begin{array}{l}\text { * Estadísticamente significativo al 1\%. ** Estadísticamente significativo al } 5 \% . \quad \mathrm{NS}=\text { estadísticamente no significativo. } \\
\text { Las valoraciones medias corresponden a una escala de medida entre } 1 \text { total desacuerdo hasta } 5 \text { total acuerdo. }\end{array}$} \\
\hline
\end{tabular}

\section{ANEXO 11}

Prueba de Kolmogorov-Smirnov para la $3^{\text {a }}$ hipótesis (Grupo de Auditores)

\begin{tabular}{|c|c|c|c|c|c|}
\hline \multirow{2}{*}{ CUESTIONES PLANTEADAS } & \multirow{2}{*}{$\mathbf{N}$} & \multicolumn{2}{|c|}{ Parámetros normales ${ }^{\mathrm{a}, \mathrm{b}}$} & \multirow{2}{*}{$\begin{array}{c}\mathrm{Z} \text { de } \\
\text { Kolmogorov- } \\
\text { Smirnov }\end{array}$} & \multirow{2}{*}{$\begin{array}{l}\text { Sig. asintót. } \\
\text { (bilateral) }\end{array}$} \\
\hline & & Media & $\begin{array}{l}\text { Desviación } \\
\text { típica }\end{array}$ & & \\
\hline \multicolumn{6}{|l|}{$\begin{array}{l}\text { 1. Exprese su grado de acuerdo con las siguientes } \\
\text { afirmaciones: }\end{array}$} \\
\hline $\begin{array}{l}\text {-la redacción del informe del auditor está } \\
\text { excesivamente estandarizada }\end{array}$ & 332 & 3.84 & 1.33 & 4.565 & $0.000 *$ \\
\hline $\begin{array}{l}\text {-las salvedades que se incluyen en el informe son } \\
\text { comprensibles }\end{array}$ & 332 & 3.82 & 0.98 & 3.745 & $0.000^{*}$ \\
\hline $\begin{array}{l}\text {-el lenguaje utilizado en el informe de auditoría es } \\
\text { muy técnico }\end{array}$ & 331 & 3.71 & 1.23 & 3.611 & $0.000^{*}$ \\
\hline $\begin{array}{l}\text {-se realiza una redacción de las salvedades } \\
\text { excesivamente escueta }\end{array}$ & 331 & 3.27 & 1.21 & 2.950 & $0.000^{*}$ \\
\hline $\begin{array}{l}\text {-el propósito de la auditoría está claramente } \\
\text { expresado en el informe }\end{array}$ & 330 & 4.05 & 1.12 & 4.939 & $0.000^{*}$ \\
\hline $\begin{array}{l}\text {-el informe es un adecuado medio de comunicación } \\
\text { con los usuarios }\end{array}$ & 331 & 3.29 & 1.11 & 3.520 & $0.000 *$ \\
\hline $\begin{array}{l}\text {-el lenguaje utilizado en el informe de auditoría es } \\
\text { ambiguo }\end{array}$ & 332 & 2.63 & 1.23 & 3.023 & $0.000 *$ \\
\hline -la opinión que emite el auditor es comprensible & 331 & 3.90 & 0.99 & 3.742 & $0.000 *$ \\
\hline \multicolumn{6}{|l|}{$\begin{array}{l}\text { a. La distribución de contraste es la normal } \\
\text { b. Se han calculado a partir de los datos }\end{array}$} \\
\hline * Estadísticamente significativo al 1\%. ** Estadís & & tive & $\mathrm{NS}=\mathrm{es}$ & amente no & nificativo. \\
\hline
\end{tabular}




\section{ANEXO 12}

Prueba de Kolmogorov-Smirnov para la $3^{\text {a }}$ hipótesis (Grupo Entidades de Crédito)

\begin{tabular}{|c|c|c|c|c|c|}
\hline \multirow[b]{2}{*}{ CUESTIONES PLANTEADAS } & \multirow[b]{2}{*}{$\mathbf{N}$} & \multicolumn{2}{|c|}{ Parámetros normales ${ }^{\mathrm{a}, \mathrm{b}}$} & \multirow{2}{*}{$\begin{array}{l}\text { Z de } \\
\text { Kolmogorov- } \\
\text { Smirnov }\end{array}$} & \multirow{2}{*}{$\begin{array}{r}\text { Sig. asintót } \\
\text { (bilateral) }\end{array}$} \\
\hline & & Media & $\begin{array}{c}\text { Desviación } \\
\text { típica }\end{array}$ & & \\
\hline \multicolumn{6}{|l|}{$\begin{array}{l}\text { 1. Exprese su grado de acuerdo con las siguientes } \\
\text { afirmaciones: }\end{array}$} \\
\hline $\begin{array}{l}\text {-la redacción del informe del auditor está } \\
\text { excesivamente estandarizada }\end{array}$ & 78 & 4.06 & 1.05 & 2.206 & $0.000 *$ \\
\hline $\begin{array}{l}\text {-las salvedades que se incluyen en el informe son } \\
\text { comprensibles }\end{array}$ & 78 & 3.60 & 0.93 & 2.253 & $0.000 *$ \\
\hline $\begin{array}{l}\text {-el lenguaje utilizado en el informe de auditoría es } \\
\text { muy técnico }\end{array}$ & 77 & 2.83 & 1.06 & 2.096 & $0.000 *$ \\
\hline $\begin{array}{l}\text {-se realiza una redacción de las salvedades } \\
\text { excesivamente escueta }\end{array}$ & 78 & 3.60 & 0.93 & 2.026 & $0.001 *$ \\
\hline $\begin{array}{l}\text {-el propósito de la auditoría está claramente } \\
\text { expresado en el informe }\end{array}$ & 78 & 3.88 & 0.87 & 2.166 & $0.000 *$ \\
\hline $\begin{array}{l}\text {-el informe es un adecuado medio de comunicación } \\
\text { con los usuarios }\end{array}$ & 78 & 2.95 & 1.06 & 1.641 & $0.009 *$ \\
\hline $\begin{array}{l}\text {-el lenguaje utilizado en el informe de auditoría es } \\
\text { ambiguo }\end{array}$ & 78 & 2.92 & 1.03 & 1.622 & $0.010^{*}$ \\
\hline -la opinión que emite el auditor es comprensible & 78 & 3.86 & 0.82 & 2.756 & $0.000^{*}$ \\
\hline \multicolumn{6}{|l|}{$\begin{array}{l}\text { a. La distribución de contraste es la normal } \\
\text { b. Se han calculado a partir de los datos }\end{array}$} \\
\hline \multicolumn{6}{|c|}{$\begin{array}{l}\text { * Estadísticamente significativo al 1\%. } * * \text { Estadísticamente significativo al } 5 \% . \quad \mathrm{NS}=\text { estadísticamente no significativo. } \\
\text { Las valoraciones medias corresponden a una escala de medida entre } 1 \text { total desacuerdo hasta } 5 \text { total acuerdo. }\end{array}$} \\
\hline
\end{tabular}

\section{ANEXO 13}

Prueba de Kolmogorov-Smirnov para la $3^{\text {a }}$ hipótesis (Grupo Ag. y Soc. valores)

\begin{tabular}{|c|c|c|c|c|c|}
\hline \multirow[b]{2}{*}{ CUESTIONES PLANTEADAS } & \multirow[b]{2}{*}{$\mathbf{N}$} & \multicolumn{2}{|c|}{ Parámetros normales $^{\mathrm{a}, \mathrm{b}}$} & \multirow{2}{*}{$\begin{array}{l}\text { Z de } \\
\text { Kolmogorov- } \\
\text { Smirnov }\end{array}$} & \multirow{2}{*}{$\begin{array}{l}\text { Sig. asintót. } \\
\text { (bilateral) }\end{array}$} \\
\hline & & Media & $\begin{array}{c}\text { Desviación } \\
\text { típica }\end{array}$ & & \\
\hline \multicolumn{6}{|l|}{$\begin{array}{l}\text { 1. Exprese su grado de acuerdo con las siguientes } \\
\text { afirmaciones: }\end{array}$} \\
\hline $\begin{array}{l}\text {-la redacción del informe del auditor está } \\
\text { excesivamente estandarizada }\end{array}$ & 33 & 4.09 & 1.18 & 1.516 & $0.020 * *$ \\
\hline $\begin{array}{l}\text {-las salvedades que se incluyen en el informe son } \\
\text { comprensibles }\end{array}$ & 32 & 3.28 & 0.96 & 1.370 & $0.047 * *$ \\
\hline $\begin{array}{l}\text {-el lenguaje utilizado en el informe de auditoría es } \\
\text { muy técnico }\end{array}$ & 33 & 3.15 & 1.12 & 1.266 & $0.081^{\mathrm{NS}}$ \\
\hline $\begin{array}{l}\text {-se realiza una redacción de las salvedades } \\
\text { excesivamente escueta }\end{array}$ & 33 & 3.55 & 1.09 & 1.536 & $0.018 * *$ \\
\hline $\begin{array}{l}\text {-el propósito de la auditoría está claramente } \\
\text { expresado en el informe }\end{array}$ & 33 & 3.55 & 1.09 & 1.188 & $0.119^{\mathrm{NS}}$ \\
\hline $\begin{array}{l}\text {-el informe es un adecuado medio de comunicación } \\
\text { con los usuarios }\end{array}$ & 33 & 3.30 & 1.19 & 1.187 & $0.120^{\mathrm{NS}}$ \\
\hline $\begin{array}{l}\text {-el lenguaje utilizado en el informe de auditoría es } \\
\text { ambiguo }\end{array}$ & 33 & 2.94 & 1.06 & 1.089 & $0.187^{\mathrm{NS}}$ \\
\hline -la opinión que emite el auditor es comprensible & 33 & 3.48 & 0.94 & 1.458 & $0.029 * *$ \\
\hline \multicolumn{6}{|l|}{$\begin{array}{l}\text { a. La distribución de contraste es la normal } \\
\text { b. Se han calculado a partir de los datos }\end{array}$} \\
\hline \multicolumn{6}{|c|}{$\begin{array}{l}\text { * Estadísticamente significativo al 1\%. ** Estadísticamente significativo al } 5 \% . \quad \mathrm{NS}=\text { estadísticamente no signi } \\
\text { Las valoraciones medias corresponden a una escala de medida entre } 1 \text { total desacuerdo hasta } 5 \text { total acuerdo. }\end{array}$} \\
\hline
\end{tabular}




\section{ANEXO 14}

Prueba de Lilliefors para Agencias y Soc. de valores ( $3^{a}$ hipótesis)

\begin{tabular}{|c|c|c|}
\hline CUESTIONES PLANTEADAS & $\begin{array}{c}\text { Estadístico } \\
\text { Kolmogorov- } \\
\text { Smirnova }^{\mathrm{a}}\end{array}$ & $\begin{array}{l}\text { Sig. asintót. } \\
\text { (bilateral) }\end{array}$ \\
\hline \multicolumn{3}{|l|}{$\begin{array}{l}\text { 1. Exprese su grado de acuerdo con las siguientes } \\
\text { afirmaciones: }\end{array}$} \\
\hline $\begin{array}{l}\text {-la redacción del informe del auditor está } \\
\text { excesivamente estandarizada }\end{array}$ & 0.278 & $0.000 *$ \\
\hline $\begin{array}{l}\text {-las salvedades que se incluyen en el informe son } \\
\text { comprensibles }\end{array}$ & 0.242 & $0.000^{*}$ \\
\hline $\begin{array}{l}\text {-el lenguaje utilizado en el informe de auditoría es } \\
\text { muy técnico }\end{array}$ & 0.223 & $0.000^{*}$ \\
\hline $\begin{array}{l}\text {-se realiza una redacción de las salvedades } \\
\text { excesivamente escueta }\end{array}$ & 0.272 & $0.000^{*}$ \\
\hline $\begin{array}{l}\text {-el propósito de la auditoría está claramente } \\
\text { expresado en el informe }\end{array}$ & 0.195 & $0.003 *$ \\
\hline $\begin{array}{l}\text {-el informe es un adecuado medio de comunicación } \\
\text { con los usuarios }\end{array}$ & 0.209 & $0.001 *$ \\
\hline $\begin{array}{l}\text {-el lenguaje utilizado en el informe de auditoría es } \\
\text { ambiguo }\end{array}$ & 0.199 & $0.002 *$ \\
\hline -la opinión que emite el auditor es comprensible & 0.243 & $0.000^{*}$ \\
\hline \multicolumn{3}{|l|}{ a. Corrección de la significación de Lilliefors } \\
\hline \multicolumn{3}{|c|}{$\begin{array}{l}* \text { Estadísticamente significativo al 1\%. } \\
\text { NS= estadísticamente no significativo. }\end{array}$} \\
\hline
\end{tabular}

\section{ANEXO 15}

Prueba de Kolmogorov-Smirnov para las empresas ( $1^{\mathrm{a}} \cdot 1^{\mathrm{o}}$. hipótesis)

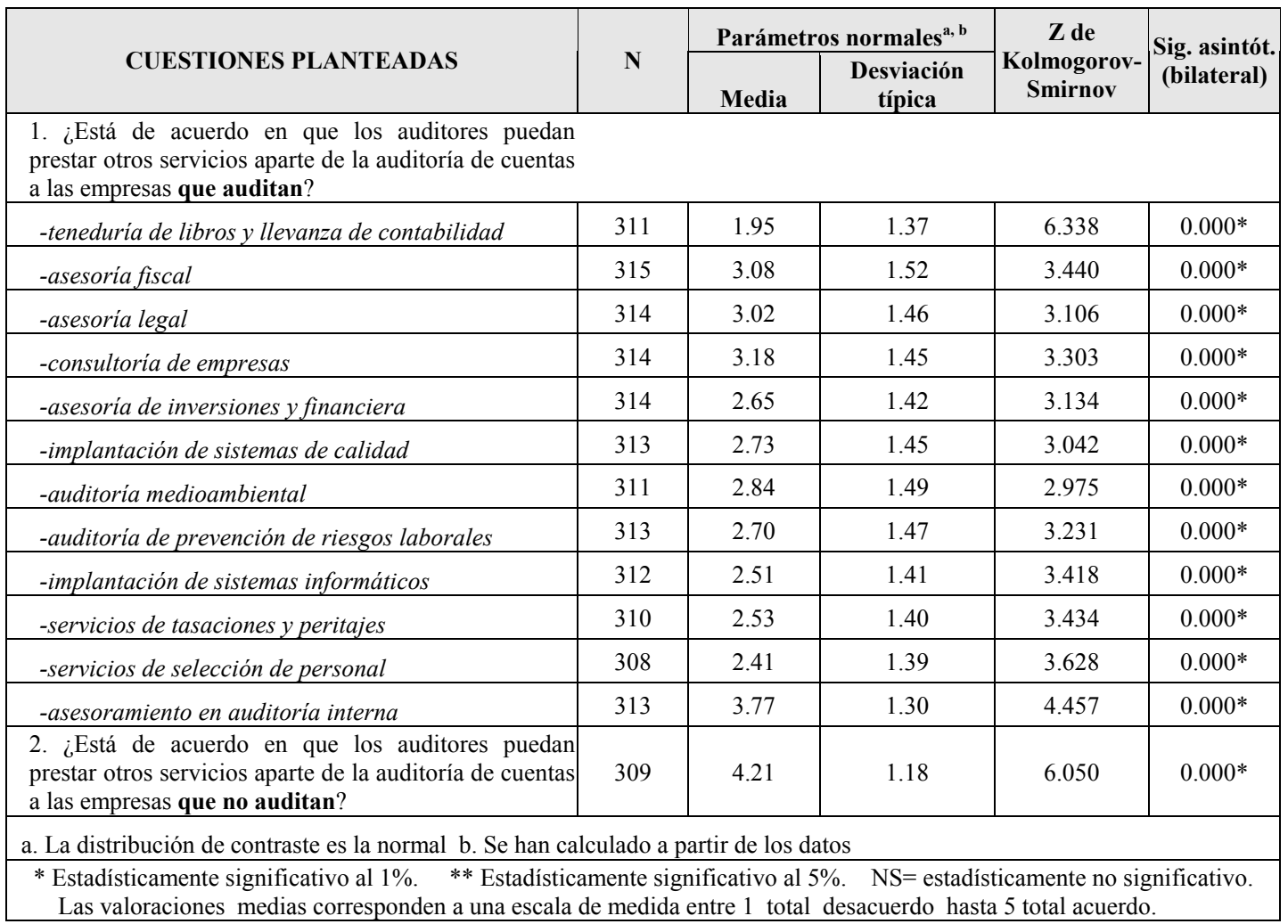




\section{ANEXO 16}

Prueba de Kolmogorov-Smirnov para los auditores $\left(1^{\mathrm{a}} \cdot 2^{\mathrm{o}}\right.$. hipótesis)

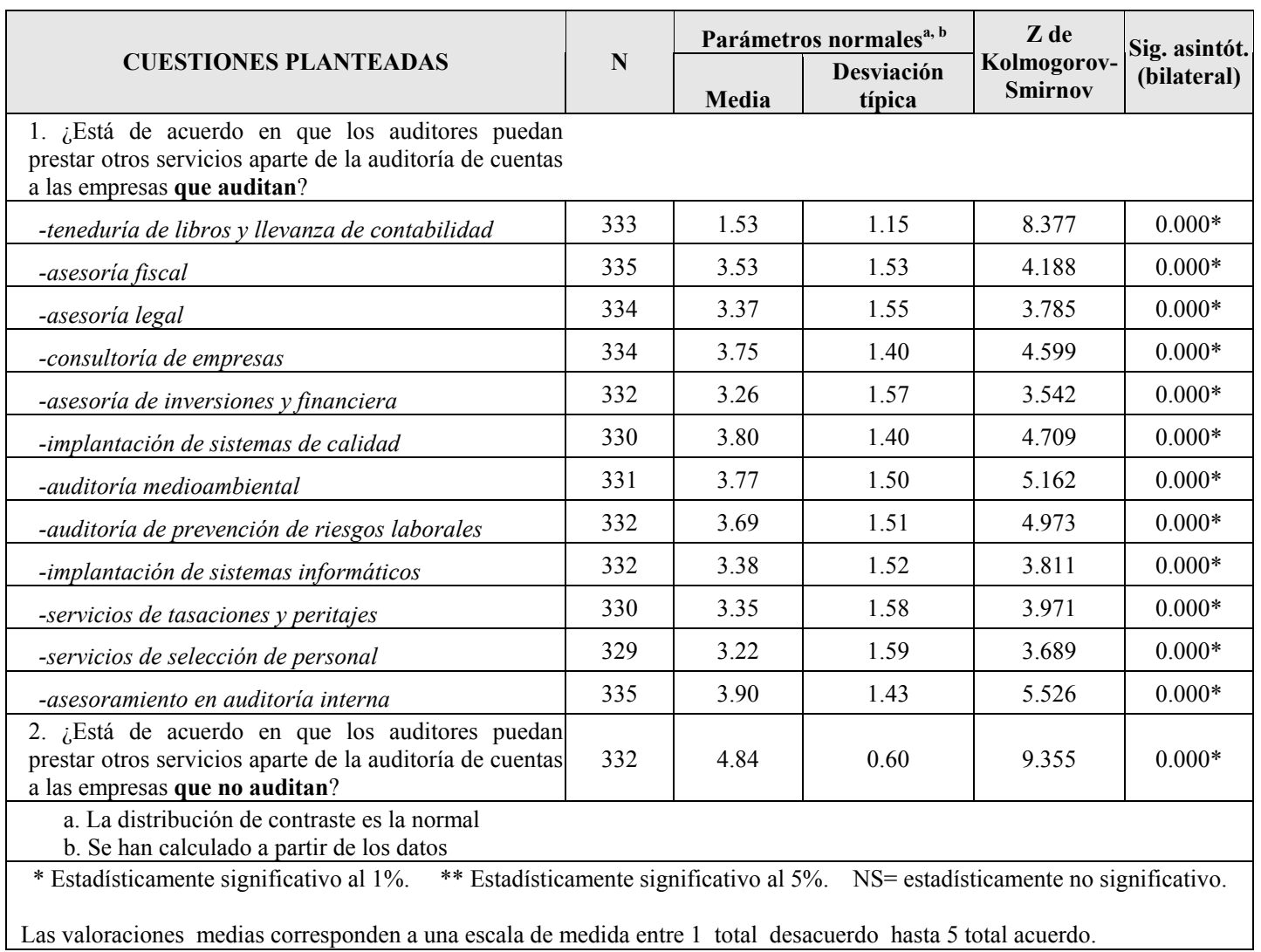




\section{ANEXO 17}

Prueba ANOVA para los cuatro grupos de estudio (1 $1^{\text {a hipótesis) }}$

\begin{tabular}{|c|c|c|c|c|c|c|}
\hline \multicolumn{2}{|l|}{ CUESTIONES PLANTEADAS } & $\begin{array}{c}\text { Suma } \\
\text { de } \\
\text { cuadrados }\end{array}$ & gl & $\begin{array}{c}\text { Media } \\
\text { cuadrática }\end{array}$ & $\mathbf{F}$ & Sig. \\
\hline \multicolumn{7}{|l|}{ 1.Es responsabilidad del auditor: } \\
\hline \multirow{2}{*}{ - preparar y formular las cuentas anuales auditadas } & Inter-grupos & 233.48 & 3 & 77.826 & 40.857 & $0.000 *$ \\
\hline & Intra-grupos & 1411.48 & 741 & 1.905 & & \\
\hline \multirow{2}{*}{-llevar la contabilidad de la empresa auditada } & Inter-grupos & 0.74 & 3 & 0.247 & 0.884 & $0.449^{\mathrm{NS}}$ \\
\hline & Intra-grupos & 204.77 & 734 & 0.279 & & \\
\hline \multirow{2}{*}{-revisar toda la contabilidad de la empresa auditada } & Inter-grupos & 245.74 & 3 & 81.912 & 33.900 & $0.000 *$ \\
\hline & Intra-grupos & 1797.70 & 744 & 2.416 & & \\
\hline \multirow{2}{*}{$\begin{array}{l}\text {-detectar los fraudes y/o ilegalidades que se puedan } \\
\text { desprender de la gestión }\end{array}$} & Inter-grupos & 396.44 & 3 & 132.148 & 67.690 & $0.000 *$ \\
\hline & Intra-grupos & 1452.48 & 744 & 1.952 & & \\
\hline \multirow{2}{*}{$\begin{array}{l}\text { 2.El auditor se encarga de verificar si las cuentas anuales } \\
\text { expresan la imagen fiel de la situación económico- } \\
\text { financiera de la empresa de acuerdo a los principios de } \\
\text { contabilidad. }\end{array}$} & Inter-grupos & 1.26 & 3 & 0.421 & 1.832 & $0.140^{\mathrm{NS}}$ \\
\hline & Intra-grupos & 173.78 & 756 & 0.230 & & \\
\hline \multirow{2}{*}{$\begin{array}{l}\text { 3.El auditor sólo se pronuncia en su informe sobre las } \\
\text { cuentas anuales (Balance, Cta. de P y G y Memoria). }\end{array}$} & Inter-grupos & 30.60 & 3 & 10.199 & 5.573 & $0.001 *$ \\
\hline & Intra-grupos & 1372.54 & 750 & 1.830 & & \\
\hline \multirow{2}{*}{$\begin{array}{l}\text { 4.El informe del auditor es una opinión razonable pero no } \\
\text { un certificado de absoluta garantía sobre las cuentas } \\
\text { anuales. }\end{array}$} & Inter-grupos & 31.75 & 3 & 10.584 & 11.886 & $0.000 *$ \\
\hline & Intra-grupos & 667.85 & 750 & 0.890 & & \\
\hline \multicolumn{7}{|l|}{$\begin{array}{l}\text { 5.Se espera que el trabajo del auditor aporte seguridad } \\
\text { sobre: }\end{array}$} \\
\hline \multirow{2}{*}{-que se cumple con las normas contables } & Inter-grupos & 1.35 & 3 & 0.451 & 1.347 & $0.258^{\mathrm{NS}}$ \\
\hline & Intra-grupos & 251.79 & 752 & 0.335 & & \\
\hline \multirow[t]{2}{*}{-que no existen fraudes y/o ilegalidades } & Inter-grupos & 191.74 & 3 & 63.913 & 43.685 & $0.000 *$ \\
\hline & Intra-grupos & 1097.30 & 750 & 1.463 & & \\
\hline \multirow[t]{2}{*}{-que la gestión de la empresa es adecuada } & Inter-grupos & 29.21 & 3 & 9.737 & 5.367 & $0.001 *$ \\
\hline & Intra-grupos & 1358.80 & 749 & 1.814 & & \\
\hline \multirow{2}{*}{$\begin{array}{l}\text {-que la situación financiera de la empresa } \\
\text { es solvente }\end{array}$} & Inter-grupos & 9.28 & 3 & 3.092 & 1.543 & $0.202^{\mathrm{NS}}$ \\
\hline & Intra-grupos & 1491.13 & 744 & 2.004 & & \\
\hline \multirow{2}{*}{-que el control interno funciona correctamente } & Inter-grupos & 14.04 & 3 & 4.681 & 2.919 & $0.033 * *$ \\
\hline & Intra-grupos & 1206.09 & 752 & 1.604 & & \\
\hline \multirow{2}{*}{$\begin{array}{l}\text {-que se cumplen las normas legales que afectan a } \\
\text { la empresa }\end{array}$} & Inter-grupos & 4.66 & 3 & 1.553 & 1.136 & $0.334^{\mathrm{NS}}$ \\
\hline & Intra-grupos & 1027.08 & 751 & 1.368 & & \\
\hline \multirow{2}{*}{-que la empresa continuará funcionando } & Inter-grupos & 96.51 & 3 & 32.172 & 14.943 & $0.000^{*}$ \\
\hline & Intra-grupos & 1608.29 & 747 & 2.153 & & \\
\hline
\end{tabular}




\section{ANEXO 18}

Prueba ANOVA para los cuatro grupos de estudio (2a hipótesis)

\begin{tabular}{|c|c|c|c|c|c|c|}
\hline \multicolumn{2}{|l|}{ CUESTIONES PLANTEADAS } & $\begin{array}{c}\text { Suma } \\
\text { de } \\
\text { cuadrados }\end{array}$ & gl & $\begin{array}{c}\text { Media } \\
\text { cuadrática }\end{array}$ & $\mathbf{F}$ & Sig. \\
\hline \multicolumn{7}{|l|}{$\begin{array}{l}\text { 1. Exprese su grado de acuerdo con las siguientes } \\
\text { afirmaciones: }\end{array}$} \\
\hline \multirow{2}{*}{$\begin{array}{l}\text {-las cuentas anuales muestran la imagen real de las } \\
\text { empresas }\end{array}$} & Inter-grupos & 29.31 & 3 & 9.772 & 7.064 & $0.000 *$ \\
\hline & Intra-grupos & 1019.47 & 737 & 1.383 & & \\
\hline \multirow{2}{*}{$\begin{array}{l}\text {-la auditoría aporta fiabilidad a las cuentas anuales } \\
\text { de las empresas }\end{array}$} & Inter-grupos & 13.28 & 3 & 4.430 & 8.438 & $0.000 *$ \\
\hline & Intra-grupos & 392.14 & 747 & 0.525 & & \\
\hline \multirow{2}{*}{$\begin{array}{l}\text {-la auditoría aporta "valor añadido" a la sociedad } \\
\text { auditada }\end{array}$} & Inter-grupos & 70.96 & 3 & 23.653 & 20.056 & $0.000 *$ \\
\hline & Intra-grupos & 877.46 & 744 & 1.179 & & \\
\hline \multirow{2}{*}{-el coste de la auditoría está justificado } & Inter-grupos & 245.58 & 3 & 81.863 & 74.699 & $0.000 *$ \\
\hline & Intra-grupos & 818.63 & 747 & 1.096 & & \\
\hline \multirow{2}{*}{$\begin{array}{l}\text {-la auditoría se realiza exclusivamente por ser una } \\
\text { obligación legal }\end{array}$} & Inter-grupos & 8.79 & 3 & 2.931 & 1.777 & $0.150^{\mathrm{NS}}$ \\
\hline & Intra-grupos & 1231.98 & 747 & 1.649 & & \\
\hline \multirow{2}{*}{-la auditoría es un servicio de interés público } & Inter-grupos & 84.97 & 3 & 28.325 & 21.132 & $0.000 *$ \\
\hline & Intra-grupos & 998.60 & 745 & 1.340 & & \\
\hline \multirow{2}{*}{$\begin{array}{l}\text {-la opinión que emite el auditor es completamente } \\
\text { independiente }\end{array}$} & Inter-grupos & 80.47 & 3 & 26.826 & 26.813 & $0.000 *$ \\
\hline & Intra-grupos & 746.36 & 746 & 1.000 & & \\
\hline \multirow{2}{*}{$\begin{array}{l}\text {-la opinión del auditor conlleva un alto grado de } \\
\text { subjetividad }\end{array}$} & Inter-grupos & 8.58 & 3 & 2.863 & 2.012 & $0.111^{\mathrm{NS}}$ \\
\hline & Intra-grupos & 1057.29 & 743 & 1.423 & & \\
\hline \multicolumn{7}{|l|}{ 2. Exprese su acuerdo con las siguientes afirmaciones: } \\
\hline \multirow{2}{*}{$\begin{array}{l}\text {-las cuentas anuales aportan información para la } \\
\text { toma de decisiones }\end{array}$} & Inter-grupos & 42.11 & 3 & 14.038 & 9.720 & $0.000 *$ \\
\hline & Intra-grupos & 1071.64 & 742 & 1.444 & & \\
\hline \multirow{2}{*}{$\begin{array}{l}\text {-el informe del auditor aporta información adicional } \\
\text { para la toma de decisiones }\end{array}$} & Inter-grupos & 65.88 & 3 & 21.961 & 14.491 & $0.000 *$ \\
\hline & Intra-grupos & 1112.36 & 734 & 1.515 & & \\
\hline \multirow{2}{*}{$\begin{array}{l}\text {-la carta de recomendaciones aporta información } \\
\text { adicional para la gestión }\end{array}$} & Inter-grupos & 67.43 & 3 & 22.478 & 20.095 & $0.000 *$ \\
\hline & Intra-grupos & 824.40 & 737 & 1.119 & & \\
\hline \multirow{2}{*}{$\begin{array}{l}\text {-el informe es útil para determinar si la empresa es } \\
\text { financieramente viable }\end{array}$} & Inter-grupos & 8.59 & 3 & 2.866 & 1.967 & $0.118^{\mathrm{NS}}$ \\
\hline & Intra-grupos & 1072.51 & 736 & 1.457 & & \\
\hline \multirow{2}{*}{$\begin{array}{l}\text {-un informe limpio aporta información más relevante } \\
\text { que uno con salvedades }\end{array}$} & Inter-grupos & 28.06 & 3 & 9.354 & 4.435 & $0.004 *$ \\
\hline & Intra-grupos & 1550.32 & 735 & 2.109 & & \\
\hline
\end{tabular}

* Estadísticamente significativo al 1\%. ** Estadísticamente significativo al 5\%. NS= estadísticamente no significativo. 


\section{ANEXO 19}

Prueba ANOVA para los cuatro grupos de estudio ( $3^{\text {a }}$ hipótesis)

\begin{tabular}{|c|c|c|c|c|c|c|}
\hline \multicolumn{2}{|l|}{ CUESTIONES PLANTEADAS } & $\begin{array}{c}\text { Suma } \\
\text { de } \\
\text { cuadrados }\end{array}$ & gl & $\begin{array}{c}\text { Media } \\
\text { cuadrática }\end{array}$ & $\mathbf{F}$ & Sig. \\
\hline \multicolumn{7}{|l|}{$\begin{array}{l}\text { 1. Exprese su grado de acuerdo con las siguientes } \\
\text { afirmaciones: }\end{array}$} \\
\hline \multirow{2}{*}{$\begin{array}{l}\text {-la redacción del informe del auditor está } \\
\text { excesivamente estandarizada }\end{array}$} & Inter-grupos & 15.15 & 3 & 5.050 & 3.836 & $0.010 *$ \\
\hline & Intra-grupos & 976.84 & 742 & 1.317 & & \\
\hline \multirow{2}{*}{$\begin{array}{l}\text {-las salvedades que se incluyen en el informe son } \\
\text { comprensibles }\end{array}$} & Inter-grupos & 10.72 & 3 & 3.574 & 3.730 & $0.011 * *$ \\
\hline & Intra-grupos & 712.91 & 744 & 0.958 & & \\
\hline \multirow{2}{*}{$\begin{array}{l}\text {-el lenguaje utilizado en el informe de auditoría es } \\
\text { muy técnico }\end{array}$} & Inter-grupos & 112.80 & 3 & 37.602 & 25.971 & $0.000 *$ \\
\hline & Intra-grupos & 1074.31 & 742 & 1.448 & & \\
\hline \multirow{2}{*}{$\begin{array}{l}\text {-se realiza una redacción de las salvedades } \\
\text { excesivamente escueta }\end{array}$} & Inter-grupos & 10.54 & 3 & 3.514 & 2.798 & $0.039 * *$ \\
\hline & Intra-grupos & 929.48 & 740 & 1.256 & & \\
\hline \multirow{2}{*}{$\begin{array}{l}\text {-el propósito de la auditoría está claramente } \\
\text { expresado en el informe }\end{array}$} & Inter-grupos & 12.97 & 3 & 4.326 & 3.657 & $0.012 * *$ \\
\hline & Intra-grupos & 875.34 & 740 & 1.183 & & \\
\hline \multirow{2}{*}{$\begin{array}{l}\text {-el informe es un adecuado medio de comunicación } \\
\text { con los usuarios }\end{array}$} & Inter-grupos & 9.96 & 3 & 3.321 & 2.614 & $0.050 * *$ \\
\hline & Intra-grupos & 939.03 & 739 & 1.271 & & \\
\hline \multirow{2}{*}{$\begin{array}{l}\text {-el lenguaje utilizado en el informe de auditoría es } \\
\text { ambiguo }\end{array}$} & Inter-grupos & 12.99 & 3 & 4.333 & 3.260 & $0.021 * *$ \\
\hline & Intra-grupos & 986.09 & 742 & 1.329 & & \\
\hline \multirow{2}{*}{-la opinión que emite el auditor es comprensible } & Inter-grupos & 5.18 & 3 & 1.728 & 1.896 & $0.129^{\mathrm{NS}}$ \\
\hline & Intra-grupos & 676.89 & 743 & 0.911 & & \\
\hline
\end{tabular}

* Estadísticamente significativo al 1\%. ** Estadísticamente significativo al 5\%. NS= estadísticamente no significativo. 


\section{ANEXO 20}

Prueba T para empresas y auditores $\left(1^{\mathrm{a}} \cdot 1^{\mathrm{o}}\right.$. hipótesis $)$

\begin{tabular}{|c|c|c|c|}
\hline CUESTIONES PLANTEADAS & $\mathbf{t}$ & gl & Sig. bilateral \\
\hline \multicolumn{4}{|l|}{$\begin{array}{l}\text { 1. ¿Está de acuerdo en que los auditores puedan prestar } \\
\text { otros servicios aparte de la auditoría de cuentas a las } \\
\text { empresas que auditan? }\end{array}$} \\
\hline -teneduría de libros y llevanza de contabilidad & 4.099 & 607.93 & $0.000^{*}$ \\
\hline - asesoría fiscal & -3.755 & 648 & $0.000 *$ \\
\hline -asesoría legal & -2.927 & 645.99 & $0.004 *$ \\
\hline -consultoría de empresas & -5.153 & 646 & $0.000^{*}$ \\
\hline -asesoría de inversiones y financiera & -5.241 & 642.63 & $0.000^{*}$ \\
\hline -implantación de sistemas de calidad & -9.488 & 641 & $0.000 *$ \\
\hline -auditoría medioambiental & -7.871 & 640 & $0.000 *$ \\
\hline -auditoría de prevención de riesgos laborales & -8.439 & 643 & $0.000^{*}$ \\
\hline -implantación de sistemas informáticos & -7.528 & 642 & $0.000 *$ \\
\hline -servicios de tasaciones y peritajes & -7.018 & 635.80 & $0.000 *$ \\
\hline -servicios de selección de personal & -6.829 & 631.99 & $0.000 *$ \\
\hline -asesoramiento en auditoría interna & -1.230 & 645.41 & $0.219^{\mathrm{NS}}$ \\
\hline $\begin{array}{l}\text { 2. ¿Está de acuerdo en que los auditores puedan prestar } \\
\text { otros servicios aparte de la auditoría de cuentas a las } \\
\text { empresas que no auditan? }\end{array}$ & -8.397 & 450.35 & $0.000^{*}$ \\
\hline
\end{tabular}




\section{ANEXO 21}

Prueba T para entidades de crédito (hipótesis $2^{\mathrm{a}} .1^{\circ}$ )

\begin{tabular}{|c|c|c|c|c|c|}
\hline \multirow[t]{2}{*}{ CUESTIONES PLANTEADAS } & \multirow[t]{2}{*}{$\mathbf{t}$} & \multirow[t]{2}{*}{\begin{tabular}{c|} 
sig. \\
(bilateral)
\end{tabular}} & \multirow[t]{2}{*}{$\begin{array}{l}\text { Diferencia }^{a} \\
\text { de medias }\end{array}$} & \multicolumn{2}{|c|}{$\begin{array}{l}95 \% \text { Intervalo } \\
\text { de confianza para } \\
\text { la diferencia }\end{array}$} \\
\hline & & & & Inferior & Superior \\
\hline \multicolumn{6}{|l|}{$\begin{array}{l}\text { 1. La presentación del informe de auditoría es } \\
\text { imprescindible para que se presten servicios, a una } \\
\text { empresa obligada a auditarse, en el caso de: }\end{array}$} \\
\hline -conceder una línea de crédito & 11.184 & $0.000^{*}$ & 1.27 & 1.04 & 1.50 \\
\hline -conceder un préstamo a corto plazo & 10.056 & $0.000 *$ & 1.17 & 0.94 & 1.40 \\
\hline -conceder un préstamo a largo plazo & 12.606 & $0.000^{*}$ & 1.38 & 1.17 & 1.60 \\
\hline - abrir una línea de descuento comercial & 8.553 & $0.000^{*}$ & 0.97 & 0.75 & 1.20 \\
\hline -conceder un aval bancario & 9.389 & $0.000^{*}$ & 1.13 & 0.89 & 1.37 \\
\hline \multicolumn{6}{|l|}{$\begin{array}{l}\text { 2. La información más relevante al conceder un } \\
\text { préstamo se obtiene de: }\end{array}$} \\
\hline -el informe de auditoría & 6.081 & $0.000 *$ & 0.68 & 0.46 & 0.90 \\
\hline -la central de riesgos & 12.739 & $0.000 *$ & 1.18 & 1.00 & 1.36 \\
\hline -bases de datos privadas & 3.436 & $0.001^{*}$ & 0.42 & 0.18 & 0.67 \\
\hline -conocimiento personal & 11.277 & $0.000^{*}$ & 1.15 & 0.94 & 1.35 \\
\hline -declaraciones tributarias & 3.920 & $0.000^{*}$ & 0.47 & 0.23 & 0.70 \\
\hline -cuentas anuales & 9.594 & $0.000 *$ & 0.97 & 0.77 & 1.18 \\
\hline -tener buenas referencias & 3.749 & $0.000 *$ & 0.44 & 0.20 & 0.67 \\
\hline \multicolumn{6}{|l|}{ 3. Exprese su acuerdo con las siguientes afirmaciones: } \\
\hline $\begin{array}{l}\text {-el tipo de opinión influye en la decisión de } \\
\text { conceder el préstamo }\end{array}$ & 9.940 & $0.000^{*}$ & 1.03 & 0.82 & 1.23 \\
\hline $\begin{array}{l}\text {-el tipo de opinión influye en la decisión de la } \\
\text { cuantía a prestar }\end{array}$ & 2.606 & $0.011 * *$ & 0.36 & 8.47E-02 & 0.63 \\
\hline \multicolumn{6}{|l|}{$\begin{array}{l}\text { 4. El tipo de salvedades que más pueden influir en su } \\
\text { decisión al conceder un préstamo son: }\end{array}$} \\
\hline -incertidumbres en cuanto a la vida de la empresa & 24.517 & $0.000 *$ & 1.69 & 1.55 & 1.83 \\
\hline -por incumplimiento de principios contables & 4.768 & $0.000 *$ & 0.47 & 0.28 & 0.67 \\
\hline -incertidumbres fiscales & 7.211 & $0.000 *$ & 0.67 & 0.48 & 0.85 \\
\hline -por valoración de activos & 9.918 & $0.000 *$ & 0.90 & 0.72 & 1.08 \\
\hline -por incumplimiento de normas legales & 8.211 & $0.000^{*}$ & 0.81 & 0.61 & 1.00 \\
\hline -por limitaciones al alcance & 7.479 & $0.000 *$ & 0.73 & 0.54 & 0.93 \\
\hline $\begin{array}{l}\text {-por relaciones con empresas del grupo o } \\
\text { asociadas }\end{array}$ & 6.883 & $0.000 *$ & 0.69 & 0.49 & 0.89 \\
\hline
\end{tabular}

* Estadísticamente significativo al 1\%. ** Estadísticamente significativo al 5\%. NS= estadísticamente no significativo. a. el valor de prueba de la media es $=3$ 


\section{ANEXO 22}

Prueba T para Agencias y Sociedades de valores (hipótesis $2^{\mathrm{a}} .2^{\circ}$ )

\begin{tabular}{|c|c|c|c|c|c|}
\hline \multirow[t]{2}{*}{ CUESTIONES PLANTEADAS } & \multirow[t]{2}{*}{ t } & \multirow[t]{2}{*}{$\begin{array}{c}\text { sig. } \\
\text { (bilateral) }\end{array}$} & \multirow[t]{2}{*}{$\begin{array}{r}\text { Diferencia }^{a} \\
\text { de medias }\end{array}$} & \multicolumn{2}{|c|}{$\begin{array}{l}95 \% \text { Intervalo } \\
\text { de confianza para } \\
\text { la diferencia }\end{array}$} \\
\hline & & & & Inferior & Superior \\
\hline \multicolumn{6}{|l|}{$\begin{array}{l}\text { 1. La información más relevante al realizar una } \\
\text { inversión se obtiene de: }\end{array}$} \\
\hline -realizar un análisis técnico & 3.566 & $0.001 *$ & 0.69 & 0.29 & 1.08 \\
\hline -realizar un análisis fundamental & 8.182 & $0.000^{*}$ & 1.10 & 0.82 & 1.37 \\
\hline -el informe de auditoría & -1.000 & $0.325^{\mathrm{NS}}$ & -0.19 & -0.57 & 0.19 \\
\hline -la central de riesgos & 1.510 & $0.142^{\mathrm{NS}}$ & 0.29 & -0.10 & 0.68 \\
\hline -bases de datos privadas & -0.171 & $0.865^{\mathrm{NS}}$ & $-3.23 \mathrm{E}-02$ & -0.42 & 0.35 \\
\hline -conocimiento personal & 3.898 & $0.001 *$ & 0.63 & 0.30 & 0.97 \\
\hline -declaraciones tributarias & -1.622 & $0.115^{\mathrm{NS}}$ & -0.32 & -0.73 & $8.35 \mathrm{E}-02$ \\
\hline -cuentas anuales & 4.116 & $0.000 *$ & 0.66 & 0.33 & 0.98 \\
\hline -tener buenas referencias & 0.895 & $0.378^{\mathrm{NS}}$ & 0.16 & -0.20 & 0.51 \\
\hline \multicolumn{6}{|l|}{ 2. Exprese su acuerdo con las siguientes afirmaciones: } \\
\hline $\begin{array}{l}\text {-el tipo de opinión influye en la decisión de } \\
\text { invertir o no en una empresa }\end{array}$ & 4.605 & $0.000 *$ & 0.81 & 0.45 & 1.17 \\
\hline -el tipo de opinión influye en la cuantía a invertir & 1.852 & $0.074 * * *$ & 0.41 & $-4.11 \mathrm{E}-02$ & 0.85 \\
\hline \multicolumn{6}{|l|}{$\begin{array}{l}\text { 3. El tipo de salvedades que más pueden influir en su } \\
\text { decisión de inversión son: }\end{array}$} \\
\hline -incertidumbres en cuanto a la vida de la empresa & 9.048 & $0.000^{*}$ & 1.31 & 1.02 & 1.61 \\
\hline -por incumplimiento de principios contables & 4.695 & $0.000^{*}$ & 0.78 & 0.44 & 1.12 \\
\hline -incertidumbres fiscales & 4.633 & $0.000 *$ & 0.75 & 0.42 & 1.08 \\
\hline -por valoración de activos & 9.711 & $0.000 *$ & 1.06 & 0.84 & 1.29 \\
\hline -por incumplimiento de normas legales & 5.190 & $0.000^{*}$ & 0.84 & 0.51 & 1.18 \\
\hline -por limitaciones al alcance & 2.886 & $0.007 *$ & 0.52 & 0.15 & 0.88 \\
\hline $\begin{array}{l}\text {-por relaciones con empresas del grupo o } \\
\text { asociadas }\end{array}$ & 3.129 & $0.004 *$ & 0.59 & 0.21 & 0.98 \\
\hline \multicolumn{6}{|c|}{$\begin{array}{l}\text { * Estadísticamente significativo al } 1 \% \text {. } * * \text { Estadísticamente significativo al } 5 \% . * * \text { Estadísticamente significativo al } 10 \% \\
\text { NS= estadísticamente no significativo. } \\
\text { a. el valor de prueba de la media es }=3\end{array}$} \\
\hline
\end{tabular}




\section{ANEXO 23}



\section{UNIVERSIDAD POLITÉCNICA DE CARTAGENA}

Facultad de Ciencias de la Empresa

Dpto. de Economía Financiera y Contabilidad

Estimado/a Sr./Sra.:

Con motivo de la investigación que realizo, para elaborar la Tesis Doctoral, en la que se pretende estudiar la auditoría de cuentas en un ámbito nacional, y más concretamente la percepción que tienen tanto los auditores, empresas auditadas, entidades financieras, como las agencias y sociedades de inversión, sobre la función actual que cumple el servicio de auditoría. Les solicito su valiosa colaboración consistente en dar contestación al cuestionario que se adjunta.

Algunas cuestiones pueden parecer obvias para el auditor, no obstante la investigación necesita de evidencias empíricas para contrastar las diferentes percepciones que, en su caso, se pueden dar entre los diferentes grupos encuestados, por ello solicitamos encarecidamente una respuesta completa.

Esta investigación está participada por las dos Universidades públicas de la Región de Murcia, tanto la Universidad de Murcia como la Universidad Politécnica de Cartagena, teniendo un carácter estrictamente científico y siendo su finalidad la de contribuir a la mejora de un servicio que los profesionales de la auditoría prestan a las empresas y a la sociedad en general.

Agradeciendo de antemano su atención, le saludo cordialmente.

$\mathrm{V}^{\mathrm{o}} \mathrm{B}^{\mathrm{O}}$

Cartagena, a 26 de enero de 2001

El Director de la Tesis

Fdo.: Antonio Duréndez Gómez-Guillamón Profesor Universidad Politécnica de Cartagena

Fdo.: Pedro Luengo Mulet

Catedrático de Economía

Financiera y Contabilidad

de la Universidad de Murcia

NOTA: Los resultados de la investigación quedan a disposición de todas las personas y entidades que colaboran en el proyecto, en la dirección que aparece al pie de la carta. Cualquier aclaración o consulta puede realizarse en la misma dirección.

Paseo Alfonso XIII, 50 - 30203 Cartagena - Tel. 968325610 - Fax: 968325782 - e-mail: Antonio.durendez@upct.es 


\section{ANEXO 24}



\section{UNIVERSIDAD POLITÉCNICA DE CARTAGENA}

Facultad de Ciencias de la Empresa

Dpto. de Economía Financiera y Contabilidad

Estimado/a Sr./Sra.:

Con motivo de la investigación que realizo, para elaborar la Tesis Doctoral, en la que se pretende estudiar la auditoría de cuentas en un ámbito nacional, y más concretamente la percepción que tienen tanto los auditores, empresas auditadas, entidades financieras, como las agencias y sociedades de inversión, sobre la función actual que cumple el servicio de auditoría. Les solicito su valiosa colaboración consistente en dar contestación al cuestionario que se adjunta.

Esta investigación está participada por las dos Universidades públicas de la Región de Murcia, tanto la Universidad de Murcia como la Universidad Politécnica de Cartagena, teniendo un carácter estrictamente científico y siendo su finalidad la de contribuir a la mejora de un servicio que los profesionales de la auditoría prestan a las empresas y a la sociedad en general.

Agradeciendo de antemano su atención, y recordándole que su colaboración es imprescindible para el desarrollo de esta investigación, le saludo cordialmente.

$\mathrm{V}^{\mathrm{o}} \mathrm{B}^{\mathrm{o}}$

Cartagena, a 26 de enero de 2001

El Director de la Tesis

Fdo.: Antonio Duréndez Gómez-Guillamón Profesor Universidad Politécnica de Cartagena

Fdo.: Pedro Luengo Mulet

Catedrático de Economía

Financiera y Contabilidad

de la Universidad de Murcia

NOTA: Los resultados de la investigación quedan a disposición de todas las personas y entidades que colaboran en el proyecto, en la dirección que aparece al pie de la carta. Cualquier aclaración o consulta puede realizarse en la misma dirección.

Paseo Alfonso XIII, 50 - 30203 Cartagena - Tel. 968325610 - Fax: 968325782 - e-mail: Antonio.durendez@upct.es 


\section{ANEXO 25}

\begin{tabular}{|l|l|} 
UNIVERSIDAD POLITÉCNICA DE CARTAGENA & $\begin{array}{l}\text { ENCUESTA SOBRE AUDITORÍA DE CUENTAS } \\
\text { Exprese su grado de acuerdo o desacuerdo con las } \\
\text { siguientes expresiones marcando con una "X" }\end{array}$ \\
Dacultad de Ciencias de la Empresa \\
Dpto. de Economía Financiera y Contabilidad
\end{tabular}

EDAD:

HOMBRE $\square$

MUJER $\square$
$N^{\circ}$ DE ANTOS DE EXPERIENCIA

PROFESIONAL EN EL ÁMBITO FINANCIERO:

PUESTO EN LA EMPRESA (detallar)

\section{NIVEL DE ESTUDIOS: $\quad$ Estudios primarios}

Estudios universitarios grado medio

Estudios de postgrado

\section{$\square \quad$ Bachiller/formación profesional \\ $\square \quad$ Estudios universitarios superiores $\square$}

FUNCIÓN DE LA AUDITORÍA

1.Es responsabilidad del auditor:

-preparar y formular las cuentas anuales auditadas - llevar la contabilidad de la empresa auditada

-revisar toda la contabilidad de la empresa auditada

-detectar los fraudes y/o ilegalidades que se puedan desprender de la gestión

total desacuerdo $\begin{array}{llllll}1 & 2 & 3 & 4 & 5 & \text { total acuerdo }\end{array}$

$\square \square \square \square \quad \square$

$\square \square \square \square \square$

$\square \square \square \square \square$

$\square \square \square \square \square$

2.El auditor se encarga de verificar si las cuentas anuales expresan la imagen fiel de la situación económico-financiera de la empresa de acuerdo a los principios de contabilidad:

$\begin{array}{ccccccc}\text { total desacuerdo } & 1 & 2 & 3 & 4 & 5 & \text { total acuerdo } \\ & \square & \square & \square & \square & \square & \end{array}$

3.El auditor sólo se pronuncia en su informe sobre las cuentas anuales (Balance, Cta. de P y G y Memoria):
total desacuerdo 1
2
3
$3 \quad 4$
5
total acuerdo

4.El informe del auditor es una opinión razonable pero no un certificado de absoluta garantía sobre las cuentas

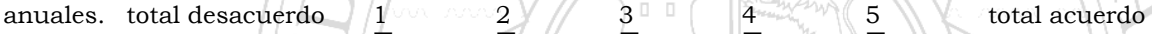

5.Se espera que el trabajo del auditor aporte seguridad sobre: total desacuerdo

-que se cumple con las normas contables

-que no existen fraudes y/o ilegalidades

-que la gestión de la empresa es adecuada

-que la situación financiera de la empresa es solvente

-que el control interno funciona correctamente

-que se cumplen las normas legales que afectan a la empresa

-que la empresa continuará funcionando



6. Está de acuerdo en que los auditores puedan prestar otros servicios aparte de la auditoría de cuentas, a las empresas que auditan? $\quad$ total desacuerdo

-teneduría de libros y llevanza de contabilidad

-asesoria fiscal

-asesoria legal

-consultoria de empresas

-asesoría de inversiones y financiera

-implantación de sistemas de calidad

-auditoría medioambiental

-auditoría de prevención de riesgos laborales

-implantación de sistemas informáticos

-servicios de tasaciones y peritajes

-servicios de selección de personal

-asesoramiento en auditoría interna

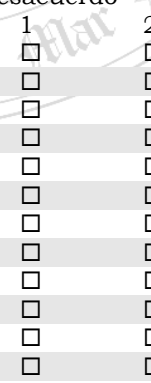

$\begin{array}{ll}2 & 3 \\ \square & \square \\ \square & \square \\ \square & \square \\ \square & \square \\ \square & \square \\ \square & \square \\ \square & \square \\ \square & \square \\ \square & \square \\ \square & \square \\ \square & \square \\ \square & \square\end{array}$

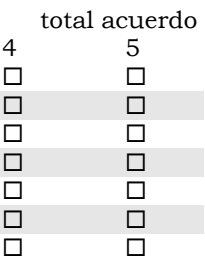

7. ¿Está de acuerdo en que los auditores puedan prestar otros servicios aparte de la auditoría de cuentas, a empresas




8.El auditor debe expresar en su informe cualquier tipo de ilegalidad observada en el desarrollo de su trabajo:



9.Existe un sentimiento de insatisfacción en los usuarios, sobre el propósito y objetivos que viene a cumplir la auditoría



UTILIDAD DE LA AUDITORÍA

10.Exprese su grado de acuerdo con las siguientes afirmaciones:

-Las cuentas anuales muestran la imagen real de las empresas

-La auditoría aporta fiabilidad a las cuentas anuales de las empresas

-La auditoría aporta "valor añadido" a la sociedad auditada

-El coste de la auditoría está justificado

-La auditoría se realiza exclusivamente por ser una obligación legal

-La auditoría es un servicio de interés público

-La opinión que emite el auditor es completamente independiente

-La opinión del auditor conlleva un alto grado de subjetividad

total desacuerdo $\begin{array}{llllll}1 & 2 & 3 & 4 & 5 & \text { total acuerdo }\end{array}$

$\square \quad \square \quad \square \quad \square$
$\square \quad \square$

$\begin{array}{lllll}\square & \square & \square & \square & \square\end{array}$

$\square \square \square \quad \square \quad \square$

$\square \square \square \quad \square \quad \square$

$\begin{array}{llll}\square & \square & \square & \square\end{array}$

$\square \square \square \square \square$

$\square \square \square \quad \square \quad \square$

$\square \square \square \square \square$

11.Señale quién/quienes exigen las cuentas anuales de las empresas auditadas:

$$
\begin{aligned}
& \text { - Accionistas } \\
& \text { - Clientes } \\
& \text { - Entidades financieras } \\
& \text { - Compañias de seguros }
\end{aligned}
$$

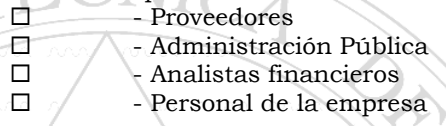

12.Exprese su acuerdo con las siguientes afirmaciones:

total desacuerdo $\quad \begin{array}{llllll}1 & 2 & 3 & 4 & 5 & \text { total acuerdo }\end{array}$

-Las cuentas anuales aportan información para la toma de decisiones

-El informe del auditor aporta información adicional para la toma de decisiones

-La carta de recomendaciones aporta información adicional para la gestión

-El informe es útil para determinar si la empresa es financieramente viable

-Un informe limpio aporta información más relevante que uno con salvedades

13.Ampliaría el trabajo del auditor de manera que le permitiera pronunciarse, en su informe, de manera expresa sobre:

-la detección de fraudes e irregularidades

-la eficacia de la gestión empresarial

-la evolución futura de la sociedad

-el control interno de la empresa.

-la rentabilidad de la empresa

-la solvencia de la empresa total desacuerdo

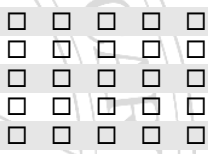

COMPRENSIÓN DEL INFORME DE AUDITORÍA

14.¿Cuántos informes de auditoría ha leído?
$>100 \square$
entre 100 y $25 \square$
menos de $25 \square$
Ninguno $\square$

15.Exprese su grado de acuerdo con las siguientes afirmaciones:

total desacuerdo $\begin{array}{llllll}1 & 2 & 3 & 4 & 5 & \text { total acuerdo }\end{array}$

-La redacción del informe del auditor está excesivamente estandarizada -Las salvedades que se incluyen en el informe son comprensibles

-El lenguaje utilizado en el informe de auditoría es muy técnico

-Se realiza una redacción de las salvedades excesivamente escueta

-El propósito de la auditoría está claramente expresado en el informe

-El informe es un adecuado medio de comunicación con los usuarios

-El lenguaje utilizado en el informe de auditoría es ambiguo

-La opinión que emite el auditor es comprensible

$\begin{array}{ccc}1 & 2 & 3 \\ \square & \square & \square \\ \square & \square & \square \\ \square & \square & \square \\ \square & \square & \square \\ \square & \square & \square \\ \square & \square & \square\end{array}$

total acuerdo

\begin{tabular}{llc}
3 & \multicolumn{2}{c}{ total acuerdo } \\
$\square$ & 4 & 5 \\
$\square$ & $\square$ & $\square$ \\
$\square$ & $\square$ & $\square$ \\
$\square$ & $\square$ & $\square$ \\
$\square$ & $\square$ & $\square$ \\
$\square$ & $\square$ & $\square$ \\
$\square$ & $\square$ & $\square$
\end{tabular}




\section{ANEXO 26}

\begin{tabular}{|l|l|l|} 
UNIVERSIDAD POLITÉCNICA DE CARTAGENA & $\begin{array}{l}\text { ENCUESTA SOBRE AUDITORÍA DE CUENTAS } \\
\text { Exprese su grado de acuerdo o desacuerdo con las } \\
\text { siguientes expresiones marcando con una "X" }\end{array}$ \\
Facultad de Ciencias de la Empresa \\
Dpto. de Economía Financiera y Contabilidad
\end{tabular}

EDAD:

HOMBRE $\square$

MUJER $\square$
$N^{\circ}$ DE ANOOS DE EXPERIENCIA

PROFESIONAL EN EL ÁMBITO FINANCIERO:

PUESTO EN LA EMPRESA (detallar)

NIVEL DE ESTUDIOS: $\quad$ Estudios primarios

Estudios universitarios grado medio

Estudios de postgrado $\begin{array}{lll}\square \quad \text { Bachiller/ formación profesional } & \square \\ \square \quad \text { Estudios universitarios superiores } \quad\end{array}$

FUNCIÓN DE LA AUDITORÍA

1.Es responsabilidad del auditor:

- preparar y formular las cuentas anuales auditadas - llevar la contabilidad de la empresa auditada

-revisar toda la contabilidad de la empresa auditada

-detectar los fraudes y/o ilegalidades que se puedan desprender de la gestión

total desacuerdo $\begin{array}{llllll}1 & 2 & 3 & 4 & 5 & \text { total acuerdo }\end{array}$

$\square \square \square \square \quad \square$

$\square \square \square \square \square$

$\square \square \square \square \square$

\section{$\square \square \square \square \quad \square$}

2.El auditor se encarga de verificar si las cuentas anuales expresan la imagen fiel de la situación económico-financiera de la empresa de acuerdo a los principios de contabilidad:

$\begin{array}{lllllll}\text { total desacuerdo } & 1 & 2 & 3 & 4 & 5 & \text { total acuerdo } \\ & \square & \square & \square & \square & \square & \end{array}$

3.El auditor sólo se pronuncia en su informe sobre las cuentas anuales (Balance, Cta. de P y G y Memoria):
total desacuerdo 1
2
3.
4
total acuerdo

5

4.El informe del auditor es una opinión razonable pero no un certificado de absoluta garantía sobre las cuentas anuales. total desacuerdo 1

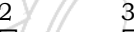

1

23

3
$\square$



5 total acuerdo

5.Se espera que el trabajo del auditor aporte seguridad sobre: total desacuerdo

-que se cumple con las normas contables

-que no existen fraudes y/o ilegalidades

-que la gestión de la empresa es adecuada

-que la situación financiera de la empresa es solvente

-que el control interno funciona correctamente

-que se cumplen las normas legales que afectan a la empresa

-que la empresa continuará funcionando

\begin{tabular}{l|r}
1 & 2 \\
$\square$ & $\square$ \\
$\square$ & $\square$ \\
$\square$ & $\square$ \\
$\square$ & $\square$ \\
$\square$ & $\square$ \\
$\square$ & $\square$ \\
$\square$ & $\square$
\end{tabular}

total acuerdo

6.Existe un sentimiento de insatisfacción en los usuarios, sobre el propósito y objetivos que viene a cumplir la auditoría de cuentas: total desacuerdo

\begin{tabular}{ccccc}
$\square$ & $\square$ & $\square$ & 3 & 4 \\
& & $\square$ & $\square$ & $\square$ \\
\hline
\end{tabular}

7.Exprese su grado de acuerdo con las siguientes afirmaciones:

-Las cuentas anuales muestran la imagen real de las empresas

total desacuerdo $\begin{array}{llllll}1 & 2 & 3 & 4 & 5 & \text { total acuerdo }\end{array}$

- La auditoría aporta fiabilidad a las cuentas anuales de las empresas

-La auditoría aporta "valor añadido" a la sociedad auditada

-El coste de la auditoría está justificado

-La auditoría se realiza exclusivamente por ser una obligación legal

-La auditoría es un servicio de interés público

-La opinión que emite el auditor es completamente independiente

-La opinión del auditor conlleva un alto grado de subjetividad

\section{5 total acuerdo}

8.Exprese su acuerdo con las siguientes afirmaciones:

total desacuerdo $\begin{array}{llllll}1 & 2 & 3 & 4 & 5 & \text { total acuerdo }\end{array}$

-Las cuentas anuales aportan información para la toma de decisiones

-El informe del auditor aporta información adicional para la toma de decisiones

-La carta de recomendaciones aporta información adicional para la gestión

-El informe es útil para determinar si la empresa es financieramente viable

-Un informe limpio aporta información más relevante que uno con salvedades



西



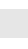

. 
9.Ampliaría el trabajo del auditor de manera que le permitiera pronunciarse, en su informe, de manera expresa sobre:

$\begin{array}{lcccc} & \text { total desacuerdo } & \text { total acuerdo } \\ \text {-la detección de fraudes e irregularidades } & 1 & 2 & 3 & 5 \\ \text {-la eficacia de la gestión empresarial } & \square & \square & \square & \square \\ \text {-la evolución futura de la sociedad } & \square & \square & \square & \square \\ \text {-el control interno de la empresa. } & \square & \square & \square & \square \\ \text {-la rentabilidad de la empresa } & \square & \square & \square & \square \\ \text {-la solvencia de la empresa } & \square & \square & \square & \square \\ \end{array}$

10.¿Cuántos informes de auditoría ha leído?
$>100 \square$
entre 100 y $25 \square$
menos de $25 \square$
Ninguno $\square$

11.Exprese su grado de acuerdo con las siguientes afirmaciones:

total desacuerdo $11243 \quad 4 \quad 5$ total acuerdo

-La redacción del informe del auditor está excesivamente estandarizada -Las salvedades que se incluyen en el informe son comprensibles

-El lenguaje utilizado en el informe de auditoría es muy técnico

-Se realiza una redacción de las salvedades excesivamente escueta

-El propósito de la auditoría está claramente expresado en el informe

-El informe es un adecuado medio de comunicación con los usuarios

-El lenguaje utilizado en el informe de auditoria es ambiguo

-La opinión que emite el auditor es comprensible



\title{
DECISIONES DE FINANCIACIÓN
}

12.La presentación del informe de auditoría es imprescindible para que se presten servicios, a una empresa obligada a auditarse, en el caso de: total desacuerdo

-conceder una línea de crédito

-conceder un préstamo a corto plazo

-conceder un préstamo a largo plazo

-abrir una línea de descuento comercial

-conceder un aval bancario

\begin{tabular}{l|l}
1 & \\
$\square$ & \\
$\square$ & \\
$\square$ & $\square$ \\
$\square$ & $\square$ \\
$\square$ & $\square$
\end{tabular}

2
$\square$
$\square$
$\square$
$\square$
$\square$

\begin{tabular}{l|l|l}
3 & & total acu \\
$\square$ & & \\
$\square$ & $\square$ & $\square$ \\
$\square$ & $\square$ & $\square$ \\
$\square$ & $\square$ & $\square$ \\
$\square$ & $\square$ & $\square$
\end{tabular}

13.La información más relevante al conceder un préstamo se obtiene de: total desacuerdo

-el informe de auditoria
-la central de riesgos
-bases de datos privadas
-conocimiento personal
-declaraciones tributarias
-cuentas anuales

$\begin{array}{ll}1 & 2 \\ \square & \square \\ \square & \square \\ \square & \square \\ \square & \square \\ \square & \square \\ \square & \square \\ \square & \square\end{array}$

$\begin{array}{ll}2 & 3 \\ \square & \square \\ \square & \square \\ \square & \square \\ \square & \square \\ \square & \square \\ \square & \square \\ \square & \square\end{array}$

$\begin{array}{ll}3 & 4 \\ \square & \square \\ \square & \square \\ \square & \square \\ \square & \square \\ \square & \square \\ \square & \square \\ \square & \square\end{array}$

$\begin{array}{lc} & \text { total acuerdo } \\ 4 & 5 \\ \square & \square \\ \square & \square \\ \square & \square \\ \square & \square \\ \square & \square \\ \square & \square \\ \square & \square\end{array}$

14.Exprese su grado de acuerdo con las siguientes afirmaciones:

-El tipo de opinión influye en la decisión de conceder el préstamo

total desacuerdo $\begin{array}{llllll}1 & 2 & 3 & 4 & 5 & \text { total acuerdo }\end{array}$

-El tipo de opinión influye en la decisión de la cuantía a prestar

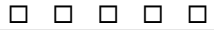

$\square \square \square \quad \square \quad \square$

$\square \square \square \square \square$

15.El tipo de salvedades que más pueden influir en su decisión al conceder un préstamo son:

$\begin{array}{lccccc} & & & \text { total acuerdo } \\ & \text { total desacuerdo } & & & 5 \\ \text {-incertidumbres en cuanto a la vida de la empresa } & 1 & 2 & 3 & \square & \square \\ \text {-por incumplimiento de principios contables } & \square & \square & \square & \square & \square \\ \text {-incertidumbres fiscales } & \square & \square & \square & \square & \square \\ \text {-por valoración de activos } & \square & \square & \square & \square & \square \\ \text {-por incumplimiento de normas legales } & \square & \square & \square & \square & \square \\ \text {-por limitaciones al alcance } & \square & \square & \square & \square & \square \\ \text {-por relaciones con empresas del grupo o asociadas } & \square & \square & \square & \square & \square\end{array}$

A CONTINUACIÓN INTRODUZCA EL CUESTIONARIO EN EL SOBRE ADJUNTO Y REMITALO EN EL MENOR PLAZO POSIBLE POR CORREO O POR FAX AL 9683257 82/968 325781.

LE AGRADECEMOS SU COLABORACIÓN Y OUEDAMOS A SU DISPOSICIÓN. SI DESEA RECIBIR LOS RESULTADOS DEL ESTUDIO CONTACTE CON NOSOTROS EN LA DIRECCIÓN INDICADA AL PIE.

\author{
MUCHAS GRACIAS
}

Paseo Alfonso XIII, 50 - 30203 Cartagena - Tel. 9683256 10/93 - Fax: 96832 57 82/81 - e-mail: antonio.durendez@upct.es 


\section{ANEXO 27}

UNIVERSIDAD POLITÉCNICA DE CARTAGENA

Facultad de Ciencias de la Empresa

Dpto. de Economía Financiera y Contabilidad

\section{ENCUESTA SOBRE AUDITORÍA DE CUENTAS}

Exprese su grado de acuerdo o desacuerdo con las siguientes expresiones marcando con una " $\mathrm{X}$ "

\section{DATOS PERSONALES}

EDAD:

HOMBRE $\square$

MUJER $\square$
$N^{\circ}$ DE ANTOS DE EXPERIENCIA

PROFESIONAL EN EL ÁMBITO FINANCIERO:

PUESTO EN LA EMPRESA (detallar)

\section{NIVEL DE ESTUDIOS: $\quad$ Estudios primarios}

Estudios universitarios grado medio

Estudios de postgrado

\section{$\square \quad$ Bachiller/formación profesional \\ $\square \quad$ Estudios universitarios superiores $\square$}

FUNCIÓN DE LA AUDITORÍA

1.Es responsabilidad del auditor:

-preparar y formular las cuentas anuales auditadas -llevar la contabilidad de la empresa auditada

-revisar toda la contabilidad de la empresa auditada

-detectar los fraudes y/o ilegalidades que se puedan desprender de la gestión

total desacuerdo $\begin{array}{llllll}1 & 2 & 3 & 4 & 5 & \text { total acuerdo }\end{array}$

$\square \square \square \square \square$

$\square \square \square \square \square$

$\square \square \square \square \square$

\section{$\square \square \square \square \quad \square$}

2.El auditor se encarga de verificar si las cuentas anuales expresan la imagen fiel de la situación económico-financiera de la empresa de acuerdo a los principios de contabilidad:

$\begin{array}{lllllll}\text { total desacuerdo } & 1 & 2 & 3 & 4 & 5 & \text { total acuerdo } \\ & \square & \square & \square & \square & \square & \end{array}$

3.El auditor sólo se pronuncia en su informe sobre las cuentas anuales (Balance, Cta. de P y G y Memoria):
total desacuerdo 1
12
3
5
total acuerdo

4

4.El informe del auditor es una opinión razonable pero no un certificado de absoluta garantía sobre las cuentas anuales. total desacuerdo 1

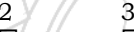

1

23

3
$\square$

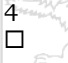

5

total acuerdo

5.Se espera que el trabajo del auditor aporte seguridad sobre: total desacuerdo

-que se cumple con las normas contables

-que no existen fraudes y/o ilegalidades

-que la gestión de la empresa es adecuada

-que la situación financiera de la empresa es solvente

-que el control interno funciona correctamente

-que se cumplen las normas legales que afectan a la empresa

-que la empresa continuará funcionando
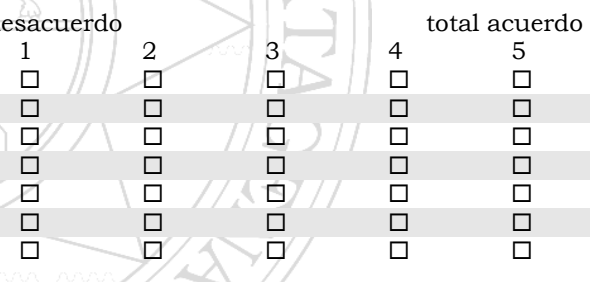

6.Existe un sentimiento de insatisfacción en los usuarios, sobre el propósito y objetivos que viene a cumplir la auditoría

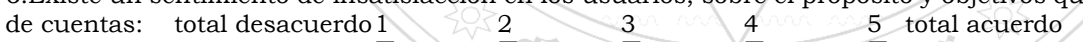

$\begin{array}{lllll} & \square & 3 & 4 & 5 \\ & \square & \square & \square\end{array}$

\section{UTILIDAD DE LA AUDITORÍA}

7.Exprese su grado de acuerdo con las siguientes afirmaciones:

-Las cuentas anuales muestran la imagen real de las empresas

- La auditoría aporta fiabilidad a las cuentas anuales de las empresas

-La auditoría aporta "valor añadido" a la sociedad auditada

-El coste de la auditoría está justificado

-La auditoría se realiza exclusivamente por ser una obligación legal

-La auditoría es un servicio de interés público

-La opinión que emite el auditor es completamente independiente

-La opinión del auditor conlleva un alto grado de subjetividad

total desacuerdo $1 \quad 2 \quad 3 \quad 4 \quad 5$ total acuerdo

8.Exprese su acuerdo con las siguientes afirmaciones:

total desacuerdo $\begin{array}{llllll}1 & 2 & 3 & 4 & 5 & \text { total acuerdo }\end{array}$

-Las cuentas anuales aportan información para la toma de decisiones

-El informe del auditor aporta información adicional para la toma de decisiones

-La carta de recomendaciones aporta información adicional para la gestión

-El informe es útil para determinar si la empresa es financieramente viable

-Un informe limpio aporta información más relevante que uno con salvedades



Paseo Alfonso XIII, 50 - 30203 Cartagena - Tel. 9683256 10/93 - Fax: 9683257 82/81 - e-mail: antonio.durendez@upct.es 
9.Ampliaría el trabajo del auditor de manera que le permitiera pronunciarse, en su informe, de manera expresa sobre:

$\begin{array}{lcccc} & \text { total desacuerdo } & \text { total acuerdo } \\ \text {-la detección de fraudes e irregularidades } & 1 & 2 & 3 & 5 \\ \text {-la eficacia de la gestión empresarial } & \square & \square & \square & \square \\ \text {-la evolución futura de la sociedad } & \square & \square & \square & \square \\ \text {-el control interno de la empresa. } & \square & \square & \square & \square \\ \text {-la rentabilidad de la empresa } & \square & \square & \square & \square \\ \text {-la solvencia de la empresa } & \square & \square & \square & \square \\ \end{array}$

COMPRENSIÓN DEL INFORME DE AUDITORÍA

10.¿Cuántos informes de auditoria ha leído?
$>100 \square$
entre 100 y $25 \square$
menos de $25 \square$
Ninguno $\square$

11.Exprese su grado de acuerdo con las siguientes afirmaciones:

total desacuerdo $\begin{array}{llllll}1 & 2 & 3 & 4 & 5 & \text { total acuerdo }\end{array}$

-La redacción del informe del auditor está excesivamente estandarizada -Las salvedades que se incluyen en el informe son comprensibles

-El lenguaje utilizado en el informe de auditoría es muy técnico

-Se realiza una redacción de las salvedades excesivamente escueta

-El propósito de la auditoría está claramente expresado en el informe

-El informe es un adecuado medio de comunicación con los usuarios

-El lenguaje utilizado en el informe de auditoría es ambiguo

-La opinión que emite el auditor es comprensible

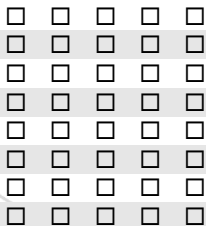

\title{
DECISIONES DE INVERSIÓN
}

12.La información más relevante al realizar una inversión se obtiene de: total desacuerdo

-realizar un análisis técnico

-realizar un análisis fundamental

-el informe de auditoría

-la central de riesgos

-bases de datos privadas

-conocimiento personal

-declaraciones tributarias

-cuentas anuales

-tener buenas referencias

(3)

13.Exprese su grado de acuerdo con las siguientes afirmaciones:

$$
\text { total desacuerdo }
$$

-El tipo de opinión influye en la decisión de invertir o no en una empresa -El tipo de opinión influye en la cuantía a invertir

2
2
$\square$
$\square$
$\square$
$\square$
$\square$
$\square$
$\square$
$\square$
$\square$



14.El tipo de salvedades que más pueden influir en su decisión de inversión, son:



A CONTINUACIÓN INTRODUZCA EL CUESTIONARIO EN EL SOBRE ADJUNTO Y REMITALO

EN EL MENOR PLAZO POSIBLE POR CORREO O POR FAX AL 96832 57 82/968 325781.

LE AGRADECEMOS SU COLABORACIÓN Y QUEDAMOS A SU DISPOSICIÓN. SI DESEA RECIBIR LOS RESULTADOS DEL ESTUDIO CONTACTE CON NOSOTROS EN LA DIRECCIÓN INDICADA AL PIE.

\author{
MUCHAS GRACIAS
}

Paseo Alfonso XIII, 50 - 30203 Cartagena - Tel. 9683256 10/93 - Fax: 9683257 82/81 - e-mail: antonio.durendez@upct.es 
